\title{
LIBELLULINAE GUROPAEAE
}

\author{
DESCRIPTAE AC DEPICTAE
}

A

\section{TOUSSAINT DE CIARPENTIER.}

CUM TABUlis XLVIII COLORATIS.

\section{LIPSIAE.}

L E O P O L D V V O S S .

MDCCCXL.

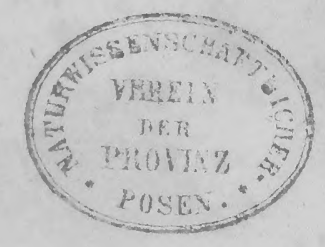


Pauca insectorum genera colores post mortem tantopere commutant, quantopere Libellulinae. Quamvis enim varius atque insignis sit colorum ornatus, quo insecta huius ordinis viventia splendent, tamen plurima eorum illud ornamentum maxima ex parte post mortem amittunt et nonnulla plane decolorantur. Lo magis necessaria videtur pictura horum animalium accurata et ad vivum facta. IIac de causa iam pluribus abhinc annis permagnum, vel potius maximum Libellulinarum Europaearum numerum ad vivum depinxi, cuius rei rationem reddidi in monographia de his animalibus conscripta, in libello, s. t. Horae Entomologicae, Vratislaviae 1825. edito. Exceptis autem appendicibus caudalibus marium Libellulinarum nullas istis pagellis adieci earum icones. Cum vero conventui naturae scrutatorum anno 1835. Bonnae celebrato interessem et pluribus viris Entomologiae operam navantibus icones illas Libellulinarum a me confe- 
ctas monstravissem, ab his viris dignissimis commotus atque impulsus sum, ut illas tabellas publice ederem.

Haec est origo huius opusculi, quod fortasse hac de causa iis, qui insectorum naturam perscrutantur, haud ingratum erit, quod Entomologia iconibus huius ordinis insectorum accurate depictis adhuc caret. De Europaeis potissimum tria habemus opera iconographica, scilicet Roeselii, Schaefferi et Harris. Sed figurae ipsae earumque colores saepissime non admodum diligenter reddita, sed vitiosa sunt et numerus Libellulinarum depictarum est perexiguus. Clarissimi viri Drury, Donavan et Palisot de Beaurais nonnullas et satis elegantes dederunt icones, sed tantummodo exoticarum Libellulinarum. In aliorum operibus e. g. Panzeri, Sulzeri, Reaumurii, De Geerii pauca videmus delineata et plerumque haud bene facta.

Itaque affirmari potest, Entomologiae studiosos adminiculo iconographico huius classis animalium adhuc non gaudere.

Caeterum icones a me delineatas permagni pretii esse haudquaquam affirmare audeo, cum in arte pictoria non admodum sim versatus: sed has figuras accuratas et ad naturam factas et hunc in finem persedulo esse elaboratas, ut horum insectorum cognitio constituatur 
atque augeatur, iure profiteri possum: quamobrem Entomorum sectatores eas benigne excepturos esse spero.

Cum vero pictura vel accuratissima et optime elaborata in animalibus dignoscendis plerumque non prorsum sufficiat, haud supervacaneum putavi descriptiones accuratas atque plenas uniuscuiusque speciei addere: et cum quaeque res, de qua disserendum est, ut nomen quoddam habeat necesse sit, haud ineptum mihi videbatur omnes partes corporis Libellulinarum diligentissime describere et eis, quae adhuc propria et peculiari denominatione carebant, nomina apta imponere. Linnei enim et $\mathrm{Fabricii}$ verba hac in causa iam dudum non sufficere, quis est qui nesciat?

Attamen clarissimi Horismologi Illiger et Kirby et Spence eximia harum rerum tractatione, quae meam laudem non requirit, scientiae per accuratiorem omnium corporis insectorum partium contemplationem, denominationem et descriptionem maxima paraverunt commoda. Horum igitur potissimum virorum vestigia sequi conatus sum. Cum vero peculiaris ordinis disquisitionem tractarem, ad singula quam maxime spectantem, nullo modo fieri potuit, quin et illorum virorum tam magna terminorum, quos vocant, technicorum, copia interdum haud esset sufficiens, quapropter quodammodo coactus 
sum, plures easque novas tentare denominationes. Nam maximi mihi videtur esse momenti, unamquamque vel minimam particulam corporis horum insectorum peculiari et definita designari denominatione: summo enim iure illustrissimus Linné in philosophia botanica dicit: „,nomina si nescis, perit et cognitio rerum“. 
Ordo, cui insecta, quae hoc loco tractaturus sum, adscripta sunt a Linne o et post eum ab omnibus fere scriptoribus e. g. De Geer, Latreille, Kirby, Neuropterorum ordo appellatus est: nomen ab alarum, quae plurimis nervis seu venis distinctae sunt, reticulatione desumtum. Fortasse denominatio a cl. Clairville proposita „Dictyoptera" melior et rectior est: illa autem, in universum fere recepta, cum eundem praebeat sensum, retinenda mihi videtur.

Fabricius Libellulinas in diversis suis scriptis, quibus Entomologiam tractavit, diversis adnumerat ordinibus. Primum in „Systemate Entomologiae“ eas una cum generibus „Iulus, Scolopendra, Trombidium, Aranea et Phalangium" in classem "Unogatorum" coniunxit, quod in "Speciebus Insectorum" addito genere „Scorpio“ retinuit. Postea in „Entomologia systematica“ e Libellulinis peculiarem condidit classem, sub denominatione „Odonata“.

Temporibus recentioribus nomen „Neuroptera" praecipue a cl. Latr eille restitutum et ab omnibus fere scriptoribus receptum est.

Classis Odonatorum Fabricii solummodo genera „Libellula, Aeschna et Agrion“ amplectebatur: cl. autem Latreille quodammodo antiquum Linnei ordinem seu classem Neuropterorum restituit et sic Odonatis Fabricii nonnulla alia genera adiunxit: Odonata autem Fabricii tanquam peculiarem familiam constituit, eiusque generibus nomen „Libellulinarum" imposuit. 


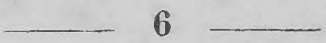

Libellulinae igitur genera Fabricii: Libellulam, Aeschnam et Agrion complectuntur, quae tam metamorphoseos, quam instrumentorum cibariorum structurae et compositionis ratione habita, genera seu familias efficiunt tam naturales et tam clare inter se distinctas, ut introductio novornon generum vix sit approbanda. Cum vero numerus Libellulinarum nuper inventarum tantopere sit auctus, cumque omnino nonnullae species inter se sint similiores, quam reliquae eiusdem generis, haud male actum videtur, si, retentis generibus principalibus, haec in quaedam subgenera dividantur, quae inprimis eo spectant, ut species uniuscuiusque generis secundum quandam inter se similitudinem in unam cohortem seu seriem coniungantur, ideoque recens repertae et descriptae facilius possint dignosci.

Characteres sive signa talibus subgeneribus efficiendis inservientia non ab una eademque parte seu qualitate animalis desumta sunt, neque desumi potucrunt, sed a toto habitu et a pluribus partibus. Hi igitur characteres subgenerici variam habent stabilitatem, quo fit, ut aliud subgenus evidentius alio sit, pro characteris distinctivi significantia.

Si igitur familiam Libellulinarum in genera et genera in subgenera dividere volumus, necessarium videtur nomina generum hucusque usurpata commutare et iis denominationes magis collectivas substituere. Sint Libellulis, Aeschnis, Agrionis.

Character artificialis secundum methodum ex instrumentorum cibariorum structura desumtam est hic:

Familiae Libellulinarum: labium trifidum: antennae tenuissimae, breves, filiformes.

Generis Libellulidum: labii lacinia intermedia lateralibus (multo) minor. 
Generis Aeschnidum: labii laciniae aequales (interdum intermedia emarginata).

Generis Agrionidum: labii lacinia intermedia lateralibus maior, (apice alte exciso).

Characteres hi artificiales constantissimi sunt, simulque naturae maxime convenientes: structura enim labii insectorum perfectorum illis generibus adscriptorum optime quadrat cum forma labii larvarum et chrysalidum, ita ut statim e larva et chrysalide cognosci possit, utrum Libellulidibus an Aeschnidibus, an Agrionidibus insectum sit adnumerandum. - Si quis os horum generum comparare vult, picturas inspiciat additas operibus:

Réaumur: Tom.VI. Tab.36. fig.10-14. Tab.38. fig.6-8.

De Geer: Tom. II. P. II. Tab. 19. fig. 7. 15-17. Tab. 20. fig. 7. Tab.21. fig. 7.8 .

Roesel: Tom.II. Tab.III. fig.e.f. Tab.IX. fig. 3.4.

H a r ris: Exposition of english insects. Lond. 1782. Tab. XII.

Lyonet: Recherches sur l'anatomie des insectes. Paris 1832. Tab. 18. fig. $12-15$.

Brullé: Observations; dans les annales de la societé d'Entomologie. 1832.

Quod si strictissime et diligentissime de hac re agere voluerimus, iuveniemus, structuram seu formam labii in omnibus et universis Libellulinarum fere speciebus haudquaquam unam eandemque, contra ex parte diversam esse et in unaquaque specie paullulum a reliquis recedere. Ad hoc demonstrandum Tab. 47. figuris 1-6. labia plurium specierum Libellulidum depicta sunt, scilicet fig. 1. Lib. bimaculatae; fig. 2. Lib. quadrimaculatae; fig. 3. Lib. vulgatae; fig. 4. Lib. flaveo- 


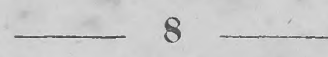

lae; fig. 5. Lib. aeneae; fig. 6. Lib. metallicae, e quibus iconibus apparet, unamquamque speciem in labii structura aliquantum ab reliquis diversam esse. Characterem vero principalem: „labium trifidum, lacinia intermedia lateralibus minore“ omnes servant tanquam generalem et communem. Fundamentum jgitur novorum condendorum generum non praebent, si systemati Fabriciano, secundum instrumentorum cibariorum formam condito, inniti volumus.

Caeterum characteres generum a labio desumti, in scriptis $\mathbf{F}$ abricii et eorum, qui eum hac in re sequati sunt, ex parte mutandi mihi sunt visi. Dicit enim praeclarus vir:

1) De Libellulis: "labium trifidum, lacinia dorsali minutissima“. Terminus „,minutissima“ vagus mihi videtur ideoque vitandus. Sufficit dicere „lacinia dorsali (seu intermedia) lateralibus mi-

- nor, vel multo minor. Minutissima enim dici non potest, cum fere semper quintam partem magnitudinis laciniae lateralis aequet.

2) De Aeschnis: „labium trifidum, laciniis aequalibus, lateralibus truncatis, dentatis, intermedia emarginata“. Verba „lateralibus truncatis, dentatis" delenda mihi videntur: nam laciniae laterales Libellularum revera magis etiam truncatae et omnino dente instructae sunt. Hoc igitur criterion non distinctivum, sed aliis quoque Libellulinarum generibus commune est. Nota „intermedia emarginata" minime omnibus Aeschnae speciebus convenit. Sufficit igitur criterion, lacinias aequales esse.

3) De Agriis idem vir doctiss. proponit haecce: „labium trifidum, laciniis exterioribus bifidis". - Hoc loco laciniae laterales vocantur exteriores. Laciniae vero hae laterales et in Libellulis et saepius in Aeschnis apice bidentato instructae sunt, et in qui- 
busdam Aeschnarum speciebus, v. c. A. forcipata, serpentina etc., dentes laciniarum tam longi et distincti sunt, ut laciniae iis instructae optimo iure bifidae possint appellari. Hac de causa verba Fabricii de charactere generico Agriorum „laciniis exterioribus bifidis" delenda mihi videntur, eorumque loco dicendum „lacinia media lateralibus maior".

Criterion secundarium generis Agriorum in eo conspicitur, quod lacinia media profunde est excisa, ita ut fere bifida possit appellari Tab. 47. figura 8. talem structuram demonstrat, scilicet labium Agrii tuberculati.

Sufficiant haec pauca, ut comprobetur, me non temere characteres genericos a $\mathrm{F}$ abricio propositos mutavisse.

\section{DE IIBECLULINARUM SUPGENGIRIBUS.}

Uti iam supra diximus, divisio Libellulinarum in tria genera, Libellulam, Aeschnam et Agrion, secundum instrumenta earum cibaria instituta, tam apta est, ut nova genera vix recte sint instituenda. Si vero species horum trium generum secundum similitudines quasdam atque unam alteramve proprietatem et formam, quae pluribus earum communis est, in singulares quasdam dividere volumus turbas seu agmina, his verissime nomen subgenerum imponendum erit, et in hanc partem accipienda proponam haec.

Classis seu familia:

\section{LIBELLULINA.}

Genus: A. Libellulis.

B. Aeschnis.

C. Agrionis. 
Subgenus:

A. Libellulidum:

1) Epitheca.

2) Libellula.

3) Diplax.

4) Chlorosoma.

B. Aeschnidum:

1) Cyrtosoma.

2) Aeschna.

3) Thecaphora.

4) Diastatomma.

C. Agrionidum:

1) Epallage.

2) Calopteryx.

3) Anapetes.

4) Sympycna.

5) Pyrrhosoma.

6) Erythromma.

7) Ischnura.

8) Agrion.

9) Platycnemis.

Horum subgenerum divisio fortasse inserviet copiae Libellulinarum melius et facilius animis legentium imprimendae. In dissertatione ipsa, qua Libellulinae describuntur, divisionem in tria genera, Libellulam, Aeschnam et Agrion retinui, cum haec divisio sola secundum regulas artis iusto fundamento inniti videatur.

Subgenera autem ipsa, si ea admittere licet, his characteribus distinguuntur. 


\section{HIBETIUUTIDUM}

Subgenus

\section{EPITHECA.}

Nomen ex vocabulis Graecis ż $\pi i$ et $\Im \dot{\eta} \approx \eta$ compositum, propter longissimas foeminae appendices ad valvam oviparam. *)

Characteres subgenerici hi sunt: insignis structura partium foeminae et maris genitalium. Et in mare quidem eximio modo prominent et postica parte in lobum longum incumbentem, e processu seginenti ventralis secundi ortum, inclusae sunt. In foeminis (vide Tab. I. figuram in fine adiectam) longis constant lamellis; subcylindricis, depressis, ad aperturam oviparam positis.

Porro in hoc subgenere verrucae ventrales reperiuntur, quae in Libellulidibus rarissimae sunt, et praeterea tantum in subgenere "Chlorosoma" occurrunt.

Plerumque trigonulum (vide infra eius descriptionem) alarum anticarum, quod in omnibus fere aliis Libellulidibus una vel duabus venis parallelis divisum est, in subgenere Epitheca venis tribus e centro communi oriundis, tripartitum est.

\section{LIBELLULA.}

Nomen a plurimis scriptoribus receptum ab Hydrotechnicorum instrumento "libella" desumtum est, quod directionem, quae vocatur, horizontalem indicat: hoc enim animal in sedendo alas planas et quasi horizontali situ positas gestat.

*) Adnot. Pauca hoc loco de nominibus afferenda puto. Fabricius in praefatione Entomologiae systematicae affirmat de nominibus insectis impositis: ,optima esse ea, quae omnino nihil significent". Equidem iis potius adsentio, qui putant, optima aut certe bona nomina esse ea, quae qualitatem aliquam seu criterion insecti peculiare indıcent, ex quo animal statim possit recognosci, aut quod aliquam certe veri speciem innuat. 
Characteres subgenerici sunt: corpus triquetrum, plerumque depressum, in basi paullulum inflatum, globulare: ad apicem paullatim attenuatum. Prothorax in postica parte in medio elevatus, ibique unum tantummodo lobum efficit.

\section{DIPLAX.}

Nomen e Graecis vocabulis dis et $\pi \lambda \alpha^{\prime} \xi$ derivatum, ob prothoracis formam.

Characteres subgenerici sunt: corpus cylindricum, magnitudinis plerumque mediocris: abdomen alis vix longius, saepe brevius, in basi paullulum inflatum, apud mares versus apicem plerumque crassius quam in medio. Prothorax in postica parte elevatus seu erectus in plagulam seu discum a duobus semicirculis formatum, pilisque longis ciliatum (vide Tab.47. fig. 17). Alae, imprimis posticae, in basi latiores sunt quam versus apicem.

\section{CHLOROSOMA.}

Nomen e Graecis $\chi^{2} \omega \omega o$ ós et $\sigma \tilde{\omega} \mu \alpha$ compositum, propter colores in huius subgeneris speciebus Europaeis obvios.

Characteres subgenerici sunt: corpus cylindricum, ad basin in utroque sexu globosum, appendicibus longis et singularis formae: in maribus margo abdominalis alarum posticarum paullulum excisus est aeque atque in maxima Aeschnarum parte. Color animalis viridis, aeneo-splendens. Mares, non aeque foeminae, verrucas ventrales habent.

Antea (in Horis Entomol.) Chlorosomata ad genus Aeschnam pertinere putavi, propter formam abdominis cylindricam et appendicum marium structuram, propter praesentiam verrucarum ventralium et ob marginem alarum posticarum excisum, saltem angulatum. Examen vero rigidius instrumentorum cibariorum et cognitio accuratior larva- 


\section{$-13$}

rum chrysalidunque me docuit, haec Neuroptera omnino in genere Libellulidum proferenda esse: id quod et ramificatione alarum venarum confirmatur, cum Chlorosomata trigonulum alarum anticarum pariter constructum habeant, atque omnes aliae Libellulides.

[Adnot. In cl. Kirby opere: Introductio etc. Tom.III. pag. 139. interpretationis Germanicae, affirmatur, clarissimum Le a ch Libellulam aeneam ( - quae ad subgenus nostrum Chlorosoma pertinet -) ea de causa peculiare constituere genus, quod eius larva a larvis Libellularum affinium diversa sit: eius enim os non laciniis duabus lateralibus concavis, sed laciniis ungue mobili, denteque interno esse instructum. Affertur, tales huius Libellulae partes depictas esse in De Geerii operis Tom. II. fig. 17. sub litteris $\boldsymbol{g} \boldsymbol{g}, \boldsymbol{d}$ et $\boldsymbol{h}$. Haec vero affirmatio plane ex errore aliquo orta videtur: nam clarissimus De Geer in explicatione tabularum p. 341 et 342 (interpret. German.) disertis verbis dicit, has partes depictas ad larvaun familiae secundae figura 12. depictam (scil. Aeschnae alicuius) pertinere: larvam vero sub fig. 1. et 2. illius tabulae depictam Libellulae aeneae (fig. 8.) esse. Quod etiam ex mea ipsius experientia affirmare possum, cum haud raro Lib. aeneae chrysalides earumque exuvias repererim, easque plane uti chrysalides Lib. quadrimaculatae ac depressae conformatas esse observarim.]

\section{A ESCHINIDUM}

Subgenus

\section{CYRTOSOMA.}

Nomen e Graecis vocabulis xverós et $\sigma \tilde{\omega} \mu c$ hac de causa compositum, quod haec animalia, certe mares, inter volandum mediam corporis partem sursum flexam habeant, cum aliae Aeschnidum species abdomen rectum in volatu gerant. 
Character subgenericus est: abdomen subdepressum (imprimis maris), quasi ensiforme, structurac igitur ab abdomine cylindrico reliquarum Aeschnidum specierum diversae; in maribus alae posticae marginem basalem habent rotundatum, haud excisum aut angulatum, uti omnes fere aliae Aeschnides. Oculi maximo fere spatio in parte suprema sunt connati: frons valde producta est.

Ex Europaearum Aeschnidum speciebus una tantum hoc constituit subgenus (Cyrtosoma azureum): inter exoticas vero nonnullas quoque alias reperi.

\section{AESCHNA.}

Nomen a prioribus scriptoribus introductum est. Fabricius primus hac denominatione usus est, qui tamen scripsit: Aeshna. Clar. Illig er (Magazin. Tom. I. P. I. p.126) et cum eo omnes scriptores sequentes forma: Acschna utuntur; cl. Lamark scribit: Oeschna, nescio quo iure. Etymologia verbi: „heschna“ mihi est ignota. Illiger putat illud nomen a Graeco vocabulo cirøív esse derivandum.

Characteres subgenerici sunt: magnitudo eximia, pictura maxime varia, abdomen cylindricum, appendices caudales magnae, inferior scaphiformis: margo basalis alarum maris posticarum excisus seu sinuatus seu angulatus est.

\section{THECAPHORA.}

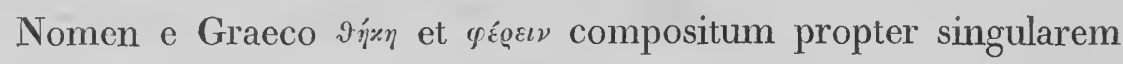
valvulae oviparae foeminarum huius subgeneris formam.

Character subgenericus est: Oculi connati quiden, sed multo minori spatio quam in reliquis Aeschnidibus: labii lacinia media fere canaliculata, apice valde emarginato, abdominis segmenta dorsalia a ventralibus sutura nulla separata, potius fere totum abdomen cingentia, pictura e coloribus nigris et flavis composita, foeminae valva ovi- 
para in vaginam aculeiformem excurrit, et segmenta abdominalia ultima seu apici propiora non cylindrica, sed antice posticeque coarctata sunt, igitur fere globularia.

Ex Europaeis huius subgeneris animalibus tantummodo una species, scil. "Thecaphora lunulata" huc referenda. Verum e Syria et America septentrionali duas alias possideo Aeschnides in hoc subgenere collocandas.

\section{DIASTATOMMA.}

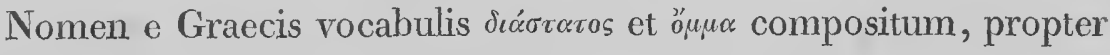
oculos inter se remotos seu distantes.

Characteres subgenerici sunt: caput parum globosum, potius transversum, oculi haud connati sed remoti, et per cuneum seu rugan elevatam separati, ocelli approximati, in triangulo positi, laciniae labii laterales suborbiculares, dentibus duobus validis (palporum instar) instructae: magnitudo mediocris, segmenta abdominis dorsalia a ventralibus non distincta, sed continuo cuti ventrali annexa, ita ut segmenta totum fere ventrem cingant, qualiter in Agrionidibus solent; colores praecipue e nigro et citrino compositi; pedes breves, validi; alae maris posticae ad marginem basalem sinuatae seu excisae, membranula accessoria minima, angustissima, nitida, glabra.

Neuroptera huius subgeneris ob oculos distantes, caput transversum et membranulam accessoriam tam parvam, vix conspicuam Agrionidibus accedere videntur, et fere transitum ab Aeschnidibus ad illas faciunt, secundum instrumenta vero cibaria et alarum reticulationem omnino ab Agrionidibus haec Neuroptera separanda sunt.

Foeminae subgeneris „Diastatomma“ partes genitales externas plane non eodem modo ac reliquarum Aeschnidum foeminae instructas habent, sed apertura ovipara ad finem segmenti ventralis octavi tantum valvula quadam clausa est, uti apud Libellulides. 
Duarum specierum foeminae, scil. "Diast. serpentini et hamati“" eximio et singulari modo corniculis in capite sunt instructae, uti in descriptione specierum demonstrabitur. Signum in nullis, quod sciam, aliis Libellulinis occurrens, si species Europaeas nonnullas $\Lambda$ grionidum excipio, item cornicula in occipite gerentes.

\section{AGRIONIIDUII}

Subgenus

\section{EPALLAGE.}

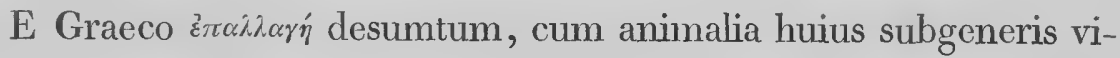
deantur efficere transitum seu quasi medium inter Diastatommata et Neuroptera sequentis subgeneris, Calopterygis.

Criterion subgenericum difficile est ad constituendum et vaccillans, nam unum solum exemplum huius subgeneris, e Turcia allatum, examini subiicere potui: conferatur infra accuratior eius descriptio.

Instrumenta cibaria omnem dubitationem eximunt, quin hoc animal ad Agrionides pertineat: et reticulatio alarum hanc Epallagen ad subgenus sequens Calopterygem referendam esse nos monet. $\mathrm{Pe}-$ culiare autem subgenus ex ea constitui poterit his notis: abdomine breviore, crassiore, quam in reliquis Agrionidibus, et pictura coloreque Diastommatibus plane simili.

Haec pauca momenta haudquaquam sufficiunt, quod minime me fugit: sed cum non amplius quam unam speciem nactus sim, quin etiam, cum unum tantum eius exemplum habeam, cumque ne marem quidem huius insecti oculis perlustrare potuerim, plura adferri a me nequeunt.

\section{CALOPTERYX.}

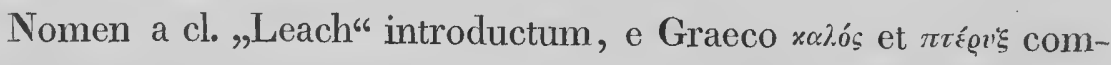
positum, ob plurimarum specierum colorem pulcherrimum tam corporis quam alarum. 
Species huius subgeneris Agrionidum iamiam in larvarum conditione a reliquis Agrionidibus recedunt. Larvae enim Agrionidum plurimarum ad abdominis finem insignes sunt foliolis tribus longis, latiusculis, ad apicem rotundatis: in Calopterygum larvis haec foliola sunt perangusta, apice acuto. Icones larvarum Calopterygum videas in „Roesel“ Vol.II. Tab.IX. fig.1.2. - „Reaumur“ Tom. VI. Tab.38. fig. 1.2.5. Tab.41. fig.1.2.- „Harris“ Tab. XXX. fig.6. - Reliquarum Agrionidum in Roesel. I. c. Tab.X. fig.1.2. Tab.XI. fig. 8. - Reaum. Tab. XXXVIII. Fig. 3. - Harris. Tab. XXIX. fig. $\boldsymbol{b}$.

Insectum perfectum labio instructum est, cuius lacinia media triangularis est, acuta, et ad apicem profunde excisa. - Alae plane diverso modo atque apud alia Agrionidum subgenera reticulatae sunt: nam secundum venas longitudinales Aeschnidibus sunt similiores, venarum vero copia permagna, areolarum igitur multitudine ab omnibus aliis Libellulinis magnopere recedunt. - Etiam forma seu ambitus alarum peculiaris est atque singularis. Omnes Libellulides et Aeschnides membrana accessoria praeditae sunt: Agrionides ea plane carent; maxima subgenerum pars ad Agrionides pertinentium alas ad basin, versus pectus, habent repente attenuatas, ita ut quasi stylatae sint, cum margo inferior ad basin sinum seu angulum formet. Calopterygum autem alae ad basin paullatim attenuatae sunt et margo alarum inferior rotundatus, angulo seu sinu non effecto, excurrit.

Omnes paene species Calopterygum, et exoticae, alas habent pulchris coloribus exornatas, certe mares; reliquae Agrionides fere semper hyalinas, non coloratas.

Omnes huius subgeneris species Europaeae, cum mares, tum foeminae, sicuti eae quoque, quas e Syria et ex America septentrionali accepi, post oculos ad tempora gerunt mucronem seu denticulum parvum, acutum. Septem species ex India orientali allatae, quae in museo nostro asservantur, hoc mucrone non instructae sunt. 
Mares specierum Europaearum parastigmate carent: foeminae loco eius gerunt maculam parvam, subopacam, albam, cum pluribus venis transversalibus continuis, quibus parastigmata aliarum Libellulinarum plerumque carent.

Inter exoticas vero Calopteryges inveniuntur foeminae integro parastigmate praeditae, eoque tali, quod utrimque vena terminali circumdatum sit, et per quod nullae venulae transversales percurrant. Sunt quoque nonnullae species, quarum mares parastigmata habent, foeminae autem nulla.

\section{ANAPETES.}

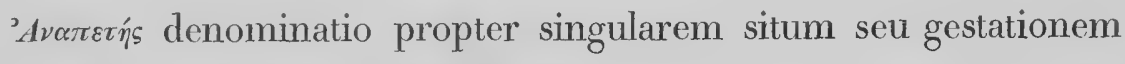
alarum huic subgencri attributa est.

Habent enim huius subgeneris species, dum vivunt, hanc singularitatem, ut inter sedendum alas gerant patulas, expansas, paullulum retro directas, qua in re Libellulidibus haud dissimiles sunt. Omnia vero alia Agrionidum subgenera in quiete gerunt alas conniventes, erectas. Cum animalia huius subgeneris recens exclusa sunt, ideoque nondum adulta, alas omnino erectas gerunt, id quod in insectis alatis fere omnibus locum habet, itaque in omnibus quoque Libellulinis.

Iam cl. Reaumur (Tom. VI.) monet, has Libellulinas, Anapetes nostras, positionem alarum habere patulam, et miror, tam multos de Libellulinis scripsisse, quos observatio illa prorsus fugit. Ita etiam Linnei divisio Libellularum in Libellulas alis patentibus et alis erectis fuit manca. Sane post animalis mortem haec alarum qualitas observari non potest: nihilo tamen minus criterion illud est magni momenti et eo gravius, cum ad animalis vitae genus omnino pertineat.

Aliud huius subgeneris criterion externum, quamvis minus ei prae caeteris proprium, est illud, quod areolae alarum versus apicem, intra sectorem principalem et nodalem, quinque nervis seu venulis 
terminantur seu includuntur, ita ut pentagonales fiant, cum in reliquis Agrionidibus quadratae seu quatuor tantum laterum sint. Hoc tamen criterion et subgeneri sequenti est commune.

Mares subgeneris Anapetis appendices superiores habent curvatas seu plus minusve semicirculares.

Color corporis partis superioris semper est laete viridis, nitens seu sericeus, maxime marium: foeminarum saepe paullulo obscurior: et animalium vetustorum magis in colorem fuscum, aeneo admixto, transit. In inferiore corporis parte color semper flavidus est.

\section{SYMPYCNA.}

Nomen a Graeco б́́pлv*vos desumtum, propter alarum arcte erectarum situm, quem animal vivens in sedendo prae se fert.

Reticulatio alarum eadem est atque in Anapetis speciebus, a quibus tamen hoc subgenus eo valde recedit, quod animalia, dum vivunt, inter sedendum alas gerunt non patentes et divaricatas, sed erectas et conniventes. Adspectus animalis mortui nullum praebet signum ad hoc subgenus a praecedenti distinguendum, cum et unica Sympycnae species Europaea appendices maris superiores semicirculares habeat. Hac de causa prius haec duo subgenera in unum sub nomine „Pentagonium" iunxeram. Diversus autem modus alarum gerendarum postea gravior mihi videbatur, quam ut illud subgenus in duo non separarem.

Dolendum est, quod, cum specierum nondum descriptarum exempla plerumque demum post mortem et arida facta examini subiicere possimus, semper dubium erit, utrum ad subgenus Anapetes, an ad subgenus Sympycna pertineant.

\section{PYRRHOSOMA.}

Nomen e Graeco สvọọós et $\sigma \tilde{\omega} \mu \alpha$ compositum, propter coccineum specierum huius subgeneris colorem. 
Criterion subgenericum est: labrum et nasus valde prominentia, porrecta fere, pilis longis, atris obsita. Color principalis lacte coccineus in utroque animalis sexu.

Ex Europacis unam tantummodo novi speciem, Pyrrhosoma minium. Alia a cl. V an der Linden sub nomine "Agrion rubella“ descripta fortasse ad hoc subgenus est referenda. Exoticarum plurium possideo exempla specierum huius subgeneris, eorumque unum ex America septentrionali allatụm, quod omnium Libellulinarum a me hucusque cognitarum minimum est, longitudine vix octo lineas exaequans.

\section{ERYTHROMMA.}

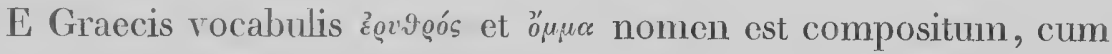
mares, dum vivunt, oculorum habeant colorem mire rubrum.

Criterion huius subgeneris distinctivum, color ruber oculorum maris, post mortem non amplius conspici potest. Aliud criterion minus caducum est structura appendicum abdominalium maris, quae dolabriformes et divaricatae sunt: porro color atro-acneus, et pruina albido-cocrulea, diluta, totum fere corpus animalis adulti obtinens.

\section{ISCHNURA.}

Nomen e Graeco i $\sigma x \nu o ́ s$ et ởéá compositum, ob abdominis eximiam tenuitatem.

Signa distinctiva huius subgencris sunt: abdoınen, praecipue medium, valde attenuatum seu angustum, caput minus latum, quam in reliquis subgeneribus: alae, habita longitudinis corporis ratione, perbreves. Caeterum ultimum abdominis segmentum in dorso vel ad marginem posticum mucronibus aut tubcrculis munitum est.

Species nonnullae exoticae Agrionidum ad hoc subgenus fortasse haud iniuste referendae, quae abdomine longissimo praeditae sunt, e. g. Agrion lineare Fabr, et aliae. 
Foeminae quarundam specierum Europaearum recens exclusae colorem capitis, pedum, thoracis et reliquarum partium, qui in adultis laete viridis aut flavo-viridis est, habent croceum seu aurantiacum, qui interdum et in venis sen nervis alarum invenitur, et adeo post mortem animalis remanet.

\section{AGRION.}

Nomen, a clarissimo Fabricio toti Agrionidum generi impositum, ad hoc subgenus significandum retinui. Vocabulum "Agrion" cl. vir fortasse a Graeco črọøús „venator", aut ab ärọıs „ferus" desumsit, cui opinioni Illiger (Magazin I. I. p.126.) adstipulatur.

Species huius subgeneris inter se congruunt abdominis crassitudine aequali: marium colore ex atro - virescente cum laete-coeruleo alternante. Foeminae aut simili modo pictae, (sed colore viridi superante), aut obscuro-virides et in inferiore corporis parte laete flavo-virescentes.

Ornnes species permagnam, quod ad colorem et picturam attinet, inter se habent similitudinem (- qua de causa prius hoc subgenus „Enallagma“6 vocavi - ) et utriusque sexus segmenta abdominis, imprimis priora, thoraci propiora, accurate sunt examinanda, quia eorum pictura diversa optime illae species distingui et secerni poterunt.

\section{PLATYCNEMIS.}

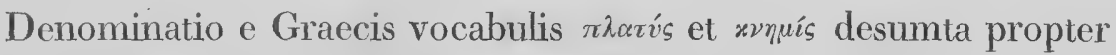
tibiarum latera in membranulam dilatata.

Non solum autem proprietate, per ipsam denominationem expressa et indicata, hoc distinguitur subgenus a reliquis, cum eius species tibias pedum mediorum et posticorum ad utrumque latus, per totam longitudinem habeant dilatatas in membranulam attenuatam: sed etiam eo prae aliis distinguitur, quod caput est valde latum, oculi igitur inter se valde distant. 
Color albidus speciebus huius subgeneris peculiaris esse videtur, sed ita tamen, ut nunc in subcoeruleum, nunc in subluteum colorem quasi vergat. Maris appendices caudales sunt depressae, horizontales.

Europa unam tantummodo speciem Platycnemidis hucusque praebuit. Ex America et ex India eiusdem subgeneris plures species possideo.

Libellulinae Europaeae mihi notae, quas in his pagellis descripturus sum, illis subgeneribus in hunc fore modum sunt adnumerandae:

\section{MTBELIULIDES.}

\section{Epitheca:}

bimaculata.

\section{Libellula:}

conspurcata.

quadrimaculata.

depressa.

cancellata.

coerulescens.

coccinea.

3. Diplax:

pedemontana.

flaveola.

nigripes.

striolata.

vulgata.

albifrons.

ruficollis. 
nigra.

pectoralis.

caudalis.

4. Chlorosoma:

aeneum.

metallicum.

flavomaculatum.

\section{AESCHIIDIES.}

1. Cyrtosoma :

azureum.

2. Aeschna:

virens.

iuncea.

pilosa.

affinis.

mixta.

picta.

grandis.

chrysophthalmus.

3. Thecaphora:

lunulata.

4. Diastatomma:

hamatum.

uncatum.

forcipatum.

flavipes.

serpentinum.

anguinum. 
AGIRIONIDES.

1. Epallage:

Fatime.

2. Calopteryx:

Virgo.

Vesta.

Parthenias.

xanthostoma.

5. Anapetes:

forcipula.

virens.

leucopsalis.

barbara.

4. Sympycua:

phallata.

5. Pyrrliosoma:

minium.

6. Erythromma:

chloridion.

viridulum.

7. Ischnura:

speciosa.

tuberculata.

pumilio.

8. Agrion:

interruptum.

furcatum.

mercuriale. 


\section{$-25$ \\ hastulaturn. \\ lunulatum. \\ cyathigerum. \\ armatum.}

\section{Platycuemis:}

lactea.

Hanc divisionem Libellulinarum in plura subgenera solummodo tanquam tentamen offero, eanque minime absolutam et perfectam propono, cum gravitas signorum illa subgenera constituentium omnino in diversis subgeneribus diversa sit, quemadmodum e. g. subgenera Thecaphora, Diastatomma, Calopteryx, Anapetes inulto significantius, et, ut ita dicam, multo eridentiore modo a reliquis subgeneribus distincta sunt, quam alia. Propria vero genera ex iis ea de causa non efficienda et proponenda sunt, quod criteria generica, in forma instrumentorum cibariorum fundata, non satis discrepant a reliquis suae tribus: qua de causa in sequenti specierum descriptione divisionem Fabricianam in tria genera, Libellulam, Aeschnam et Agrion retinui.

Caeterum notatu haud indignum videtur breviter monere, in hoc opusculo sexaginta species Libellulinarum Europaearum descriptum iri, cum cl. Linné et cl. Fabricius tantum sedecim, et cl. Latreille tantum quatuordecim in scriptis suis protulerint. Praeterea sunt omnino nonnullae species, parum numerosae, Europa oriundae, quas cum non ipse viderim, ideoque examini accuratiori subiicere non potucrim, in hoc libello praeterire coactus sum. In fine tamen eas indicabo, sicuti scripta, in quibus prolixius de iis disputatum est.

Verúm tamen, priusquam ad singularum specierum descriptionem aggrediar, accuratior explanatio partium seu artuum Libellulinarum necessario praemittenda mihi videtur, ut, si de is ipsis sermo sit 
futurus, nulla exoriatur dubitatio, de qua parte disseratur, et ut quaelibet pars iusta intelligatur denominatione.

Agendum igitur est de Libellulinarum capite, trunco cum alis pedibusque, et de abdomine.

\section{DE TIBELLULINATUN CARITE.}

Caput horum animalium trunco non coalitum est, sed distinctum, liberum, et cum trunco per collum coniunctum: collum membranaceum est et parvae diametri. Circa collum caput faciliter rotando, tanquam circum axem, circiter per 180. circuli gradus verti potest.

Caput Libellulidum et Aeschnidum magis globosum est, quam hemisphaericum, et maxime ad antica valde convexum, ad postica concavum, quamris tempora ipsa, seu oculorum pars postica, satis inflata et turgida appareant. Hacc capitis forma globosa praecipue eo efficitur, quod oculi ipsi sunt valde globosi, magni, inter se propinqui: id quod minus valet de Agrionidibus, quae oculos quidem et ipsae quam maxime globosos habent, tamen eos inter se non propinquos, sed valde distantes et inter se separatos, quare earum caput transversum seu transverso-cylindricum appellandum est. Transitum ad hanc capitis formam Aeschnidum subgenus Diastatomma conficit.

In Libellulinarum capite spectanda imprimis est eius pars antica seu sinciput, et pars postica seu occiput.

In parte capitis antica, quae a nonnullis scriptoribus etian denominatur „facies“, exstat „Os", quod superne labro, inferne labio clausum est. Labrum (Tab.47. fig. 13. sub b) semper transversum, angulis rotundatis, subconvexum, antice in medio parum sinuatum.

[A dnot. A cl. Fabricio, in Philosophia entomologica aliisque suis scriptis, labrum appellatum est „clypeus“. Itidem Linneus sub nomine "clypei“ labrum intellexit; interdum tamen sub clypei denominatione totam faciem comprehendit.] 
Labium, os ab inferna parte claudens, e tribus compositum cst lamellis seu laciniis (Tab. 4\%. fig. 13. sub $\boldsymbol{a}$, ubi tamen antica tantum earum pars, quasi transversaliter secta, cernitur): hae mento superimpositae et coalitae sunt. Laterales intermediam quasi includunt et in apice ad internum latus denticulos habent duos.

Ad utrumque labii latus prominet basis seu stipites maxillarum (l. c. fig. 13. sub c, c), qui praccipue in Agrionidibus conspiciuntur.

Labro supcme adhaeret rhincrium (l.c. fig. 13. sub e), membrana quaedam, quac secundum motum labri, os aut apcrientis aut claudentis, replicari aut extendi potest. Nomen „rhinarium“6 a clariss. Kirby introductum est.

Supra rhinarium est nusus, qui illud semper fere ab utroque latere amplectitur (l. c. sub f.). Nasus non est flexibilis, sed naturae solidae. Si insecta huius ordinis os apcriunt, labrum supine movetur seu replicatur, quo fit, ut rhinarium membranaceum, plicatile in se ipsum revolvatur, seu sub naso abscondatur, cui ipsum est adnatum. Clarissinus Kirby opinatur, sensum olfactus in his animalibus sedem habere in rhinario et naso, quod et eo firmari videtur, quod in naso omnium ferc Libeflulinarum adsunt loculi duo parvi, nunc oblongi, nunc in puncti formam conditi, impressi, qui frequenter alius texturae esse videntur, atque reliqua superficici pars. - Praeterea haud negligendum est inter observandum, labrum plurimarum Libellularum gerere loculum rotundum, quam inaxime glabrum, quasi politum, et haud raro peculiari colore insignem. Similem disculum laevigatum permulta quoque Orthoptera gerunt in labri medio.

Nasus in superna parte „frontem" gerit (l.c. sub g), quae plerumque prominens, globosa et quasi turgida est. Frons plurimarum Libellulinarum superne lineam transversalem elevatam seu rugulam callosam gerit, saepe scabram. 
Frons cum naso, rhinario et labro in Libellulidibus et Aeschnidibus eadem fere planitie posita sunt: id quod in Agrionides non cadit, in quibus haec angulum constituunt, cum nasus atque labrum valde promineat.

Supra fiontem et supra illam lineam eius callosam' est „vertex", cuius in latere utroque ,antennae“ insertae sunt. In verticis parte postica Libellulidum Aeschnidumque est gibba quaedan perelevata, saepe bimucronata, quam „vesiculam verticis“ appellavi (l. c. sub $\boldsymbol{h}$ ). Plerumque est subpilosa, et iuxta eam positi sunt tres ocelli. In Aeschnidibus vesicula verticis multo minor est, quam in Libellulidibus, el subgenus Diastatomma loco eius tantum rugam seu lineam habet elevatam.

Ad latera capitis positi sunt „oculi“, maximi, globosi, vacui, in animalibus vivis plerumque coloribus micantes, post mortem fuscobrunnei. Hemisphaerae plerumque habent formam, etiam globosiorem; si post verticem coëunt, aut si invicem sibi vicini sunt, id plerumque fit angulo acutiusculo: in pluribus Aeschnidibus spatio maiore.

Intra oculos et faciem in quibusdam Libellulinis deprehenditur cuticula glabra, expansa, ad utrumque latus fronlis ac nasi (Tab. 47. fig. 13. sub $\boldsymbol{d}$, $\boldsymbol{d}$ ), quae a cl. Kirby "gena“ appellatur.

Postica pars hemisphaerae oculis formatae — „tempora oculorum" - plerumque convexa et quasi turgida est.

In omnibus Libellulidibus et longe plurimis Aeschnidibus oculi in capitis vertice coëunt, i. e. se tangunt (oculi contigui). In Libellulidibus oculi tantum angulo acuto, in pluribus Aeschnidibus spatio maiori se tangunt: in Diastatommatibus omnibus oculi invicem inter se remoti sunt aut divergunt.

In Libellulidum speciebus omnibus, uti etiam in Aeschnidibus, eo loco, quo coniunctio oculorum fit, et quidem postica capitis parte, 
observatur protuberantia quaedaun parva, cornea, convexa vel planior, plerumque triangularis vel cordiformis, saepe linea media inpressa, et postice pilis ciliata. Hanc protuberantian „cuneum" appellavi (Tab.4\%. fig.13. sub i), qui, cun colore interdum insigni ornatus sit, bonum in nonnullis Libellulinarum speciebus praebet signum distinctivum. In subgenere „Diastatomma“, quod oculos distantes seque invicem non tangentes lrabet, ille cuneus oculos connectit, et habet formam prisuaticam, superne acie instructam. In Agrionidibus cuneus prorsus abest, rel margine tantum temporum supra collum distinctiore repraesentatur.

Oculi a temporibus non semper linea terminali continua seu integra separantur, sed plerumque hacc linea flexuosa est, ita ut loculum paullulum excurrentem habeat. Imprimis Aeschnides et nonnullae Libellulides talem oculorum offerunt structuram. Sed saltem in Chlorosomatibus Europaeis illa linea non tam flexuosa est, ut, secundum meam sententiam, dici possit, eam quasi oculum secundarium formare.

Oculi Libellulinarum e lenticulis numerosissimis compositi sunt, ideoque superficiem quasi reticulatam habent. Praeter hos duos oculos omnes Libellulinae tribus gaudent oculis simplicibus seu ocellis, qui a nonnullis scriptoribus et „stemmata“ vocantur. Hi semper in capitis vertice positi sunt, iuxta vesiculam verticalem: in Libellulidibus Aeschnidibusque idque in triangulo, rarius in directione rectolineari. Horum ocellorum medius plerumque reliquis est maior. In Agrionidibus, quae vesicula verticis carent, ocelli in trianguli spatio, paullulun elevato, positi sunt.

Ocelli semper fere sunt fulvi, pellucidi, interdum nigri: in paucis Agrionidibus coerulei.

In medio occipite, quasi excavato, cum latera ipsa seu oculorum tempora turgida et convexa sint, parvun quoddam foramen, recipiendae faucis seu colli membranacei causa, conspicitur. 


\section{0}

Praeter illas externas Libellulinarum capitis partes, de quibus hucusque sermo fuit, contemplandae sunt „antennae“. Hae in Libellulinarum omnibus generibus fere uno eodemque modo constructae sunt: in Agrionidibus paullulo sunt longiores, quam in reliquis generibus. Sunt breves, tenues, nudae, capitis vertici ad oculorum marginem insertae, setigerae, quinquies articulatae. Articulus primus, cui nomen est „scapus", itemque secundus, qui „pedicellus" vocatur, semper reliquis multo crassiores sunt: reliqui autem setam formant triarticulatam, articulis tam tenuibus et continuis, ut eorum articulatio vix bene possit distingui.

\section{DE LIBELLULINATEUR ORTS PARTIBUS INTEIR IIS.}

Libellulides os labro et labio fere totum clausum habent: Aeschnides et magis etiam Diastatommata labrum labiumque paullulmn patentia habent: Agrionides vero adeo insigni modo os habent apertum, ut, vel labio labroque clauso, partium internarum particulae plures oculo se offerant.

Os aperitur labro reflexo et e statu perpendiculari in statum fere horizontalem recedente, quod rhinario replicato, et labio, quod in mento tanquam in cardine movetur, retro verso efficitur. Simul laciniae laterales paullulum versus latus amoventur.

Ore sic plane aperto adspiciuntur superne ad utrumque latus „Inandibulae", crassae, corneae, trigonales, subtus validae, rotundatae, supra dentibus exterioribus curvatis, longioribus, acutis, inter se connatis instructae.

Sub his mandibulis affixae sunt ad oris partem internam „maxillae“6. Hae mandibulis sunt similes, sed minores et biarticulatae, namque stipiti insidunt tanquam stylo: dentibus curvatis, elongatis, et ab externa parte (quasi dorso) articulo cylindrico, curvato, ab exteriore 
parte valde piloso sunt instructae, qui „palpum" repraesentans plane eiusdem est staturae atque "galea" Orthopterorum.

In intima oris parte conspicitur porro corpusculum quoddam rotundum, saepe cylindricum, glabrum, faucem obtegens, quod ab aliis „lingua", ab aliis „palatum" appellatur.

Quod ad mandibularum et maxillarum structuram attinet, Libellulides, Aeschnides et Agrionides non admodum inter se diversae sunt, sed illas partes quam maxime simillimas gerunt.

Multo autem maior est differentia naturae labii et laciniarum eius lateralium. His enim respectis non solum illa tria genera valde inter se discrepant et diversa sunt, sed etiam unaquaeque species fere aliquantulum ab aliis recedit. Tab.47. fig. 1-6. labia Libellulae bimaculatae, quadrimaculatae, vulgatae, flaveolae, aeneae atque metallicae delineata sunt, et statim videmus, unamquamque a reliquis diversam esse. Libellulidum labium a labio Aeschnidunn (Tab.4\% fig. \% labium A. serpentinae est depictum) et Agrionidum (fig. 8. Agr. tuberculati labium) maxime distinctum est, quod laciniae eius laterales (differentia principali „lacinia media lateralibus multo minore“ omissa) ad angulum internum seu ad suturam denticulum habent parvum, acutum, immobilem, ita ut, ore clauso, hi utriusque laciniae denticuli apice paene se tangant. - Aeschnidés pari fere modo denticulo instructas habent lacinias laterales, sed prope, et quidem ante eum, alio mobili, quasi articulato.

[Ad̦not. In subgenere Diastatomma hic denticulus mobilis curvatus est et multo crassior, quam in reliquis Aeschnidibus, et signum illius subgeneris constituendi haud spernendum est. In subgenere Thecaphora praeter hunc denticulum aliquantisper mobilem plures conspiciuntur minores in superno laciniae latere, et in pagina eius interiore adest alter denticulus leviter reflexus, in rugulam excurrens.] 
Agrionides labii lacinias laterales multo mobiliores, quam reliqua duo genera habent. Ad apicem dente perlongo, parum curvato, immobili, quam maxime acuto instructae sunt et pone eum, in externa parte, habent denticulum, vix illo breviorem, articulatum, mobilem.

[A d not. Plura de his oris partibus scripsit cl. Brullé. 1832. in Ephemeride periodica, quam vocant "Annales de la societé d'Entomologie“, affirmans, lacinias labii laterales palpos oris ipsos esse, in qua re cum eo consentire non possum.]

\section{DE GIBELTULINARUM TIRENCO.}

Caput Libellulinarum omnium collo membranaceo cum „trunco“ cohaeret, qui pedibus et alis instructus est, et cui postice abdomen annatum est. Truncus oculo statim offert segmenta seu divisiones duas distinctas: alteram, capiti propiorem, cui ab inferiore parte pedes anteriores inserti sunt: alteram maiorem, validiorem, a priori separatam, quae superne alas, inferne pedes medios et posticos sustentat.

Cum nonnulli scriptores, e. g. cl. Kirby, pedes anteriores seu anticos „manus“ nominaverint, ea trunci pars, cui illos iunctos esse vidimus, „manitruncus“, altera vero pars „alitruncus“ vocatur.

Manitruncus in Libellulidibus et Aeschnidibus semper est parvus, et in nonnullis tam parvus et ab occipite tantopere obtectus est, ut, animali superne adspecto, vix sit discernendus. In Agrionidibus semper maior, semperque conspectui valde patens est. Structura et color manitrunci in multis speciebus insignis est, et speciei ab affinibus discernendae bene conveniens.

Latus manitrunci superius „prothorax“, inferius „,antepectus“ vocatur. (A pluribus scriptoribus et a me quoque in Horis entomologicis haec corporis pars "collare“ vocabatur.) 


\section{- 33}

In Libellulinis manitruncus plerumque cylindricus, supcrne globosus, antice coarctatus, postice elevatus seu ascendens, ibique hand raro discum unum rel duos, aut lobum productuin format.

Alitruncus, obiter oculis inspectus, unus atque indivisus esse videur: accuratius rero si illum perlustramur, in duas partes eum divisum esse apparet, quamris ralde cohacrentes, sed cuticula separatas. Pars capiti propior superna ,mesothora." inferna ,mediopechus": pars a capite remotior superna ,metathor'ax", inferna ,postpectus" appellatur. Clariss. Linné et plurimi scriptores alitrunci partem superiorem

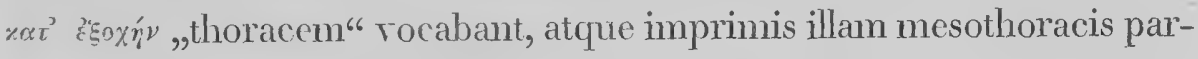
tem, cui cl. Kirby (vid. infra) nomen „collare“ imposuit.

Contemplatio enim mesothoracis statim oculo offert particulam quandam anteriorem, magnam, plerumque strigis coloratis pictam, et semper sutura quadam elevata bipartitam (Tab. 4\%. fig.14. sub a.b.). Haec sutura postice latior et quasi hians est, et ad utrumque latus excurrit in loculos duos obliquos, angustos, paullulum excavatos, marginibus crassioribus, saepissime crenulatis cinctos, quos „septa vol septula" vocare licebit (l. c. sub c.c.).

Posterior mesothoracis pars et totus metathorax particulas plures valde elevatas et variac formae monstrat, de quibus hic amplius est disserendum. Has particulas tuberosas, globosas, in descriptione specierum Libellulinarum sequenti interdum nomine collectivo ,tubercula dorsalia seu interalaria" significabo.

Horum tuberculorum prinum, collari proximum, plerumque quinquangulare vel subquadratum vel rotundulum est, et „dorsulum vocatur (Tab.4\%. fig.14. sub e.). Sequens tuberculum plerumque duplex apparet, tanquam globuli duo glabri et coloris splendidioris: ,scutelli" nomen ei est inditum (l. c. fig.14. sub f.). Ciuius ad latera "frenım" utrimque (1. c. sub g.g.) additum est. Sequitur tuberculum tripartitum, ita ut e tribus particulis constructum videatur (fig. 13. 
sub p.), cui cl. Kirby nomen "pnystega“ imposuit. - In antica parte et iuxta dorsulum ,axes" alarum anticarum reperiuntur, quae callo plicato obteguntur, quem „callum axillarem“ voco (fig. 13. sub $\boldsymbol{d}$.d.). Alae interdum, vel plerumque, duos habent callos axillares, anteriorem, hic descriptum, et posteriorem, illi vicinum, ad postica positum, simplicem, ab alarum nervorum radicibus inclusum.

Hae sunt particulae superiores mesothoracis, earumque analogam repetitionem (collari excepto) offert superficies superna metathoracis. Etenim „postdorsulum“ (fig. 14. sub h.): „postscutellum“ (sub $i$.) et „metapnystega" (sub k.). Postdorsulum in omnibus fere Libellulinis scutello multo maius est, rotundatum, in media parte impressum, et ad postica in apicem mucronatum desinens. Postscutellum a scutello plerumque non diversum: metapnystega autem una tantummodo particula constat, non tribus, uti pnystega, et ea multo minor est. Postfrena (fig. cit. sub $l$. l.) utrimque ad metapnystegae latera a mesothoracis frenis non discrepant.

In Agrionidibus tubercula interalaria eandem fere habent structuram.

Color callorum axillarium in pluribus speciebus sedulo inspiciendus est, cum saepe criterion distinctivum optimum praebeat.

\section{DE TIBELTULTNATEM ALIS.}

Plures viri Entomologiae operam navantes, et imprimis clari Jurine et Kirby, determinationes et descriptiones accuratissimas venarum seu nervorum, per insectorum alas perductorum, dederunt. Valent hae determinationes omnino de Hymenopteris ac Dipteris, et eorum alis potissimum adaptatae sunt. Verum in Libellulinarum speciebus eae non sufficiunt, cum animalia huius classis ramificationem seu reticulationem alarum multo magis compositam seu multiplicatam habeant, quam illa; atque in nullis fere insectis systema venarum in 
alis obviarum, si ita dicere fas est, tam excultum et multitudine venarum tam magna praeditum est, quam in Libellulinis. Termini paucis illis Hymenopterorum Dipterorumque alarum venis attributi non sufficiunt in Libellulinis, attamen alarum horum insectorum reticulatio accuratissime et eo maiore cum studio est examinanda, cum mirum et constantissimum diversorum illorum generum et quorundam subgenerum praebeat signum distinguendorum.

Hac de causa ausus sum, pluribus venis seu nervis Libellulinarum nova imponere nomina, cum nomina, a cl. Jurine, Kirby et aliis introducta, haudquaquam sufficiant ad reticulationem horum insectorum rite et distincte describendam.

Notandum est, in ordine seu classe Libellulinarum praecipue quatuor diversas formas alarum principales occurrere, quae in Libellulidibus, in Aeschnidibus, in subgenere „Calopteryx“ et in Agrionidibus reperiuntur. Signa omnibus Libellulinarum alis communia haec sunt: alae sunt homogenes, planae, extensae, attenuatae, rotundatae, longae, integrae, ad basin callo corneo thoraci adnatae, massae membranaceae, vasis (i. e. venis seu nervis, ita vulgo dictis) numerosissimis reticulatae, permultas areolas constituentibus.

Alae sunt homogenes, i. e. anteriores eiusdem massae seu substantiae atque posteriores sunt.

Alae sunt planae, i. e. sine plicis; notandum tamen, si diligentissime eas contemplemur, videbimus, venas crassiores, quam alarum membranam ipsam esse, ita ut areolae quodammodo excavatae nominari possint. - Porro venae plurium specicrum longitudinales, ne dicam omnium, inter se alternant, quod ad ipsarum situm attinet: alia enim aliis vicinis paullulo altius posita est, ita ut, si dissectionem alae transversalem efficias, inde linea constituatur obtuso-angulata.

Alae sunt attenuatae: semper enim longiores sunt, quam latae. Alarum latissimarum latitudinis ratio est tertia pars longitudinis, et 
angustissimarum quinta pars longitudinis alae: certe hoc valet de omnibus speciebus Europaeis.

Alae sunt rotundatae, cum apex sine angulo acuto circuli partem efficiat.

[Unicam eamque exoticam speciem hoc loco excipiendam censeo, Agrion „Amalia“ (Burmeister. Vol.II. Tom.II. p.818.), Agr. „Lucretiae" Druryi, seu Agr. „lineari“ Fabricii simile, cuius mas in alis posticis ad parastigma loculum habet dilatatum.]

Alae sunt longae: plerumque alae abdominis longitudinem aequant, neque abdominis apicem attingunt. Sunt quidem nonnullae species exoticae, quarum alae abdomine paullo longiores sunt.

Alae sunt integrae: namque nec appendicibus, nec lobis instructae sunt, omnibusque aliis elevationibus aut superficiei aut marginum carent.

Alae sunt membranaceae: haec membrana tenuissima est, plerumque hyalina, rarius colorata. Est duplicata, cum e duabus membranis, superiore et inferiore, sit composita. Sectione anatomica hanc membranae duplicitatem, ut ita dicam, demonstrare mihi non contigit, manifesta autem facta est duobus phaenomenis. Sunt enim nonnullae Libellulinae exoticae alis coloratis, quae in pagina superiore plane alium habent colorem, atque in pagina inferiore. Veri igitur simile mihi visum est, duplicem esse illam alae membranam, cum vix mihi persuadere possem, simplicem cuticulam tam tenuem in altera pagina aliter pictam esse, atque in altera, quippe cum hi colores Libellulinarum non pulvere, aut, uti in Lepidopteris, squamulis minutis efficiantur, sed ipsa alae materia. Multo autem evidentius ex eo mihi apparuit, membranam alae duplicem esse, quod repererim Libellulinas, quarum una alterave ala, venis nonnullis fortasse paullo post insecti perfecti ex exuviis exclusionem ruptis, tota erat impleta humore seu aqua flavida, ita ut adspectum vesicae magnae offerret. Hoc 
phaenomenon, quod in Orthopteris saepius observatur, extra dubitationem posuit, membranulam illam duplicem esse.

Libellulinae recens exclusae alas iam usque ad magnitudinem consuetam extensas per plures horas habent splendore singulari praeditas, pariter atque si solutione gummi arabici sint obductae. Postea hunc splendorem anittunt, et nitorem vitreum adipiscuntur. Si per plures hebdomades virunt, etiam hic nitor vitreus deminuitur, et membrana fit minus hyalina et fere turbida seu nubila.

Venae alas per longitudinem et latitudinem magno percurrentes numero a pluribus scriptoribus „nervi“ sunt appellatae. Cum vero sint revera tubuli, per quos brevi temporis spatio post animalis exclusionem, relicto statu chrysalidis, succus quidam propellitur ad totam alam extendendam, cumque fortasse etiam aer hoc modo per illos tubulos emittatur in alam, ductus pneumato-succiferi esse videntur, ideoque denominatio venarum fortasse melior est, quam nervorum.

Hae venae in plurimis Libellulinis, ne dicam in omnibus, hamulis minutissimis instructae sunt. Neque solum venae longitudinales, sed etiam transversales tales habent hamulos, qui non erecti, sed apice versus alae apicem directi sunt, ita ut, si digitus ab alae basi ad apicem movetur, eoque ala stringitur, illi hamuli vix attactu sentiri queant. Sin autem digitus retrorsum movetur, hamuli illi quam maxime tangendo percipiuntur. Usus autem eiusmodi armaturae mihi non videtur quaerendus in adminiculo, quo insectum, dum excluditur atque e chrysalidis exuviis prorumpit, uti possit ad alas melius e vaginis extricandas, quibus antea includebantur: nam dum haec fiunt, totae alae sunt molles et prorsus flexibiles.

Crediderim potius, hamulos illos versus alae apicem directos inservire animalis volatui, idque tum maxime, cum per arborum herbarumque folia densa pervolat. 
Quamquam autem magnus est numerus harum venarum in $\mathrm{Li}$ bellulinarum alis, tamen secundum mirabilem ordinem semper sitae sunt, et venae per longitudinem alae excurrentes in unaquaque specie prorsus eodem modo constructae sunt atque in reliquis: venae autem transversales in exemplis eiusdem speciei haud raro variant, aut potius in unoquoque exemplo paullulum diversae sunt. Transversales igitur venae minus praecipuae esse videntur, ideoque numerus et figura areolarum non in omnibus exemplis plane eadem sunt.

Structura autem alae per venas formatur et firmatur, cum ala ipsa seu membrana non solum toto margine tali vena includatur, sed etiam quasi secundum leges determinatas in areas quasdam regulares dividatur. Haec alae constructio diversis generibus et quibusdam eorum subdivisionibus plane est propria, ideoque eius demonstratio accuratior haud videtur supervacanea.

Caeterum notandum est, in Libellulinis duas alarum formas inveniri. Partim enim alae membranula accessoria praeditae sunt, partim ea sunt destitutae.

Quippe membranula illa accessoria est cuticula quaedam non hyalina, sed opaca, ad marginem alarum basalem sita. Ea tantum in Libellulidibus et Aeschnidibus reperitur: Agrionides ea carent.

Itaque in Libellulinarum alis contemplandis spectanda est taun earum materia, quam earum forma seu constructio. Membrana alae est tenuissima, secundum longitudinem vix plicata, vasculis seu venis in areolas numerosissimas divisa: ad ambitum seu marginęm vena marginali terminata, plerumque hyalina, semper fere iridea, rarius colorata. Membranula accessoria (Tab.47. fig.9.10. sub $\boldsymbol{A}$.) margini abdominali seu basali alae Libellulidum Aeschnidumque annata, angusta, plerumque acuto-triangularis, opaca, saepe alba aut cinerea: semper venis omnino caret.

Alarum partes sunt: 
a) basis, pars abdomini proxima.

b) apex, pars priori opposita.

c) medium seu discus, pars intra illas sita.

Basis alarum alitrunco annexa est axillis, quae callis (vid. supra) obtectae sunt.

In apice, ante finem extremun, ad marginem alae anteriorem, exstat parcastigma (Tab.47. fig.9.10. sub $\boldsymbol{d}$.), quod est particula alae membranae peropaca, quasi cornea, venis duabus longitudinalibus duabusque transversalibus inclusa: ideo plerumque quatuor latera efficit.

Parastigma est particula alae quam maxime notabilis, idque Libellulinis prae caeteris Neuropteris est peculiare, cuius tamen usus nondum est erutus. Omnes Libellulinae eo fere instructae sunt, exceptis nonnullis Agrionidibus, inter quas species quaedam reperiuntur, parastigmate in uno alterove sexu carentes. - Est plagula densa, opaca, et cornea massa constare videtur: haud raro circa venas, quibus coarctatur, paullulo pellucidior est: plerumque albida aut obscuri coloris, in foeminis tamen non ita raro coloris lucidioris, quam in maribus. Semper fere est unicolor: raro bicolor, e. g. in Agrio barbaro.

Denominatione „parastigma“ Illiger in editione Rossii Faunae Etruscae (Tom. II. p. 193.) primus, quod sciam, usus est; deinde in opere, cui titulus „Magazin für Insectenkunde“ Tom. V. p.20. amplius hac de re disseruit. Cl. Kirby (Introd. Tom.III. p.409.) illam videtur imitatus esse. $\mathrm{Ab}$ aliis et praecipue $\mathrm{ab}$ antiquioribus scriptoribus significatur nominibus: stigma, stigma ordinarium, punctum alae, macula ordinaria, e. s. p.

Figura alae conficitur ambitu seu peripheria, ad cuius limites seu margines attendendum est. Margo alae constat vena reliquis paullo crassiore, quae totam alae membranam includit, excepta membranula accessoria, quae ab externa parte margini adnata est. 
Margo alarum, qui vena marginali seu costa efficitur, est:

a) anticus seu anterior, inde a basi alae in antica eius parte ad apicem ductus (Tab.4\% fig. 9 -12. sub a e.).

b) posticus seu posterior, a basi alae, posteriore parte, ad apicem ductus (1. c. sub ble.).

Interdum praeterea observandus est:

c) basalis seu abdominalis. Si basis alarum posticarum latior est, quam reliqua alae pars, atque in ea margo posticus non paullatim deminuitur, sed angulum, vel rotundum vel acutiorem, format, pars marginis postici ab hoc angulo ad iuncturam alae cum trunco „margo basalis seu abdominalis“ vocatur.

Huiusinodi autem structuram in pluribus Aeschnidum speciebus observavimus.

Margo anticus plerumque rectus et ad apicem rotundus et flexus est, ad formandum apicem. In nonnullis tamen exoticis speciebus margo anticus sinuatus sive flexuosus est.

Margo posticus semper magis curvatus seu rotundus est, quam anterior, et sic plerumque sensim sensimque ad alae iuncturam cum trunco extenditur. In nonnullis Libellulidibus Aeschnidibusque, uti supra iam commemoratum est, margo posticus quodammodo angulum efficit, ibique incipit margo basalis. In omnibus Agrionidibus, exceptis paucissimis earum subgeneribus, margo alarum posticus versus basin angulum internum seu sinum effingit, quo fit, ut haec alae pars, basi proxima, aperte angustior sit, quam reliqua alae superficies: ala vero hoc modo conformata quasi petiolo instructae praebet adspectum.

Margo basalis inAeschnidum plurimis subgeneribus ac speciebus, sed tantummodo in earum maribus, insigniter et fere in alia specie alio modo sinuatus sive flexuosus est. In Libellulidibus Europaeis 
eiusmodi structura non comparet, exceptis speciebus Chlorosomatis subgeneris.

Maxime autem insignis est alarum reticulatio seu venarum ramificatio. Omnes Libellulinarum venae sunt aut „longitudinales“, aut „transversales“, quibus accedit „vena marginalis“ seu „costalis“, ambitum alae efficiens. Venae longitudinales sunt, quae per longitudinem alae procurrunt: venae autem transversales eae sunt, quae cum longitudinalibus et inter se cohacrentes, „areolas" seu particulas alarum membranae parvas, ab illis venis inclusas, constituunt.

Vena marginalis seu costalis „costa“ quoque seu „margo“ appellatur.

In marginis antici media parte, basi tamen semper proprior, quam apici, oculo se offert venula transversalis, vicinis crassior, quasi cornea. Hanc voco „nodum". (Tab.47. fig.9-12. sub c.) ")

Apici alae propius marginem anticum tangit parastigma, de quo supra dictum est.

Nervi igitur longitudinales sunt venae, quarum directio plus minusve secundum alae longitudinem constituta est. Sunt aut

Radii seu radiales, qui e basi alae excurrunt, aut

Sectores, qui ex aliis nervis orti sunt, ad marginem procurrunt eumque attingunt.

Nervi transversales sunt venae seu nervi transverse aut oblique per alas ducti, qui alios transversales aut longitudinales tangunt aut secant, et hoc modo illas areolas formant, quarum plures vicinae „area" vocantur.

Omnes Libellulides et Aeschnides, et ex Agrionidibus subgenera Epallage et Calopteryx, quatuor habent radios, reliquae Agrionides tres.

*) A dnot. Hanc venulam callosam a cl. K irby (Tom. III. translat. germ. p. 409.) „stigma“ esse nominalam suspicor. Cum vero verbum, stigma" a nonuullis scriptoribus aliis partibus sit impositum, verbum ,nodus" in eius locum substitui. 
$\boldsymbol{R A D I I}$ in Libellulinarum alis hi sunt:

a) Radius internodalis, e basi alae exiens, et in media nodi parte desinens (l.c. fig. 9 -12. sub $n \boldsymbol{p}$.).

ß) Radius principalis, e basi alae exiens per totam alam, prope marginem anticum, usque ad apicem ductus (fig. alleg. sub $\boldsymbol{o}$ e.): ante apicem cum margine ipso parastigma constituit.

r) Radius medius a basi alae exiens, in margine alae postico (in eius medio, aut apici propior) finitus (fig. alleg. sub $q \boldsymbol{k}$.).

ঠ) Radius spurius seu infimus ex infima basis parte excurrens, marginem nusquam attingens, sed cum radio medio aut cum venis transversalibus coniunctus (fig. 9. sub $r s$; fig. 10.11. sub $r$ t.).

SECTORES in alis Libellulinarum hi sunt:

a) Sector medius, excurrens e venula transversali (semper fere angulata) in medio alae (l. c. sub $v_{\text {. }}$ ), marginem posticum propius ad apicem secat (sub $v i$.).

в) Sector principalis incipit a basi sectoris medii (in Calopterygibus a basi radii principalis), et iuxta radium principalem procurrens in apice terminatur (sub $w f$.).

r) Sector nodalis est continuatio nodi, isque e nodo versus alae apicem usque ad marginem ductus est (sub $\boldsymbol{c}$ g.).

d) Sector subnodalis, cum antecedente parallelus, exit e basi sectoris principalis (in Calopterygibus e basi radii principalis), et currit ad marginem posticum apici propiorem (sub $\boldsymbol{x} \boldsymbol{h}$.).

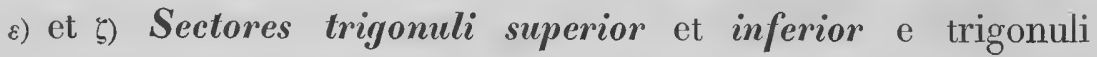
(cf. infra) apice exeunt, et marginem posticum tangunt (sub . $\boldsymbol{l} \boldsymbol{l}$ et $\boldsymbol{t} \boldsymbol{m}$.).

п) Arculus. In alae particula, inter radium principalem et radium medium, et a basi alae satis remota conspicitur vena 


\section{3}

transversalis, plerumque reliquis crassior et quasi angulata. E medio huius venae transversalis progreditur sector brevis, curvatus et in radio medio desinens (fig. 9.10. sub vu.). Hunc sectorem ,arculum“ appello. - In Agrionidibus quoque arculus apparet, sed minus curvatus, (fig.12. sub $\boldsymbol{u v}$.) et in subgenere Calopteryx non usque ad radium medium protenditur (fig. 11. sub $v u_{\text {.) }}$, sed nodulum quendam (fig.11. sub $u_{\text {.) }}$ ) format, et inde usque ad ipsum alae marginem (l.c. sub $i$ i.) porrectus est.

Praeter hos nervos longitudinales Libellulinarum praecipuos in subgenere Calopteryx permulti alii reperiuntur, qui in structuram alae principalem parum cadunt, et plerumque e nervis transversalibus exeuntes alae marginem tangunt: secundarii appellari possunt eiusmodi sectores.

Areolae sunt particulae alarum a nervis inclusae, quae formantur vel nervis longitudinalibus, quae cum transversalibus coëunt, vel transversalibus solis cum aliis nervis transversalibus coniunctis. Areolae illae, priore loco commemoratae, plerumque quadrangulae sunt: ad alteram si spectant rationem, haud raro sunt quinque aut sex laterum.

Ex areolarum numero una potissimum distinguitur, et tam magnitudine, quam figura prae reliquis notabilis est atque insignis. Cernitur ea in alis Libellulidum et Aeschnidum: in Agrionidibus deest.

Est vero haec areola ea, quae in media ala, basi propior, a duobus nervis transversalibus constituitur, e medio radii medii exeuntibus, et versus alae marginem inferiorem in angulum coëuntibus, ita ut triangulum, apice deorsum verso, formet (Tab.47. fig.9.10. subuvt.). Nomen ,trigonuli“ ei imposui, cum saepe eius mentio facienda sit.

Libellulinae trigonuli acumen habent acutum, Aeschnides saepe obtusum. 


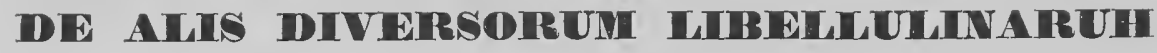 GENERTI.}

Quod in Libellulinis ad structuram alae attinet, uti iam supra monui, quatuor formae principales statim ab initio distinguendae sunt: alarum Libellulidum, alarum Aeschnidum, alarum Calopterygum et alarum reliquarum Agrionidum.

\section{DE MIBETIUIIDUM ATIS.}

Criterion admodum distinctivum alarum huius generis, et quod statim in oculos incidit, est trigonulum alarum anticarum liberum, i. e. cuius acumen radio spurio seu infimo non attingitur (fig. 9. litt. $t$, seu potius $s u t$.), qui igitur in trigonuli basi (sub litt. $s$.) terminatur. Quod criterion secundarium Libellulides optime ab Aeschnidibus distinguit, et constantissimum est.

Acumen trigonuli Libellulidum nunquam angulum obtusum, ne rectum quidem, sed semper acutum efficit.

In alis posticis trigonulum non est liberum, radius enim spurius acumini eius, nec tamen basi adhaeret.

Alae Libellulidum aut aequant abdominis longitudinem, aut eo sunt paullo longiores: sunt latiusculae, praesertim posticae, latitudine tertiam longitudinis partem aequantes. Posticae versus basin haud raro latiores, quam versus apicem sunt, quo fit, ut formam quasi triangularem repraesentent. In Europaeis Libellulidibus margo alarum anticus semper rectus: inter exoticas inveniuntur, quae margine antico sinuato aut dilatato instructae sunt.

Margo alarum posticarum posterior in basi sensim usque ad alitruncum procurrit, ideoque nullum marginem alae basalem format. Excipiendum ex hac regula est subgenus Chlorosoma, cuius mares 
marginem illum posticum paullulum angulatum gerunt, et secundum hoc signum Aeschnidibus accenseri possunt.

Nunerus areolarum in Libellulidibus satis magnus est, sed diversus in diversis speciebus, et diversus in ala antica et postica. Lib. bimaculata in ala antica habet 250. areolas, in ala postica 400. Lib. vulgata in ala antica 224. in ala postica 292. Agrion Virgo in ala antica 1050. in ala postica 1280 .

\section{DE AESCHNIDUM AHIS.}

Aeschnides alas habent Libellulidum alis similes, plerumque nervis crassioribus: recedunt $\mathrm{ab}$ iis plane et constantissime structura reticulationis circa trigonulum. Aeschnides enim hoc nunquam habent liberum, sed acumine cum radio spurio seu infimo iuncto (Tab. 47. fig. 10. sub $\boldsymbol{t}$.), idque tam in alis anticis, quam in posticis. In Aeschnidibus trigonuli angulus apicalis non tam acutus est, quam in Libellulidibus, sed obtusior, quin etiam interdum maius spatium, quam 145. circuli gradus complectitur.

Radius spurius plerumque non recta linea, sed deorsum flexus seu quasi arcuatus est: in subgenere vero Diastatomma aut rectus, aut per angulum flexus usque ad trigonuli apicem extenditur.

Alae Aeschnidum posticae in maribus longe plurimarum specierum (quin omnium Europaearum, si subgenus Cyrtosoma et Aeschnam pilosam excipias) valde a foeminarum alis recedunt. Margo enim alae posticus non sensim curvatus alitruncum attingit, sed versus basin repente flexus quasi angulum efficit: margine igitur postico flexo marginem peculiarem (marginem basalem seu abdominalem) constituit. Hic in diversis speciebus semper fere diversus, diversoque modo aut sinuatus est, aut angulatus, aut flexuosus.

Aeschnidum maxima pars alas habet ecoloratas: Aesch. grandis et chrysophthalmus alas totas habent lutescentes, et Aesch. pilosae foe- 
mina hic illic flavescentes. - Aliae picturae, e.g. vittae, fasciae, maculae, in Europaeis speciebus non occurrunt, atque etiam ex exoticarum numero raro vidi exempla in hunc modum picta.

Numerus areolarum satis magnus est in Aeschnidibus, et numerum areolarum in Libellulidibus observatarum facile superat: versus apicem areolae saepe minimae sunt.

Vena marginalis et omnes fere radii admodum sunt crassi, quo fit, ut volatus Aeschnidum sit valde rapidus, velox, et per longum temporis spatium permanens.

\section{DE CAMOPTERYGUM ATIS.}

Agrionidum subgenus Calopteryx, ut iam supra monui, structura alarum tantopere a reliquis Agcionidibus recedit, ut separatim de eius alis disserendum mihi videatur.

Omnes Agrionides, alarum ratione habita, statim eo a Libellulidibus Aeschnidibusque diversae sunt, quod alas membranula accessoria destitutas habent, quod earum venae multo graciliores sunt, et alae ad basin multo angustiores sunt, quam ad apicem.

Calopteryges (certe omnes Europaeae) ambitum alarum habent oblongum, ovalem, in apice rotundatum, in basi paullatim attenuatum. Alae ipsae sunt satis latae, et earum margo posticus prope truncum non angulatus aut sinuatus, sed continuo rotundatus. Eximia multitudine areolarum - ad 800. - 1000. et ultra in unaquaque ala insignes sunt Calopteryges, id quod magna sectorum secundariorum copia praecipue efficitur. Radiorum numerus idem atque in generibus praecedentibus, nervi autem transversales sunt numerosissimi. Structura nervorum longitudinalium magnopere cum Libellulidum et Aeschnidum alis convenit: arculus vero in Calopterygibus non in radio medio ad apicem terminatur, sed in sectore arculi (Tab.47. fig.11. sub $\boldsymbol{u}$ ii.), et dein usque ad marginem posticum procurrit. Cum 
trigonulum non sit plane integrum, e loculo, quo illud repraesentatur, unus tantum trigonuli sector (l.c. $t \boldsymbol{l}$.) excurrit.

Parastigma in nonnullis Calopterygum speciebus deest: in maribus Europaearum omnibus, et in foeminis earundem non tam distincte venis transversalibus intra venam marginalem et radium principalem limitatum seu inclusum est, quam in reliquis Libellulinis. Subgenus tamen Epallage, quod, ratione alarum reticulationis habita, plane cum Calopterygibus convenit, etiam in sexu foeminino parastigma consueto modo formatum ostendit. Est in foeminis Calopterygum Europaearum parastigma alae loculus marginis antici, apici propior, albus, opacus, venulis albis transversalibus perviis.

Alae Calopterygum longe plurimarum pulchre sunt coloratae, praesertim marium: foeminae alas quidem coloratas, sed multo minus splendidas habent: venae tamen longitudinales plures colorem nitide cyaneum aut viridem ostendunt.

\section{DE IBELIQUARUM AGTRONIDUM ALIS.}

Reliqua Agrionidum subgenera in universum parem habent alarum formam, et plerumque similem reticulationem. Excipienda sunt subgenera „Anapetes" et „Sympycna“, quae paullulum a reliquis recedunt, uti infra demonstrabo.

Alae Agrionidum sunt longae, angustae, in apice rotundatae, in basi valde attenuatae, ut fere petiolatae vocari possint, cum margo posticus non continuo usque ad alitruncum procurrat, sed paullulum ab eo distans angulum internum obtusum seu sinum constituat, et ala ibi repente angustior fiat. — Nodus ab alae apice multo remotior, et ad tertiam totius marginis antici partem versus basin positus est.

Radii Agrionidum sunt tres, radio spurio seu infimo plane deficiente: radius medius (fig.12. sub $q k$.) non recta via a basi ad margi- 
nem posticum porrigitux, sed venula transversa et alia, arculum repraesentante (fig. 12. sub vu.), in anguli modum interruptus est.

Sectoribus secundariis perpaucis Agrionidum alae instructae sunt. Unus tamen plerumque, plus minus distinctus, invenitur intra sectorem principalem (fig. 12. sub $v \boldsymbol{f}$.) et sectorem nodalem (sub $\boldsymbol{c} \boldsymbol{g}$.). Est in plurimis huius tribus subgeneribus rectus, et cum illis sectoribus (principali et nodali) areolas rectangulas, subquadratas constituit. In "Anapete“ autem et „Sympycna" ille sector secundarius angulatus seu lateribus areolarum quinque angulos habentium constitutus est. Area igitur in apicali hac alae parte, intra sectorem principalem et nodalem, areolis pentagonis impleta est, qua structura areolarum illa duo subgenera a reliquis distinguuntur.

Parastigma in omnibus his Agrionidibus conspicitur, et est vel rectangulum vel rhombeum. Illud semper oblongum est: hoc haud raro lateribus constat aequalibus angulo acuto, superiore ad apicem spectante. Parastigmata rectangula plerumque unius, rarius duplicis sunt coloris, fusca, opaca: rhombea vero plerumque in centro magis colorata sunt, quam versus ambitum.

Omnes Agrionides, exceptis subgeneribus Epallage et Calopteryx, alas omnino non coloratas et plane hyalinas habent, certe ita se habent, quotquot earum species hucusque vidi.

\section{DE HIBELTULINAREM PEDTRUS.}

Pedes Libellulinis seni sunt, iique mediocris longitudinis: Libellulidum breviores, Agrionidum longiores sunt, quam reliquarum. Sunt pedes teretes, femoribus subcompressis, tibiis linearibus (raro dilatatis), tarsorum articulis tribus, unguibusque magnis, curvatis, apud nonnullas species in apice bifidis. Tibiae semper, femora plerumque pilis longis, rigidis ab utroque latere ciliata sunt. Hi pili in medio tibiarum longiores sunt, quam reliqui, et in interiore tibiarum latere, 
ad eius apicem, densiores, breves, rigidiores, quasi pectinem formantes. Femora quarundam Libellulidum et maxime Aeschnidum loco pilorum denticulos parum acutos gerunt.

Pedes postici, praesertim eorum femora, in plurimis Libellulinis longiores sunt, quam medii et antici. In Libellulidibus et Aeschnidibus femora fere duplo crassiora, quam tibiae, in Agrionidibus eiusdem sunt crassitudinis: in illis femora postica anticis longiora, in his omnia eiusdem fere longitudinis.

Tarsorum articuli tres, quorum primus est perbrevis, pubescentes: ultimus autem unguiculis duobus longiusculis, saepe bifidis instructus.

Caeterum pedes Libellulinarum non sunt gressorii, i. e. non ad gradiendum apti, nam Libellulinae nunquam fere ingrediuntur: pedes contra inserviunt sedendo; neque ad raptum capiendum, sed ad raptum tenendum sunt idonei. Raptum ipsum semper volitantes capiunt, ore, labro labioque valde hiantibus, atque statim, cum insectulum devorandum mandibulis maxillisque tradiderint, pedibus illud tenentibus foliolis vel herbis insidentes comedunt.

Praeterea haud raro vidi Libellulinas, caput et potissimum oculos pedibus anticis detergentes et purificantes, quasi pectinis instar.

Porro mas, si ad concubitum exercendum propensus est, pedibus capiti foeminae insidit, idque tenet, donec appendicibus caudalibus prothoracem foeminae amplecti potest.

\section{DE LIBILLULINATUM ABDOMINE.}

Abdomen horum insectorum est sessile, elongatum, tenue, alis plerumque longius, perraro paullo brevius, ad basin in maxima eorum parte inflatum seu crassius, segmentis decem, quorum primum brevissimum est, instructum: ad apicem appendicibus, formam aut folio- 
lorum aut stylorum parvorum prae se ferentibus. In Aeschnidibus globositas abdominis proxime ad basin seu truncum admodum insignis est, et in maribus quidem etiam magis conspicua, quam in foeminis. In illis segmentum secundum ad postica, et multo magis tertium in medio, valde est attenuatum seu coarctatum.

Ex illis decem segmentis potissimum spectanda sunt tria „basalia“ (Tab. 47. fig. 18. et 19. sub litt. a.b.c.), quae trunco sunt proxima, quorum color et pictura in Aeschnidibus Agrionidibusque saepissime maxime ad diversas species distinguendas est idoneus. Segmenta quatuor sequentia, i. e. quartum, quintum, sextum et septimum (l.c. sub d.e.f.g.), "media“ seu ,intermedia“" vocari possunt, inter se plerumque eiusdem fere longitudinis eiusdemque picturae. Ultima tria, „apicalia“ (l. c. sub h.i.l..), uti basalia, colore et pictura saepe, longitudine semper valde inter se discrepant, sed ita, ut eorum ultimum semper sit brevissimum.

Abdomen Libellulidum nonnullarum, et interdum etiam aliae corporis partes, aetate animalis permatura, quasi pruina quadam in aliis cinereo-coerulea densa obducta sunt plane: in aliis tantummodo hic illic, praesertim subtus et ad latera, pruina alba, quasi pulvere farinoso, conspersa sunt. Haec pruina contactu facile detergetur. In Agrionidibus ea multo rarior et minus extensa est. In Aeschnidibus eam nondum vidi. - Mares praecipue illo modo sunt quasi pruinosi, in foeminis id rarius, et minus significanter observatur.

Segmenta abdominis sunt massae durioris, quam inembrana seu cuticula, quae totum abdomen circumdat, ita ut segmentorum membrana instar scuti in illa cute sit affixa, quo fit, ut abdomen non minus facile possit flecti et curvari. Libellulidum et Aeschnidum segmenta duo prima et ultimum fere totum abdomen continenter circumdant: reliqua ad latera sutura quadam quasi partita sunt, igitur tanquam segmenta dorsalia et ventralia distingui possunt. 
Per abdominis dorsum, a segmento quarto usque ad ultimum, hoc excepto, in Libellulidibus, praecipue autem in Aeschnidibus (non aeque in Agrionidibus) excurrit linea elevata, denticulata seu serrulata, et margo segmentorum mediorum et apicalium posticus plerumque denticulis minimis quasi ciliatus est. Praeterea segmenta dorsalia a segmentis ventralibus disiuncta sunt linea elevata, sicuti omnes reliqui margines (seu suturae) paullulum crassati sunt.

Cuticula, cui illa quasi scuta segmentorum annata seu affixa sunt, inter segmenta singula aliquantulum prominet, et interdum diverso suo colore et pliculis longitudinalibus ab illis distincta est, e. g. in Thecaphorae subgeneris foeminis.

Inter segmenta rentralia haec cutis coniunctiva mollior et tenuior esse videtur et per longitudinem plicatilis, ita ut secundum animalis respirationem vel extendatur vel coarctetur.

In Agrionidibus scuta rentralia desunt, et dorsalia e continenti uscie ad cutem ventralem plicatilem excurrunt et cum ea connectuntur. Similem structuram habent Aeschnidum subgenera Thecaphora et Diastatomma.

Segmenta singula quasi ex duabus conficiuntur partibus: divisa enim esse videntur sectura quadam transversali in duas partes, quae sectura in segmentis trunco proximis per medium, in sequentibus basi propior, et in ultimis cum margine segmenti basali fere concidere videtur. Haud raro haec sectura diversitate coloris et pictura insignis est.

Notatu dignissima sunt tubercula duo ad latera inferiora segmenti secundi, quae in omnibus fere Aeschnidibus et in nonnullis Libellulidibus plerumque in maribus, interdum etiam in foeminis se offerunt. "Verrucas abdominales" ea appello et Tab.47. fig.18. et 19. sub $\boldsymbol{l} . \boldsymbol{l}$. delineavi. Eiusmodi verrucae plerumque sunt rugae vel tubercula, in apice acuta vel compressa, erecta vel incumbentia, ad apicem versa, 
et aut in acie ipsa serrulata, aut ab latere interiore denticulis parvis instructa.

Usum harum verrucarum abdominalium equidem ignoro. „Harris" (Exposition of english Insects p. 49.) affirmat, alas posteriores margine basali ad has verrucas fricare, et fricando strepitum efficere: quod ego non crediderim, cum et plures foeminae, illis verrucis carentes, e quiete excitatae et subito evolantes, pariter ac mares strepitum illum efficiant, et plures species, in utroque sexu illis verrucis non instructae, eundem strepitum volantes excitent. Clarissimus De Geer (Vol.II. Tom.II. p.50. translat. germ.) de his verrucis fusius disseruit, et Tab.XIX. fig.11. ad litt. $a$, et Tab.XX. fig. 16. ad litt. $\boldsymbol{c}, \boldsymbol{c}$, eas delineavit. Opinatur, eas concubitui inservire, et Libellulinarum foeminarum abdominis finem illis verrucellis seu hamulis inter coëundum retineri. Haud ineptam mihi videri hanc explicationem, libenter profiterer, nisi ei obstaret, quod, uti antea dixi, mares plurium specierum illis verrucis carent, contra vero aliarum foeminae eis sunt praeditae.

\section{DE IIBELTULINATUM APPENTICHBUS CAUDALITBUS.}

Insecta huius ordinis maxime insigni modo ad ultimum abdominis finem appendicibus quibusdam instructa sunt, quae saepissime in diversis speciebus diversissimae sunt structurae. In Horis Entomologicis amplius de iis disputavi, earumque miram differentiam in speciebus affinibus Tab. Ima, illi opusculo adiecta, exhibui. Et iam inımortales viri Linné et De Geer de singulari quarundam Libellulinarum institutione, in his appendicibus deprehensa, mentionem fecerunt.

Maxime sunt mares appendicibus illis insignes: foeminae eas minus diversas et sibi peculiares habent. Mares Libellulidum et Aeschnidum 
appendices habent tres, duas superiores, unam inferiorem; Agrionides quatuor, scil. duas superiores et duas, ut videtur, inferiores. Foeminae omnes tribus appendicibus sunt praeditae, inferiore plerumque triangulari aut conica, brevissima.

In Libellulidum maribus appendices superiores plerumque longitudinem penultimi segmenti habent, ad utrumque segmenti latus: cylindricae sunt, in basi parum attenuatae, ad apicem acute et oblique truncatae. Inferior appendix est brevior, planata, paullulum in pagina supina excavata, in apice angustior et interdum excisa. Quaedam, e. g. Chlorosoma aeneum, appendicis inferioris apicem habent bifidum et in stylos duos tantopere productum, ut cauda quadricornis esse videatur. Mares Aeschnidum appendices superiores (l. c. fig.18.19.20. sub $n . n$.), plerunque ut foliola habent compressas, saepe tortuosas, oblique directas, et denticulo vel ruga vel eminentia quadam munitas: in latere interno semper fere pilis longis, subrigidis instructas. Inferior appendix (l.c. sub o.), in pluribus est plus minus triangularis seu pyramidalis, superioribus brevior, in utraque pagina subcavata.

Foeminarum appendices superiores eiusdem sunt ac marium longitudinis, interdum paullo maioris, instar foliolorum compressae, saepe linea media longitudinali elevata instructae, et ad apicem rotundatae. Inferior, sextam longitudinis superiorum partem aequans, est conica, et in una eademque fere planitie atque illa posita, quare potius appendix media seu intermedia appellanda erit.

Agrionides in sexu masculo appendices habent diversissimae structurae. Superiores enim saepe aut denticulatae, aut dolabriformes, aut reniformes. Inferiores, quae plerumque duae esse solent, aut tanquam styli, in apice rotundatae aut curvatae, aut ad apicen denticulatae sunt. Foeminae duas illas appendices laterales seu superiores semper habent breves, ultra extremum segmentum paullulum productas: mediam seu inferiorem paullo breviorem et obtusiorem. 
Sunt hae appendices inarticulatae, sed ad basin mobiles: in maribus earum usus facile patet, quippe cum mas, coitum exerciturus, foeminae caput is corripiat, foeminamque tam diu retineat, usque dum illa abdomen curvet, et genitalia sua maris genitalibus admoveat.

[Adnot. Omnis quidem dubitatio mihi nondum exemta est, an mas appendicibus suis foeminae caput aut prothoracem arripiat. In Agrionidibus sane animadverti arreptionem prothoracis fieri: in Chlorosomate aeneo autem ipse vidi marem foeminae caput arripientem, et apice appendicis inferioris ocellos laterales obtegentem. Cornicula in occipite foeminae „Diastatommatis hamati" etiam huic rei inservire videntur, ut mas appendicibus suis curratis et ad apicem bifidis, foeminam retinere possit.]

Sub appendice inferiore deprehenditur apertura ani, quae sphinctere, corpusculo rotundo-compresso, saepius pilis rigidis obsito clausa est (Tab.47. fig. 18. - 20. sub p.).

\section{DE GIBELIULINARUM PATTIBUS GENTTALIBUS.}

Iam progrediar ad partes Libellulinarum maxime insignes, de quibus tempore recentiore sententiae plane novae atque fere inauditae a nonnullis scriptoribus sunt propositae. Hae sunt partes genitales. De earum situ in Libellulinarum foeminis nulla exoriri potest dubitatio. Est enim vulva seu apertura ovipara ad finem octavi segmenti, seu potius intra octavum et nonum segmentum, et contegitur plerumque squamula seu valvula, quae c processu segmenti ventralis octavi oritur. Hic processus est variae formae: plerunque incumbens, apice rotundo, interdum apex eius est emarginatus et fere bifidus: interdum reflexus (in Lib. vulgata): interdum in dentem (si hoc verbo uti licet 
hac in re) cavum, aculeiformem erectus (in Lib. metallica): interdum in foliola duo rigida compressa, vaginae instar productus (in subgen. Thecaphora).

Genitalia maris omnes paene scriptores in iis partibus agnoverunt, quae in rentris segmento secundo collocatae sunt (Tab. 47. fig. 18.19. sub m.). Atque eo magis hanc opinionem amplexi sunt, cum quilibet inter observandum facile videat, foeminam, capite aut collo a nare appendicibus suis arreptam, abdomen flectere et genitalia sua maris genitalibus admovere et iisdem iungere.

Hoc vero loco non omittendum est, mares omnium Libellulinarum in basi segmenti ventralis noni (Tab.47. fig.19.20. sub q.q.), squamulas duas seu foliola duo minima, incumbentia gerere, quorum usus hucusque nondum apparuit. Hunc locum clarus „Henricus Rathke" in dissertatione de Libellularum partibus genitalibus (Regimontii. 1832.), pro orificio genitalium masculorum accipit, et illas sub segmento secundo latentes partes, foeminis ad coitum excitandis destinatas esse declarat. Quam sententiam clariss. "Siebold" in Promtuario historiae naturalis a clar. "Wiegmann" edito, Ann. IV. a.1838. fasc. V. p. 375. impugnare videtur, promittens, se in Promtuario Mülleriano amplius hac de re disserturum. - Consulendus est locus libri, a doctissimo „Burmeister" conscripti, Promtuarium Entomologiae Vol.II. Tom. II. P.II. pag. 807.

Equidem de rebus his anatomicis plane taceo, sed hoc unum afferam, me ne semel quidem Libellulinas utriusque sexus partibus ventralibus, ad abdominis apicem proxime admotis, iunctas vidisse: haec vero appropinquatio aut coniunctio necessaria et inevitabilis foret, si organa maris fecundantia illo loco, in basi segmenti ventralis noni, condita essent. Porro saepissime observavi, foeminas Libellulinarum, procul ab aliis et solae volitantes, captas et acu transfixas ovula nulla parere: si vero vel per brevissimum tempus genitalibus suis cum 
masculi genitalibus cohaeserunt, et deinde captae et acu transfixae sunt, statim ovulorum magnam copiam e vulva emiserunt. Hae observatiunculae opinionem priorem firmare fortasse videntur, genitalia maris revera eo loco collocata esse, quo pristini scriptores et observatores ea statuenda esse putaverunt. 


\section{SPECHERUI DESCRIPTID.}

\section{LIBELLULA BIMACULATA.}

Tab. I. mas et foem.

Lib. luteo-testacea, nigro-maculata, alis flavescentibus, ad marginem anticum saturatioribus, posticis ad basin macula magna, atra.

Ch arp. Hor. Entom. pag. 43. Lib. bimac.

Eversmann. Bulletin de la societé des naturalistes à Moscou. 1835. pag. 235. Tab. II. fig. 2. mas. Lib. Fuchsiana.

Habitat in Silesia et Saxonia, ineunte vere: praeterea in provincia Casanensi.

Caput undique pilosum. Labium et labrum luteum, hoc ad latera fuscum. Nasus luteus, pilis fulvis obsitus. Frons subinflata, punclis impressis, luteo-flava, pilis brevibus, atris. Vertex ater, paullulum excaratus. Vesicula verticis transversa, subcordiformis, luteofusca, punctis impressis.

Oculi virentes, superne brunnei: ocellus medius ante vesiculam situs, duobus lateralibus, iuxta vesiculam positis, triplo maior. Antennae nigrae. Cuneus parvus, ater, glaber. Tempora glabra, atra, immaculata, una cum cuneo pilis flavidis fimbriata.

Truncus. Prothorax niger, margine antico tenui, elevato, flavido, postico crassiore, magis elevato, in lobum medium, parvum, horizontalem dilatato. Alitruncus undique, maxime superne, flavidovillosus, luteo-fuscus, ad latera plagis tribus nigris. Spatium inter alas atrum, tuberculis dorsalibus lurido-luteis.

Pedes nigri, pilis rigidis ab utroque latere ciliati: femoribus vulgari modulo paullo longioribus, minus pilosis, denticulatis. 
Alae: flavido-fulvescentes, maxime versus marginem anticum per totam longitudinem multo magis, praecipue in foeminis, coloratae: alae posticae ad basin maculam gerunt magnam, atro-brunneam, venis flavidis divisam, margines alae non attingentem. Membranula accessoria opaca, albida, in apice fusca. Parastigma atrum.

Saepissime et in longe maximo numero huius Libellulae trigonulum alarum anticarum in tres divisum est areolas per venulas e centro communi excurrentes, cum reliquarum Libellulidum trigonulum tantum una vel duabus venulis parallelis in areolas dividatur.

Abdomen: est eadem longitudine atque alae, globosum ad basin, subtriquetrum; versus apicem sensim sensimque deminuitur. Mas verrucas ventrales gerit, quibus maximus Libellulinarum numerus caret. Abdomen est luteo-flavum, superne cum vitta lata, quae in maribus angulosa est, a basi tertii segmenti usque ad apicem ducta, atro-brunnea. Idem in summo dorso pilis brevibus, flavidis leviter obsitum. Vitta illa atra tam lata est, ut segmenta duo ultima tota fere atra appareant, et secundum segmentum et sequentia usque ad sextum, superne adspecta, atra esse, maculasque laterales luteas gerere videantur.

Appendices caudales maris superiores longiusculae, validae, triquetrae, subtortuosae, divaricatae: inferior rectangula, in apice subfurcata. Omnes atrae, superiores ad internum latus paullulum luteopellucidae. Appendices foeminae cylindricae, atrae, pilosae. Valva aperturae oviparae ad finem habet lamellas duas perlongas, in basi connatas, quasi inflatas, ad apicem acutiusculas, lutei coloris, quae hanc Libellularum speciem prae caeteris distinguunt. Tab. I. figura asterisco signata, huius valvae lamellatae iconem exhibui, scala valde aucta.

Maris genitalia in basi ventris posita valde prominent, et quasi inclusa sunt valvis concavis, luteis, e processu segmenti secundi ventralis ortis. Hae valvae (seu processus) tantae sunt, ut fere hamum cylindricum, horizontalem, in apice rotundatum, forment. 
Haec Libellula inter nostrates maxima, et tam pictura, quam partium genitalium structura singulari insignis est. Volatum ea habet minus velocem atque celerem, quam plurimae aliae Libellulae, et saepe considit. Larva a larvis reliquarum Libellulidum non recedit, nisi ventre paullulo crassiore et latiore.

\section{LIBELLULA CONSPURCATA.}

Tab. II. mas et foem.

Lib. luteo -ferruginea, in abdomine vitta subangulosa, nigra: alis hyalinis, antice lutescentibus, ad apicem (praesertim foeminarum) fuscis. Mas adultus coeruleo-pruinosus.

Fab r. Ent. Syst. Suppl. p. 283. Lib. conspurcata.

C harp. Hor. Ent. p. 42. Lib. consp.

Van der Lind. Monogr. p. 8. Lib. consp.

Harris. Tab. 46. fig.2.

Burme ister. Vol.II. Tom. II. P.II. p. 860.

Habitat in Europa media: haudquaquam est frequens.

Caput globosum, parum fusco-pilosum, luteum, labio luteo, margine antico fusco: fronte modice inflata, in medio subcanaliculata, spatio magno distincto punctis irregulariter impressis; vertex niger; vesicula verticalis lutea, elevata, sub-bisacuminata. Oculi virescentes, superne brunnei. Tempora luteo-flava, in medio fusca, flavido-pilosa. Antennae nigrae: cuneus triangularis, flavidus.

Truncus. Prothorax niger, margine antico elevato, flavo: postico crassiore, lacuna magna ab antico separato, antice linea flava picta, quae in medio duplicata est, et ad lobum prothoracis posticum recurrit: hic valde dilatatus est, niger, maculis duabus flavis, conniventibus pictus.

Alitruncus luteus, suturis dorsalibus atris: tubera dorsalia lutea sunt, nigro-limbata. 
Alae hyalinae, margine antico a basi versus apicem vitta latiuscula, flava seu fulva: apices ipsi (plerumque in foeminis, rarius in masculis) macula modo minori, modo maiori, atro-fusca insignes.

Alae omnes in basi lineolam gerunt fuscam: posticae praeterea ad basin maculam maiorem, atro-fuscam, venis flavis seu luteis divisam. Venae intra illam vittam fulvam, ad marginem anticum, etiam fulvae seu flavae sunt: reliquae omnes atrae. Color hic venarum flavus tam ardens est, ut animal per solem volitans tanquam squamulam auream repraesentare videatur. Parastigmata oblonga, atro-fusca. Membranula accessoria e cinereo nigrescens, satis angusta.

Pedes atri, teneri.

Abdomen subtriquetrum, in basi parum globosum, luteo-ferrugineum (marium adultorum leviter coeruleo-pruinosum), a basi tertii segmenti incipit vitta e triangulis nigris, acuminibus ad antica spectantibus, ad abdominis finem maioribus, composita. Venter luteus, marginibus atris.

Appendices maris caudales nigrae, superiores cylindricae, eiusdem longitudinis atque penultimum segmentum: inferior triangularis, subacuta, subtus concava, pilosa.

[Adnot. In horis Entomologicis pag.42. iconem e Roeselian o opere Tom.II. Tab.VII. fig.4. ad hanc Lib. conspurcatam retuleram. Sed parum apta est illa icon, et potius ad Lib.cancellatam referenda, cum maculae illae magnae triangulares in alis posticis desint.]

\section{LIBELLULA QUADRIMACULATA.}

Tab. III. mas et foem.

Lib. 'Iuteo-ferruginea, alis posticis ad basin, omnibusque ad nodum macula nigricante instructis. 
Linn. S. N. p. 901.

Linn. F. Spec. p.371. no. 1459.

Fabr. E. S. Tom. II. p.373. Lib. alis posticis basi, omnibusque me* dio antico macula nigricante, abdomine depresso tomentoso.

L atr. Hist. Tom. XIII. p. 11.

Ge offr. Tom. II. p. 224. no. 1. la françoise.

De Villers. Tab. VIII. fig. 1.

H a ris. Tab. 46. fig. 1 .

Sch a ff. Icon. Ratisb. Tab.IX. fig. 13. (variet. cum alis ad apicem fusco-umbratis).

Panz. Fasc. 88. Tab. 19. foem.

Charp. Hor. Ent. p. 41 .

Van der Lind. p. 9.

Habitat in pluribus Europae regionibus: interdum numeri infiniti agmina efficiens migrat. Secundum cl. Latreille circa Parisios rarior.

Caput globosum, pilis atris obtectum. Labrum atrum, nitidum, maculis duabus flavis, pilis fulvis ciliatum, loculo rhinarium attingente, cordiformi, impresso seu excavato, polito. Labium quadrato-transversum, postice latius, luteum; lacinia media et medium laciniarum lateralium atrum. Rhinarium, nasus et frons virescentia, fronte biglobulosa, coloris dilutioris. Vertex niger. Vesicula verticalis subbituberculata, virescens, punctis impressis: antennae nigrae.

Oculi lurido - virescentes, superne brunnei. Cuneus virescens, et, sicut tempora, pilis canis longiusculis ciliatus. Tempora nigra, glabra, ad marginem oculorum maculis duabus flavis distinctis.

Truncus. Prothorax niger, opacus, postice in lobum rotundatum ascendens: ante eum ruga incrassata, transversa. Summus margo anticus flavus, et duae lineolae flavae reflexae in illa ruga.

Alitruncus flavidus, superne luteus, in lateribus linea curvata, atra: undique pilis longis flavidis tomentosus. Dorsula, scutella et pnystegae luteo-virescentia: calli axillares atri, opaci. 
Alae tenuissime fuscescentes: ab antica parte plaga lata, apicem non attingente, fulvescenti, in basi magis colorata. - Areolae nonnullae, nodo proximae, fusco-atrae; interdum (quod tantummodo in foeminis vidi) ad alae apicem, sub parastigmate, adest macula fusco-umbrata, magna, haud raro per totam latitudinem alae ducta. In alis posticis ad basin magna cernitur macula triangularis, saturate atrofusca, in qua venae flavae sunt. Nonnullae venae, praesertim in antica alarum parte, tam transversales, quam longitudinales, flavidae sunt; reliquae atrae.

Vena marginalis antica a basi usque ad nodum flavida est, cui atra adiecta, et ad nodum in exteriore latere quasi dissecta et paullulum hians est. - Membranula accessoria angusta, tota alba. Pedes atri.

Abdomen depressum, subtriquetrum, versus apicem paullatim (praesertim in maribus) attenuatum, undique pilis albidis, longiusculis tectum: e virescenti luteum seu ferrugineum, ultimis segmentis nigris; segmenta dorsalia, maxime 5. 6. \%. et 8vum, ad latera habent maculam distinctam, laete flavam: segmenta ventralia atra, in medio fulvomaculata.

Maris appendices caudales superiores longitudinem ultimi penultimique segmenti habent, teretes, cylindricae, ad basin angustiores, in apice sub-divergentes, atrae, pilosae; inferior triangularis, apice bifido, supra infraque paullulum excavata, atra. Appendices foeminae superiores mari similes, paullulum convergentes.

Observatio. Nonnunquam Libellulinae huius speciei insigni modo augentur, et tanta quidem copia, ut totis agminibus per aërem volitent, unam eandemque quasi directionem sequentes: sic Locustarum seu Acridiorum agmina exercitus instar progrediuntur. De eiusmodi migrationibus plures scriptores mentionem iniecerunt, e. g. Roes el (Vol.II. p.135. de Locustarum migrationibus); cl. Meineck en (Nat. 


\section{3}

Forsch. Vol. VII. pag. 110.); cl. Germar (Promt. Vol.II. pag. 336.); cl. Kirby (Introduct. Vol.II. pag.12.). Ego duas tales peregrinationes Libellulae quadrimaculatae diversis annis vidi. Cl. Germar l. c. affert, migrationes, de quibus disserat, etiam ab hac Libellularum specie instituias esse, et omnes fere alii scriptores hac in re verba faciunt de „Libellula quadam magna, crassa“. Clarissimus Kirby solus I. c. refert, se ab observatore quodam diligentiore audivisse, ipsum in comitatu quodam Anglicano agınen Agriorum immensum vidisse a mari in terram volitantem, quorum tanta fuerit copia, ut magnam agri partem quasi umbra contexerint. Quum vero nullus alius observator hucusque de Agriorum migrationibus mentionem fecerit, quumque Agriorum volatus nimis videatur infirmus, eorumque alae tenerịtate alis Libellularum multo sint inferiores, ideoque ad itinera longinqua haud facile idoneae, ad credendum propensus sum, hanc narrationem errore quodam ortam esse, et illa animalia potius ad Ephemerarum genus pertinuisse.

\section{LIBELLULA DEPRESSA.}

Tab. IV. mas et foem.

Lib. lutescens, alis omnibus in basi nigro-maculatis: abdomine lato, depresso (maris adulti coeruleo-pruinoso), maculis lateralibus flavis.

Linn. S. N. p.902.

Linn. F. Suec. p. 172.

Fabr. E. S. II. p. 373 .

L a tr. Hist. Tom. XIII. p. 12. foem.

Ré a u m. Tom. VI. Tab. 35. fig. 1. foem. fig. 2. mas.

Ro es el. Vol. II. Aquat. Tab. VII. fig. 3. mas. Tab. VI. fig. 4. foem.

Ge o ffr. Tom. II. p. 225. no.7. Tab. XIII. fig. I. foem. l'Eleonore.

Ibid. no. 8. mas, la Philinte.

Petagna. Tom.II. Tab.VI. fig. 1. 
Sch a ffer. Icon. Tab. 106. fig. 1. mas. Tab. 52. fig. 1. foem.

Panz. Faun. fasc. LXXXIX. Tab.22. mas.

Charp. Hor. Ent. p. 40.

Van der Lind. p. 7.

Burme is ter. Vol. II. Tom. II. p. 860.

Habitat in tota fere Europa.

Ciap u tolum luteum, pilosum: tempora maculis subnigris. Oculi virescentes, superne brunnei: vesicula verticalis elevata, bituberculata: frons in medio impressa.

Truncus. Prothorax in medio coarctatus, postice in lobulum rolundatum elevatus: ater, opacus, in margine anteriore' et linea media, ad latera latiore, flava, nec non duabus maculis flavis in lobo postico. Alitruncus luteus, flavido-pilosus. Ad latera collaris plaga albida seu diluta, nigrae adiacens.

A la e hyalinae, parastigmate atro-fusco: ad basin alarum macula atro-fusca, anticarum oblonga, posticarum triangularis. Intra hanc maculam venae sunt luteae: marium saepe rufescentes.

Pedes crassi, breviores quam in speciebus congenericis, nigri, trochantere et femorum basi luteis.

Abdomen depressum, subtriquetrum, ad basin subangustum, globosum, versus apicem repente attenuatum. Foeminarum abdomen latius, quam marium, et magis depressum. Color abdominis est e virescenti luteus, postice fuscus; ad segmentorum 4. ad 8vi latera maculae laete flavae. Subtus abdomen luteo-ferrugineum est, in margimibus et versus apicem atrum.

Mares adulti pruina densa et laete coerulea abdomen habent obductum, quae pruina maculas laterales flavas non abscondit. Foeminae quoque vetustae tali colore coerulescenti obducuntur, sed multo dilutiore, minusque denso. 
Appendices maris caudales superiores penultimo segmento haud longiores, teretes, subconniventes, atro-fuscae, pilosae: inferior lutea, triangularis, subtus excavata, ad apicem integra, fuscescens. Foeminarum fuscae.

Mares iuniores colore abdominis a foeminis plane non discrepant, et post plures dies demum colorem abdominis coeruleum adipiscuntur.

Cl. Latreille l. c. foeminam huius Libellulae recte describit. De masculo autem disserens clarissimus auctor errorem commisit, et Libellulam cancellatam fortasse pro mare Lib. depressae habuit, dicens, abdomen esse elongatum, subtus nigricans, et basin alarum immaculatam.

\section{ร. LIBELLULA CANCELLATA.}

Tab. V. mas et foem.

Lib. alis immaculatis, flaro-lutea, in abdominis dorso linea utrimque atra maculari.

Linn. S. N. p.902.

Linn. Faun. Spec. p.373.

Fabr. E. S. II. p. 378.

Latr. Hist. Tom. XIII. p. 13.

Kirby Introd. Tab. III. fig. 5. (editionis anglicae).

Schaeffer. Icon. Tab. 206. fig. 3. mas.

C h a rp. Hor. Ent. p. 44. Lib. lineolata.

Van der Lind. p. 11.

B u rme is ter. Vol. II. Tom. II. p. 859. Lib. cancellata.

Habitat in pluribus Europae regionibus.

Caput pro portione totius corporis consueto minus, fronte prominula, viridi-flavum. Labii lacinia media nigra, et interdum haec nigritudo etiam in lacinias laterales extenditur: reliqua oris pars flava. Frons elevata, antice utrimque globulis duobus instructa, qui globuli 
linea elevata cincti, et punctis impressis scabri sunt. Vesicula verticalis viridi-lutea, subbituberculata: a vertice, iuxta hanc vesiculam, plaga atra ad genas descendit. Antennae atrae. Cuneus cordiformis, flavus: tempora glabra, atra, maculis plurimis flavis picta. Oculi virescentes.

Truncus. Prothorax ater, opacus, antice cum lobulo sublunato, postice maiore lobo, utroque flavo: antice coarctatus, postice tumidus, linea transversali flava per mediam partem usque ad lobum posticum ducta: margines laterales limbo circumscripti. Truncus in postica parte pilis perlongis flavidis obsitus. Mesothorax luteo-flavus, fuscescens: collaris plagula abbreviata, lateribusque lineis duabus irregularibus atris. Calli axillares atri, in centro flavo-lutei, scutello tamen et postscutello laetiore colore flavis.

A la e hyalinae, parastigmate atro-fusco. Margo anticus et plures venae in alae parte basali flavida: reliquae venae atrae. Membranula accessoria cinerea, subnigricans.

Pedes mediocres, atri, in femorum basi, praesertim foeminarum, lutei: trochanteres pedum posticorum et mediorum lutei, cum macula in medio atra.

Abdomen ad basin paullum attenuatum, deinceps globosum: reliqua pars subtriquetra, paullatim ad apicem angustata. Color eius est flavo-luteus, marginibus omnibus segmentorumque suturis nigris. In dorso abdominis cernitur utrimque linea e maculis atris composita, quae ad basin dorsi interruptae, versus caudam distinctiores sunt. Interdum hae maculae ad abdominis apicem tam latae sunt et magnae, ut ultima segmenta fere tota atra appareant. Ventris color itidem luteus est, in medio et ad apicem ater. Mares adulti nanciscuntur pruinam leviter coeruleam in dorso abdominis.

Appendices maris caudales superiores penultimo segmento paullo breviores, teretes, subcurvatae, fuscae. Inferior triangularis, curvata, 
subtus excavata, ad apicem emarginata. Foeminarum appendices sunt breviores, acutiores.

Fugacissima haec est Libellula, et ramulis aut plantis rarius insidit: solet potius in ripis aquarum stagnantium humidis versari.

[A dnot. Non dubito, quin Libellula hoc loco descripta vere sit Lib. cancellata Linnei, quamvis verba eius in Systemate Naturae et in Fauna Suecica olim me commoverint, ut aliam speciem illa denominatione significatam esse suspicatus sim: hinc in errorem inductus in Horis Entomologicis pag. 44. huic Libellulae nomen „lineolatae“ imposui.

O. Fr. Müller in Act. Soc. Caes. pag. 124. et in Fauna Friedrichdalensi de Libellula cancellata disserens, aperte marem Libellulae nigrae (vid. infra) ante oculos habuit, idque marem recens exclusum. - Cl. Latreille (Hist. Tom. XIII. pag. 13.) sub no.4. Libellulam vulgatam describens, addit verba: „persimilem eam esse speciei sequenti (Lib. cancellatae sub no.5.), quin etiam illam fortasse esse meram eius varietatem“. Haec affirmatio sine dubio in errore quodam nititur, qui fortasse ex eo ortus est, quod sub no.6. Libellulam flaveolam descripsit, quae omnino Lib. vulgatae quam maxime est affinis. Clarus ille vir, uti opinor, in scribendo opere Lib. flaveolam statim post Lib. vulgatam posuit, et fortasse postea descriptionem Lib. cancellatae inter illas descriptiones intercalavit, verba autem supra allata, uti debebat, non mutavit.]

\section{LIBELLULA COERULESCENS.}

Tab. VI. mas et foem.

Lib. fusco-lutescens, alis subhyalinis, parastigmate oblongo, fusco, subpellucido: abdomine acuto-triquetro, luteo (marium adultorum dense coeruleo-pruinoso), marginibus suturisque nigris. 
Fabr. E. S. Suppl. p. 234. Lib. alis hyalinis : stigmate marginali fusco: corpore coerulescente.

Scopoli Entom. carniol. p.261. Lib. vulgata.

Sch a eff. Icon. Tab. 206. fig. 1.2. mas. Tab.174. fig.1. foem.

Charp. Hor. Ent. p.46. Lib. coerulescens. p. 45. Lib. opalina.

Van der Lind. pag. 12.

Annales de la Soc. Entom. Tom. VI. Tab.5. fig.1. mas. fig.2. foem. (coloris nimis viridis). Tab.6. fig. 3. (Lib. brunnea) foem. fig. 1.2. Lib. Olympia.

Burmeister. Vol. II. Tom. II. p. 859.

Habitat in Europa australi et media.

Caput flavescens, paullum in colorem viridem abiens, vertice pone vesiculam atro. Labium flavido-lutescens, in maribus in medio fuscum. Frons tumida, antice linea elevata seu acie cincta et punctis cicatricosis scabra, pilis brevibus atris obsita. Summum vesiculae verticalis distincte bituberculatum est. Nasus eo loco, ubi excipitur rhinarium, valde excisus. Cuneus fuscus, glaber; tempora glabra, valde tumida, luteo-fusco-maculata. Oculi alliaceo-virides. Ocelli laterales non pone vesiculam verticalem, sed in ipsa eius latera, versus basin, quasi impressi sunt.

Truncus. Prothorax, ut in congenericis, in medio coarctatus, postice in lobum rotundum ascendens. In maribus totus ater, opacus: in foeminis lobus posticus flavidus, et in medio prothoracis linea transversalis flava, ad latera latior, in medio retroflexa et duplicata. Margo posticus pilis longis, luridis ciliatus. Mesothorax et metathorax luridolutei, pilosi; collaris plaga utrimque albida. Latera strigis nonnullis fuscis praedita. Tubera interalaria lurido-lutea, scutello et postscutello lacte flavis. In maribus totus alitruncus interdum coeruleo-pruinosus. Calli axillares in utroque sexu atri, interdum leviter coeruleoobducti. 
A la e leviter gilvo-fuscae, ad apicem densius coloratae: foeminarum alae versus marginem anticum plerumque magis coloratae. Parastiginata oblonga, fusco-lutea, subpellucida. Membranula accessoria albida.

Pedes marium atri, femoribus ad latus lutescentibus, foeminarum lutei toti, spinulis atris instructi.

Abdomen ad basin paullum globosum, tenue et leviter versus apicem attenuatum, plane triquetrum, carina dorsali valde prominente. Mares iuniores et foeminae abdomen habent luteum, omnibus marginibus ac suturis atris: in maribus adultis abdomen totum pruina coerulea, densa obductum est, qui color haud raro et reliquas corporis partes implet. In foeminis hunc colorem nunquam vidi: earum vero abdominis pagina inferior saepe pruina albida seu levissime coerulescente obtecta est. In singulis abdominis segmentis, postice et pone carinam dorsalem, adsunt lineolae duae minimae, transversales, atrae. Color abdominis foeminarum variat interdum, et mox in virescens, mox in brunneum transit. (Libellulam hoc modo pictam, et fortasse propter recentissimam exclusionem e chrysalide valde splendentem, in Horis Entom. tanquam peculiarem explicavi speciem, quam Lib. opalinam vocavi.)

Maris appendices caudales superiores longitudinem penultimi segmenti aequant: sunt crassae, aequales, teretes, ad apicem acutae, et praesertim ad inferiorem partem scabrae, conniventes. Inferior triangularis, subtus cava, ad apicem obtusa: omnes atro-fuscae. Foeminarum appendices breviores, luteae, magis conniventes.

Margo posticus segmenti ventralis octavi, aperturam oviparam obtegens, puncta seu tubercula duo parva, glabra gerit.

Haec Libellula insignis est eo, quod haud raro magnitudine diversa est, id quod in Libellulis haudquaquam frequenter occurrit. Praeterea notabilis ea est ob abdomen fere aequale, quasi lineare, et 
tam distincte triquetrum: porro ob colorem oculorum insignem, affatim alliaceum, qui in reliquis Libellulis Europaeis non apparet. Recens exclusa exempla splendore eximio quasi fulgent, ut non solum alae, sed etiam totum corpus tanquam gummi Arabico obducta videantur.

\section{LIBELLULA COCCINEA.}

Tab. VII. mas et foem.

Lib. mas unicolor, coccineus, foemina luteo-flava, alis hyalinis, posticis ad basin macula lutea.

Van der Lind. pag. 13. Lib. ferruginea (scil. Lib. ferrugineam Fa bricii E.S. II. p. 380. pro hac specie Europaea sumens).

B u rm e is t er. Vol. II. Tom. II. p. 858. Lib. ferruginea.

Habitat in Italia, Hispania. Accepi etiam exempla ex Hungaria australi, Gallia meridionali, Corsica et India Orientali.

Descriptio ad exempla emortua et siccata est concimmata.

Caput globosum, in maribus coccineum, ad os lutescens: frons valde elevata, turgida, quasi canali profundo in duo tubera subdivisa. Vesicula verticalis bituberculata, valde elevata, antice fere paullulum nutans. Antennae nigrae. Tempora prominentia, lutescentia. Foemina lutea, ubi mas est rufus.

Truncus. Prothorax antice coarctatus, postice in lobum parvum semicircularem subelevatus. Alitruncus in maribus coccineus, in foeminis luteus, paullum pilosus.

Alae hyalinae, foeminarum interdum subflavescentes; parastiginate oblongo, gilvo-fusco. Plures marium venae coccineae, foeminarum lutescentes. Alarum basis anticarum spatio minimo fulva, posticarum macula maiore fulva, quae capitis fere magnitudinem aequat, in foeminis multo minore. Membranula accessoria cinerea. 
Pedes secundum sexum aut rufi, ant lutei: tibiarum pili rigidi, longi, atri sunt.

Abdomen triquetrum, subdepressum, coccineum (foeminae luteum), carina marginibusque fuscis. Foeminae lineam utrimque lateralem subobsoletam nigram habent. In utroque sexu ad apicem singulorum segmentorum pone carinam cernitur lineola parva, atra, transversalis.

Appendices maris caudales superiores rufae, teretes, ad apicem acuminatae, penultimum segmentum longitudine aequant: inferior minus colorata, triangularis, subcavata, ad apicem integra. Foeminarum breviores, conniventes, luteae.

[Adnot. Quaedam de nomenclatura et synonymia huius Libellulae necessario addenda mihi videntur. "Cl. Van der Linden in Monographia Libellulinarum l. c. hanc Libellulam Fabricii esse Lib. ferrugineam, eandemque, quam Drury (Tom.I. Tab.47. fig.6.) depinxerit, et Lib. Serviliam appellaverit, esse contendit, et haud negandum est, maximam partem descriptionis Fabriciana e Libellulae a nobis designatae bene convenire, et diagnosin in Ent. Syst. exhibitam huic speciei bene congruere. Sed ante omnia eruendum est, quamnam Libellulam Fabricius sub Lib. ferrugineae nomine intellexerit. In Systemate Entomologiae a.1775. pag. 423. affert Lib. ferrugineam ex America, cui attribuit diagnosin „Lib. alis albis, corpore ferrugineo, ore puncto utrinque flavo“. Icones non attulit; addit verba: „statura Lib. unbratae, corpus totum ferrugineum, puncto utrinque flavo ad os". In Speciebus Insectorum (a.1781. pag.523.) eandem Lib. ferrugineam ex America affert: pag. 531. autem aliam, sub nomine Lib. ferruginatae, e promontorio bonae spei allatam, producit cum hac diagnosi: "alis ad basin flavescentibus, corpore obscure ferrugineo". In de- 
scriptione addit verba: „corpus totum obscure ferrugineum. Alae albidae reticulatae, basi flavescentes apiceque stigmate ordinario fusco. Pedes valde ciliati“. - Idem Entomologiae syst. Tom. II. p. 380. utramque speciem coniungere videtur: affert enim Lib. ferrugineam, et pro synonyma etiam Lib. ferruginatam, Mantissae p. 336. no.11.; porro commemorat Libellulam Serviliam e Druryano opere: mutavit autem diagnosin, dicens: „Lib. alis albis, basi flavis, corpore rubro“, et descriptionem e Systemate Ent. repetit. Itidem mutavit patriam, neque, uti antea, Americam et promontorium bonae spei affert, sed Chinam.

Equidem credo, Fabricium tres species diversas confudisse: nam 1) Lib. ferruginea non est Lib. Servilia Druryi, quia illi „punctum flavum utrinque ad os" attribuitur, cuius nec icon, nec verba Druryana ullam faciunt mentionem. 2) Lib. ferruginea non est Lib. ferruginata, quae „corpus obscure ferrugineum" habet, et „pedes valde ciliatos", utroque autem signo Lib. ferruginea caret: sicuti etiam de puncto flavo ad os nec in diagnosi, nec in descriptione Lib. ferruginatae ulla mentio fit.

Verum tamen nostra Lib.coccinea nec Lib. ferruginea, nec Lib. ferruginata, nec Lib. Servilia est: non enim habet illa puncta flava ad os, nec habet abdomen obscure ferrugineum et pedes valde ciliatos, nec maculas luteas ad alarum bases tam saturate coloratas et tam distinctas, quam Lib. Servilia. His rationibus commotus sum, ut nomen Lib. coccineae nostrae Libellulinae Europaeae imponerem.

Commemorandum hoc loco est, in museis pluribus sex vel octo species Libellularum e diversis regionibus congestas reperiri, quae omnes abdomen rufo-ferrugineum et maculam luteam ad basin alarum oculo offerunt: igitur haec signa sola non sufficiunt ad diversitatem specierum demonstrandam. 
Specimina nonnulla huius Libellulae, ex India orientali allata, in utroque sexu ab Europacis plane non discrepant.]

\section{LIBELLULA PEDEMONTANA.}

Tab. VIII. mas et foem.

Lib. alis hyalinis, fascia apicali fusca: maris abdomine rufo, focminae luteo.

F a br. E.S. Tom.II. p.378. Lib.alis planis, cinereis, fascia apieis fusca.

Fuessly Catal. ins. helv. p. 44. Lib. rubra.

Sulzer Hist. Tab. 24. fig. 1. Lib. Harpedone.

Gmel in Linn. p. 2620. Lib. Sibirica.

Lepeehin iter per Siberiam. Tom.I. p.77. Tab.IV. fig.8. (Edit. Altenburg. 1774.)

Ch a rp. Hor. Ent. p. 50.

Van der Lind. p. 14.

Burmeister. Vol.II. Tom. II. p. 851.

Habitat in Helretia, Italia, in Silesiae montibus, in Siberia.

Caput perglobosum, gilvo-rufescens (foeminarum luteum). Labium quadratum: fronte globosa, bituberculata, cicatricosa: vertex prope oculos niger, vesicula verticali livida: antennae nigrae. Facies tota in superiore parte atro-pilosa. Cuneus cordiformis, flavidus, tempora flavo-lutea, atro-maculata. Oculi inferne lutescentes, superne badii.

Truncus. Prothorax ater, opacus, margine antico paullulum elevato, maculis lateralibus, lineaque media ad postica flexa, flavis. Margo prothoracis posticus in lobos duos semiorbiculares, flavos, pilis luteis valde ciliatos, elevatus. Alitruncus rufus (in foemina luteo-ferrugineus), supra pilosus, lateribus laete flavis, linea una alterave irregulari nigra. Coxae et trochanteres flavi, femoribus tibiisque atris: femorum lateribus internis luteis, praesertim pedum anteriorum. 
Alae hyalinae venis fusco-ferrugineis, in basi parum fulvescentes. Parastigma oblongum, apud mares in utraque pagina rufum; foeminarum laete sulphureum, venis crassulis fuscis cinctum. Fascia fusco-ferruginea, latiusçula, subsinuata, per totam alae latitudinem in apice eius ducta.

Pedes atri, femoribus ad basin luteis.

Abdomen teres, in basi paullum globosum, maris rufum, foeminae luteum, segmentorum mediorum et apicalium marginibus leviter atris. Segmentum primum et secundum ad basin fuscum. Foeminae venter nigricans, saepe albido-pruinosus. Segmentum ventrale octavum ad marginem posticum paullisper porrectum, et valde emarginatum. Appendices caudales iis tales sunt, quales congenericis.

Mares iuniores coloribus similes sunt foeminis, aetate provecta abdomen et truncus rufescit.

[Adnot. Verba et icon, a cl. Lepechin loco supra allato exhibita, optime huic Libellulae conveniunt. Dicit enim illustris ille peregrinator de hac Libellula „corpore rubicundo, alis hyalinis, fascia transversa lata, ferruginea prope apices. - Mares ad costam alarum maculam habent oblongam, quadrangularem, rufam, foeminae flavam".]

\section{LIBELLULA FLAVEOLA.}

Tab. IX. mas et foem.

Lib. alis hyalinis, ad basin late luteis; abdomine maris rufo, foeminae luteo.

Linn. S. N. p. 901. Lib. flaveola.

Eiusd. F. Suec. p. 372. Lib. flaveolata.

Fabr. E. S. Tom.II. p. 375 .

Latr. Hist. Tom. XIII. p. 14.

Sch a eff. Icon. Tab.IV. fig. 1. foem. 
Charp. Hor. Ent. p. 49.

Van der Lind. p. 15.

Burmeister. Vol.II. Tom.II. p. 851.

Habitat in tota fere Europa, tempore autumnali.

Cap ut flavum: labii lacinia media fere tota, et laterales ad suturam fuscae: frons tumida, subbiglobosa (in mare rufescens), vertice prope oculos distincte nigro; vesicula lucida, elevata, ad apicem vix bituberculata, cum fronte atro-pilosa. Oculi flavido-virescentes, superne rufo-brumnei.

Cuneus flavus, linea longitudinali impressa. Tempora flavo-lutea, maculis tribus nigris, inferna maxima.

Truncus. Prothorax in margine antico incrassatus, in medio modice coarctatus, postice in lobos duos semiorbiculares ascendens: niger, opacus, margine antico lineaque media flava, quae interdum cum lobis marginis postici cohaeret; lobi ipsi lutei, et ad marginem pilis longis, luteis ciliati. - Mesothorax rufo-luteus, margine collaris antico late atro, et per plagulam transversam flavam cum lateribus flavo-maculatis cohaerens. Tubera interalaria maris rufa, foeminae luridolutea.

Alae hyalinae, renis subferrugineis luteisque, ad basin macula magna, fulva. Variant hae maculae ambilu et coloris intensitate: foeminae has maculas basales saepissime in plagam oblongam ad marginem alae anticum extensas habent. Parastigma utriusque sexus est fusco-ferrugineum, venis crassiusculis cinctum: in exemplis iunioribus flavidum est.

Pedes atro-fusci, femoribus linea, tibiis in latere externo luteis.

Abdomen marium alis vix longius, ad basin subglobosum, cylindricum, foeminarum haud raro quasi compressum; rufum in maribus: segmento primo fere toto, secundo ad basin atro. Carina segmenti octavi et noni maculam parvam, atram gerit: segmentorum 
mediorum marginibus lateralibus atris. Subtus abdomen est atrum, hic illic luteo-maculatum. Foemina pari modo picta, colore luteo in rufi locum succedente. Venter saepe albido-pruinosus.

Appendices maris caudales superiores rufae, teretes, ad basin leviter attenuatae, versus apicem et parte prona crassiores, ad apicem ipsum atrae, acuminatae. Inferior triangularis, antice latiuscula, subemarginata. Foeminarum lutescentes, breviores, subconniventes. Valvula aperturae oviparae incumbens, margine exciso, ut fere bifida appareat.

[A dnot. Plures auctores affirmant, hanc Libellulam interdum sine maculis fulvis seu flavis ad basin alarum reperiri. Equidem hoc nunquam vidi, neque id affirmare possum. Credo potius, eos, qui illam opinionem protulerint, unam alteramve speciem sequentium Libellularum, quae omnino et statura et colore magnam cum Lib. flaveola habent similitudinem, alas autem sine illis maculis basalibus, fulvis gerunt, cum Lib. flaveola confudisse et pro eius varietate sumsisse.]

Iam progrediar ad descriptionem nonnullarum Libellularum, quae sibi inter se tam similes et affines sunt, ut hucusque a nullo fere scriptore tanquam species diversae et peculiares propositae sint, qui potius fortasse eas omnes pro una eademque habuere specie. Subtilia quidem, et tantum oculis sedulo observantibus conspicua sunt signa harum specierum distinctiva: sunt vero tam constantia, ut semel cognita facile idoneam praebeant rationem ad illas species bene dignoscendas. Sunt autem quinque species harum Libellularum tam affinium, quarum tres in tota Germania et alibi occurrunt: quarta Lusitaniae, quinta Helvetiae sunt propriae. Specierum exempla e nostris terris allata, sexcenties examinavi viventia, iisque in copula captis, differentias sexuales, diversarum specierum accuratissime observavi, 
et sic mihi quam maxime est persuasum de earum diversitate specifica.

Sunt vero, uti monui, quinque species, quae hucusque omnes sub nomine Lib. vulgatae proferebantur, quarum prima a me appellatur

\section{LIBELLULA NIGRIPES.}

Tab. X. Fig. 1. mas et foem.

Lib. corpore cylindrico, lutescens, abdomine maris rufo, foeminae luteo: pedibus in utroque sexu nigris totis; fronte maris flavida, summa eius parte rufa.

Habitat in Silesia, Saxonia.

Referenda est inter Lib. minores Europaeas, atque congenericis etiam minor; mas plerumque aliquantulo quam foemina maior.

Caput globosum, flavidum, levissime in colorem viridem transiens: maris adulti frons in superiore parte saturate rufa. Oculi gilvi, supra rufi, in brunneum abeuntes: tempora nigra, glabra, maculis nonnullis distinctissimis, flarissimis.

Truncus. Prothorax ater, opacus, postice lobos duos semiorbiculares, erectos gerens: margine antico posticoque leviter flavo. Alitruncus lurido-luteus, in lateribus sulphureus, lineis nonnullis nigris. Tubercula interalaria maris adulti rufa. Collaris margo anticus limbo satis late nigro.

Al a e hyalinae, ad basin minima ex parte flavescentes, maris venis rufis, foeminae luteis: illius parastigmate fusco, huius lutescente.

Pedes toti quam maxime atri, trochanteribus flavis, cum macula nigra: foeminarum femora ad basin flava.

Abdomen teres, cylindricum, in medio paullum attenuatum, carinula modice elevata: foeminae abdomen est ad postica admodum paullo crassius, quae crassitudo ad ultimum usque segmentum obtinet. 
Maris abdomen rubrum, segmento primo ultra dimidium, secundo ad apicem nigris: segmenta omnia ad apicem prope carinam dorsalem lineolam utrimque habent atram, transversalem, subimpressam. Segmenti octavi ac noni dorsum gerit maculam mediocrem atram, et margines atro colore circumsepti sunt.

Foemina pari modo picta, colore luteo in rufi locum succedente: subtus interdum albido-pruinosa. Appendices maris ad penultimi segmenti longitudinem productae, cylindricae, rectae, in apice acuminatae, rufae, ut in congenericis: foeminarum luteae.

\section{LIBELLULA STRIOLATA.}

Tab. X. Fig. 2. mas et foem.

Lib. corpore cylindrico, lutescens: abdomine maris rufo, foeminae luteo, in lurido-virescens abeunte: pedes in utroque sexu lutei, nigro - lineati, fronte maris flavida.

Habitat in Silesia.

Haec Lib.praecedente paullulo maior, et in utroque sexu eiusdem magnitudinis est.

Caput globosum, flavidum: maris adulti frons semper flavida. Oculi gilvi, superne rufo-brunnei. Tempora flava, glabra, maculis nonnullis minus distinctis nigris.

Truncus. Prothorax ater, opacus, postice in lobos duos semiorbiculares elevatus: margine antico et postico flavo. Alitruncus lurido-luteus, in lateribus sulphureus, lineis nonnullis atris. Collaris margo anţicus colore vix nigro terminatus. Tubercula interalaria maris adulti rufa.

Ala e hyalinae, ad basin non coloratae: maris venis rufis, foeminae luteis: illius parastigmate fusco, huius lutescente.

Pedes flavo-lutei, femoribus utroque latere, tibiis interno linea atra pictis. 
Abdomen teres, cylindricum, ad basin subglobosum, in medio leviter attenuatum, rersus apicem crassius, et in summo apice denuo attenuatum, id quod etiam de foemina valet.

Color abdominis maris idem est, atque in Lib. nigripede. Foeminae color e luteo aliquantulum in lurido-viridem transit, et macula nigra in segmento octavo et nono tam magna et dilatata plerumque est, ut totum fere segmentum impleat, et in medio uiriusque lateris disculus maneat luteus. Caeterum margines omnes ac suturae linea tenui, atra terminantur. In ipsis segmentorum lateribus, praecipue mediorum, adiacet lineola longitudinalis, atra, abbreviata, basin singulorum segmentorum norr attingens.

Valva aperturae oviparae incumbens, in margine antico paullulum excisa.

\section{LIBELLULA VULGATA.}

Tab. XI. Fig. 1. mas et foem.

Lib. corpore cylindrico, lutescens: abdomine maris rufo, foeminae olivaceo-luteo (pervetustae rubro-maculato), pedibus luteis, ad internum latus atris.

Habitat in pluribus Europae regionibus.

Congenericis est paullo maior atque crassior, foeminae abdomine plerumque crasso.

Cap ut globosum, flavidum, in viridem colorem transiens: maris adulti frons rarissime et parum rufa. Oculi gilvi, superne rufo-brunnei. Termpora lutescentia, maculis nigris, quasi obsoletis et rutilomixtis.

Truncus. Prothorax ater, opacus, postice in lobos duos semiorbiculares elevatus: margine antico et postico flavo. Alitruncus lurido-luteus, in lateribus sulphureus, lineis atris. Tubercula interalaria maris adulti rufa. 
Alae, praesertim marium, haud raro levissime fuscae: venis lurido-luteis, apud mares parum rufescentibus. Parastigmata fusca.

Pedes flavidi, femorum tibiarumque latere interno linea nigra terminato.

Abdomen maris uti in praecedentibus comparatum, ad segmenti secundi latera haud raro adest lineola parva, atra, transversa. Foeminae abdomen crassius, minus in medio attenuatum, cylindricum, coloris lurido-viridis: in ultimis segmentis macula nigra obsoleta aut fere nulla; linea laterali tenui, in singulis segmentis abbreviata, atra. Cum foeminae aetatis maturioris sunt, haud raro in dorso abdominis maculae rufae, irregulares, cohaerentes apparent.

Appendices caudales uti in praecedentibus comparatae sunt. Eo autem foemina Lib. vulgatae magnopere distincta est, quod valva aperturae oviparae non est incumbens, sed in apice erecta seu hians, et hamulum obtusum fere constituens. Hoc signo a congenericis facillime dignoscitur.

\section{LIBELLULA RUFICOLLIS.}

Tab. XI. Fig. 2. mas.

Lib. lurido-lutea, superne et in prothorace rufa: alis hyalinis, in basi paullulum flavis.

[Marem tantum cognovi, et secundum exempla tria siccata descripsi.]

Habitat in Lusitania.

Haec est praecedentibus satis maior et coloris rubri densioris, ad brunneum paullisper abeuntis, glabra.

Caput ut in congenericis, fronte rufa. Oculorum tempora flava, maculis aliquot obsoletis, atris. Cuneus flavus.

Truncus. Prothorax minus brevis, quam in congenericis, et minus in medio coarctatus, glaber, rufus totus. Mesothorax lurido- 


\section{$-81$}

luteus : collari rufo, unicolore; calli axillares rufi, reliqua tubercula interalaria lurido - flavida.

Alae hyalinae, ad basin spatio parvo gilvae. Venae eiusdem coloris (in vivis fortasse rufae), parastigmato fusco.

Pedes lutei, femoribus et tibiis interno latere fuscis.

Abdomen teres, cylindricum, in basi inflatum, versus apicem vix incrassatum, rufum; segmento primo et secundo dimidia parte atris, et macula parra eiusdem coloris in dorso octavi et noni segmenti.

\section{LIBELLULA ALBIFRONS.}

Tab. XI. Fig. 3. mas.

Lib. lurido-lutea, fronte tumida albida, abdomine (maris) rufo, postice maculis lateralibus atris.

Haec Libellula, e regione Basileensi ad amicissimum Germar, Halensem, missa, mecum est communicata. Unum igitur tantum huius Libellulae exemplum examini potui subiicere.

Praecedentibus aliquantulo minor et gracilior, fronte valde tumida, albida, et abdominis pictura a praecedenti, cui alioquin simillima est, bene distinguenda.

Cap ut globosum, tota facie, maxime fronte, tumida et quasi prominente, albidum, in gilvo - viridem colorem abiens. (Oculi siccati).

Tempora flavida, maculis rufo-fuscis.

Truncus. Prothorax e lutescenti viridis: lateribus lucidioribus et atro-lineatis. Calli alares rufi, tubercula reliqua lutescentia.

A la e hyalinae, in basi summa flavescentes, venis lutescentibus.

Pedes lutescentes toti.

Abdomen cylindricum, carina leviter prominente, ideoque paullulum compressum: in basi quam minime inflatum, et versus apicem 
vix incrassatum. Color rufus: segmentum primum in basi atrum; segmenta media et versus apicem ad utrumque latus atra: postice latius atro-colorata, quam antice.

Manca omnino est haec descriptio Lib. albifrontis, cum tantum unum exemplum masculum siccatum, neque unquam huius speciei foeminam ante oculos habuerim.

[Adnot. Haec Lib. albifrons neutiquam confundenda est cum Libellula eiusdem nominis, a clariss. Burmeister (Promt. Vol.II. Tom.II. P.II. pag. 851.) descripta, quae potius Libellulae pectorali affinis est. Vid. infra. Confusionis vitandae causa aliud nomen Lib. albifronti nostrae attribuissem, nisi tabula, in qua illud exstat, iam ante annum lapidi incisa fuisset.]

Lib. albifrons et ruficollis, quamvis primo adspectu tribus antecedentibus simillimae, tamen facile ab iis distingui possunt. Illae vero inter se tam similes sunt, ut facillime permisceri possint. Hac de causa de earum synonymia nihil fere afferre possum.

Videndum autem est, quamnam revera celeberrimus Linné sub Libell. sua „vulgata“ (S.N. p.901. Faun. Suec. p.372.) intellexerit.

Dicit enim „Lib. alis hyalinis, corpore griseo, cauda simplici“: diagnosis sane inextricabilis! saltem Libellula nostra vulgata caudam non simpliciorem habet, quam omnes reliquae Libellulae. - Fabricius non multo clarius disserit de Lib. vulgata, nam mutavit verba Linnei in haec „abdomine cylindrico rufo", et Roeselianas icones (Vol.II. Tab.8.) conferri iubet. Hae figurae et verba in opere Roeseliano, in quibus de „pedibus atris totis“ sermo est, fortasse Lib. nigripedi conveniunt. Nec ego ipse in Horis entomologicis (p. 49.) rem clariorem reddidi: manifesto autem Lib. vulgatam, in his pagellis descriptam, ante oculos habui, cum de singulari foeminae valva ad aperturam oviparam disseruerim, quae solummodo huic speciei con- 
venit. Sed hoc est satis superque de synonymia huius animalis vix extricabili.

\section{3ั. LIBELLULA NIGRA.}

Tab. XII. mas iunior, adultus et foem.

Lib. alis hyalinis, labii medio nigro, collari aut nigro toto, aut lurido - virescente, cum macula magna, triangulari, nigra; postpectore maculis tribus inter se proxime admotis, sulphureis, distinctis.

Van der Lind. Monogr. p. 16. Lib. nigra (mas).

Charp. Hor. Ent. p. 48. Lib. Veronensis (foem.).

Eversm. Bullet. de Mose. p.240. Tab.I. fig. 1.2.(mares). Lib. nigricula (fig. 3. foem.?).

Burmeister. Vol.II. Tom. II. p. 851 .

Habitat in Silesia, Italia, Russia.

Libellularum Europaearum facile minima, abdomine maris adulti nigro insignis.

Caput magnum, perglobosum, pilis atris crebrioribus obtectum. Facies laete flava: labii medio toto nigro; labro atro; rhinario fusco, nasique parte media atra. In fronte macula maxima, biloba, atrofusca, cicatricosa: vertex ater, vesicula livida, interdum flavida. $\mathrm{Cu}$ neus flavus, cordiformis, linea longitudinali impressa. Oculi virescentes, superne fusco-brunnei. Tempora ad marginem oculorum maculis quatuor laete flavis, distinctis, exterioribus oblongis, intermediis quadratis. In foeminis color faciei ater minus intensivus, et magis in fuscum transiens.

Truncus. Prothorax antice coarctatus, postice lobo duplici elevatus, in medio coarctatus, ater, opacus. Margo anticus in medio flavus, et linea in dorso prothoracis brevis, flava, conspicua est, quae in medio recurva et bifida est. Lobi prothoracis postici in mare atri, in foemina lutei, atro-cincti, in utroque sexu pilis longis, luridis ciliati. 


\section{4}

Mesothorax marium adultorum ater totus, ad latera vittis duabus latis, maculisque pluribus flavissimis distinctus: undique, praesertim superne, pilis longis flavo-luridis villosus. Marium iuniorum aut recens exclusorum, nec non foeminarum mesothorax eo diversus est, quod collare viridi-luridum est, in antica parte nigrum, qui color niger figura cuneiformi seu triangulari inde ab acumine usque ad dorsulum extenditur. Postpectus obscure et lurido-virescens, in postica parte maculas tres sulphureas, valde distinctas gerit, sibi invicem vicinas; media maiore lateralibus minoribus inclusa. Hae maculae potissimum in foeminis conspici possunt.

Ala e hyalinae, ecoloratae: in foeminis tantum ad basin pauxillulum flavidae. Parastigma breve, rectangulum, atrum, subtus ad fines albidum.

Calli alarum anteriores atri, puncto medio flavo: posteriores flavi. Tubera interalaria lurida.

Pedes valde sunt atri: foeminarum coxae et trochanteres flavi, cum macula atra.

Abdomen alarum fere longitudinem aequat, in basi subglobosum, cylindricum: in foeminis leviter compressum, in maribus medio paullulum attenuatum. In sexu masculo color abdominis non multo post exclusionem e chrysalide flavus est, brevi autem tempore praeterlapso nigrescit, et sic totum fere abdomen obducit, ita ut aut plane atrum fiat, aut tantummodo ad basin et hic illic in segmentorum dorso locula flavida remaneant. In foeminis color flavo-luteus est, suturis marginibusque omnibus atris; segmentum abdominis primum totum atro inficitur colore, secundum ad basin, octavum ac nonum in medio dorso: itidem omnia foeminarum segmenta ad latera atra evadunt. Secundum segmentum in latere atro maculam gerit flavam, magnam, triangularem, adiacentibus duabus minoribus. Venter in foeminis saepe albo-pruinosus, et regio circa aperturam oviparam fusca est. 
Appendices maris caudales superiores teretes, atrae, paullo longiores, quam segmentum antepenultimum, atro-pilosae. Inferior brevior, triangularis. Foeminarum breviores, luteae, valde pilosae. Valvula aperturae oviparae margine postico paullulum porrecto praedita est, et in cuticulam concavam ascendit.

[Adnot. In Horis Entomologicis huius Libellulae nigrae marem pro varietate Libellulae vulgatae habui, sed immerito. Focminam, a me circa Veronam captam, sub nomine Libellulae Veronensis attuli et descripsi. Cum vero postea animalia utriusque sexus in copula iuncta saepe ceperim, melius de iis sum edoctus, et cum nomen a cl. Van der Linden in Libellulinarum Monographia, quae posteriore tempore in manus meas pervenit, propositum (pag. 48.) „Lib. nigrae“ melius esse existimaverim, nomen Lib. Veronensis cum illo commutavi.]

\section{LIBELLULA PECTORALIS.}

Tab.XIII. mas, cius variet. et foem. Tab. XLVII. fig. 15. abdominis masculi apex.

Lib. alis hyalinis, posticis macula ad basin nigra: thorace viridiaeneo, fulvo-maculato; abdomine cylindrico, nigro, maculis dorsalibus fulvis; appendicibus atris.

Charp. ILor. Ent. p. 46.

Ly on net. Recherches etc. Paris. 1832. p. 197. et 562. Tab. XVIII.

fig. 8. 9. Lib. pector. Eiusd. metamorphosis fig. 10. -16.

Van der Lind. p. 16. Lib. dubia.

Eversmann. p.237. Lib. infuseata. p. 238. Lib. melanostoma.

Burmeister. Vol. II. Tom.II. p.851. Lib. pectoralis.

Habitat in Silesia, Belgia, Hollandia, Russia.

C'aput globosum, glabrum. Frons, nasus et rhinarium alba, levissime in viridem colorem transeuntia, pilis brevibus, nigris sparsa. 
Labrum in maribus gilvum, postice utrimque subfuscum, margine antico nigro: in foeminis nigrum totum. Labium utriusque sexus atrum totum. Vertex prope oculos niger, vesicula subbituberculata, lurida vel fusca. Oculi inferne virescentes, superne atro-fusci. Tempora glabra, atra, in media parte puncto unico flavo. Cuneus glaber, flavus. Totum occiput lurido-pilosum.

Truncus. Prothorax niger, opacus, margine antico lineaque flexuosa flavis. Mesothorax atro-viridi-aeneus, nitens, pilis longis, fuscis obsitus. Collare vittis duabus latis, angulosis (postice interdum interruptis), fulvis seu aurantiacis. Ad latera mesothoracis maculae sunt plures irregulares eiusdem coloris. Calli tuberaque interalaria in utroque sexu fulvo-lutea: in maribus haud raro sanguinea.

Ala e hyalinae, foeminarum interdum paullum flavescentes: parastigmate rectangulo, brevi, subquadrato, atro-fusco: in maribus interdum fusco-sanguineo. Alae anticae in basi ad radium spurium maculam minimam, rectangulam, atram habent: posticae maiorem. Alae omnes in basi leviter fulvo-coloratae sunt. Versus apicem eaedem particulam radiorum et sectorum pone parastigma, et duplo quam illud longiorem, gerunt albo-coloratam, quae animalis volantis adspectum alas nubecula albida ornatas habentis praebet.

Pedes mediocris longitudinis, toti atri.

A bdomen alis vix longius, cylindricum, versus basin vix incrassatum: foeminae aequale, maris in medio admodum leviter attenuatum, valde atrum; segmento primo ad marginem posticum leviter flavo: segmenta secundum usque ad septimum supra macula magna, fulva, postice coarctata, praedita sunt: macula fulva septimi segmenti in maribus saepe coloris vivacioris est, quam reliquae, quin etiam post animalis mortem saepe laete flava permanet, dum reliquae lutescunt, aut obscurae fiunt. Mares frequenter variant colore macularum abdominis et tuberum alarium, et loco fulvi colorem habent sanguineum, 


\section{$+\quad s 7$}

qualem varietatem Tab.XIII. fig. media repraesentavi. Notandum est, exempla sic colorata umbra flava alarum ad earum bases plane carere, et alas totas prorsus ecoloratas esse. Foemina subtus haud raro albido-pruinosa est, pruina tamen parum densa, et nunquam in superiore abdominis parte conspicua.

Maris appendices caudales superiores atrae, teretes, ad apicem acuminatae, subscabrae: inferior dimidia parte brevior, lata, antice paullo angustior, polita, ad apicem alte emarginata, atra. Foeminae appendices multo breviores, atrae, conniventes. Marium appendices Tab.47. fig. 15. cum a pagina inferiore, tum a latere delineatae sunt.

[Adnot. 1. Non plane mili persuasum est, an haec Lib. pectoralis sit Lib. rubicunda Linnei. Descriptio ab hoc viro exhibita satis illi convenit: sed cum in Fauna Suec. afferatur „thorax niger", cumque in Syst.Nat. icon e Roeseliano opere Vol. II. Aquat. Tab. 7. fig. 4. commemoretur, quae varietatem Aeschnae iunceae repraesentat, facile credam, Linneum sub Lib. rubic. sua aliam intellexisse speciem.

A d not. 2. Clarissimus mihique carissimus Burmeister Libellulam mecum communicavit, quam in promtuario suo Lib. albifrontem appellavit. Eiusdem Libellulae exempla nonnulla, in Moravia montibus capta, ante oculos habeo, et disquisitio exacta, quatenus in animalibus mortuis et aridis factis, quorum igitur colores obsoleti sunt, institui potest, me docuit, hanc Libellulam illi, quam s. n. Lib. pectoralis descripsi, esse peraffinem, omnino autem ei iura peculiaris speciei posse vindicari. Cum denominatio „Lib. albifrontis", alii speciei iam antea a me sit imposita, huic attribuamus nomen „Lib. leucorhinus“.

Est haec Libellula Lib. pectorali simillima, recedit vero ab ea his notis: semper est minor et multo gracilior, quam Lib. pectoralis: alas habet multo angustiores, praesertim versus ipsa- 
rum basin: color fulvescens ad alarum basin in Lib. leucorhino non adest, sed alae sunt plane ecoloratae, hyalinae, macula alarum posticarum basali atra excepta: Lib. leucorhinus abdomen habet pertenue, angustum: collare aut atrum totum aut fuscobrunneum, et maculae collaris fulvae vix sunt conspicuae. Abdominis segmenta secundum et tertium paullulum sunt flavomaculata: maris reliqua segmenta atra tota, in segmento tamen septimo conspicitur macula flava. Foeminarum segmenta abdominalia septem priora maculam dorsalem flavam, haud magnam gerunt. Appendices maris fere ut in Lib. pectorali comparatae: superiores in uno exemplo albae, in aliis nigrae. Inferior fusca, medio lucidiore. - Horum insectorum viventiun, certe nondum retustorum, observatio retractata atque repetita docebit, utrum Lib. leucorhinus revera peculiaris sit species, an potius varietas Libellulae pectoralis. Prius si verum est, quasi transitum a Lib. nigra ad Lib. pector. format.

Adnot. 3. Singulare omnino est phaenomenon illud, mares Libellulae pectoralis tam saepe maculis abdominalibus purpureis sive sanguineis loco vulgarium crocearum seu fulvarum reperiri: in eiusmodi exemplis parastigmata quoque purpureo-tincta sunt, non aeque vero collaris vittae, quae etiam in exemplis purpureo-maculatis semper fulvae sunt. Sed exempla non desunt etiam aliarum Libellulinarum, colore purpureo in locum alius cuiusdam vulgaris succedente, interdum inventarum: Roesel. Vol.II. Aquat. Tab.II. fig.21. marem Aeschnae iunceae rubro-maculatum depinxit, et Van der Linden in Monogr. pag. 24. de simili varietate Aeschnae mixtae mentionem facit. Fortasse talis pictura morbo animalis alicui attribuenda est, sicuti icterus in genere humano: et fortasse color ille purpureus ex acido purpurico, aut ex acido erythrico, aut 


\section{$-89$}

ex acido rosaceo oritur, quae in urina continentur. Hoc et eo confirmari videtur, quod excrementa plurium Aeschnarum, formae oblongae, cylindricae, ad apicem sacpissime coloris sunt rosacei. Praesentiam autem vasculorum urinalium et substantiae ad urinam pertinentis in insectis clari viri John et Audouin planam fecerunt.

Notum est, Glossata sive Lepidoptera statim post exclusionem e chrysalide humorem quendam per guttas plures emittere, qui coloris est rutili, sacpe sanguinei, et tanta interdum copia editur, ut hoc phaenomenon ansam dederit narrationis, quae de imbre sanguineo circumfertur. Cum vero in plurium insectorum larvis praesentia acidi urici observata sit, (cf. Hu en efeldi librum s. t. physiologische Chemie P. II. pag. 144.), quaeritur, annon illius pluriae sanguineae color acido purpurico, quippe quod in acido urico contineatur, attribuendus sit.]

\section{LIBELLULA CAUDALIS.}

Tab. XLIV. mas, foem. eiusque varietas. Tab.|XLVII. Fig. 16. maris abdominis apex.

Lib. alis hyalinis, posticis in basi macula nigra: thorace viridiaeneo, fulvo-maculato, abdomine ad basin apicemque valde inflato, in media parte attenuato, atro: segmentis tantum basalibus fulvo-maculatis, appendicibus albis.

In Silesia capta.

Species praecedenti simillima, sed specifice et signis constantissimis ab ea diversa.

Caput uti in Lib. pectorali comparatum, fronte paullo .minus impressa: cuneus ater vel fuscus: tempora glabra, nigra, inmaculata. 
Truncus. Prothorax ater, opacus, et tantum ad marginem anticum linea tenuissima, flava limbatus. In medio ater, unicolor: lobi postici pilis fuscis creberrimis ciliati. Alitruncus atro-viridi-aeneus, nitens, collari maculis duabus fulvis instructo, uti in Lib. pectorali, sed paullo angustioribus.

Alae abdomine longiores, hyalinae: posticis ad basin macula opaca, atra, omnibusque ad basin flavescentibus. Parastigma oblongiusculum, rectangulum, fuscum. Radii et sectores spatio haud magno albido-flavidi circa regionem parastigmatis. Foeminae haud raro ad apicem alarum gerunt maculam magnam, fuscam, antice apicem alae attingentem, postice distincte terminatam.

Pedes atri, ut in Lib. pectorali.

Abdomen alis brevius, eximio modo clavatum, ad basin enim subinflatum, in medio valde attenuatum, dein eximie incrassatum, et versus apicem deminutum, ita ut formam clavae repraesentet. Est rotundum, paullum depressum: atrum totum, subglabrum. Primum segmentum immaculatum: segmenta secundum usque ad quartum aut quintum macula magna dorsali fulva, quae tamen multo minor est, quam in Lib. pectorali. Segmentum secundum ad ventrem gerit utrimque maculam magnam, fulvam. Appendices caudales in utroque sexu albae seu niveae: superiores maris, ut in Lib. pectorali, teretes, in apice acuminatae, subscabrae: inferior autem eiusdem fere longitudinis atque superiores, subtriangularis, et apice integro (vid. Tab.47. fig.16). Hac appendicum structura optime a Lib. pectorali distinguitur.

Foeminarum appendices breviores sunt, et pari modo album habent colorem. Haud raro foeminae non solum paginam abdominis inferiorem, sed etiam superiorem, et praecipue versus basin, pruina nivea, satis densa habent obductam. Haec Libellularum species, saltem inter Europaeas, abdomine tam insigniter clavato notatu dignissima est. 


\section{LIBELLULA AENEA.}

Tab. XIV. mas et foem.

Lib. alis hyalinis, in basi paullum fulvis; facie tota, trunco abdomineque viridi-aeneis, nitentibus; ventris basi inflata, lutea.

Lin n. Faun. Suec. p. 373. n.1466. $\beta$.

Linn. S. Nat. p. 902.

Falbr. E. S. Tom. II. p. 381 .

L a tr. Hist. Tom. XIII. p. 14.

De Geer. Tom. II. Vol.II. Tab. 19. fig. 8. imago : fig.9. appendices maris.

Ge offr. Tom. II. p.226. n.10. l'Aminthe.

Roesel. Tom.II. Tab.V. fig. 2.

Sch a effer. Icon. Tab. 167. fig. 4. foem. Tab. 182. fig. 1. mas (?).

H a rris. Tab. XXVII. fig. 2.

Pan z. Faun. Gernı, fascic. 88. Tab. 20.

Ch a rp. Hor. Ent. p. 38. Tab. I. fig. 9. appendices maris caudales.

Van der Lind. p. 17.

Burmeister. Vol.II. Tom.II. P.II. p. 846. Epophthalmia aenea.

Habitat fere ubique in Europa; in Silesia frequentissima est, in Gallia (sec. Latreille) rarior.

Caput globosum, fronte prominula, lata, inflata, cum naso, vertice vesiculaque verticali laete viridi-aeneo-nitente, et punctis impressis scabra, pilis flavidis, brevibus obtecta. Ad latera frontis, supra nasum, loculus glabrior et paullulum cupreo-nitens. Rhinarium flavidum: labrum atro-fuscum, labium luteum. Oculi aureo-virides, supra paullisper in brunneum transeuntes. Tempora et cuneus atroaenea, unicoloria, glabra, pilis flavidis ciliata.

Truncus. Prothorax ater, cylindricus, antice parum coarctatus, postice in lobulum obtuso-triangularem, incumbentem, rugulosum extensus: margine antico posticoque fulvo. Mesothorax undique 
viridi-aureus seu aeneo-nitens vel splendens, margine collaris antico atro, undique pilis flavidis villoso.

Ala e hyalinae, ecoloratae: foeminarum tamen plerumque flavidae seu vinaceae. Foeminae alas omnes, mares posticas ad basin spatio parvo fulvas seu croceas habent. Parastigma oblongum, rectangulum, atro-fuscum. Membranula accessoria antice alba, postice in cinereum transiens.

Foeminae marginem alarum posteriorum posticum habent in basi rotundatum, et ad membranulam accessoriam areolas vulgaris formae: mares autem illum alarum marginem habent subrepente flexum seu quasi angulatum, et areolam, membranulae accessoriae proximam, consueto maiorem et una tantum vena transversali divisam. - Calli alarum atri: tubera lutescentia.

Pedes consueto aliquantulo breviores, atri.

Abdomen teres, in utroque sexu ad basin valde globosum, in medio attenuatum, ad apicem latius, viridi-aeneum, postice (praesertim in foeminis) in cupreum colorem abiens: segmentum primum viridi-aeneum totum, secundum et tertium macula utrimque permagna, fulva ad ventrem insigne: cuticula coniunctiva, segmentum secundum cum tertio coniungens, flava, in medio dorsi aenea. Reliqua segmenta omnia viridi-aenea, in ventre paullum lutescentia. Mares huius et sequentium duarum specierum in medio laterum segmenti secundi rugulam gerunt, in tuberculum fere seu verrucam prosilientem, quales verrucas Aeschnides fere omnes atque etiam Lib. bimaculata habent. Praeterea apices postici segmenti secundi ventralis marium in lobulum acutum, ascendentem producti sunt, ad genitalia recipienda.

Maris appendices caudales insigni modo constructae sunt. Earum icones conferas in opere De Geeriano et Horis Entomol. supra allatis. Aequant longitudinem ultimorum duorum segmentorum: sunt 
cylindricae, pilosae, subrectae, paullulum divergentes, apice ipso extrorsum flexo, atro-aeneae. Inferior eiusdem fere longitudinis atque superiores, in basi crassa, e medio in duo brachia divaricata excurrens, quae ante apicem recurvatum, mucronem acutum seu dentem validum gerunt.

[Adnot. Appendice inferiore tam insigni modo in duas partes divisa et quasi furcata plures scriptores commoti sunt, ut appendices duas inferiores, ergo omnino quatuor appendices huic Libellulae attribuerent.]

Foeminarum appendices eiusdem atque marium longitudinis, teretes, ad basin apicemque attenuatae.

Valvula aperturae oviparae terminatur lamella lutea, triangulari, ultra medium bifida, quae lacinias duas acutas, incumbentes format. Squamulae illae duae maris in nono segmento ventrali, de quibus cl. Rathk e disseruit, semicirculares, atrae, luteo-cinctae sunt.

Cl. Linné in Fauna Suecica l. c. duas species sub denominatione Lib. aeneae descripsit, quarum altera sub $\beta$. exhibita Libellula supra descripta est, quod ex verbis „mas cauda quadridentata, dentibus superioribus pilosis, inferioribus singulis duplici denticulo" facile apparet. Altera, eodem loco ab illo clarissimo viro descripta, nostra Lib. flavomaculata est, de qua infra.

E Libellulinarum speciebus imprimis Libellula aenea Gamasis minimis (Acarus Libellulae, De Geer. Tom.VIII. p.59. - Acarus Gymnopterorum Linn. Fabr. - Generis denominatio "Gamasus“ a cl. Latreille instituta est), coccinei coloris infestatur, ac foeminae multo magis hoc malo laborant, quam mares. Haud raro tota abdominis pars inferior huius Libellulae per illos Acaros obducta atque tantopere consita est, ut abdomen intumescat, et quasi turgidum appareat. 
Praeter hanc Libellulam nonnulla quoque Agria his insectulis parasiticis, sed multo minus numerosis, molestata, Libellulinas autem rarissime vidi his Gamasis obsessas. Aliquando Lib. aeneae foeminam statim post exclusionem e chrysalide et exuvias modo dereliquentem conspexi, quae ventris superficiem a permultis istiusmodi hospitibus iamiam impletam habebat. Veri igitur simile est, eos iam in ipsa Libellulae larva habitavisse, cum haec adhuc in aqua degeret.

Hi Gamasi fortasse ansam dederunt erroris cuiusdam, a claro Frischio commissi, qui Tomo VIIIvo, pag.1\%. descriptionum insectorum affirmat, Libellulas quasdam, abdomine cylindrico praeditas, ovula non oblonga, sed plane globularia parere, eaque non statim aquae immittere, sed antea proprii abdominis parti ventrali agglutinare, et postea demum ea abstergere, ut in aquam cadant. Quae res per se veri parum similis est, et potius crediderim, clarum virum Gamasos illos rotundos, et haud raro inde ab abdominis fine usque ad pectus animali insidentes, pro ovulis habuisse.

\section{LIBELLULA METALLICA.}

Tab. XV. mas et foem. additis utriusque sexus appendicibus.

Lib. alis hyalinis (foeminarum margine antico flavescente), naso maculaque magna distincta frontis et trunco abdomineque viridi-aeneis, abdominis basi fulvo - maculata.

Char p. Hor. Ent. p. 39.

Van der Lind. p. 18.

Sch a eff. Icon. Tab. 113. fig. 4. mas.

Burme ister. Vol. II. Tom. II. p. 846. Epophthalmia metall.

Habitat in Silesia, Saxonia, Belgia.

Caput globosum, fronte prominula. Vertex cum vesicula viridi-aenea: frons lutea, macula quadam maxima viridi-aenea, antice 


\section{5}

distincta, postice cum verticis colore commixta: pars frontis lutea reliqua parte multo glabrior; nasus viridi-aeneus: rhinarium luteum, labrum atro-aeneum, labium luteum. Oculi viridi-nitentes, superne fuscescentes. Cuneus perglobosus, glaberrimus, aeneo-nitens; tempora nigra, nitida, pilis flavis ciliata.

Truncus. Prothorax fusco-ater, glaber, antice flavus, postice in lobulum incumbentem, luteum extensus. Mesothorax viridi-aeneus, nitens, pilis flavidis villosus. Spatium intra collaris suturam et septula ipsa lutescentia, atro-marginata.

Alae hyalinae, haud raro, praesertim in foeminis flavescentes: in hoc sexu plerumque plaga lata, ad totum marginem anticum flava, admodum densa.

In marium alis posticis ad membranulam accessoriam albo-cineream, macula conspicitur fulva seu crocea, haud magna. Parastigma fuscum aut lurido-luteum, vix et ne vix quidem pellucidum.

Pedes nigri, ad femorum anticorum basin, praesertim ad interius latus, lutei.

Abdomen maris in basi inflatum, in medio segmenti tertii attenuatum, tunc paullatim usque ad septimum segmentum incrassatum, et hinc sensim sensimque angustatum. Color est viridi-aeneus, nitens, subtus potius nigro-aeneus. Ad utrumque latus segmentorum secundi et tertii adsunt in dorso maculae duae parvae, distinctae, fulvae, et duae aliae multo maiores, utrimque ad ventrem. Cutis coniunctiva segmenti secundi ac tertii itidem flava est. Mas verrucas ventrales habet parvas, acuminatas, atras. Venter in medio ater.

Appendices maris caudales eiusdem longitudinis sunt atque ultima duo segmenta, viridi-aeneae, subcylindricae, antice attenuatae, apice recurvato; ad basin crassiores, ibique dente armatae, et versus apicem ad latus inferius acumine obtuso instructae: ad basin sunt divergentes, ad apicem convergentes. Inferior acuto-triangularis, 
superioribus brevior (vid. Tab. XV. fig. * et Hor. Entom. Tab. I. fig. 8.).

Foeminarum abdomen alis longius, cylindricum, in basi inflatum, et usque ad apicem paullatim attenuatum. Ad posticam partem quodammodo triquetrum vocari potest, carina dorsali aliquantulum elevata. Color et pictura uti in maribus: maculae fulvae nunc maiores, nunc minores, nunc oblitteratae. Inferne abdomen luteum fere totum. Appendices ultimis duobus segmentis dimidia parte longiores, teretes, tenuissimae, atro-pilosae, ad apicem paullum divergentes. Valvula aperturae oviparae modo perinsigni (Tab. XV. fig. **) in uncum magnum, concavum, angulo recto flexum producta est.

\section{LIBELLULA FLAVOMACULATA.}

Tab. XVI. mas et foem.

Lib. alis hyalinis (foeminarum flavidis), in basi flavescentibus: naso, fronte verticeque viridi-aeneis, cum maculis duabus distinctis, luteis, ad frontis latera: alitrunco viridi-aeneo, ad latera fasciis duabus fulvis: abdomine viridi-aeneo, ad latera maculis fulvis.

Linn. Faun. Suec. edit. Ima a.1746. p. 231. sub n. 768.

Edit. IIda p. 373. n. 1466. Lib. aenea, sed non sub litt. $\beta$. descripta.

Van der Lind. p.19. Marem tantum novit.

Burme is ter. Vol.II. Tom. II. Epophthalmia flavomaculata.

Habitat in Silesia (circa Vratislaviam, Bregam), in Belgia.

Caput fronte prominula, cum vesicula verticeque viridi-coeruleo-aenea, nitens: punctis altis impressis. Frontis latera usque ad oculos lutea, glabra. Nasus viridi-aeneus, glaber: rhinarium luteum; labrum atro-aeneum, labium luteum. Oculi virides. Cuneus luridus, glaber. Tempora atro-aenea, nitida, pilis albidis ciliata. 
Truncus. Prothorax ater, opacus, antice leviter flavidus, postice in lobulum luteum, incumbentem assurgens. Mesothorax viridiaeneus, splendens, pilis flavidis villosus. In lateribus fasciae duae distinctae, latac, flavac. Sutura et septula collaris lutea. Tubera alaria et calli lutea, hi nigro - limbati. Pcctus viridi-aeneum, postice luteum.

Ala e hyalinae, foeminarum flavidae, ad basin fulvescentes: marium iuxta membranulam accessoriam cinerescentem intensius fulvocoloratae.

Pedes atri, femorum basi interdum fusca.

Abdoinen maris uti in specie praecedenti comparatum, in basi inflatum, in medio segmenti tertii coarctatum, dein paullatim ac modice versus apicem incrassatum, et pone caudam iterum attenuatum: magis cylindricum, quam triquetrum. Est viridi-aeneum. Segmentum primum atrum, cum marginibus flavis. Secundum segmentum margine antico posticoque, nec non maculis duabus magnis lateralibus fulvis. Segmenta tertium usque ad octavum utriusque lateris ad basin macula triangulari, fulva insignia. Subtus omnia segmenta lutea, intermedia ad apicem nigricantia.

Verrucae ventrales admodum paullum prominent, potius rugulae elevatae vocandae.

Foeminae abdomen in basi globosum, cylindricum, usque ad basin sensim sensinque attenuatum. Est viridi-aeneum, maculis magnis lateralibus, ad basin singulorum segmentorum, fulvis seu croceis instructum.

Appendices maris caudales superiores longitudinem aequant ultimorum duorum segmentorum, atque etiam ultra extensae sunt: viridiaeneae, cylindricae, antice attenuatae, acutae, apice ipso recurvo seu reflexo. Sunt rectae, parallelae (non divergentes), inferius ad basis latus dente valde acuto, alteroque minore obtusissimo versus apicem armatae. Inferior appendix triangularis, brevior, acuta. 
Foeminae appendices longitudini ultimorum duorum segmentorum sunt pares, graciles, subcylindricae, compressiusculae, aeneovirides.

Valvula aperturae oviparae brevis, flavida, apice profunde exciso.

Equidem nullus dubito, quin haec Libellula, sub denominatione „flavomaculatae“ descripta, eadem sit atque ea, quam cl. Linné iam ante multos annos novit et descripsit. In priore enim Faunae Suecicae editione a.1746. speciebus animalium descriptis nomina trivialia nondum attribuit clarus vir. Descriptionem igitur pag. 231. allati operis, exhibet duarum Libellularum sub no.768. et 769. his verbis:

„no. 768. Lib. thorace viridi-nitido: lineis flavis: alis pallidis, abdomine nigro." Addit: „Caput et thorax viridia, nitida. Oculi sub„fusci: lineae duae flavae ad latera thoracis: alae flavescente-albae, in "quibusdam ad basin flavae, punctum marginale fuscum. Abdomen "cylindricum nigrum, subtus flavum, marginis colore deaurato. Cauda "diphylla angusta".

„no. 769. Lib. viridi-inaurata, alis pallidis, pedibus nigris"“. Addit verba: „Praecedenti simillima, sed alia. Mas cauda quadriden„tata, dentibus superioribus pilosis, inferioribus singulis duplici denti"culo. Foeminae cauda foliolis 2. lanceolatis: caput, thorax, abdomen „cupreo-inaurata: thorax pilosus absque maculis; margo alarum po„sticarum pone versus abdomen macula membranacea. Oculi pra„sini. Labium pallidum. Abdomen subtus hinc inde pallide-albe"scens."

Hae descriptiones tam accuratae tamque planae sunt, ut nulla restet dubitatio, quin Libellula sub no. 768. commemorata Lib. flavomaculata sit, et altera, sub no.769. descripta, Lib. aenea. Linne us in editione posteriore Faunae Suec. a. 1761. utramque speciem sub nomine Lib. aeneae in unam coniunxisse, tamen eas iterum distinxisse videtur, cum unam earum addita littera $\beta$. ab altera separaverit. 


\section{AESCHNA AZUREA.}

Tab. XYII. mas. Tab. XLV. fig. 1. foem.

Aesch. thorace aeruginoso, immaculato, abdomine depressiusculo, brunneo, azureo-maculato.

Ch a r p. Hor. Ent. p. 31. Tab. I. fig. 1. appendices maris.

Van der Lind. p. 20. Aesch. formosa p. 79.

Ann. de la Soc. Ent. Tom.VII. Tab.V. fig. 1. mas. Aesch. formosa.

Burmeister. Vol. II. Tom. II. p. 840. Aesch. azurea.

Habitat in Hungaria, unde eam clarissimus L. B. de Ocskay primus mecum sub illo nomine communicavit: praeterea in Lusitania, Italia, Silesia.

Caput: frons valde prominens, flavida, sicuti tota facies: labium ad margines internos leviter brunneum, labrum latius, brunneum. Rhinarium fuscum. Frons rugula quadam distincta a vertice separata, in quo iuxta lineam transrersalem macula est coerulea. Post hanc maculam cernitur alia, rhombea, fusca, vesiculam verticalem tangens. Vesicula antice flava, postice brunnea, parva: ante eam ocellus medius, magnus, et ad latera, in ipsa resicula, duo ocelli minores. Cuneus flavidus, obtusus, postice cum oculorum margine connatus. Oculi marium laete coerulei, foeminarum in viridem colorem transeunt; in summa parte spatio magno connati. Temporum pars superior atra, inferior flava.

Truncus. Prothorax brevis, fuscus, postice flavidus. Alitruncus laete et pulchre aeruginosus, breviusculus, subglobosus, septulis laete coeruleis. Margines tenuissime nigri. Pectus flavum, latius atro-marginatum. Calli alares brunnei, in medio flavi: tubercula interalaria laete aeruginosa, reliqua mesothoracis et metathoracis pars fusca, pilosa. 
Ala hyalinae: maris ecoloratae, foeminae flavidae seu fulvescentes, versus basin autem non coloratae. Parastigmata perlonga, angusta, fusca, subpellucida. Nervi atri. Margo autem anticus valde crassus, laete flavus, in externo latere punctulis, in interno linea crassa, atra instructus. Margo alarum posticarum posticus utriusque sexus arcu rotundo ad basin extenditur, nec, uti in plurimis aliis Aeschnidibus, quasi angulum format.

Membranula accessoria parva, ad basin albida, versus apicem canescens.

Alae marium in nonnullis exemplis pauxillum fuscescentem offerunt oculo colorem.

Pedes atro-fusci: tibiis utrimque pilis longiusculis, rigidis ciliatis: femoribus ab interiore latere utrimque denticulis acutis, minimis instructis.

Abdomen ad basin in utroque sexu valde inflatum, segmentis duobus sequentibus attenuatis, reliquis aequalibus: cylindricum, maris subdepressum et verrucis ventralibus destitutum. Mas inter volitandum abdomen non gerit rectum, sed in medio sursum versum, seu arculum obtusum constituens, quo ab omnibus aliis Aeschnidibus paullulum recedit. Color principalis est atro-fuscus. Segmentum maris primum in basi atrum, loculos duos eiusdem coloris postice emittit: in medio dorso gilvum, ad latera aeruginosum. Secundum laete coeruleum, superne gilvum, linea subbasali, transversa, et media longitudinali atra, cui lineolae duae transversae adiacent.

Omnia segmenta sequentia in dorso utrimque laete et pulcherrime coerulea, ita ut tantum margines et vitta lata dorsalis, plures dentes ad latera quasi emittens, atro - fusca appareant.

Foemina simili modo picta et colorata, colore gilvo in dorsi basi magis in viridem transeunte, et vitta dorsali atra minus angulosa.

Pagina abdominis inferior fusca, versus basin flavida. 
Appendices maris superiores (Hor. Ent. Tab. I. fig. 1.) penultimo segmento fere longiores, ad basin attenuatae, in medio latae, ad apicem obtusae, atro-fuscae: ab interno latere pilis longiusculis, gilvis dense ciliatae. Inferior ultra dimidiam partem brevior, subquadrata, versus apicem paullum attenuata. Foeminarum appendices eiusdem sunt longitudinis, versus apicem valde attenuatae, acutae.

Haec nostratium Aeschnarum facile pulcherrima in volando quam maxime perseverat: per horas enim integras supra aquam in aëre pendet, Antliata et Glossata haudquaquam minima, e. g. Pap. Pamphilum, Lysandrum, capiens.

\section{AESCHNA VIRENS.}

Tab. XXII. mas et foem.

Aesch. trunco viridi, collari brunneo, plagis duabus magnis viridibus: abdomine brunneo, foeminae viridi-maculato, maris ad basin viridi-maculato, in reliqua parte coeruleo-maculato.

Eversmann. Bulletin. p.242. Tab. II. fig. 1. A. viridis foem.

Habitat in Germania media, in Russia australi: in Silesia tempore autumnali.

Haec Aeschna mediae est magnitudinis, colore utrinsque sexus valde discrepante.

Caput globosum, fronte valde prominula: oculis arcte connatis. Os flavum, labrum supra infraque fuscum, superiore parte saepe lineolam brunneam ad medium emittens. In foeminis flavum totum. Faciei reliqua pars virescens, aut flavida. Nasus in medio habet puncta duo obliqua, impressa, magna, glabra: nasus a fronte per marginem fuscum, frons a vertice per rugam valde elevatam separata. Pone hanc rugam macula atra, transversa posita est, e medio lineolam versus vesiculam emittens. Vertex viridis, postice ater: vesicula atra, antice flavido - virescens. 
Oculi marium laete et lucide coerulei, foeminarum laete gilvo-virides. Cuneus flavidus. Tempora atro-fusca, cum plaga gilva.

Truncus. Prothorax valde ab oculis tectus, brevissimus, antice admodum coarctatus, postice elevatus, pilis gilvis sparsim ciliatus, gilvus, in medio fuscus. Alitruncus laete viridis, ex aeruginoso colore in pomaceum transiens, collari vittis tribus latis, brunneis, media latiori, antice cum lateralibus connexa, (aut, si vis, brunneo, vittis seu plagis duabus viridibus), septulis viridibus. Callis alaribus posticis, scutellisque laete flavis, reliquis tuberculis interalaribus laete viridibus, reliqua mesothoracis et metathoracis parte brunnea.

Alae vulgari modulo paullulo latiores, abdomine satis breviores, subfuscescentes, atque, praesertim in foeminis, ad totum marginem anticum flavescentes. Parastigma longum, perangustum, luteo-fuscum, subpellucidum. Margo posticus alarum posteriorum maris, versus abdomen, in angulum satis acutum, fere rectum, flexus est. Membranula accessoria valde minuta, albo - cinerea.

Pedes brunnei vel ferruginei.

Abdomen ad basin crassum, paullum globosum, cylindricum. Pictura in maribus ad basin viridis cum maculis fuscis, reliqua abdominis pars atro-brunnea cum maculis coeruleis: in foeminis fuscoferruginea est basis cum maculis viridibus: quod accuratius in hunc modum definiendum est, ut maris segmentum abdominale primum viride sit totum, supra basin macula brunnea distinctum: secundum, basi viridi, versus apicem coeruleum sit, cum macula dorsi utrimque atra, flexuosa. Tertium in medio valde attenuatum, atro-brunneum, lateribus coeruleis, maculis coeruleis ad basin apicemque latioribus, in dorso fere confluentibus. Segmenta quartum et sequentia usque ad nonum pari modo picta, maculis basalibus pedetentim deminutis. Decimum atro-brunneum, maculis duabus magnis, coeruleis, vel confluentibus, vel macula una alterave, parva, atra separatis. Foemina 


\section{3}

simili modo picta est, abdominis vero color fusco-ferrugineus cum maculis laete viridibus. Segmentum secundum in dorso diversam a mare habet picturam: est viride, maculis duabus adnatis utrimque in acumen excurrentibus, ferrúgineis. Caeterum maculae in reliqua abdominis parte minus sunt rotundae, quam in mare, quare maculae dorsales, ferrugineae potius rectangulae apparent. Venter marium brunneus, foeminarum ferrugineus.

Appendices maris longitudinem ultimorum duorum segmentorum aequant: tenues, graciles, in apice rotundatae, in basi attenuatae, fusco-atrae. Inferior dimidia parte brevior, acuto-triangularis. Foeminae appendices eiusdem sunt longitudinis: tenues, compressae, aequales.

Volitat haec Aeschna tempore autumnali, atque oculorum maris tam laete et lucide coeruleorum, foeminae flavo-viridium causa insignis est.

\section{AESCHNA IUNCEA.}

Tab. XXIII. mas et foem.

Aesch. alitrunco atro-brunneo, ad latera vittis duabus, latis, viridibus, tertiaque intermedia maculari, collarisque vittis duabus similibus, et ante eas macula parva, viridibus: abdomine valde maculato.

Linn. S. N. p. 903. Lib. iuncea.

Linn. Faun. Suec. p. 374.

La tr. Hist. Tom. XIII. p.7. Aeschna maculatissima.

Charp. Hor. Ent. p. 34. Aesch. maculatissima. Tab. I. fig. 4. maris appendices.

Van d c r Lind. p. 22. Aesch. maculatissima.

Ro es el. Vol. II. Aquat. Tab. II. fig. 1. mas. fig. 2. maris variet. pur. pureo - maculata.

Schaefferi Icon. Tab. VI. fig. 10. mas.

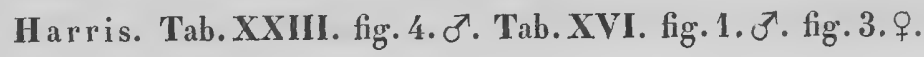


Petagn a Tab. VI. fig. 2. mas. Aesch. grandis.

Burmeister Vol. II. Tom. II. p. 838. Aesch. iuncea.

[Non dubitari posse puto, quin Lib. iuncea Linnei eadem sit atque illa, quam plures sub nomine Lib. maculatissimae descripserunt. Verba Linnei bene in eam quadrant, et icon e Schaefferi opere, in Syst. Nat. l.c. proposita, rem plane facit certam.]

Est ad maximas totius fere Europae Aeschnides referenda, et usque ad tempus autumnale horis vespertinis volitat solitaria.

Caput haud magnum, labium labrumque flavidum, marginibus tenuiter fuscis. Nasus cum fronte viridis, punctis duobus impressis, glabris. In vertice ad rugam macula transversa triangulari, atra, in medio cum margine postico, tenuiter atro connexa: vesicula verticalis flava, postice atra. Oculi maris coerulei, foeminarum virescentes: tempora atra, glabra, plaga magna subtransversa, impressiuscula, gilva, in foeminis multo minore.

Truncus. Prothorax parvus, brevis, antice angustus, postice in lobos duos modicos erectus, fusco-ater, antice lateribusque gilvus, postice pilis gilvis ciliatus. Alitruncus atro-brunneus. In collari plagae seu vittae duae, latae, magnae, laete virides, et ante eas macula parva, rotunda, eiusdem coloris. Septula itidem viridia. Latera alitrunci atro-brunnea, vittis duabus latissimis, viridibus, in utroque latere: ante anteriorem vittam subtus macula flavo-viridis, et inter vittas tres aut quatuor maculae virides, subcohaerentes. Calli alares fuscoatri, in medio virides, externe flavi. Tubera interalaria laete viridia, pnystegae saepe flavae. Reliqua dorsi thoracis pars fusco-atra, parum pilosa.

Alae, maxime foeminarum, paullulum fuscescentes, venis fuscis, marginali antica lucidiore. Parastigmata subbrevia, rectangula, plus minus fusco-opaca. Membranula accessoria minima, triangularis, 
cinerescens. Angulus abdominalis seu basalis alarum maris posticarum valde prominens, subacutus.

Pedes fusco-brunnei, potius ferruginei.

Abdomen in utroque sexu ad basin inflatum, globosum, segmenti tertii medio in mare valde, in foemina minus coarctato: marium atro-brunneum, foeminarum in ferrugineum transiens.

Marium segmentum primum brevissimum, margine postico superne viridi, sinuato: subtus ad genitalia macula permagna, flava distinctum. Secundum sıpra basin macula acuta, sagittiformi, lineolis duabus mediis, transversis, et duabus magnis, rotundis, ad marginem posticum viridibus: ad latera et subtus macula maxima, coerulea, cui adiacet alia macula flava, et pone eam, genitalibus proxima, alia minima, coerulea. Tertium et sequentia segmenta usque ad septimum, ad laterum basin macula coerulea; superne ad basin macula parva, duabusque transversis in medio, et duabus magnis, ad marginem posticum viridibus sunt insignia.

Ad octavi segmenti basin macula parva, viridis, punctaque duo coerulea in medio dorsi, et maculae duae magnae, coeruleae ad marginem anticum. Nonum et decimum segmentum ad apicem habet maculam maximam, coeruleam. Subtus abdomen fuscum, foeminae ferrugineum, ad basin segmentorum macula coerulea aut viridi, cuticula ventris ipsa atra. Foemina pari fere modo picta est, sed maculae omnes laete virides.

Appendices maris caudales (Hor. Entom. Tab. I. fig. 4.) singularis sunt structurae. Superiores fere longitudinem segmenti decimi et noni exaequant, oblique directae (nec verticales, nec horizontales), divergentes, in basi valde attenuatae, in medio fere rotundato-dilatatae, et apice acuto incurvo: margines crassi, atri, membrana intra margines albida, et ante apicem rugula perelevata, quae fere crista nominari potest, brevis, scabra. Inferior dimidia parte brevior, triangularis, acuta. 
Foeminarum appendices paullulo breviores, compressae, ad basin apicemque attenuatae, marginibus incrassatis, fuscae.

\section{AESCHNA PILOSA.}

Tab. XXI. mas et foem.

Aesch. trunco abdominisque basi pilosis, thorace brunneo, collari plagis duabus flavo-viridibus, abdomine maris maculis coeruleis, foeminae flavis.

Ch a rp. Hor. Ent. p. 37. A. pilosa. Tab. I. fig. 5. appendices maris.

Har is Tab. XXVII. fig. 3. foem.

Van der Lind. p. 21. A. vernalis.

Ann. d.1. Soc. Ent. Tom.VII. Tab.V. fig.2. p.81. A.vernalis foem.

Habitat in Germania, Gallia.

Caput facie prominente, virescenti-flavida: labii laciniarum labrique marginibus atris: rhinario nigro: naso a fronte linea atra separato: in vertice macula transversa, atra, quae in parte media cum margine postico, atro connexa est. Vesicula atra, antice flava. Oculi maris coerulescentes, foeminae ferruginei, subtus virescentes. Cuneus flavus. Tempora atra, glabra, cum plaga maxima, gilva.

Truncus. Prothorax brevis, laevis, ater, postice pilis perlongis, flavidis ciliatus. Mesothorax flavo-viridis, ad latera lineis quatuor nigris. Collare rufo-brunneum, maris utrimque plaga longa, lata, flavo-viridi: in foemina aut unicolor, aut plagula tantum brevi, antice posita pictum. Dorsum thoracis brunneum, tuberculis interalaribus viridibus. Calli atri, flavo-maculati. Totus truncus valde pilosus.

Ala e abdomine breviores, latiusculae, ad apicem rotundae: parastigmate perlongo, gilvo-fusco, subpellucido: costa ipsa eiusdem est coloris. Foemina alas gerit ad marginem anticum, et praecipue ad basin flavescentes. Membranula accessoria brevis, triangularis, albida. 


\section{7}

Praeterea notandum est, alas maris posticas ad basin sine angulo usque ad abdomen protendi: igitur non formant marginem abdominalem.

Pedes nigri toti.

Abdomen utriusque sexus cylindricum, rectum, foeminae paullo robustius: ad basin crassius, quam versus apicem, sed non inflatum, nec globosum: in segmenti tertii medio non coarctatum. Maris abdomen atro-brunneum, maculis dilute coeruleis et sulphureis; foeminae atrum, paullisper in viride abiens, maculis admodum dense sulphureis.

Pictura ipsa haec est in mare: in segmento primo superne in medio macula rotunda, subtus ad latera maior, flava. In secundi segmenti basi macula angusta, ad latera magna: postice duabus magnis coeruleis: ante has ad suturam lineolae duae transversales, flavae. Segmentum tertium et sequentia usque ad octavum eodem modo picta sunt, nisi quod versus apicem tantum maculis duabus coeruleis instructa sunt: decimum simile, maculis coeruleis saepe in unam confluentibus, vel totum atrum. Foeminae pari modo pictae, sed maculae omnes flavae, et in segmento ultimo superne macula magna, rotunda, flava, similisque, sed minor, in appendice intermedia. Maculae abdominis laterales, flavae in foeminis paullo maiores sunt, quam in maribus. Praeterea in utroque sexu abdomen, potissimum ad basin, pilis brevibus, densis, nigris valde obsitum.

Appendices maris (Hor. Ent. Tab. I. fig. 5.) superiores subtortuosae, ultimis duobus segmentis longiores, ad apicem latiores, ibique in medio cuiusque cristula seu carina valde elevata, versus abdomen sensim sensimque complanata. Margines appendicum externi subincrassati. In latere interiore appendices pilis longissimis, atris instructae. Appendix inferior ultra dimidiam partem minor, paullum curvata, quadrata, versus apicem paullo angustior: superna pagina cavata, polita. 


\section{$-108$}

Foeminae appendices superne eiusdem sunt longitudinis, paullatim attenuatae, fuscae: media brevissima, atra, cum puncto parvo, flavo.

Sequuntur descriptiones trium specierum quam maxime affinium, quarum mares potissimum pictura primorum segmentorum et appendicum forma distinguuntur.

\section{AESCHNA AFFINIS.}

Tab. XVIII. mas et foem.

Aesch. alitrunco viridi: collari brunneo, maculis duabus parvis, flavido-viridibus: ad latera lineis nigris; abdomine brunneo, segmentis maris coeruleo-maculatis, foeminae flavido-maculatis: segmento primo macula lata, triangulari insigni.

Van der Lind. p. 24.

Ann. de la Soc. Ent. VIII. p.91. Tab.4. fig. 1.2. mas et foem.

Habitat hic illic in Silesia; in Italia, Hungaria.

Caput globosum, non nimis latum: labio flavo: labro virescente, margine antico sinuato, atro. Reliqua faciei pars coerulescens, ruga verticis lata, atra, postice cum faciei margine postico, atro, cohaerente. Vesicula atra, antice flavida. Oculi maris coerulei: foeminae virescentes, connati. Cuneus triangularis, flavus. Tempora atra tota.

Truncus. Prothorax ater. Alitruncus laete viridis, in lateribus lineis quatuor nigris, obliquis. Collare globosum, brunneum, ad latera viride, plagulis duabus parvis, angustis, viridibus. Dorsum alitrunci brunneum, tuberculis interalaribus coeruleis, foeminarum in virescens transeuntibus. Calli alares atri, cum lunula flavida antica, et maculis coerulescentibus posticis.

Ala e latiusculae, pellucidae: foeminarum ad basin paullulum flavicantes. Parastigma oblongum, fusco-gilvum, subpellucidum. Membranula accessoria cinerea. 
Pedes fusci, ad basin brunnei.

Abdomen ad basin in utroque sexu inflatum, in segmenti tertii medio attenuatum, cylindricum, apud mares atro-brunneum, apud foeminas ferrugineo-brunneum.

Maris segmentum primum breve, in medio dorso macula lata, triangularis, coerulea, et in utroque latere macula maxima, flavo-viridis. Segmentum secundum coeruleum fere totum, in dorsi medio utrimque pictura atra, et ante eam utrimque macula permagna, rotunda, brunnea. Tertium segmentum et sequentia usque ad septimum utrimque maculis tribus magnis, coeruleis, prioribus in dorso coëuntibus, reliquis a carina distantibus, sunt instructa. In octavo, nono et decimo segmento maculae tantum duae minores. Venter brunneus.

Foeminae abdomen ferrugineo - seu testaceo-brunneum, cum maculis flavis, interdum in laete viridem colorem abeuntibus et atrocinctis pictum.

Segmentum primum superne habet maculam formae trianguli lati similem, et ad utrunque latus maculas duas maximas. - In segmenti secundi dorso macula angusta, longitudinalis, sagittiformis, cum duabus transversis nigro-cinctis: ipsum segmentum ad latera et subtus late flavo-viride. - In segmento tertio usque ad septimum carina dorsalis atra, cui in medio et ad apicem adiacent maculae duae, quarum priores sunt minores, atro-cinctae, et alia ad utrumque latus. - Segmentum octavum, nonum et decimum tantum ad apicem duas habent maculas.

Appendices maris superiores foliaceae, tortuosae, ultimorum duorum segmentorum longitudini aequales, ad basin attenuatae, ibique in latere inferiore dentem habent (vide fig. Tabulae XVIII. adiectam): apex appendicum acuminatus est. Inferior longitudinem dimidiam superiorum attingit; est triangularis, et valde attenuata. - Foeminarum paullo breviores, foliaceae, aequales. 


\section{$-110$}

Simillima est haec Aeschna affinis speciei sequenti: mas pictura primorum segmentorum, colore macularum omnium dorsalium coeruleo et earum magnitudine, nec non appendicum forma distinctus; foemina colore flavido magis in viridem transeunte, abdomine graciliore, maculisque minoribus a foemina sequentis speciei distincta.

\section{AESCHNA MIXTA.}

Tab. XIX. mas et foem.

Aesch. thorace brunneo, fasciis duabus lateralibus, latis, flavis, maculaque minima ad anticum collaris: abdomine brunneo, maris maculis coeruleis et flavidis, foeminae flavidis omnibus: in segmento utriusque sexus secundo macula flava, uti littera $\tau$ formata.

Latr. Hist. Tom. XIII. p.7.

H a rris Tab. XXVII. fig. 1. mas.

Ch a rp. Hor. Ent. p. 35.

Van der Lind. p. 23.

Burmeist. Vol. II. Tom. II. P. II. p. 829.

Habitat in Germania, Italia, Gallia.

Caput globosum: labium flavum, labrum flavidum, margine antico nigro, paullulum sinuato. Reliqua faciei pars flavida, ruga frontali nigra, colore distincto, postice cum margine verticis connexo. Vesicula verticalis atra, antice flava. Cuneus flavus. Oculi maris coerulescentes, foeminae fusci. Tempora atra, cum macula parva, flava, ad os posita.

Truncus. Prothorax opacus, ad latera paullum gilvus. Mesothorax brunneus, ad latera fasciis duabus latissimis flavis, vel flavo-virescentibus, et plagulis duabus minimis eiusdem coloris in collaris parte antica. Dorsum alitrunci brunneum, pilosum: calli axillares atri cum maculis laete flavis: tubercula interalaria maris leviter fusca, scutello tamen flavo, pnystega leviter coerulea, et postdorsulo fusco, apice 
coeruleo. Foeminae tubercula flava: postdorsulo fusco, apice tantum flavo. Tuberculorum pictura bene notanda est, cum haec species a praecedente bene ea distingui queat.

A la pellucidae, foeminarum paullulum fuscae: parastigma longum, atrum, foeminae fuscum: membranula accessoria parva, cinerescens.

Pedes atro-brunnei.

A b do men utriusque sexus in basi inflatum: foeminae solito paullo crassius seu robustius: maris atro-brunneum cum maculis coeruleis et nonnullis flavis: foeminae ferrugineo-brunneum cum maculis flavis omnibus.

Primum maris segmentum superne brunneum, utrimque ad latera macula magna, flavida instructum. Secundum macula dorsali formam litterae $\tau$ refërente, lineis duabus transversis, et ad latus macula magna, flava: ad marginem posticum macula lata, triloba, coerulea. Segmentum tertium et sequentia usque ad octavum ad basin habent utrimque maculam magnam, lateralem, coeruleam, et ad marginem anticum lineam coeruleam, et similem in media segmenti parte; ad marginem autem posticum maculas duas magnas eiusdem coloris. (Lineolae coeruleae, transversales in medio illorum segmentorum interdum leviter flavidae sunt.) Segmentum nonum et decimum tantum maculis duabus coeruleis ad marginem posticum ornata sunt. Foeminae pictura est eadem, sed macularum color flavidus, et maculae omnes distincte et satis late nigro-cinctae sunt.

Appendices maris caudales (Hor. Ent. Tab. I. fig. 6.) ultimorum duorum segmentorum longitudinem aequant, foliaceae, tortuosae, versus apicem latiores, in latere interiore nigro-pilosae, integrae, (ita ut omni dente plane careant); inferior brevior, triangularis, supra excavata (vid. et fig. fundam. Tab. XXX. huic operi adiectam). - Foeminae appendices eiusdem fere longitudinis, latiusculae, ad 


\section{$-112$}

basin apicemque angustiores, foliaceae, linea media longitudinali elevata.

Alitrunci laterum et segmentorum basalium color, sicuti appendices maris dente carentes, hanc Aeschnam a praecedente bene distinguunt.

\section{AESCINA PICTA.}

Tab. XX. mas et foem.

Aesch. brunnea, thorace vittis duabus lateralibus, duabusque in collari viridibus, abdomine coeruleo-flavoque-maculato : parastigmatibus oblongis.

Habitat in Germania media, Silesia.

Est magna, vix minor quam Aeschna iuncea, cui pluribus signis congrua est. Maculis abdominis valde distinctis et parastigmatibus perlongis ab illa specie bene distinguitur.

Cap ut ut in congenericis: facies flava, ad genas nigra. Labii lacinia media in medio interdum maculam habet fuscam: laciniae omnes ad margines centrales atro - marginatae. Labrum antice posticeque et rhinarium totum atro-fuscum. Nasus flavus, punctis duobus anticis impressis, interdum atris, per lineam a fronte separatus. Frons flava. Vertex in culmine valde impressus, fere paullulum excavatus: antice adest macula perdistincta, transversa, nigra, per lineolam atram cum margine postico, atro cohaerens. Vesicula atra, antice flava. Oculi maris coerulescentes: foeminae virescentes, superne fusci. $\mathrm{Cu}$ neus flavidus. Tempora atra, cum macula parva flava, ad os sita.

Truncus. Prothorax ater, opacus, postice gilvus. Alitruncus brunneus, vittis duabus lateralibus, obliquis, flavis, et interdum tertia submaculari inter eas, omnibus nigro - cinctis. Collare brunneum, vittis duabus flavido-viridibus, postice latioribus, interdum interruptis. Haud raro collare ante marginem lateralem gerit plagulam viridem. - 


\section{3}

Calli axillares brunnei, glabri: foeminarum in medio macula flava. Marium calli tantum superiores macula distincta, lunari, et alia parva, recta, flava picti sunt: inferiores in centro habent maculam coeruleam.

Dorsum alitrunci brunneum, subpilosum: tubercula interalaria leviter coerulea, exceptis scutello et postscutello, quae laete flava. Pnystega et postdorsulum tantum ad apices coerulea, in reliqua parte sunt fusca. In foeminis tubercula omnia flavescentia sunt.

Alac hyalinae, cum areolis permultis. Parastigma oblongum, plus minus fuscum. Margo anticus flavidus aut fuscus. Membranula accessoria cinerea, basi albida.

Pedes brunnei, foeminae paullo lucidiores.

Abdomen cylindricum, longum, ad basin valde inflatum, globosum in utroque sexu, in segmento tertio coarctatum: maris atrobrunneum, foeminae lucidius. - Segmentum primum macula utrimque ventrali, lineari, ad marginem posticum flava, aliaque dorsali, transversa, coerulea, subtriloba. Secundum in dorso lineola basali, atque in medio lineolis duabus transversis, flavis: ad marginem posticum linea coerulea, lata, triloba. Praeterea utrimque maculae duae ventrales, flavidae, quae cum illis interdum cohaerent. Omnia reliqua segmenta ad marginem posticum gerunt maculas duas magnas, coeruleas, et segmentum tertium cum sequentibus usque ad octavum, ad marginem basalem et in medio, lineolam transversalem, flavan, cum macula maiori, laterali saepe cohaerentem.

Foemina pari modo est picta, sed macularum omnium color flavus.

Appendices maris vix ultimorum duorum segmentorum longitudinem aequant, foliaceae, atrae, horizontales, in latere interiore pilosae, linea longitudinali lateri interno propiore, elevata, apicibus minus acutis. Foeminae appendices laterales quarta parte breviores, planiusculae, brunneae, linea longitudinali per medium ducta, elevata: sunt 
latae, ad apicem rotundatae. Appendix intermedia minima, triangularis, brunnea, puncto distincto flavo.

Maculae in hac Aeschnarum specie paullulo minores, quam in speciebus praecedentibus, sed insignes ob ipsarum distinctam terminationem.

\section{AESCHNA GRANDIS.}

Tab. XXIV. mas et foem.

Aesch. ferruginea, alis flavidis, venis ferrugineis, callis maculisque nonnullis abdominis coeruleis.

Linn. S.N. p. 963.

Linn. Faun. Suec. p. 373.

Fabr. E. S. II. p. 384. (exclusis tamen pluribus scriptis allegatis).

Latr. Hist. Tom. XIII. p. 7 .

Cha r p. Hor. Entom. p. 32.

Van der Lind. p.26.

Ro es el. Vol. II. Aquat. Tab.IV. fig. 13. 14. mas.

Sch a eff. Icon. Tab. III. fig. 4. foem. Tab. LX. fig. 1. mas.

De Geer Tom.II. p. 46. Tab.XX. fig. 5. mas.

Harris Tab. XII. fig. 1. mas. fig. 2. foem.

Habitat ubique in Europa.

Color huius Aeschnae principalis est e rufo in flavido-ferrugineum transiens, et omnes fere eius partes, quin etiam omnes alarum venae tali modo coloratae sunt: color macularum flavus et coeruleus satis vivax est, in foeminis tamen plerumque pallidior, et in album abiens.

Caput globosum, frontis medio producto, vertice leviter impresso. Facies flavida tota. Nasus loculis duobus glabris et, sicuti frons, punctis crebrioribus impressis. Ruga verticis habet maculam transversalem, fusco-ferrugineam, haud raro obsoletam. Vertex ipse, 
sicuti vesicula verticalis, flavidus est, postice fusco-ferrugineus. Oculi utriusque sexus coerulescentes, subtus paullulum ferruginei. Cuneus flavus. Tempora fusca, immaculata.

Truncus. Prothorax ferrugineus, antice cum linea impressa, fusca, irregulari. - Alitruncus rufo-ferrugineus, perglobosus, breviusculus, ad latera vittis duabus obliquis, non nimis latis, sulphureis, fusco-cinctis. - Dorsum alitrunci rufo-ferrugineum, sicuti tubercula interalaria; scutellum tamen et postscutellum laete flava, et media pnystegae pars leviter coerulescens. Calli axillares anteriores ferruginei quidem, sed in medio macula magna, glabra, laete coerulea.

Alae latiusculae, robustae, membrana flavida, et venis omnibus, sicuti parastigmate oblongo, rufo-ferrugineis. Membranula accessoria parva, albicans.

Pedes ferruginei.

Abdomen maris ad basin globosum, in segmento tertio coarctatum, cylindricum. Foeminae abdomen ad basin crassius, et paullatim ad apicem deminutum: ferrugineum, maculis flavis et nonnullis (in mare pluribus) coeruleis. - Maris segmentum abdominale primum immaculatum. Secundum lineis duabus mediis transversalibus, flavis, ad verrucas ventrales procurrentibus, maculisque duabus maioribus cocruleis ad marginem posticum, haud raro in unam confluentibus insigne. Sequentia segmenta usque ad octavum in basi ad utrumque latus gerunt maculam coeruleam, bilobam: segmentum quartum et sequentia praeter illas maculas in dorso, ad suturam horum singulorum segmentorum transversalem habent lineolas duas parvas, flavidas.

Foemina simili modo picta est: sed maculae coeruleae in segmento secundo plerumque dimidia parte flavae sunt, et maculae abdominis laterales non coeruleae, sed albidae, et minus super dorsum extenduntur.

Appendices maris ultimo penultimoque segmento paullo breviores (Hor. Ent. Tab.I. fig. 2.), rectiusculae, in basi attenuatae, ad apicem 
rotundatae, linea media longitudinali elevata. Inferior dimidio brevior, triangularis, excavata. Foeminae appendices laterales paullo breviores et acutiores: intermedia parva, triangularis, globulosa.

Olim omnes fere Aeschnae Europaeae, Aeschna forcipata excepta, sub denominatione quasi collectiva Aeschnae grandis intellectae sunt. Linneus ipse fortasse huius rei ansam dedit, cum in F'aunae Suecicae locis commemoratis Aeschnae grandi alas tribuerit, glaucescentes, flavescentes, fulvescentes et argenteas". Clarissimum autem virum revera Aeschnam hic descriptam seu Aeschnam grandem nostram ante oculos habuisse, verbis in Syst. Nat. additis „macula coerulea supra basin alarum" comprobatur.

\section{AESCHNA CHRYSOPHTHALMUS.}

Tab. XXV. mas et foem.

Aesch. ferruginea, alis flavidis, venis nigris, macula permagna, sulphurea, sagittiformi in segmenti secundi dorso.

Charp. Hor. Ent. p.33.

Burmeister Vol.II. Tom.II. P.II. p. 838.

Van der Lind. p. 27. Aesch. rufescens.

Habitat in Silesia, Hungaria et nonnullis Germaniae atque Italiae regionibus.

Propter abdominis alarumque colorem primo adspectu Aeschnae grandi simillima, sed plerumque minor, et alioquin magnopere ab ea distincta.

Caput globosum, fronte in medio valde tumida, prominente, verticeque ante vesiculam valde impresso. Facies flavida, leviter in ferrugineum transiens. Labii labrique margines fusci. Cuneus ferrugineus. Oculi utriusque sexus laete et pulchre viridi-aurati. Tempora atro - fusca, glabra. 
Truncus. Prothorax ferrugineus. Alitruncus eiusdem coloris, cum vittis duabus flavidis, obliquis ad latera, ante quas linea, paullulum remota, atra. - $\Lambda$ litrunci dorsum ferrugineum, subpilosum: tubercula eiusdem sunt coloris. Calli alares flavidi.

Alae subpellucidae, flavidae seu fulvescentes. Posteriores ad basin valde fulvo-coloratae. Venae ipsae atrae sunt, excepta vena antica marginali, quae, uti parastigma perlongum, flavo - ferruginea est. Membranula accessoria atro-cinerea, et alarum posticarum permagna.

Pedes atro -fusci, femoribus, praesertim ad basin, ferrugineis.

Abdomen in utroque sexu ad basin globosum, in tertii segmenti medio coarctatum, flavo-ferrugineum: carina, suturis et punctis geminis ad postica singulorum segmentorum atris. Carina dorsalis atra, versus apicem latior est. Venter versus basin flavido-maculatus. Per totum segmenti secundi dorsum cernitur macula magna, sagittiformis, sulphurea, qua haec species admodum insignis est.

Appendices caudales rufo-ferrugineae: maris superiores (Hor. Ent. Tab. I. fig. 3.) eiusdem longitudinis atque segmenta duo ultima, angustae, per totam longitudinem linea elevata instructae, latere exteriore recto, interiore subcurvo, apice acuto, et in latere interno versus basin denticulum acutum gerunt. Inferior dimidio brevior, triangularis. Foeminae appendices laterales breviores, tenues, graciles: intermedia brevissima.

[Adnot. In opere: Annales de la societ. Entom. Paris. 1838. Tom. VII. p. 96. cl. auctor de Aesch. rufescente Van der Linden disserit, quae haec nostra Aesch. Chrysophthalmus est. Cum vero illi alae, basi excepta, non coloratae attribuantur, et cum in appendicum maris descriptione de denticulo basali tam insigni plane nihil afferatur, equidem crediderim, in illo opusculo fortasse diversam descriptam esse speciem.] 


\section{AESCHNA LUNULATA.}

Tab. XXVI. mas et foem.

Aesch. magna, aterrima, alitrunco vittis senis, abdomineque maculis flavissimis.

[Adnot. Nomen Aesch. annulatae, a cl. Latreille huic Aeschnae impositum, mutandum fuit, cum idem iam a Fabricio alii speciei attributum sit.]

C h a r p. Hor. Ent. p. 29. A. lunulata.

Burme is ter Vol.II. Tom.II. P.II. p. 836. A. lunulata.

L a tr. Hist. Tom. XIII. p. 6. A. annulata.

Scopoli Entom. carniol. p. 259. Lib.grandis.

H a r ris Tab. XXIII. fig. 3. Lib. forcipata, foem.

Van der Lind. p.27. A. annulata.

Habitat in Germaniae regionibus montanis.

Est e maximis, colore nigerrimo, maculis distinctis flavissimis et abdomine attenuato, longo insignis.

Caput transverso-globosum, oculis tantum angulo acuto connatis, fronte latiuscula, prominente, vertice late excavato. - Labium gilvum, lacinia media profunde excisa: labrum angustum, ita ut mandibulae flavae ad eius latera paullulum exstent, flavum, undique fuscocinctum, et e marginis postici medio lineolam atram ad antica emittens: margine antico profunde exciso, pilis flavidis ciliato. Rhinarium atrum. Nasus brevissimus, flavus, antice paullum ater, lineolis duabus transversis, impressis, glabris. Frons brevis, per lineam elevatam, angulatam a vertice separata, cum macula atra ante hanc lineam seu rugam. Vertex excavatus, flavus, in dimidia parte postica ater, sicuti vesicula verticalis. - Oculi virescentes. Cuneus flavus, pilis erectis, flavidis ciliatus. Tempora atra, glabra, cum plaga flava, ad partem 
inferiorem, quae a supina parte adspecta tanquam punctum flavum apparet, uti in icone Tabulae XXVI. depictum est.

Truncus. Prothorax ater, margine antico tenuiter flavo: postico lineolis duabus transversis, flavis. Alitruncus aterrimus, glaber, pilis brevibus, flavidis obductus: in lateribus vittae duae latae, obliquae, flavae, ac tertia intermedia, quasi lineari, interrupta. Collare vittis duabus flavis, latis, divergentibus, antice attenuatis; postica parte, prope septula, adest interdum utrimque punctum flavum. Dorsum alitrunci atro-brunneum, leviter flavido-pilosum. Tubercula interalaria fuscoatra: dorsulum tamen et postdorsulum laete flava. Calli axillares atri, glabri, cum puncto distincto, triangulari, flavo, alae ipsi propiore.

Ala a attenuatae, ecoloratae, pellucidae, parastigmate peroblongo venaque marginali fuscis. Membranula accessoria angusta, albida.

Pedes aterrimi, in tibiis tarsisque pilis rigidis, atris, brevibus ciliati.

Abdomen ad basin modice inflatum, deinceps attenuatum, et paullatim versus apicem crassius, aterrimum, subglabrum: in basi ipsa paullulum gilvo-pilosum. Segmentum primum superne quasi turgidum, subfuscum, et ad rentris latera linea postica, tenui, flava instructum: secundum cingulis duobus flavis, postico haud raro interrupto. Segmentum tertium et sequentia usque ad octavum habent cingulum medium, flavum, carina dorsali interruptum, et lineolas duas ad postica tenues, flavas. Nonum et decimum macula parva, flava ad utrumque latus sunt instructa. Verrucae maris ventrales parvae sunt, et tantum uti puncta modicae magnitudinis elevata, glabra apparent. Foemina eodem modo est picta: segmenta autem eius octavum et nonum quasi globularia sunt, et cuticula abdominis coniunctiva magnopere ad segmentorum margines prominet. Structura abdominis tota haec Aeschnae species a praecedentibus recedit: segmenta enim dorsalia totum fere abdomen cingunt, et nulla adsunt scuta seu segmenta 
lateralia sive ventralia. Hac ratione subgenus Thecaphora propius est Diastatonmatibus.

Appendices maris atrae, brevissimae, ultimo tantum segmento vix longiores (Hor.Entom. Tab. I. fig. 7.): superiores dolabriformes, ad basin incrassatae, subtus denticulo armatae: inferior dimidio brevior, quadrata, apice leviter emarginato. Foeminarum appendices etiam breves, conicae, acutae: intermedia eiusdem est lóngitudinis, lata, triangularis, pilis rigidis obtecta. Prominet autem prae his appendicibus insígnis ille processus valvulae, aperturam oviparam claudentis, qui a margine postico seginenti ventralis octavi forma conica, acuta, longa, tanquam vagina, coloris atri, abdominis finem longe excedit. Haec ragina ansam dedit ad hanc Aeschmae speciem et nomnullas exoticas, eadem vaginae structura praeditas, in subgenus peculiare coniungendas, cui nomen „Thecaphora“ impositum est.

Transitum, ut ita dicam, facere videtur haec Aeschna ad species septem sequentes, quibus nomen subgenericum „Diastatomma“ attribui.

Labii lacinia media profunde excisa, laciniarum lateralium dens maiusculus, acutus, oculi vix se tangentes sive vix connati, pedes solito breviores, et color ipse, ex atro et flavo compositus, affinitatem Aeschnae lunulatae cum Aesch. forcipata eiusdemque congenericis demonstrare videntur.

\section{AESCHNA HAMATA.}

Tab. XXVII. mas el foem.

Aesch. nigra, flavo-maculata: maris appendicibus superioribus fuscescentibus, angulatis, ad apicem bifidis: ad foeminae tempora cornicula duo flava.

Linn. S. N. p.903. Lib. forcipata. (Delendi ibi sunt fere omues loci allegati.) 
De Geer Tom. II. p.50. Tab.21. fig. 1. mas. fig. 2. eiusdem appendices.

Charp. Hor. Ent. p. 25. A. hamata. Tab.1. fig. 10. maris appendices.

B urmeist. Vol. II. Tom. II. P. II. p. 834. Diastatomma hamatum.

Van der Linden p. 31. A. unguiculata.

Schaeff. Icon. Tab. 186. fig. 1. mas.

Fabr. E.S. Tom.II. p.384. ? - fortasse hanc speciem cum A. forcipata confudit.

Habitat in Germaniae regionibus montanis, in Suecia, in Italia.

Referenda ad minores Aeschnides.

Ciaput latiusculum, subtransversum. Oris partes omnes flavae, nigro-cinctae: genae flavae. Verticis pars postica ultra dimidium atra, glabra, in medio ralde impressa. Vesicula fere nulla, ocelli enim quam maxime approximati (ocello medio paullulum usque ad anteriorem partem posito), loco vesiculae tantum lineam elevatam habent, cui appositi sunt. Oculi ipsi inter se valde remoti, viridi-grisei. Cuneus flavus, parallelopipedus, transversalis, carina acuta, quae pilis nigris ciliata est. Tempora atra, glabra, cum macula parva, flava. Foemina in temporibus prope cuneum habet cornicula duo parva, flavissima, ad apicem subcompressa et crenulata (vide Tab.XXVII. figuram fundamentalem, scala maxima delineatam). Organon hoc quam maxime singulare et peculiare, neque in ulla alia specie, a me hucusque cognita, observatum.

Prothorax ater, opacus, margine antico posticoque modice incrassato, flavo: in medio linea tumida, transversa, flavo-maculata. Alitruncus ater, ad latera vittis tribus latis, flavis, quarum media est submacularis. Collare antice posticeque habet maculas duas flavas, transversas, cum maculis duabus subobliquis, magnis fere coniunctas: praeterea lineolam tenuem, flavam ad utrumque collaris latus. Septula 
et tubercula interalaria flava, nigro-cincta. Color trunci flavus interdum aut in viridem transit, aut laete viridis est.

Alae abdomine breviores, nervis atris, hyalinae. Parastigma atrum, oblongum, in margine antico et postico paullulum dilatatum. Membranula accessoria minima, utpote quae vix conspici possit, glabra, subpellucida, flavida, angustissima. Maris alae posticae marginem basalem habent valde excisum. In foeminis alarum margo, uti assolet, rotundatus est.

Pedes breves, atri, femoribus ad basin flavis: tibiae pilis brevissimis ciliatae.

Abdomen maris in basi crassum: dein angustissimum, prope ultima vero tria segmenta iterum valde incrassatum, ideoque vere clavatum; est atrum, flavo-maculatum. Segmenta abdominis tantum dorsalia adesse videntur, et nulla ventralia; dorsalia enim in lateribus nulla sutura sunt interrupta, ut in reliquis Aeschnidibus, sed continuo fere totum abdomen circumdant, et nulla particula intercedente cum cuticula ventrali cohaerent seu ei annata sunt.

Segmentum primum postice maculam triangularem, obtusam, magnam, flavam, et aliam ad utrumque ventris latus gerit. Secundum segmentum habet maculam dorsalem, magnam, lobatam, flavam, et marginem ventralem pariter pictum. Verrucae ventrales, ibi positae, permagnae, flavae, fere globulares, cum carinula obliqua, subcrenulata. Segmentum tertium et sequentia usque ad septimum in dorso maculam gerunt flavam, subtrilobam, ad basin cum alia macula ventrali, minore connexam. Octavum et nonum superne atrum, ad latera macula parva, flava. Decimum atrum, ad marginem posticum maculis tribus, plus minus magnis, interdum cohaerentibus, flavis.

Appendices maris caudales quam maxime singularis sunt formac (vid. figuras supra allegatas). Superiores ultimo segmento aliquantulo longiores, triangulares, in basi crassiores, in apice angustiores. Ad 


\section{$-123$}

tertiam totius longitudinis ab apice partem angulo recto intus flexae sunt, et pars flexa ipsa compressa et bifida seu fissa, ita ut eius particula superior quasi digitum repraesentet. Inferior eiusdem fere longitudinis ac superiores, tenuis, ad apicem valde recurva, et ab apice paene usque ad basin fissa, ibique utrimque mucronulo acuto, horizontali armata.

Foeminae abdomen ad basin vix inflatum, cylindricum, rectum, aequale totum. Verrucas ventrales gerit, sed minimas, et quae potius rugulae elevatae nominari debeant. Foemina simili modo picta est, ut mas, sed maculae flavae maiores sunt, praesertim laterales, et segmenta octavụm et nonum ad basin flavo-marginata. Ultimum ad marginem posticum maculam habet rotundam, flavam. - Appendices flavidae: superiores longitudinem penultimi segmenti aequant; sunt conicae, acutae; intermedia brevior, pyramidalis. - Valvula aperturae oviparae ut in Libellulidibus constituta, ad finem segmenti ventralis octavi tanquam squamula quaedam tuberculosa, incumbens.

[A dnot. Iam alio loco monui, mihi videri a mare Libellulinarum coitum exercituro foeminam appendicibus non collo aut prothorace, sed capite ipso corripi ac teneri. Nisi fallor, putandum est, in mare huius Aeschnidis appendices in apice bifidas ei rei inservire, ut earum fissuram corniculis, ad foeminae tempora positis, admoveat, et sic eam optime retinere possit: saltem talis corpusculorum prominentium usus contra verisimilitudinem pugnare non videtur.]

\section{AESCHNA UNCATA.}

Tab. XLVI. mas et foem.

Aesch. nigra, flavo-maculata: maris appendicibus superioribus citrinis, angulosis, apice integro, compresso: foeminae temporibus aequalibus. 
Annales de la Societé Entomologique. Paris. 1838. Tom.VII. p. 104. Aesch. unguiculata.

Habitat in Gallia. - Ab amicissimo Prof. Kunze, Lipsiensi, Montispessulae in copula captus benigne mecum communicatus uterque sexus.

Praecedenti tam similis est, ut tantum signa hic enarraturus sim, quibus ab Aesch. hamata distincta est.

Maculae abdominis flavae multo maiores sunt, et dorsum segmenti octavi et noni in mare non nigrum, sed ad basin macula flava pictum.

Appendices maris, praesertim superiores, non fuscae, sed lacte citrinae: superiores apicibus minus horizontaliter flexis, sed paullum deorsum versis, parte flexa compressa, oblongula (quasi spatulata), et fossulis duabus seu impressuris longitudinalibus insignẹs: integrae, neutiquam bifidae. Inferior ut in Aesch. hamata comparata, fusca, in medio flavida, et, ut videtur, minus fissa.

Foeminae tempora oculorum habent glabra, aequalia, et omni tuberculo carent, quod in corniculorum locum succedat, quae sunt praecedenti speciei. Sunt atra, et a medio ad os plaga quadam magna, longa, maculari, flava distinguuntur. Abdomen minus crassum. Sed de unico exemplo difficile est recte in universum statuere et iudicare.

Fabrica appendicum maris, et defectus cornuum in foeminae temporibus satis hanc speciem a praecedenti distinguunt.

[Adnot. Verba illustr. B oy er in Annales etc. I. c. appendices maris flavas esse, et superiorum apices non bifidos, omnem dubitationem eximunt, clarum virum de hac Aeschna, neque de Aesch. hamata (Aesch. unguiculata, Van der Linden), locutum esse.] 


\section{AESCHNA FORCIPATA.}

Tab. XXVIII. mas et foem.

Aesch.nigra, flavo-maculata: in abdomine linea dorsalis flava, quae ultima tria segmenta non attingit: pedibus atris.

Linn. Faun. Suec. p. 374. (non aeque in Syst. Nat.). Lib. forcip.

Latr. Hist. Tom. XIII. p. 8. (Locus ex opere Reaumuriano delendus).

Charp. Hor. Ent. p. 24 .

Van der Lind. p. 28.

Roesel Vol.II. Aquat. Tab.V. fig. 3. foem.

Sch a eff. Icon. Tab. 160. fig. 1. mas.

Sulz. Hist. (edit. Roemer). Tab. 35. fig. 10. mas.

Panz. Faun. Germ. fasc. 88. Tab. 21. mas.

Burme is t. Vol. II. Tom.II. P.II. p. 834. Diastatomma forcip.

Habitat in tota fere Europa.

Est mediae magnitudinis, valida, rapacissima.

Caput globoso-transrersum, facie brevi, lata. Labium flavidum, in medio fuscum. Labrum flavum, supra infraque atrum. Rhinarium fuscum. Nasus brevissimus, postice cum impressuris duabus transversalibus, atris: frons flava, a vertice vix ruga separata. Vertex superne in medio impressus, antice flavus, postice ater, glaber. Ocelli linea recta, transversali positi, et pone eos, vesiculae instar, lineola elevata, cui in postica parte lacuna quaedam adiacet, quae per cuneum parallelopipedum, acutum, pilis atris ciliatum, terminatur. Oculi ipsi remoti, viridi-grisei: temporibus glabris, atris, flavo-maculatis.

Truncus. Prothorax brevis, versus marginem anticum profunde coarctatus: margine antico flavo; in marginis postici medio macula est gemina, et in utroque latere alia maior: omnes flavae: ad latera ipsa maculae duae parvae flavae. - Alitruncus ater; ad latera vittis dua- 
bus, flavis, tam latis, ut tota fere flava appareant, lineis tantum duabus nigris. Collare atrum, cum vitta utrimque lata, flava, antice introrsum, postice extrorsum flexa, ibique lineae laterali, tenui, flavae annata. Tubercula interalaria flava: calli atri, cum maculis flavis.

Ala e pellucidae, ecoloratae: parastigmata oblonga, fusca; in iunioribus et in foeminis minus colorata sunt parastigmata et subpellucida. Membranula accessoria parva, angustissima, glabra, flavida, pellucida. - Alarum maris posticarum margo basalis valde angulatus et excisus est.

Pedes breves, atro-fusci.

Abdomen alis paullo longius, cylindricum, maris in medio paullulum attenuatum, atrum, flavo-maculatum: in utroque sexu ad apicem crassius. - Segmentum primum superne totum fere flavum, sicuti ad latera. Secundum in dorso habet maculam longam, trilobam, flavam, aliamque ad ventrem, quae verrucas includit: maris genitalia externa aterrima. Tertium segmentum et sequentia usque ad septimum in dorso lineam gerunt flavam, fere continuam, in singulorum segmentorum basi latiorem. In lateribus ad ventris cutem et ad basin apparet macula parva, flava, quae in segmento tertio maior est. Linea illa dorsalis, flava, segmenta octavum nonum et decimum non tangit. Octavum et nonum latera paullisper dilatata, et macula magna, flava, insignia gerunt, sicuti margo posticus ultimorum trium segmentorum tenuiter flavus est. Foeminae eodem modo pictae sunt: pone inaculas autem flavas, laterales segmentorum 3-\% conspicitur lineola curvata, flava, ad segmentorum longitudinem procurrens.

Appendices maris atrae (Hor. Ent. Tab.I. fig. 13.), breves, ultimo segmento haud longiores. Superiores atrae, cylindricae, ad apicem repente truncatae et acuminatae: parum divergentes, parallelae fere et subinclinatae. Inferior dimidia parte brevior, lata, et ad utrumque latus in hamulum extensa: qui hamuli duo valde divergentes sunt, ita 
ut inferior appendix superne adspecta utrimque superioribus exstet. Foeminae appendices atrae, segmento ultimo longiores: exteriores conicae, acutae: intermedia triangularis.

Color huius Aeschnae flavus interdum in coeruleo-viridem transit.

[A dn ot. Sunt, qui putent, Aeschnam forcipatam hic descriptam eandem esse ac Linnei Libellulam „vulgatissimam“. Quod verisimile mihi haud videtur. Linne us enim in Fauna Suecica unam eandemque, et tam insignem speciem non bis et diversis nominibus descripsisset, et verba in Faun. Suec. edita: „a dorso longitudinaliter fusca“, de Aesch. forcipata omnino dici non possunt. Equidem potius existimo, cl. virum foeminam Libellulae „vulgatae“ sub nomine Lib. „vulgatissimae“ descripsisse, et pro specie peculiari habuisse.]

\section{AESCHNA FLAVIPES.}

Tab. XXIX. mas et foem.

Aesch. nigra, flavo-maculata: linea dorsali, flava, per omnia abdominis segmenta ducta: pedibus flavis, tenuiter atro-striatis.

Ch a r p. Hor. Ent. p. 24 .

B urm e is t. Vol. II. Tom. II. P.II. p. 833. Diastatomma flavipes.

Van der Lind. p. 30. Aesch. forcipatae var. $\beta$.

Eversmann in ,Bulletin de Moscou. 1837.66 p.24. Aeschna cognata. (Libellula sub hoc nomine Tab. I. laudati operis depicta, plane alia est.)

Habitat in Silesia et pluribus Europae regionibus.

Praecedenti simillima: abdomine attenuato, graciliori, et linea flava, usque ad abdominis finem ducta, ab illa bene distinguitur.

Caput transverso-globosum. Labium flavum: labrum cum rhinario et naso flavo-virescens: in naso impressurae duae, obliquae, 


\section{$-128$}

glabrae. Frons flavido-virescens, ad nasum atra, ruga quadam a vertice separata. Postica verticis pars atra, glabra. Oculi viridi-luridi, inter se valde remoti. Ocelli magni, per lineam curvam positi, et post eos rugula elevata, atra, ad fines flava. Cuneus flavus, parallelopipedus, acie instructus. Tempora tumida, glabra, flava, sed particula oculis propiore atra.

Truncus. Prothorax uti in praecedentibus, ater, opacus: margine antico flavo toto, postico lineola media transversali, maculaque rotunda ante posita, duabusque maculis angustis, et alia maiore ad latera flavis. Alitruncus ater, lateribus totis viridi-flavis, lineis tantum duabus et dimidia atris. Collare atrum, margine antico lato et sutura flavis: vittis duabıs ad suturae latera nigro-cinctis, et alia laterali, flava. - Tubercula interalaria flava: scutello et postscutello multo vivacioribus.

Alac ut in congenericis, parastigmate fusco, subpellucido. Maris alarum posticarum margo basalis modo angulatus, modo esinuatus.

Pedes flavi, ad latera linea atra distincti.

Abdomen, praesertim foeminae, alis paullo longius, in medio leviter angustatum, gracilius, quam in specie praecedente. Est simili modo pictum, atque in illa, atrum, cum maculis flavis, quae maculae multo maiores quam in A. forcipata sunt. Linea flava dorsalis per totum producitur abdomen usque ad eius finem, et maculae laterales itidem fere continuae. Verrucae marium flavae, permagnae: foeminarum vix conspicuae. Genitalia maris flava, quae in Aeschna forcipata atra sunt.

Appendices maris superiores atrae, conicae, acutae, ultimi segmenti longitudini pares, valde divergentes. Inferior lata, utrimque in hamulum seu spinam rectam, divergentem exiens: flava, apice hamulorum nigricante. Foeminae appendices paullo breviores: exteriores conicae, acutae, fuscae; intermedia triangularis, flava. 


\section{$-129$}

\section{AESCHNA SERPENTINA.}

Tab. XXX. Fig. 1. mas et foem.

Aesch. alitrunco laete viridi, atro-lineato: abdomine attenuato, atro, maculis appendicibusque flavis.

Charp. Hor. Ent. p. 25.

Burmeist. Vol.II. Tom. II. P.II. p. 833. Diastatomma serpent.

Schaeff. Icon. Tab.190. fig. 3. mas.

Ro esel Vol. II. Aquat. Tab. V. fig. 4. foem.

Habitat in pluribus Germaniae regionibus.

Aeschna praecedentibus aliquantulo maior, et abdomine valde attenuato, gracili insignis: sicuti coloribus vivacioribus, et foeminae cuneo, cornibus duobus brevibus (vid. fig. fundam. Tab. alleg.) instructo.

Caput globoso-transtersum: facies tota flavo-viridis, brevis, lata: vertice in medio paullulum excavato, postice atro. Océlli fere in linea recta positi, et post eos macula glabra, viridi-flava, ante cuneum prismaticum, acie instructum, flavum. Hic cuneus in foeminis insigni modo instructus est cornibus duobus brevibus, utrimque ad oculos positis, latis, flavis, superne acie crenulata seu denticulata instructis, denticulis ipsis atris. - Oculi viridi-flavescentes. Tempora glabra, atra, cum macula parva rotunda ad cuneum, et alia maxima, flava, versus os.

Truncus. Prothorax ut in congenericis, sculptus: margine antico maculis quatuor in medio, atque parvula in margine postico flavis. Alitruncus magnus, inflàtus, crassus, laete viridis, ex aeruginoso in psittacinum transiens: ad latera lineis atris instructus. Collaris particulae lineis tenuibus, atris terminantur, accedente alia linea versus latera, quae antice margini annata, postice libera est. Tubercula dorsalia viridia, scutello et postscutello citrinis. Calli axillares atri cum maculis pluribus flavis. 
Ala e hyalinae, vena marginali flavida, reliquis venis omnibus atris. Parastigma oblongum fuscum, in iunioribus subpellucidum.

Pedes flavi: femoribus tibiisque atro-striatis, tarsisque atris totis. .

A bdo men alis longius, ad basin inflatum, in medio attenuatum, et ad apicem incrassatum: segmentis septimo, octavo et nono, praesertim foeminarum, ad latera paullulum dilatatis. - Est atrum, glabrum, inaculis magnis, flavis pictum. Segmentum primum flavo-viride fere totum, cum maculis tantum duabus atris, versus latera positis. Secundum macula magna dorsali, quinqueloba, viridi aut flava, maximaque alia ad ventrem, quae verrucas ventrales (in foeminis minores) includit. Segmentum tertium et sequentia usque ad septimum macula dorsali magna, per totum fere segmentum ducta, lata, lobata, versus apicem acuminata, ad basin cum alia connexa, quae latera explet. Segmenta tria ultima maculam habent parvam dorsalem, et maiorem lateralem, flavam, cum margine externo ipso nigro. In ultimo segmento macula dorsalis et laterales haud raro in unam confluunt. Hae maculae flavae semper valde vivacis coloris, quasi citrini sunt.

Appendices caudales breves, flavae. Maris superiores (Hor. Ent. Tab.1. fig. 12.) ultimo segmento paullo longiores, conicae, leviter curvatae, ad apicem rotundatae, flavae, in interiore parte et ad apicem paullum fuscae, et in summa basi ad latus interius tuberculo minimo, glaberrimo, fusco sunt instructae. Inferior brevior, subtriangularis, ultra dimidium fissa, ita ut quasi duplex appareat, partibus lateralibus curvatis; est flavida, exterius paullum fusca.

Foeminarum appendices flavae: laterales breves, conicae, acutae: intermedia triangularis. Sphincter planus, fissus, et in partes duas, appendicibus fere longiores, depressas, ad apicem acuminatas divisus. 


\section{1}

\section{AESCHNA ANGUINA.}

Tab. XXX. Fig.2. foem.

Aesch. alitrunco viridi, atro-lineato: temporibus flavis, abdomine atro, cum linea dorsali continua, duabusque ad latera flavis. Foem.

Habitat in Gallia meridionali; unum tantum exemplum, idque foemineum, ad me missum est, quare descriptio huius speciei manca.

Statura est praecedentibus paullo minore, temporibus flavis fere totis et maxime globosis: abdomine prorsus cylindrico, nec non pictura ipsa ab Aeschna Serpentina, cui alioquin simillima est, satis distincta.

Caput parvum, fronte admodum lata: oculis valde globularibus. Facies flavo-viridis, brevis: naso a fronte linea atra distincto; frons latissima, per lineam magnopere incrassatam a vertice separata, qui in medio modice excavatus, et postice ater est. Spatium verticis inter ocellos et cuneum est planum, atrum, sine ulla rugula et sine ulla macula flava. Cuneus ipse est tenuis, perlongus, superne acutus, pilis parvis, atris ciliatus. Oculos animalis viventis non vidi: mortui gilvo-brunnei. Genae flavae sunt: tempora perglobosa, turgida, flavissima, cum macula oblonga, atra, tenui, ad cuneum, duabusque aliis minimis, ad marginem oculorum positis.

Truncus. Prothorax satis magnus, antice coarctatus: margine antico tenuiter, postico largius flavo: macula rotunda, subbiloba in summo prothoracis dorso, cum lineolis duabus minimis, ante illam collocatis, nec non maculis permagnis ad utrumque latus. - Alitruncus laete viridis, ad latera lineis atris. Collare angustatum, viride, margine antico atro, cuius ex lateribus linea atra, abbreviata, ad postica emittitur. Ad suturam collaris flavam adiacent vittae seu strigae duae, valde inter se propinquae, atrae, antice latiores. - Tubercula interalaria ut in Aesch. Serpentina comparata. 


\section{$-132$}

Alae hyalinae, vena marginali antica flava: parastigmate rufofusco, oblongo. Venae transversales in area inter venam marginalem anticam, radium nodalem et radium principalem, a basi alae ad nodum, flavidae, quarum potissimum tres valde conspicuae sunt et insignes.

Pedes flavi, cum lineis tenuibus, atris. Tarsi flavi toti, ungulis fuscis, et pilis brevibus, fuscis ciliati.

Abdomen in basi pauxillum incrassatum, cylindricum fere totum, alis longius, gracile, atrum, flavo-pictum. Segmentum primum flavum fere totum, cum maculis duabus transversis, ad basin positis. Secundum macula dorsali flava, lobata, ad basin lata. Per totam longitudinem abdominis in utroque latere procurrit vitta lata, flava, per aliam tenuem, atram divisa, ita ut duae vittae quasi efficiantur. Praeterea a basi tertii segmenti usque ad apicem ultimi producta linea dorsalis, tenuis, flava, ad basin singulorum segmentorum latior. Verrucae ventrales parvae, glabrae.

Appendices laterales ultimi segmenti longitudinem aequant, conicae, acutae, convergentes, fuscae. Intermedia brevior est, triangularis, flava. Sphincter fissus, multo brevior quam appendices caudales.

\section{AGRION FATIME.}

Tab. XLV. Fig. 2. foem.

Agr. atrum, flavo -maculatum, abdomine brevi, crasso: alis versus basin flavidis, ad apicem distincte nigris. Foem.

E Turcia, ab illustr. Frivaldsky, Budensi, ad me missum est unicum exemplum.

Primo adspectu quilibet hoc animal pro specie aliqua subgeneris Diastatomma accipiet, ad quod et abdominis forma et pictura quam maxime accedit. Alarum autem reticulatio statim ostendit, illud Agrio- 


\section{3}

nidibus esse adnumerandum, quod et structura instrumentorum cibariorum maxime confirmatur. Structura venarum cum Agrionidum subgenere, cui nomen "Calopteryx", valde convenit, sed abdomen breve, crassum, et pictura ipsa ab illo subgenere valde recedit hoc neuropteron. Hac de causa, ut supra exposui, peculiare mihi videtur constituere subgenus, cui nomen Epallage attribui.

Est Agrion Fatime alarum expansione Agrio Virgini aequale, abdomine breviore, crassiore.

Caput transversum, breve, oculis maximis, globularibus. Labii lacinia media fissa, flavida, cum maculis duabus atris; laciniae laterales flavidae, dentibus acutis, atris instructae. Labrum flavum, lineola media, longitudinali profunde impressa, glabra, atra. Rhinarium brevissimum, ita ut vix conspici possit. Nasus ipse tumidus, flavus, postica parte nigra. Frons flava, vertex niger, ocellis in triangulo positis, maculaque utrimque ad ocellum anticum flava. Loco cunei verticis pars postica ad occiput acutiuscula, flava. Tempora turgida, atra. Antennae atrae, ad oculorum marginem sitae, longe ante ocellos insertae.

Truncus. Prothorax cylindricus, in antica parte paullo angustior, ater: margine antico macula parva media et postica, duabusque magnis ad latera, lateribusque ipsis flavis. Alitruncus quadratus, non ita magnus, flavus: in lateribus lineis tribus nigris. Collaris sutura ipsa flava, puncto gemino eiusdem coloris antico. Utrimque pone suturam plaga angusta, atra, ad septula dilatata, plagisque duabus aliis lateralibus. Tubercula interalaria flava.

Ala e longae, fusco - flavidae, versus basin magis coloratae: fascia apicali, apicem ipsum implente, atra. - Parastigmata oblonga, rectangula, in medio paullulum dilatata, sulphurea.

Pedes atri fere toti, femorum marginibus solis flavescentibus. 
A b domen cylindricum, crassiusculum, alis fere brevius, aequale, ad basin haud incrassatum, atrum, linea longitudinali per totum dorsum flava, latiore altera ad latera, et tertia angusta, ad ventrem ipsum ducta. Ultimum segmentum flavum, maculis duabus parvis ad basin. Appendices parvae, conicae, angustae, et - ut videtur, - fusco-flavae.

\section{AGRION VIRGO.}

Tab. XXXI. mas et foem.

Agr. mas: cyaneo-viridi-nitens, alis cyaneis, ad basin apicemque fuscis: abdominis segmento penultimo cylindrico: - fo em.: viridi-nitens, alis pellucidis, fuscis, posticis obscurioribus: parastigmate albo, parvo.

Linn. S. N. p. 904. Lib. virgo, var. $\beta$. mas : var. $\gamma$. foem.

Linn. Faun. Suec. p. 374.

Fabr. E.S. Tom. II. p. 386. Agr. virgo, var. $\beta$. mas : var. $\chi$. foem.

Ch ar p. Hor. Entom. p. 4. (partim).

Van der Lind. p. 33.

Ro e sel Vol. II. Tab.IX. fig. 5. mas. fig. 6. foem.

Panz. F. Germ. fasc.79. Tab. 18. mas.

Burme is t. Vol. II. Tom. II. P. II. p. 828. Calopteryx Virgo.

Habitat in tota fere Europa ad flumina et rivulos.

Caput transversum, oculis perglobosis, distantibus, atro-brunneis: maris labio atro, labro antice atro, postice gilvo, lineola media impressa, atra, glabra; rhinarium minimum, quasi absconditum: nasus et frons tumida, cyanea, nitida, atro-pilosa. Vertex cyaneo-viridis, ocellis in triangulo positis, fulvo-lutescentibus, lucidis: cuneus, cuticulae elevatae angustae instar, viridi-nitens: eiusdem coloris sunt tempora, quorum in parte media corniculum conicum, breve. Genae perpolitae, atrae, et his antennae insertae sunt, atrae, scapo ipso 
lutescente seu gilvo. Foeminae caput pari modo comparatum est, colore tamen viridi-nitente, ubi mas est cyaneo-nitens.

Truncus. Prothorax parvus, antice posticeque coarctatus, cyaneo- et viridi-nitens, tuberculosus, postice in lobum ascendens. Alitruncus undique cyaneo- et viridi-nitens, atro-pilosus, lineis terminalibus atris. Tubercula dorsalia itidem cyaneo-nitentia: scutella tamen flavida sunt, praesertim foeminarum.

Alae maris latiores quam foeminarum, cyaneo-splendentes, interdum paullulum in viridem colorem vergentes: versus apicem et basin color hic cyaneus transit in atro-fuscum, subpellucidum. Mares parastigmata habent nulla. - Foeminarum alae unicolores, posteriores semper fere saturatiores. Variant colore a fusco-fumoso ad fuscescentem, quin etiam ad ferrugineo-fuscum. Vena marginalis antica viridi-nitens est: omnes renae reliquae atro-fuscae. Parastigmata foeminarum sunt parva, utpote quorum longitudo latitudinem vix dimidia parte superet.

Pedes in utroque sexu longi, tenues, pilis utrimque longis, atris ciliati.

Abdomen alis longius, plane cylindricum, tenue, versus apicem vix crassius. Notandum est, etiam penultimum maris segmentum plane esse cylindricum (de specie sequente disserens plura hac de re afferam). Color abdominis maris est cyaneus, fulgens, paullulum in viridem abiens: subtus ater. Ultimi segmenti latera et partes ventris ei vicinae rufa sunt, coloris lateritii. Foeminae abdomen viridiaeneum, et versus apicem fusco-cupreo colori accedens: vitta ad abdominis latera pone cutem ventralem flava, quae ad ultima segmenta multo latior est: in ultimis tribus segmentis linea dorsalis lutea. Segmenti ultimi dorsum carinula quasi elevata, paullulum prae margine postico porrecta, instructum est. Totum foeminarum corpus ad 


\section{$-136$}

paginam inferiorem haud raro pruina e cinereo coerulescente obductum est.

Appendices maris sunt quatuor horizontales (Hor. Ent. Tab. I. fig.15.): superiores duae ultimo segmento longiores, semicirculares, in basi attenuatae, in medio repente crassiores, externe scabrae, subdenticulatae, nigrae; inferiores breviores, in basi crassae, quasi connatae, inde rectae, subconicae: subtus rufae, antice et in pagina superiore nigrae. - Foeminae duas habent appendices laterales, breves, conicas, acutas, subdivergentes: intermedia est conica, brevissima, sub segmento ipso abscondita.

Interdum alae marium habent areolam unam alteramve, vel plures, materie colorem efficiente non imbutas, igitur ecoloratas, plane pellucidas. Putc, Agrion maculatum, ex America septentrionali allatum, in opere clari Palisot de Beauvais (Neuropt. Tab. 7. fig. 3.) depictum, fortasse eandem fortunam passum esse: certe rarissime $\mathrm{Li}$ bellulinae inveniuntur, quarum alae pictura inter se discrepent.

\section{AGRION VESTA.}

Tab. XXXII. mas et foem.

Agr. antice cyaneo — , postice viridi-nitens; mas: alis concoloribus, fuscis, vena marginali tota, radiisque ad basin cyaneis: abdominis segmento penultimo conico; - fo em.: alis pellucidis, subfuscis, nervis lucidioribus, parastigmate albo, maiusculo.

Harris Tab. XXX. fig.4. mas.

Habitat in Silesia et aliis Europae regionibus.

Species antecedenti simillima, et hucusque plerumque cum ea confusa: signis tamen constantibus, quamvis subtilibus, ab illa distincta.

Differt enim ab Agr. Virgine magnitudine, praesertim alarum: nam paullulo est minor, venis, praesertim foeminarum, non atris aut 


\section{7}

fuscis, sed luteo-luridis, ita ut alae multo sint pellucidiores, et earum reticulatio multo tenerior appareat.

Ala e marium parastigmate carent, neque cyaneae, sed atro-fuscae, et radiis nonnullis ultra dimidium cyaneis, plane concolores, quippe quae nec versus basin, nec versus. apicem aliter sint coloratae, atque in parte media. Foeminae alas anteriores et posteriores habent concolores, nam hae illis non densius sunt coloratae. - Parastigma album foeminarum magnum est, et duplo vel triplo longius quam latum. Practerea abdomen utriusque sexus ad antica est cyaneo-nitens: reliqua pars viridi-nitens. Signum distinctivum, admodum constans, est seginentum abdominis masculi penultimum semper conicum, i. e. versus abdominis apicem latius quam antice, quod in specie praecedente semper est plane cylindricum. In mare variat alarum color, qui partim est nigricanti-fuscus, partim in lutescens abit.

Appendices caudales diversae esse non videntur, sed pars abdominis postica et inferna in Agr. Vesta non rufa, sed potius testacea aut flavo - rufescens est.

\section{AGRION PARTHENIAS.}

Tab. XXXIII. mas et foem.

Agr. mas: cyaneus, nitens, alarum venis omnibus et membranae parte media cyaneis; fo em.: viridis, nitens, postice in cupreum vergens: alarum membrana ecolorata, pellucida, venis omnibus viridibus, nitentibus.

Linn. S. N. p. 905.

Linn. Faun. Suec. p. 375. Lib. virgo var. $\delta$, mas.

Fabr. E.S. Tom. II. p. 386. Agr. virgo var. $\alpha$, mas.

Bu rme ist. Vol. II. Tom. II. P. II. p. 829. Calopteryx Parthenias.

Van der Lind. p. 33. Agr. virgo var. $\alpha$.

Ro esel Vol. II. Aquat. Tab.IX. fig.7. mas. 


\section{$\longrightarrow 138$}

Harris Tab. XXX. fig. 1.mas.

Panz. F. Germ. fasc. 79. Tab. 17. mas.

Scha eff. Icon. Tab. 48. fig. 3. mas.

Habitat in Europa ad fluvios rivulosve, non cum Agr. Virgine promiscua, sed haec illam persequitur, et ex ipsarum cohortibus expellit.

Species peculiaris, admodum distincta, et quae statim ambitu alarum a praecedentibus facillime secerni possit.

Caput, truncus et abdomen maris ut in Agr. Virgine comparata: color autem magis cyaneus, minus cum virescenti mixtus, et magis nitens.

Alae multo angustiores atque in illo: maris membrana a basi fere usque ad nodum, et in apice ipso plane non colorata, pellucida: pars autem media pulchre cyanea, nitida, et venae omnes, etiam in particulis alae non coloratis, cyaneae, nitentes.

Pars ventris postica flavo-testacea est, et appendices eodem modo atque in speciebus praecedentibus comparatae sunt.

Focminae corpus est viridi-nitens, ad abdominis finem in cupreum colorem transiens, et in ultimis tribus segmentis linea dorsalis, plagaque magna, flavida, ad tota abdominis latera conspicitur. - Alarum membrana ecolorata, pellucida, venis omnibus pulcherrime viridibus, nitentibus: parastigmate niveo.

Interdum, quamvis rarissime, occurrunt foeminae, quarum alae pariter ac marium sunt pictae, quin etiam color cyaneus totum alae apicem implet. Venae in particula alae basali ecolorata in exemplis tali modo pictis virides, nitentes sunt, et parastigma album, uti vulgo. Tales varietates seu quasi aberrationes pulcherrimae sunt ad adspiciendum. 


\section{AGRION XANTHOSTOMA.}

Agr. superne viride, nitens: labio labroque, strigis duabus ad latera alitrunci et pectoris parte postica flavis. - Foem.

Charp. Hor. Ent. p.5.

E Gallia meridionali ad me missum. Foeminam tantum cognovi, his notis, ut mihi videtur, omnino a speciebus praecedentibus diversam.

Caput viride, nitens, labio et labro totis, antennarum scapo mandibularumque basibus flavis.

Truncus. Prothorax et mesothorax ut in congenericis comparati sunt: at metathorax ad latera lineas duas gerit flavas, haudquaquam angustas. Pectus totum flavum, albido-pruinosum.

Ala e breviores et multo angustiores, quam in Agr. Partheniade: membrana ecolorata, pellucida, venis omnibus viridibus, nitentibus; parastigmata parva, alba.

Abdomen viride, nitens, ad finem cupreum: latera, ad ventris cuticulam, flavo-colorata: in ultimis tribus segmentis linea flava, dorsalis non adesse videtur.

Species mihi uno tantum sexu et exemplo nota: alis tantopere attenuatis, orisque colore omnino distincta.

Sequitur descriptio quatuor Agrionidum specierum sibi invicem tam similium, ut earum diagnosis perdifficilis sit. Mares optime appendicum forma valde diversa distinguuntur: foeminae difficilius distingui possunt. Dum vivunt, alas gerunt patulas, minus tamen quam Libellulae et Aeschnae, qua de re conferatur, quod supra de subgenere „Anapetes" disserui. 


\section{AGRION LEUCOPSALLIS.}

Tab. XXXV. fig. 1. mas; fig. 2. foem.

Agr. superne viridi-nitens, inferne flavum: collaris sutura lineaque laterali postice interrupta, flava: ad alitrunci latera vittis duabus flavis, quarum prior e medio lineolam, retro versam, flavam emittit.

Ch a r p. Hor. Ent. p. 5.

Habitat in Silesia; circa Lunaeburgiam: in Gallia meridionali.

Affinibus Europaeis et abdominis longitudine et alarum expansione maius, et parastigmatibus luteo-fuscis, pellucidis facilius dignoscitur.

Caput transversum, tumidum, oculis permagnis, globosis. Labium, labrum, rhinarium et genarum pars inferior flava: nasus, frons et occiput totum viridi-nitentia, saepe cuprea. Antennae nigrae, scapo punctis duobus parvis, flavis distincto.

Truncus. Prothorax triangulari-globosus, postice recta truncatus, marginibus flavis, macula parva, gemina, media, lineolisque duabus transversalibus flavis. - Alitruncus viridi-nitens; sutura lineaque subcurvata, postice interrupta, flava ad collaris latera. Alitrunci latera viridi-nitentia, vittis duabus latis, flavidis: in prioris harum vittarum medio conspicitur lineola obliqua, retro versa, flava, cum vitta ipsa cohaerens.

Ala e pellucidae, non coloratae, parastigmate oblongo, rectangulo, luteo-fusco, pellucido, in utroque sexu.

Pedes flavi, in interiore parte fusci, pilis atris ad utrumque latus ciliati.

A bdom en longum, flavidum, cum macula maxima viridi-nitente in singulis segmentis, quae tanta est, ut abdomine superne adspecto coloris flavidi tantum spatia minima ad segmentorum basin appareant. In foeminis color viridis cupreo accedit. 
Maris appendices flavae, apice fusco. Superiores semicirculares, ultimo segmento tertia parte longiores, in latere interiore ad basin, sicuti prope ad apicem, denticulo recto armatae: inferiores brevissimae, tertiam superiorum longitudinis partem aequantes, approximatae, acutae (Hor. Ent. Tab.I. fig. 1\%).

Foeminarum appendices exteriores ultimo segmento non longiores, conicae, acutae: intermediae duae (sive una, sed profunde fissa) dimidio breviores, e segmento abdominali porrectae.

\section{AGRION FORCIPULA.}

Tab. XXXIV. fig. 1. mas, fig. 2. foem.

Agr. superne viridi-nitens, subtus flavum: alitrunci laterum superiore parte viridi, inferiore flava: collaris marium sutura lineaque laterali atra: foeminarum flava, atro - cincta.

Charp. Hor. Ent. p. 6.

Stephens British Entomology. Vol. VI. p.78. Agr. Forcip.

Burmeist. Vol. II. Tom. II. P. II. p. 824.

Habitat in pluribus Europae regionibus.

Caput transversum, tumidum, oculis maris adulti coeruleis, foeminae viridibus. Labium, labrum et inferior genarum pars flava: reliçua earum parte et occipite viridi-nitente. Ante ocellos fulvo-lucentes, et in triangulo quasi elevato positos, in externa parte plerumque cernitur plagula parva, flava. Spatium temporum viridium internum, seu ipso collo proximum flavum est.

Truncus. Prothorax triangularis, globosus, postice recta truncatus: maris viridi-nitens, coeruleo-pruinosus: foeminae flavo-marginatus, ad marginem anticum cum macula magna, et ad posticum triangulari, minori, flava: in lateribus flavo- et viridi-maculatus. Dorsum alitrunci cum callis et tuberculis flavidum, et praesertim in adultis masculis coeruleo-pruinosum. 
Alae abdominis fere longitudinem exaequant, ecoloratae, pellucidae: areolis intra sectorem principalem et nodalem plurimis pentagonis (ut in omnibus subgeneris "Anapetis“ speciebus): parastigmatibus admodum oblongis, subrectangulis, atris.

Pedes flavi, in femorum latere exteriore, in tibiarum interiore tarsisque totis atri, pilis atris ciliati.

Abdomen ad basin apicemque paullulo crassius quam in medio: flavidum, superne singulis segmentis viridi-aeneis fere totis. Foeminarum abdominis finis plerumque cupreus. Segmenta primum, secundum et ultima duo maris adulti dense coeruleo-pruinosa.

Appendices maris (Hor. Entom. Tab.I. fig. 16.) atrae fere totae, in basi tantum paullulum flavae: superiores semicirculares, ultimo segmento longiores, in latere interiore, in eius basi et ad apicem denticulo acuto, obliquo instructae, igitur quasi serratae. Inferiores appendices paullo breviores, rectae, foliaceae, tenues, cum apice rotundo. Foeminarum laterales breviores, conicae, acutae, fusco-virides, in exteriore parte flavae; intermedia minor, conica, acuta.

\section{AGRION VIRENS.}

Tab. XXXIV. fig. 3. mas, fig. 4. foem.

Agr. superne viridi-nitens, occipite et corporis latere inferiore flavo: parastigmatibus atro-fuscis totis, collaris sutura lineaque laterali flava.

Charp. Hor. Ent. p. 8.

Van der Lind. p. 35. Agr. barbarum, mas. (cl. vir Agr. virentis marem tanquam Agr. barbari Fabr. marem descripsit.)

Habitat in Silesia frequenter, in Lusitania aliisque Europae regionibus.

Variat magnitudine, semper tamen Agrio Forcipula minus, gracilius, et vivacioris coloris: occipite flavo facile ab illo distingui potest. 


\section{$-143$}

Caput ut in praecedenti, sed occipitis parte maxima distincta, flava. Oculi utriusque sexus in exemplis viventibus virides.

Truncus. Prothorax multo minus flavo-maculatus quam Agrii Forcipulae, et tantum linea marginali tenuiter flava pictus.

A la e abdomine quarta fere parte breviores, et parastigmata minus atra, potius atro-fusca.

Pedes ut in specie praecedente.

Abdomen ut in Agr. Forcip. pictum, sed maiore cum splendore. Appendices maris valde ab illis Agrii Forcipulae recedunt: sunt fuscae, ultimo segmento paullulo longiores, vix semicirculares, potius angulo obtuso introrsum flexae, sine dentibus: in latere tamen interiore, versus basin cernitur incisura parva; inferiores brevissimae, conicae, obtusae, et quae vix conspici possint, ac ne sextam quidem partem longitudinis superiorum habeant.

Appendices foeminae ut in Agr. Forcip. comparatae, flavae.

Pruina coerulea, nonnullas huius Agrii partes obducens, minus intensiva et pallidior est, quam in specie praecedente.

\section{AGRION BARBARUM.}

Tab. XXXV. fig. 3. mas, fig. 4. foem.

Agr. superne viride, subtus flavum: occipite flavo: parastigmate atro, dimidio albo-flavido.

Fa br. E. S. Suppl. p. 286.

Cha rp. Hor. Ent. p.9.

Van der Lind. p. 35. (foeminam tantum iuste descripsit).

Burmeist. Vol. II. Tom. II. P.II. p. 824.

Habitat in tota fere Europa.

Caput ut in praecedentibus: occipite toto flavo. Ad basin antennarum scapi cum macula parva, flava. Oculi utriusque sexus 
laete virides, marium vetustorum leviter in coeruleum colorem vergentes.

Truncus. Prothorax viridi-nitens, maculis flavis. Mesothoracis latera in superna parte viridi-nitentia, in inferiore flava. Collare viride, in sutura linea tenui vittisque duabus lateralibus latiusculis, flavis, postice continuis. Metathorax flavus totus. Dorsum alitrunci et tubera interalaria flavida, plerumque albido-pruinosa.

Ala e abdomine breviores, venis paullulum in brunneum colorem transeuntibus. Parastigmata oblonga, in medio admodum paullum dilatata: pars ad basin sita fusca est, pars ad apicem posita albidoflava, et maior quam illa.

Pedes ut in congenericis, colore flavo praevalente.

Abdomen laete flavum, in dorso segmentorum maculis viridisplendentibus: macula haec viridis segmenti primi bipartita est seu secundum longitudinem fissa: secundi segmenti per lineam tenuem longitudinalem quasi divisa: segmenti tertii et sequentium macula illa versus apicem latior est: noni minor, decimi minima: haec saepe albopruinosa.

Appendices maris caudales superiores (Hor. Ent. Tab. I. fig.19.) semicirculares, flavae, apice fusco: ultimo segmento paullo longiores, ad lateris interni basin dente obtusiusculo instructae. Inferiores ultra dimidium breviores, conicae, apicibus longis, acutis, tenuibus, repente extrorsum flexis. - Foeminarum appendices ut in congenericis, flavae totae.

Pruina, nonnullas horum Agriorum corporis partes interdum obducens, est tenuis et tota albida, aut levissime coerulescens.

Hae quatuor Agrionidum species, subgenus „Anapetes“ constituentes, primo adspectu simillimae, his notis facile distinguuntur: Agr. Leucopsallis et Forcipula occiput totum habent viride: Agr. virens et bar- 
barum dimidiam occipitis partem distimctam, flavam. Agr. Leucopsallis multo maius, et parastigmate pellucido, parum colorato praeditum est: $\Lambda$ gr. Forcipula minus et crassius est, et parastigmata habet atra, opaca. Agr. virens minus est, alis brevioribus, quam in Agr. barbaro, parastigmate fusco, unicolore: Agr. barbarum parastigma habet bicolor, et rittas collaris flaras, latinsculas.

\section{AGRION PHALLATUM.}

Tal. XXXV1. Fig. 1. mas et foem.

Agr. incarnatum, maculis fusco-aeneis in abdominis dorso, quae ad apicem latiores sunt, quam in basi.

Charp. Hor. Ent. p. 10. Agr. phall.

Van der Lind. p. 37. Agrion fusca.

Burmeist. Vol. II. Tom.II. P.II. p. 823. Agre phallatum.

Habitat in Europa per totam aestatem.

Ciaput: labio, labro, antica genarum parte et occipite toto incarnatis: naso, fronte verticeque e fusco cupreis. Facies pilis tenuibus albidis quasi hirsuta. Oculi marium coerulei, foeminarum virescentes. Ocelli in triangulo approximati, laete coerulei, lucidi.

Truncus. Prothorax globosus, antice angustior; in marginis postici medio in lobum rotundum productus: incarnatus, maculis quatuor maximis fuscis. Alitruncus incarnatus: mesothoracis latera vittam latam, subus angulosam, fusco-cupream habent. Collare incarnatum sive rutilum, vitta utrimque latissima pone suturam fusco-cuprea. Dorsum et tubera alaria incarnata, saepe albo-pruinosa.

Alac ut in praecedentibus speciebus, areolis in alae parte apicali media pentagonis: parastigmata oblonga, fusca.

Pedes cum tarsis incarnati, femoribus in externa parte nigrolineatis, pilis nigris ciliatis, cum ungulis atris. 
Abdomen alis tertia parte longius, cylindricum, gracile, incarnatum, maculis segmentorum dorsalibus fusco-cupreis, interdum viridi-nitentibus. Maculae hae dorsales in segmento secundo et sequentibus usque ad septimum plerumque linea longitudinali ad apicem divisae seu fissae, latiusculae, in medio paullulum attenuatae, et versus finem valde dilatatae et rotundatae sunt. In segmento octavo et nono color fuscus maximam, in decimo minimam dorsi partem implet. Margo posticus segmenti ultimi in medio excisus est.

Appendices maris (Hor. Entom. Tab. I. fig. 18.) ultimo segmento longiores, curvatae, fere semicirculares, incarnatae: in latere interno ad basin dente acuto, obliquo, et versus apicem dente obtuso, fere obsoleto instructae; in latere externo ad apicem denticulis minimis asperae. Inferiores dimidio breviores, conicae. Foeminarum appendices laterales ultimo segmento longiores, rectae, conicae, validae, incarnatae. Intermedia minima, triangularis.

Inter sedendum hoc Agrion alas non gerit patulas, sed compressas, uti omnes Agrionidum species, quae in sequentibus pagellis describentur.

\section{AGRION MINIUM.}

Tab. XXXVI. Fig. 2. mas et foem.

Agr. sanguineo-minium: atro-viridi-maculatum.

Charp. Hor. Ent. p. 13.

Harris Tab. 29. fig. 1. et 2. mas et foem.

Su lz. Hist. Ins. Tab. 24. fig. 5. Libell. Nymphula. Foem.

Van der Lind. p. 41. Agr. sanguinea.

Stephens Brit. Entom. Vol. VI. p. 75. Agr. minium.

Burmeis t. Vol. II. Tom. II. P. II. p. 821. Agr. minium.

Habitat in pluribus Europae regionibus: tarde volitat. 
Ciaput solito brevius, facie porrecta, atro-pilosa. Labium et labri pars antica flava: eius parte postica atro-viridi: rhinarium flavum, nasus atro-viridis: genarum medium et frontis antica pars flava, postica frontis pars et vertex atro-viridia; occiput cupreum: tempora valde turgida. Oculi rubri.

Truncus. Prothorax triangularis, brevis, paullum globosus, postice rotundatus, paullisper elevatus, atro - viridis, rubro-cinctus. Alitrunci latera flavido-rufa, atro- viridi-cincta. Collare viridi-aeneum, in lateribus vitta rubra, per lineam tenuem, atram oblique divisa. Dorsum inter alas atro-viride, tuberculis et callis rubris.

Ala e hyalinae, parastigmate rhombeo, atro.

Pedes atri.

Abdomen gracile, cylindricum, maris longius: sanguineo-minium seu coccineum, atro-viridi-maculatum. Maris segmentum primum macula dorsali magna, atro-viridi, aliaque minore ad ventrem praeditum est. Secundum segmentum et sequentia usque ad sextum in margine postico atro-riridi-cingulata, et ad basin macula utrimque parva, lucidiore, fere flarida. In dorso segmenti septimi macula, maximam dorsi partem implens, viridi-aenea, ac similis, ad basin annata, in ultimis tribus segmentis exstat. Foeminarum segmentum primum macula magna dorsali, atro-viridi, aliaque minore ad ventrem instructum est: secundum segmentum et sequentia usque ad sextum lineam continuam, atro-viridem aut aeneam, tenuem, postice autem latiorem, atro-aeneam habent, et ad basin utrimque maculam flavidam. Reliqua segmenta ut in mare sunt comparata, et marginis postici medium excisum est.

Appendices maris (Hor. Entom. Tab. I. fig. 14.) superiores ultimo segmento fere breviores. Superiores teretes, cylindricae, apice rotundato, atrae. Inferiores eiusdem longitudinis, cylindricae, paullisper 
recurvae, versus apicem biclentatae. Foeminarum appendices brevissimae, uti in congenericis.

\section{AGRION CHLORIDION.}

Tab. XXXVII. Fig. sup. mas et foem.

Agr. superne fusco-aeneum, subtus flavidum: maris viventis oculis rufis, abdomine cinereo-pruinoso; foeminae oculis viridibus, collaris linea utraque interrupta, lutea.

Charp. Hor. Ent. p. 14.

Van der Lind. p. 40. Agr. analis.

Stephens British Entomol Vol.VI. p.75.

Burmeist. Vol.II. Tom.II. P.II. p. 821.

Roesel II. Aquat. Tab.XI. fig. 6. mas.

Seha eff. Ieon. Tab. 121. fig.4. mas. fig. 5. foem. (?)

Habitat ubique in Europa.

Caput transversum, crassum, antice atro-pilosum, temporibus valde tumidis. Labium et genae flava, labrum flavum, atro-marginatum: rhinarium flavum; nasus atro-viridi-aeneus: frons flava, vertex et totum occiput viridi-aenea. Oculi maris viventis pulchre rubri, foeminarum virescentes.

Truncus. Prothorax triangularis, tuberculosus, in maribus ad marginem posticum elevatus, incrassatus, et in medio paullisper prominens, viridi-aeneus, ad utrumque latus macula parva fulvescente. - Foeminae similis, margine antico posticoque flavo, et postico magis ascendente, et in medio lobo acuto, triangulari instructo: maculae flavae laterales maiores sunt quam marium. - Alitrunci latera flava, lineis duabus atro-viridibus, superiore abbreviata. Collare viridi-aeneum, maris totum, foeminae vitta seu linea fulva ad utrumque suturae latus, postice interrupta, ita ut quasi signum exclamationis referat. Rarissime et marium collaris latera, in antica parte, lineolam minimam habent 
fulvam. - Tubercula interalaria flavida, in adultis dense et laete coeruleo - pruinosa.

Alae hyalinae: ad apicem admodum paullulum acutiusculae. Parastignata rhombea, brumea, subpellucida.

Pedes atri, femoribus in basi et latere interno flavis: in foeminis color flavus magis praeralet.

Abdomen cylindricum, marium in medio paullulum attenuatum: in iisdem superne est atro - viride, aeneum, nitidum, pruina modica subcoerulescente leviter obductum, subtus flavum; margo posticus et ante eum loculus luniformis segmentorum secundi et sequentium usque ad septimum illa pruina carent, ideoque obscuriores apparent. Ultima autem duo segmenta in maribus adultis pruina densissima, azurea obtecta sunt; pari modo segmentum primum coloratum est, cuius tamen dorsum maculam quadratam, ecoloratam retinet. Subtus abdomen flavidum est.

Foeminae abdomen superne viridi-aeneum, inferne flavidum, et ad apicem in coerulescentem colorem transiens. Color paginae superioris minus ad latera extenditur, quam in masculis, ideoque color flavidus ad segmentorum apices in utroque latere a dorso conspicitur.

Appendices maris (Hor. Entom. Tab. I. fig. 21.) ultimo abdominis segmento paene breviores, compressae, ad latus exterius crassiores, paullum divergentes, atrae; inferiores minimae, vix conspicuae, rotundatae, compressae, fuscae. - Foeminarum appendices ultimo segmento abdominali dimidia parte breviores, conicae, subobtusae, fuscae: intermedia minima, abscondita.

\section{AGRION VIRIDULUM.}

Tab. XXXVII. Fig. infer. mas et foem.

Agr. superne fusco-aeneum, subtus coerulescens: maris viventis oculis rubris, foeminae viridibus: in collari utriusque sexus strigis duabus fulvis. 
Habitat in Silesia.

Praecedenti aliquanto minus, gracilius, oculis maris rubris, formaque appendicum illi affine.

Caput. Os, genae et frons rutilo-flava: nasus, vertex et totum occiput atro-viridia, cupreo-subsplendentia. Os valde prominens, pilis parvis, flavidis sparsum. Oculi magni, marium rubri, foeminarum virescentes.

Truncus. Prothorax parvus, globularis, viridi-aeneus, antice coeruleus, cum macula laterali flavida. Foeminarum macula prothoracis antica et margo posticus tenuissime flavida sunt. Alitruncus ad latera coerulescens, cum linea sesquialtcra atra. Collare atro-viride, aenei vel cuprei splendoris, cum strigis duabus fulvis, plerumque continuis: foeminarum latioribus et in viridem colorem transeuntibus.

Alae subbreves, hyalinae, ad apicem paullulum acuminatae; parastigmata rhombea, fuscescentia.

Pedes cum tarsis flavidi: femoribus in exteriore, tibiis in interiore latere atris.

Abdomen cylindricum, longiusculum, gracile; maris subtus coerulescens, superne aeneum, idque in hunc modum: segmentum primum laete coeruleum, cum macula basali quadrata, atro-viridi: secundum coeruleum, margine postico et macula magna, basin non attingente, versus eam latiore et postice quasi stylo, cum margine postico cohaerente, atro-viridi. Segmentum tertium et sequentia usque ad septimum superne macula maxima, atro-viridi, anticam segmentorum singulorum partem non attingente, et ante marginem posticum ad latera coarctata. Ultina tria segmenta pulchre coerulea seu azurea, octavum et decimum cum macula magna dorsali, atra, quae in medio valde coarctata est. Margo posticus segmenti ultimi in medio paullulum excisus est, et in latere ventrali flavus. - Foeminarum abdomen simili modo coloratum, colore coeruleo magis in viridem abeunte, 
et penultima duo segmenta superne atro-viridia. Ultimi segmenti margo posticus profunde excisus est.

Appendices maris speciei praecedenti similes, ultimi segmenti longitudinem aequantes, compressae, valde divergentes; ad basin latae, quasi membranam luteam efficientes, et ad marginem crassiores, atrae, ad apicem bifidae: inferiores in abdomine absconditae; foeminarum brevissimac, conicae, obtusae, atrae.

\section{วั0. AGRION SPECIOSUM.}

Tab. XXXVIII. Fig. 1. mas et foem.

Agr. superne laete viride, subtus praesertim ad postica coerulescens, in ultimis tribus segmentis macula dorsalis laete coerulea.

Agriorum Europaeorum est minimum, gracile, et habitat in regione Lunaeburgensi: ab illustr. Heyer, Insectorum indagatore sagacissimo, mecum communicatum.

Ciaput facie prominente, oculis permagnis. Labium flavum, labrum antice flavum, postice late atrum. Rhinarium flavum, nasus atro-viridis; genae cum frontis parte antica flavae, eius pars postica et vertex viridia. Occiput viride, cum plaga transversa coerulescente post oculos, oculorum marginem non attingente. In foeminis haec plaga obsoletior est.

Truncus. Prothorax globosus, lateribus descendentibus, viridis, ad latera macula magna, coerulea. Alitrunci latera e gilvo in coerulescens transeunt. Collare laete viride, sericeum, cum linea impressa seu incisura laterali, quae ad basin et apicem laete coerulea est.

Alae breves, hyalinae, cum venis tenuissimis, fusco-luteis: parastigmate rhombeo, ferrugineo-luteo. Dorsum alitrunci flavidum, tuberculis albo-coeruleo-pruinosis.

P edes flavi, striga externa fusca, pilis atris ciliati. 
Abdomen subtus flavido-coerulescens, praesertim in masculis, antice posticeque in coeruleum colorem transiens: superne viridi-aeneum. Ultima tria segmenta pulchre picta: in octavo lateribus maculaque dorsali parva longitudinali ante marginem posticum coeruleis: nonum pariter pictum, sed macula dorsalis coerulea maxima: ultimum coeruleum totum, punctis duobus basalibus nigris. Margo segmenti ultimi posticus maris superne, in medio, et in cantho ipsius marginis, denticulos duos parros gerit approximatos (vide figuram fundamentalem, Tab. XXXVIII. adiectam).

Appendices minimae, ita ut vix bene in exemplis siccatis dignosci queant. Maris superiores brevissimae, conicae, obtusae esse videntur, et foeminarum similes.

\section{AGRION TUBERCULATUM.}

Tab. XXXVIII. Fig. 2. mas el foem.

Agr. superne viridi-aeneun, in collari strigis duabus coloratis, prothoracis margine postico trilobo, lobo intermedio ascendente: segmento abdominali antepenultimo coeruleo, nec non maris ultimo, cum tuberculo bicorni.

Charp. Hor. Entom. p. 21.

Van der Lind. p. 40. Agr. elegans.

Stephens: Brit. Entom. Vol. VI. p.72. Agr. elegans.

Burmeist. Vol. II. Tom. II. P.II. p. 819. Agr. tuberculatum.

Habitat hic illic in pluribus Europae regionibus ad aquas stagnantes.

Cap ut solito minus latum, oculis permagnis: facies flavido - viridis: labri postica parte, naso, vertice, nec non occipitis parte superiore atro-viridibus: in hac praeterea maculae duae magnae, rotundae, coeruleae; reliqua occipitis pars flavescens est. In foeminis color flavidus in fulvum vel subcroceum transit. 
Truncus. Prothorax triangularis, brevis, globosus: margine postico in medio in lobum magnum, in apice subbifidum ascendente. Est atro-viridis: marium antice et ad latera coeruleus; foeminarum fulvescens. Alitruncus lateribus coeruleis, collari atro-viridi, aeneo, strigis duabus coeruleis, in foemina fulvis. Dorsum alitrunci atrum: tubercula coerulea, in foeminis fulva.

A lae breves, hyalinae, cum venis fuscis; parastigma rhombeum, valde obliquangulum: in basi fuscum, ad apicem in album transiens.

Pedes virescentes aut flavi, latere exteriore atro.

Abdomen maris valde attenuatum, gracile, subtus fulvescens, superne viridi-aeneum. Maris segmentum primum coeruleum, macula quadrata basali atra. Secundum superne macula maxima atroviridi, antice latiore, postice, ante finem, coarctata. Tertium segmentum et sequentia usque ad septimum macula dorsali viridi-aenea, marginem posticum attingente, cum antico lineola media connexa. Octavum coeruleum totum. Nonum superne totum fere atrum. Ultimum subtus flavum, superne atrum; ad marginem posticum tuberculo magno, ad basin lato, ad apicem bicorni seu bimucronato, instructum.

Foeminae abdomen pari modo pictum, colore fulvo, fere croceo, loco flavidi marimm. Segmenti secundi macula dorsalis ad antica angustior est, postice lạta, et marginem posticum fere cingens.

Hand raro foeminae variant colore croceo valde praevalente, ita ut omnes partes, alias flavido-pictae, laete croceae appareant, et collare ipsum fere totum croceum, excepta plaga plus minus magna, ad collaris suturam, atro-viridi; parastigma in foeminis hoc modo pictis croceo-ferrugineum est.

[Eiusmodi foeminae varietas fortasse illud Agrion est, quod cl. Selys-Longchamps in: Catalogue des Lepidoptères de la Belgique. Leodii. 1837. pag. 12. tanquam speciem peculiarem sub nomine Agrii aurantiaci descripsit.] 
Appendices caudales maris (Hor. Ent. Tab. I. fig. 22.) superiores brevissimae, vix ante marginem ultimi segmenti exstantes, reniformes. Inferiores plus duplo longiores, ad latera positae, cylindricae, apice rotundo, paullulum curvatae, valde divergentes. Foeminarum minimae, conicae, obtusae, fuscae, in externa parte flavidae.

\section{AGRION PUMILIO.}

Tab. XXXIX. mas, foemina, eiusque varietas.

Agr. superne viridi-aeneum, subtus flavidum aut coerulescens, collaris margine postico leviter trilobo: ad ultimi segmenti finem in maribus tuberculum parvum, subbimucronatum.

Charp. Hor. Ent. p. 22.

Burme is t. Vol.II. Tom. II. P.II. p. 820.

Habitat in Germania.

Praecedenti simile, sed minus: Agriis Europaeis minimis adnumerandum.

Caput. Maris facies et genae flavo-virides, labri parte postica, naso, verticeque atro-viridibus. Tempora valde turgida, in antica parte atro-viridia, cum macula magna, subrotunda, coerulea: in postica parte flavido-viridia. Oculi subtus laete virescentes, supra brunnei. In foeminis color flavus plane in fulvum et croceum mutatur, et maculae marium rotundae in temporibus coeruleae, in foeminis croceae, et cum reliqua occipitis parte crocea confusae.

Truncus. Prothorax triangularis, antice coarctatus, postice in lobum rotundatum modice dilatatus, qui paullum ascendit: atro-viridis, marginibus marium coeruleis, foeminarum fulvis aut viridibus. Alitruncus atro-viridis, subaeneus, maris lateribus strigisque duabus collaris viridibus; foeminarum laete viridis aut croceus, plaga collaris suturali plus minus lata, atro-viridi. - Dorsum alitrunci aut laete viride, aut croceum, cum tuberculis eiusdem coloris. 
Alac hyalinae, tenerae, venis fuscis aut croceis, transversalibus solito paucioribus. Parastigma parvum, rhombeum, acuto-angulosum, aequilaterale, versus basin fuscum, versus apicem album. Foeminarum parastigma interdum croceum vel fere ecoloratum, pellucidum est.

Pedes laete virides aut crocei, in latere externo linea tenerrima, atra picti.

Abdomen subtus fulvum aut (in foeminis) croceum. Segmentum maris primum coerulescens, cum macula dorsali maxima, postice latiore, viridi-aenea; secundum maculam habet eiusdem coloris, anlice latiorem, postice coarctatam, et marginem segmenti anticum non attingentem. Segmentum tertium et sequentia usque ad septimum simili modo picta, et macula dorsalis lineola tenui cum margine singulorum segmentorum antico cohacret. Octavum superne fere totum atro-viride, margine postico coeruleo: nonum coeruleum totum, cum maculis interdum duabus minimis, atris: ultimum coeruleum, dorso toto atro, et in margine postico tuberculum minimum, bimucronatum, mucronibus ipsis flavis.

Foeminarum abdomen plerumque croceum totum: interdum ad basin laete viride. Segmenta duo prima aut plane non sunt picta, aut macula minima, atro-viridi-aenea. Reliqua segmenta picta sunt uti in maribus: attamen tertii segmenti macula dorsalis ad antica in acumen exit, et reliquis plerumque brevior est. Ultimorum trium segmentorum latera latius croceo - picta sunt, quam reliqua.

Appendices maris superiores (Hor. Ent. Tab. I. fig. 27.) brevissimae, latae, reniformes, atrae, subtus ferrugineae; inferiores duplo longiores, ad basin crassae, ad apicem acutae, sursum curvatae, atrae, subtus flavae. Foeminarum appendices minimae, conicae, obtusiusculae, croceae. 


\section{AGRION INTERRUPTUM.}

Tab. XL. fig. sup. mas et foem.

Agr. coeruleo-, et atro-viridi-pictum: collaris strigis duabus coeruleis (maris interruptis), prothoracis margine postico lobo medio valde prominente.

Charp. Hor. Ent. p. 16.

Stephens British Entomology Vol. VI. p.73. Agr. Puella.

Burmeis t. Vol. II. Tom. II. P. II. p. 820. Agr. interrupt.

Van der Lin d. p. 38. Agr. pulehella.

Habitat in tota Europa.

Species sex aut septem, quae in sequentibus pagellis describentur, primo adspectu inter se simillimae sunt, omnes, praesertim masculi, laete coeruleo-, et atro-viridi-pictae, signis autem constantibus bene distinctae.

Agr. interruptum a congenericis abdomine longiore, graciliore, et colore coeruleo magis vivaci seu saturatiore statim primo intuitu est insigne.

Caput temporibus valde tumidis notabile, facie coerulescente, labri parte postica, naso, et occipite atro-viridibus: in hoc maculae duae magnae, triangulares, et lineola inter eas transversa, coerulea.

Truncus. Prothorax maris triangularis, brevis, modice globosus, in margine postico lobo fere semicirculari, distincto instructus: atro-viridis, antice et ad latera coeruleus. - Foeminae minus triangularis, in margine postico bis excisus, ita ut lobulus acutior in medio paullum ascendat. Margo anticus et latera late coerulea: margo posticus tenuiter coeruleo-marginatus est. Praeterea ad utrumque dorsi latus punctum cernitur cocruleum. (Hic prothoracis margo posticus, in medio tantopere lobatus, signum valde distinctivum praebet.) - Alitruncus maris ad latera coeruleus, cum linea irregulari, sesquialtera, 


\section{$15 \%$}

atro - viridi. - Collare atro - viride, aenei nitoris, utrimque striga coerulea, interrupta, signum exclamationis, puncto ad postica posito, repraesentans. Dorsum alitrunci atrum, tuberculis alaribus coeruleis. Foeminae alitruncus pariter pictus, strigae tamen collaris non interruptae, sed continuae.

Alae hyalinae, parastigmate parvo, rhombeo, atro.

Pedes coerulescentes, femoribus externa parte, tibiis interna parte atris.

Abdomen maris longum, valde tenue, coeruleum, superne maculis atro-viridibus, aenei nitoris. Segmentum primum cum macula basali parva, atra. Secundum macula lata, antice profunde furcata, postice in lateribus coarctata, et cum segmenti margine postico cohacrente. Segmentum tertium, quartum et quintum macula dorsali atroviridi, antice bifurcata, et tam magna, ut, dorso superne inspecto, tantum tertia dorsi pars coerulea appareat. Sextum et septimum pariter picta, at color coeruleus etiam minus conspicuus est. Octavum et nonum seginentum coeruleum totum; in illo interdum, in hoc semper puncta duo lateralia, atra adsunt. Ultimum superne atrum fere totum, margine tenuiter coeruleo, et in media parte exciso.

Foeminae abdomen coeruleum, superne maculis atro-viridibus. Primum segmentum ut in masculo pictum. Secundum macula magna, margini postico annata, anticum nusquam attingente. Est haec macula fere cruciformis, quippe plaga longitudinali lata, antice subfurcata, per quam ad postica alia transversalis ducta est, cuius fines subacuti sunt. Segmenta intermedia ut in masculo picta, maculis atro-viridibus, paullo maioribus. Octavum coeruleum totum, cum maculis duabus parvis, atris. Ultima duo supra late atra.

Appendices maris superiores (Hor. Entom. Tab. I. fig.23.) brevissimae, crassae, fere absconditae, lutescentes: inferiores laterales, perbreves, divergentes, cylindricae, subcurvatae, atrae. Sphincter magnus, 


\section{8}

porrectus, profunde bifidus, albo-flavidus. Foeminarum appendices brevissimae, conicae, atrae.

\section{รั4. AGRION FURCATUM.}

Tab. XL. fig. infer. mas et foem.

Agr. mas coeruleo-viridi, foemina atro-viridi colore picta: collaris strigis duabus coeruleis (foem. viridibus): collaris margine postico rotundato, in medio levissime elevato.

Cha rp. Hor. Ent. p. 18.

Stephens Brit. Entom. Vol. VI. p.73. Agr. furcatum.

Burme is t. Vol. II. Tom. II. P.II. p. 820. Agr. furcatum.

Van der Lind. p. 39. Agr. puella.

Habitat frequentissime in Europa.

Caput ut in specie praecedente.

Truncus. Prothorax ut in praecedente, sed margo posticus modice elevatus, rotundatus, ater, undique coeruleo- (in foem. laete viridi-) limbatus, et saepissime punctis duobus coeruleis (aut viridibus).

Alae et pedes ut in Agrio interrupto: pedes foeminarum flavovirides.

Abdomen maris coeruleum (sed minus ardens, quam in specie praecedente) cum maculis atro-viridibus, aeneis. Segmentum primum macula basali parva, quadrata. Secundum macula furciformi, cum margine postico nusquam cohaerente. Tertium, quartum et quintum macula brevi, furciformi, cuius brachia in lateribus tam longa sunt, quam segmentum fere ipsum, caulis autem quintam tantum segmenti longitudinis partem implet. In sexto macula ad basin est maior, et septimum ea implet fere totum. Octavum coeruleum totum: nonum in dorso maculis duabus posticis, atris, et decimum superne atrum fere totum, margine postico emarginato. 


\section{$-159$}

Foeminae corpus laete flavo - viride, ad paginam supernam haud raro in coerulescentem colorem transiens: in abdominis dorso viridiaenco-maculatum. Segmentum primum supcrne macula atra, marginem anticum et posticum attingente, in lateribus coarctata. Secundum macula magna dorsali (fere cyathi formam habente), antice lata, cum margine segmenti antico connexa, postice attenuata, et ante finem ipsum latiore. Reliqua segmenta superne tota fere atro-viridia, ita ut tantum particula ventris parva coloris flavo-viridis, ad basin et apicem, et in lateribus singulorum segmentorum conspicua sit.

Appendices maris superiores (Hor. Entom. Tạb. I. fig. 24.) brevissimae, latae, acuminatae, atrae: inferiores sublaterales, superioribus duplo longiores, cylindricae, subcurvatae, atrae. Foeminarum appendices brevissimae, atrae, conicae.

\section{AGRION MERCURIALE.}

Tab. XLII. Fig. 2. mas et foem.

Agr. mas subtus coeruleum (foemina flavescens), superne atroviridi-aeneo-maculatum: maris segmentum secundum macula, signum Mercurii referente, notatum.

A claro Entomologo Lunaeburgensi, illustr. Heyer, sub illo nomine mecum communicatum, in illis regionibus degit.

Agrio interrupto et Agr. furcato paullo brevius, magnitudine sequentibus speciebus accedit.

Caput ut in praecedentibus; temporibus valde tumidis, vertice atro-viridi, maculis duabus lateralibus et linea intermedia coeruleis (aut virescentibus) in occipite.

Truncus. Prothorax perbrevis, antice angustatus, postico margine in media parte paullisper ascendente, atro-viridis, undique coeruleo-marginatus. Alitruncus ut in Agr. furcato. 
Abdomen maris coeruleum, superne maculis atro-viridibus, in aeneum colorem conversis. Segmentum primum maculam quadratam, magnam habet. Secundum insigne est macula magna, antice cornua tria referente, medio brevissimo, lateralibus longioribus, curvatis (vid. figuram fundamentalem, Tabulae XLII. adiectam): postice quasi petiolo armata, et ad marginem segmenti ipsum dilatata, quae haud inepte cum signo Mercurii chemico comparari potest. Segmentum tertium postice macula magna, biloba, lobo anteriore angustiore, acuminato. Quartum, quintum et sextum macula magna postica, antice triacuminata; in his segmentis intermediis macula atro-viridis dimidiam fere dorsi partem implet. Septimum superne atro-viride fere totum. Octavum coeruleum, punctis duobus posticis atris. Ultima segmenta superne atra.

Foeminae abdomen subtus virescens, superne atro-viridi-maculatum: in segmento primo macula magna, quadrata, atra. Secundum macula magna, oblonga, biloba, marginem anticum non attingente, instructum est: reliqua segmenta maculis dorsum fere implentibus, in medio paullulum angustioribus.

Species, cum pauca tantum eius exempla examinare potuerim, non penitus a me cognita.

\section{AGRION HASTULATUM.}

Tab. XLI. Fig. 1. mas et foem.

Agr. coeruleum (foem. flavo - virescens), superne atro - viridi-maculatum: in maris segmento secundo macula litterae $\tau$ formam ostendit, foeminae elongata, ad postica cruciformi.

Charp. Hor. Entom. p. 20.

Stephens British Entom. Vol. VI. p.73. Agr. hastulatum.

B u rme ist. Vol. II. Tom. II. P. II. p. 820. Agr. hastulatum.

Habitat in tota Germania. 
Agriis interrupto et furcato minus, abdomine tenui, ad postica paullulum crassiore.

Caput ut in praecedentibus.

Truncus. Prothorax margine postico angulatus, et in medio lobum parvum, incumbentem ad posticam partem emittens: atro-viridis, undique (antice quidem latius) coeruleo- (in foem. flavo-viridi-) limbatus. Alitruncus ut in Agr. furcato.

Abdomen maris coeruleum, superne atro-viridi-maculatum. Segmentum primum habet maculam basalem parvam, quadratam. Secundum margine postico atro-viridi, et ante eum macula curvata seu potius lunulata, cum margine ipso per lineolam longitudinalem connexa, ita ut formam clavuli seu quasi litterae Graecae Tau $(\boldsymbol{\tau})$ referat. Praeterea ad utrumque latus lineola longitudinalis atra, libera (quae cum lunari non cohaeret) conspicitur. Tertium segmentum et sequentia usque ad sextum macula dorsali atro-viridi, marginem posticum attingente, ct antice acumine in medio instructa. Maculae atro-virides in his segmentis mediis maiores sunt in segmentis abdominis, apici propioribus, quam in anticis. Septimum superne fere totum atro-viride. Octavum et nonum coeruleum totum: ultimum superne atrum, margine postico exciso. - Foeminarum abdomen laete e flavo virescens, superne viridi-aeneo-maculatum. Segmentum primum maculam quadratam, magnam habet, marginem anticum et posticum attingentem. Secundum macula magna, minus lata, utrumque marginem tangente, et ante posticum lobulum tenuem lateralem emittente, instructum est. Tertium segmentum et sequentia usque ad sextum macula maxima dorsali, margini postico annata, antice libera, rotundata, ante finem posticum dilatata praedita sunt. Reliqua superne atro-viridia, aeneo -splendentia fere tota.

Appendices maris superiores (Hor. Entom. Tab. I. fig. 26.) ultra marginem segmenti abdominalis ultimi vix porrectae, globulares rel 
reniformes, subpilosae, lutescentes: inferiores approximatae, superioribus paullo longiores, valde incurvatae, cylindricae. Foeminarum appendices conicae, obtusae. (Vide quae de his appendicibus in Horis Ențomologicis disserui).

\section{AGRION LUNULATUM.}

Tab. XLI. Fig. 2. mas et foem.

Agr. coeruleum, superne atro-viridi-maculatum: in maris segmento secundo macula lunata: foemina subtus dilute coerulescens, superne viridi-aeneo-maculata.

Habitat in Silesiae regionibus, quae montibus propiores sunt.

Simillimum Agrio hastulato, a quo distinguitur pictura segmenti secundi maris, abdomine toto paullulo crassiore, maculisque dorsalibus atro-viridibus, maioribus, et foeminae colore subtus non flavo-viridi, sed lucido-coerulescente.

Caput uti in Agrio hastulato pictum: maculae tamen triangulares coeruleae in occipite, pone verticem, plerumque subobsoletae sunt.

Truncus. Prothorax postice distincte trilobatus est, lobo intermedio ascendente, reflexo, apice paullisper emarginato. Est atroviridis, margine antico coeruleo (postico plane atro-viridi), lateribusque coeruleo-maculatis. Alitruncus ut in Agr. hastulato comparatus: linea tamen atra in pedum lateribus latiore, quam in illa specie.

Abdomen paullo crassius, potissimum versus apicem, quam in specie praecedente: in utroque sexu coeruleum (in foemina tamen lucidius), et maculis magis atris, quam viridibus et quasi aeneo-nitentibus. Segmentum primum habet maculam basalem parvam, atram. Secundum margine postico atro, et ante eum macula curvata, tanquam lunula, cum margine postico non cohaerente, est notatum. Praeterea lineola utrimque longitudinalis in lateribus. Reliqua segmenta pari modo atque in Agrio hastulato picta, sed maculae atrae multo maiores 
sunt, quam in illa. Ultimi segmenti margo posticus profunde excisus. - Foeminae abdomen subtus coerulescens: superne segmentis basalibus et mediis pictis uti foeminae Agrii hastulati, sed macula segmenti secundi, ad apicem sive ad thoracem spectans, angustior est, quae in illa est latior. Segmentum octavum in basi et ad latera coeruleum, in reliqua parte atro-viride. Margo posticus segmenti ultimi profunde excisus, fere incisus.

Appendices marium brevissimae: superiores rotundatae, pilosae: inferiores breviores, certe non longiores, rectae (non incurvae), atrae; examini accuratiori nondum sunt subiectae. - Foeminarum brevissimae, conico-globulares.

\section{3̈8. AGRION CYATHIGERUM.}

Tab. XLII. Fig. 1. mas et foem.

Agr. coeruleum, atro-viridi-maculatum: in maris segmento secundo macula orbicularis, postice cum margine cohaerens: foeminae maculis dorsalibus gracilioribus.

Habitat in Silesia.

Pictura constante et foeminae colore lucide coeruleo insigne.

Caput ut in congenericis.

Truncus. Prothorax triangularis, margine postico pauxillum rotundato; undique coeruleo-limbato: maculis duabus lateralibus coeruleis, distinctis. Alitruncus atro-aeneus, lateribus coeruleis: in collari strigae duae valde distinctae, coeruleae. Reliquae alitrunci partes, sicuti alae et pedes, uti in specie praecedente comparatae.

Abdomen paullo longius et gracilius, quam in Agr. lunulato: coeruleum. In segmento marium primo macula est basalis minima, atra. Secundum habet marginem posticum atrum, et in parte postica maculam magnam, orbiculatam, atram, stylo cum margine postico segmenti cohaerentem. Similes maculae in segmentis tertio et sequen- 
tibus usque ad septimum, maculae autem in his sunt magis "elongatae, et in posticis acuminatae, longiores. Octavum et nonum segmentum coeruleum totum. Decimum superne atrum, postice profunde excisum. - Foeminarum segmentum primum uti in maribus est comparatum: secundum insigne est macula antice posticeque margini annata, antice paullulum latiore, et ad postica, ante finem, in lobulum orbicularem dilatata. Sequentia segmenta media macula magna, elongata, antice acuminata, postice, ante finem, dilatata picta sunt. Septimum et octavum postice atro - viridia fere tota, qui color acumine tenui marginem segmenti anticum tangit. Ultima duo segmenta in medio dorso atra.

Appendices marium superiores brevissimae, vix extra abdomen conspicuae, globulares, subpilosae, fuscae. Inferiores longiores, laterales curvatae, cylindricae, atrae. Foeminarum appendices brevissimae, conicae, obtusae, et (ut videtur) coerulescentes.

\section{ว9. AGRION ARMATUM.}

Tab. XIIII. Fig. 1. mas.

Agr. (mas) coeruleum, superne nigro-maculatum: collari nigro, cum punctis quatuor coeruleis; appendicibus caudalibus inferioribus magnis, compressis, latis.

$\mathrm{Ab}$ illustr. Heyer circa Lunaeburgiam mas semel captus mecum communicatus.

Statura est parva, ut in speciebus praecedentibus.

Caput ut in illis comparatum, colore atro praevalente.

Truncus. Prothorax margine postico rotundato, in lobulum subacutum ascendente: ater, margine antico et laterali coeruleo. Alitrunci latera coerulea, cum linea sesquialtera atra. Collare aterrimum totum, cum punctis duobus parvis anticis et duobus posticis coeruleis. Dorsum alitrunci nigrum, tuberculis coeruleis. 
A la e hyalinae, parastigmate rhombeo, paullum colorato, e ferrugineo -fusco, subpellucido.

Pedes coerulei, femorum latere exteriore latissime atro: tarsis (ut videtur) ipsis cocruleis.

Abdo mini segmenta duo basalia paullum, apicalia magis incrassata, cocrulea, et superne maculis atris picta, quae nitorem valde tenuem, aeneum habent. Segmentum primum maculam habet basalem atram: secundum lineolam utrimque ad latera basalem et maculam permagnam, orbicularem, postice paullulum coarctatam, ad marginem segmenti posticum. In tertio macula postica atra, antice trifida, quae tam magna est, ut tertia tantum dorsi pars cocrulea appareat. Quartum segmentum et sequentia usque ad septimum in dorso atra fere tota; superne inspecta in basi singulorum segmentorum tantum punctula duo coerulea (cum ventre coeruleo connexa) conspiciuntur: Octavum coeruleum totum, et nonum macula magna postica valde sinuata, atra insigne est. Decimum superne atrum totum, margine postico valde exciso seu emarginato.

Appendices maris caudales (vid. Figuras Tab.XLIII. adiectas) admodum singulares. Superiores parvae, rotundatae, lutescentes, pubescentes: inferiores maximae, ad latera positae, ultimo segmento fere dimidia parte longiores, latissimae, compressae, ad apicem rotundatae, quasi cavae seu semiinvolutae, atque tantopere incurvatae, ut apices se fere tangant: atrae, in interiore latere et cantho superiore ad basin albidae.

\section{AGRION LACTEUM.}

Tab.XLIII. Fig. 2. mas et foem.

Agr. albidum, nigro-lineatum, tibiis pedum mediorum et posticorum in membranam utrimque dilatatis.

Charp. Hor. Entom. p. 11. 
Burme ist. Vol.II. Tom. II. P.II. p. 822. Agr. lacteum.

Van der Lind. p. 37. Agr. platypoda.

Stephens Brit. Ent. Vol. VI. p.76. Agr. platypoda.

Fabric. Spec. Insect. p.528. Agr. puellae varietas.

Habitat frequenter in Europa.

Ad maiora Agria referendum: colore albido, capite valde lato, tibiisque dilatatis facile dignosci potest. Color albidus marium plerumque in languido - coerulescens transit, foeminarum in gilvum.

Caput valde latum, in medio angustum, album. Os et nasus alba: frons alba, et in medio macula transversalis angulata, atra, quae utrimque per genas albas percurrit. Vertex et anterior occipitis pars atra, cum linea transversali alba. - Oculi marium languido - coerulescentes: foeminarum virescentes.

Truncus. Prothorax subcylindricus, scaber, fere inaequalis, tuberosus: maris postice modice angulatus, flavidus, in toto medio ater, maculaque atra minore ad latera: foeminae prothorax marginem posticum habet elevatum, excisum, et in medio replicatum seu lobo medio acuto retro flexo. Est simili modo atque in mare pictus. Alitruncus ad latera albus, cum lineis duabus atro-viridibus, nitentibus, superiore latiore. Collare atro-viride, sutura tenui strigaque lata utrimque maris coeruleo-albidis, foeminae gilvis. Dórsum alitrunci atrum, cum tuberculis albis.

Al a e hyalinae, parastigmate oblongo-rhombeo, ferrugineo-fusco, pellucido.

Pedes albi, in femoribus lineis duabus, tibiis linea una, nigris, in latere externo. Tibiae pedum intermediorum et posticorum per totam longitudinem, ad utrumque latus, in membranam tenuem, angustam, in medio paullo latiorem sunt dilatatae. Tarsi albi. Femora ac tịiae pilis atris ciliata. 
Abdomen perlongum, attenuatum, postice vix incrassatum, albidum; marium subcoeruleum, foeminarum interdum in gilvum aut in virescens transiens. Foeminarum abdomen ad postica semper fere in subferrugineum colorem transit. Segmentum primum maculam parvam, quadratam, atram habet: secundum maculam magnam, latam, longitudinalem, ante finem latiorem. Tertium segmentum et sequentia usque ad sextum margine postico atro, lineaque angusta, atra, dorsali, marginem anticum vix attingente, et ante finem utrimque lobulum lateralem emittente insignia sunt. Septimum et octavum maculam habent magnam, dorsalem, sutura alba fissam. Nonum ad dorsi latera macula atra, magna, laterali est instructum, et ultimum macula parva laterali. Mares hac ratione picti colorem albidum habent in coerulescens abeuntem. Sunt vero crebrae varietates, quarum color in gilvum transit, et in his maculae atrae segmenti secundi et mediorum prorsus fere absunt, et conspiciuntur solummodo margines postici atri, et ante eos lineolae duae obliquae, utrimque ad dorsi latera positae. Pari modo pictae sunt foeminae; in earum varietate subvirescente linea dorsi atra, aequalis, fere per totam longitudinem, certe in segmentis intermediis, et in summo dorso linea tenuissima albida divisa est. Varietas quaedam magis alba, et magis in gilvum abiens, loco illius lineae longitudinalis atrae, lineolas tantum duas minimas transversales ad postica singulorum segmentorum gerit.

Appendices maris superiores ultimi segmenti longitudinem habent: sunt triangulares, albidae, depressae, horizontales, ad apicem subemarginatae: inferiores duplo longiores, curvatae, ad basin crassiores, albae, interdum in basi atrae (Hor. Entom. Tab. I. fig. 20.). Foeminarum appendices brevissimae, conicae, obtusae, albidae. 


\section{$-168$}

Hisce pagellis descripsi Libellulinas Europaeas, a me ipso conspectas atque examinatas. Addam notitiam talium specierum, quas ipse non vidi, quarum tamen descriptiones accuratae in diversis libris sunt exhibitae.

1. Libellula nitens. In opere: Annales de la societé Entomologique. Paris. 183\%. Vol. VI. pag. 146. (Monographie des Libellulines par Mr. Boyer de Fonscolombe) describitur haec Libellula: „aenea, capite thoraceque immaculatis, segmen„tis omnibus abdominis macula dorsali, geminata seu simplici „lutea: maculà marginali alarum brunnea“6. Tab.V. fig. 3. laudati operis icon huius Libellulae exhibita est, et quidem foeminae.

Habitat in Gallia meridionali: secundum notitiam in libro „Archiv für Naturgeschichte" auctore Wi e g m an n, Berol.1838. Ann. IV. Fasc. 5. pag. 236. expositam, haec species etiam in Lusitania invenitur.

Ad subgenus Chlorosoma pertinere videtur haec Libellula.

Cordulia Curtisii a claro Stephens in opere: Illustrations of British Entomology Vol.VI. pag. 90. descripta, et Angliae tanquam indigena vindicata, eadem esse videtur. *)

2. Aeschna Irene, in opere supra laudato: Annales etc. Vol.VII. pag.93. Tab.VI. fig.1. allata: „brunneo viridique variegata, tho„race subgloboso: abdomine maris foeminaeque post basin co„arctato: macula marginali alarum brunnea: nervis aliquot fla„vis: membranula accessoria parva, cinerescens“.

Habitat in Gallia meridionali. Species insignis!

*) Adnot. Valde doleo, opus praestantissimum supra allatum non prius mihi ad manus venisse, quam pagellis huius mei operis iamiam prelo mandatis et omnibus fere iam impressis: qua de causa paucissima tantum, quae in illo opere proposita sunt, in usum meum convertere poluj. 
3. A eschna tetraphylla. Van der Linden, Monogr. p.32.: „Aeschna lutea, thorace supra strigis quatuor tribusque utrim„que lateralibus nigris: abdomine nigro maculato, septimi et „octavi segmenti lateribus utrimque appendice membranacea „,instructis: alarum macula marginali valde elongata, rufescente. „Foem.“

In regno Neapolitano capta. In opere: Description de l'Egypte. Neuropt. Tab. I. fig. 15. Libellulina depicta est, quae cum descriptione prioris quadrat: fortasse eadem species.

Ad subgenus Diastatomma adnumeranda esse videtur.

4. Agrion Virgo, var. $\delta$, quod Rossi in Faun.Etrusc. Tom.II. pag. 120. (Edit. Illigeri pag.195.) sic describit: „specimen ha„bemus heic recensendum statura et habitu prioribus similli„mum, corpore toto nigro, alis aterrimis, nitidis, basi tantum „excolore, margine immaculatis. Mas."

Cum hac specie coniunxit cl. Van der Linden l. c. p.34.: „Agrion haemorrhoidale: nigro-coeruleum, abdominis apice „subtus rubro: alis nigro coeruleis, basi hyalinis (mas), aut viri„di-aenea, alis rufescentibus, posticis apice fuscis, omnibus „,macula marginali alba (foem.).“

Habitat in Italia, praesertim meridionali.

Sine dubio ad subgenus „Calopteryx" pertinet.

5. Agrion rubella. Van der Linden, Monogx. p. 42. „Agr. „capite et thorace supra fusco-aeneis, abdomine nigro, basi rubro.“

Habitat in Italia. 
Stephens (British Entomology). Vol.VI. p.71. Tab.XXIX. fig. 4. (Foemina).

Agrio (Pyrrhosomati) minio affinis: sed omnino distincta et diversa species.

\section{DE LIBELTULINTS PETREFICATIS.}

Quam maxime memorabile et notatu dignissimum illud phaenomenon esse videtur, Libellulinas, quae animalia tam eximiae teneritatis et fragilitatis sint, etiam in statu petreficato inveniri. Hoc praecipue, et quod sciam unice, in petra illa calcaria Solenhofensi, quae arte Lithographica tam famosa est, reperitur. Plures de his petrefactis scripserunt, inter quos clarus "Germar" in Actis Academ. Caesar. Leop. Carol. Vol. XIX. P.I. pag. 189. sqq. imprimis nominandus est. Is descripsit et depinxit plures Libellulinas petreficatas Solenhofenses, e Musco ditissimo Comitis de Münster, Geologi eximii Bayruthensis, ipsi ad utendum permissas. Alium eiusdem loci Libelluliten descripsit L. de Buch in dissertatione, cui titulus: „Ueber den Jura in Deutschland“. Berolin. 1839, et tabula adiecta iconem illius Libellulitae exhibet.

In opere cl. Schmidelii: Vorstellung merkwürdiger Versteinerungen, Tab.XIX. similis species est depicta. Specimen egregium eiusmodi in petra Solenhofensi petreficati insecti, ab utroque latere expressi, ex longo iamiam tempore, fortasse per quadraginta annos et amplius, asservatur in Museo regio Dresdensi, cuius benigne mecum communicati Tab.48. fig.1. accuratam proposui delineationem.

Aliam figuram Libellulinae petreficatae exhibet "Kaehler“ in cl. Leonhardi Zeitschrift für Mineralogie. 1826. nro.9. pag. 231. Tab. VIII. fig. 3. 
Quod si quis scit, quam difficile interdum sit oculo vel diligentissimo, diversas horum animalium viventium species, inter se saepe sibi tam similium, discernere atque distinguere, libenter is confitebitur, paene fieri non posse, quin species etiam unius eiusdemque generis petreficatas pro earum diversitate constitui atque determinari queant. Acquiescamus ergo in eo, impressuras seu petreficata Solenhofensia formam horum animalium saepius tam bene conservatam oculis offerre, ut plerumque saltem genus dignosci possit.

Praeter icones supra commemoratas plures a claro Comite de Münster mecum communicatas examini potui subiicere, cuius summa haec est.

Plurima Libellulinarum petrificata sunt generis Aeschnidum: sed Agrionides non desunt, nec non Libellulides, quae tamen sunt rariores, inveniuntur.

Aeschnides petreficatae eximia magnitudine insignes sunt, sicuti etiam nonnullae Agrionides, quae tamen et minores reperiuntur, magnitudine nostratibus fere inferiores. Talium duas icones Tab. 48. fig.2. et 3. delineavi. Aeschnides petreficatae structura sua hodieque viventibus sunt simillimae, quin adeo radiorum et sectorum ratio in iis deprehenditur maxime congrua, saltem icon Libellulitae Dresdensis, a me summa cum cura atque veritate delineata (Tab.48. fig.1.), illos nervos longitudinales revera cum Aeschnidibus nostri aevi plane convenientes ostendit. Petreficatum hoc Solenhofense tam bene conservatum est, ut pedes duo anteriores, nervi longitudinales, atque etiam in postica alarum parte parvuli minores et transversales bene conspici possint. Tota forma illius animalis antediluviani demonstrat, illud Aeschnidum generi sine ulla dubitatione esse adscribendum. Porro autem propter segmentum abdominis basi propius, fortasse tertium, valde attenuatum seu coarctatum, deinde propter formam appendicum caudalium, prae caeteris autem propter marginem basalem alarum 
posticarum excisum, plane certum mihi videtur, hoc animal masculi fuisse generis.

Petrefactum, in Buchian o opusculo depictum, et ipsum ad Aeschnides pertinet. Abdomen autem basi aequale, non coarctatum, alarumque posticarum forma veri esse simile demonstrant, hoc exemplum foeminam alicuius Aeschnidis fuisse.

Icone in Le onhardi opere supra allato proposita eis, qui Entomologiae operam navant, planum fit, hoc insectum Aeschnidum subgeneri „Diastatomma“ adnumerandum esse. In descriptione huius petreficati (l. c. pag. 233.) affertur, Aeschuae grandi simillimum, sed paullo maius esse. Hac in re error commissus mihi videtur, nam A. grandis nostri aeri prorsus eiusdem magnitudinis atque illa depicta, imo alis multo latioribus praedita est, et abdomen Aeschnae grandis, praecipue eius apex, ab insecto illo petreficato quam maxime recedit.

Icones, a clarissimo Germar l. c. Tab.XXIII. sub nro.12.13. et 14. exhibitae, paene sine omni dubitatione Aeschnides et verisimiliter foeminas repraesentant. Fig. 15. tanquam Libellula quaedam explicatur: rationes vero, quibus hoc confirmetur, comprobare omnino non possum, nam totus habitus magis Aeschnidibus mihi convenire videtur. - Figura 16. animal, quod capite plane caret, oculo offert; secundum structuram nervorum seu venarum, siquidem recte delineatae sunt, de qua re nullam moveo dubitationem, omnino Agrionis aliqua Giganteae formae repraesentatur, et fortasse species subgeneris "Calopteryx", quod eiusmodi nervorum reticulatione peculiari a reliquis Agrionidibus distinguitur.

Cl. Comes de Münster etiam plures alias icones Libellulinarum petreficatarum e lapidicinis Solenhofensi et Eichstadtiensi, idque exempla specierum maxime diversarum ad me misit: Aeschnidum maximarum, Libellulidum valde distinctarum, Agrionidum parvarum, quarum duas minimas Tabulae 48. addidi. - In numero earum, quae 
Libellulidibus fortasse adscribendae sunt, excellit species, abdomine medio tenuissimo, postice admodum globosa, qua forma Libellulae Sabinac c China (Drury Tom. I. Tab.48. fig.5.) magnopere accedit: satis tamen est maior.

Larvas Libellulinarum petreficatas depinxit „Knorr“ in opere: de Petrefactis, Tab. XXXIII. fig.2.3.4. verum non addidit notitiam de locis, in quibus haec petreficata reperta sint; quin hae icones veras Libellulinarum larvas repraesentent, plane dubitari nequit.

Locus hic mihi videtur idoneus, ut commemorem, Libeilulinarum larvas omnes quidem in aqua degere, sed, quod hucusque observatum est, non in aqua marina vivere. Ad hanc rem in disquirendo illo petreficationis prope Solenhofen repertae phaenomeno recte respiciendum est.

\section{DE CONSERVATIONE TIREMTULINARUM IN MUSEIS.}

Omnes fere amatores et collectores insectorum valde dolent, colores Libellulinarum, tam pulchros et vivaces animali vivente, post mortem eius perire et tantopere evanescere, ut saepissime plane non possint dignosci. Hac de causa methodum quandam facillimam (fortasse pluribus harum rerum studiosis haud ignotam) cum lectoribus communicabo, qua adhibita Libellulinarum, praesertim Aeschnidum, colores post animalis mortem melius conserventur. Libellula enim seu Aeschna capta in hunc modum sinistra manu tenetur, ut venter sursum spectet: tunc scalpello aut acu in pectoris parte media, aut infra pedes posteriores, incisura quaedam parva infertur, itemque altera ad finem ventris, circa antepenultimum segmentum. Quo facto caulis graminis alicuius altioris, rispa aliquantulum frondosa 
praeditus, e. g. Poae, sumitur, et in incisuram pectoris immittitur, ac torquendo ita intrudendus est, ut per totum abdomen transeat, et per alteram incisuram ad finem ventris (aut etiam per anum ipsum) prodeat. Caulis hoc modo ventre exstans manu apprehendendus et semper torquendo cum rispa ipsa per totum animalis abdomen trahendus est. Hoc artificio viscera extrahuntur, id quod modo semel facta, modo iterata eiusmodi purgatione efficitur. Viscerum remotione impeditur animalium putredo, quae in his insectis mortuis fere semper colores corrumpit: illa vero causa putredinis remota colores ipsi saepe optime conservantur, certe eorum pictura fere semper conspicua est. - Tales autem eligendi sunt graminum caules, quorum rispae insecti magnitudini conveniunt: nam si rispa Libellulinae abdomine est maior, abdomen rumpitur.

Abdomine a visceribus purgato straminis seu ligni sicci particula adaptata, pro crassitudine et longitudine abdominis, insecti ventri evacuato est inserenda, quae ibi maneat necesse est, ne abdominis membrana siccata complicetur et quasi contabescat, neve abdomen ipsum formam amittat, quam animali vivente habebat. 


\section{Ad TABULAS EXPLICANDAS.}

Scala, secundum quam Libellulae et Aeschnae depictae sunt, plerumque dimidia parte maior est, quam animalis magnitudo naturalis: atque illa, secundum quam Agria delineata sunt, duplo maior est.

Partes singulae, uni alterive tabulae adiectae, secundum scalam magis auctam delineatae sunt.

Lineae iconibus ad latus additae naturalem animalis viventis longitudinem, inde a fronte usque ad apicem mensurati, designant. Signum $\mho$ maris, $q$ foeminae longitudinem indicat.

Equidem non credo, delineationem, quae ad scalam auctam facta est, Entomophilis displicituram esse, cum haec animalia, quorum pictura et partium structura saepe admodum minuta et intricata est, magnitudine naturali depicta oculo differentias et naturam vix satis clare offerant. Si quis haec naturae magis congruentia inspicere vult, utatur vitro concavo, quod obiecta dimidia parte deminuit.

Tab. I. Libellula (Epitheca) bimaculata, mas et foem. Sub * foeminae est valva aperturae oviparae lamellata.

Tab. II. Libellula conspurcata, mas et foem.

Tab. III. Libellula quadrimaculata, mas et foem.

Tab. IV. Libellula depressa, mas et foem.

Tab. V. Libellula cancellata, mas et foem.

Tab. VI. Libellula coerulescens, mas et foem.

Tab. VII. Libellula coccinea, mas et foem. 
Tab. VIII. Libellula (Diplax) pedemontana, mas et foem.

Tab. IX. Libellula (Diplax) flaveola, mas et foem.

Tab. X. Libellula (Diplax) Fig. 1. nigripes, mas et foem.; Fig. 2.

L. striolata, mas et focm.

Tab. XI. Libellula (Diplax) Fig. 1. vulgata, mas et foem.; Fig. 2.

L. ruficollis, mas; Fig.3. L. albifrons, mas.

Tab. XII. Libellula (Diplax) nigra, mas iunior, mas adultus et foemina.

Tab. XIII. Libellula (Diplax) pectoralis, mas, maris varietas et foemina.

Tab. XIV. Libellula (Chlorosoma) aenea, mas et foem.

Tab. XV. Libellula (Chlorosoma) metallica, mas et foem.; sub * appendices maris caudales; sub ** apex foeminae abdominis.

Tab. XVI. Libellula (Chlorosoma) flavomaculata, mas et foem.

Tab. XVII. Aeschna (Cyrtosoma) azurea, mas.

Tab. XVIII. Aeschna affinis, mas el foem., et appendices maris caudales.

Tab. XIX. Aeschna mixta, mas et foem., et appendices maris caudales.

Tab. XX. Aeschna picta, mas et foem.

Tab. XXI. Aeschna pilosa, mas et foem.

Tab. XXII. Aeschna virens, mas et foem.

Tab. XXIII. Aeschna iuncea, mas et foem.

Tab. XXIV. Aeschna grandis, mas et foem.

Tab. XXV. Aeschna Chrysophthalmus, mas et foem.

Tab. XXVI. Aeschna (Thecaphora) lunulata, mas et foem.

Tab. XXVII. Aeschna (Diastatomma) hamata, mas et foem. addita capitis foeminae parte supina, ad cormicula temporum demonstranda.

Tab. XXVIII. Aeschna (Diastatomma) forcipata, mas et foem.

Tab. XXIX. Aeschna (Diastatomma) flavipes, mas et foem.

Tab. XXX. Aeschna (Diastatomma) Fig. 1. serpentina, mas et foem. addita parte capitis foeminae antica, ad cornicula cunei demonstranda; Fig.2. A. anguina, foem.

Tab. XXXI. Agrion (Calopteryx) Virgo, mas el foem.

Tab. XXXII. Agrion (Calopteryx) Vesta, mas et foem.

Tab. XXXIII. Agrion (Calopteryx) Parthenias, mas et foem. 


\section{$17 \%$}

Tab. XXXIV. Agrion (Anapetes) Fig.1.2. Forcipula, mas et foem.; Fig. 3.4. A.virens, mas et foem.

Tab. XXXV. Agrion (Anapetes) Fig. 1.2. Leucopsalis, mas et foem.; Fig. 3.4. A.barbarum, mas et foem.

Tab. XXXVI. Fig. 1. Agrion (Sympyena) phallatum, mas et foem.; Fig. 2. Agr. (Pyrrhosoma) minium, mas et foem.

Tab. XXXVII. Agrion (Erythromma) Fig.1.Chloridion, mas et foem.; Fig.2. A. viridulum, mas et foem.

Tab. XXXVIII. Agrion (Ischnura) Fig. 1. speciosum, mas et foem. addita apicis marium abdominalis parte supina; Fig. 2. A.tuberculatum, mas et foem.

Tab. XXXIX. Agrion (Ischnura) Pumilio, mas, foemina iunior et foemina adulta.

Tab. XL. Fig. 1. Agrion interruptum, mas et foem.; Fig.2. Agr.furcatum, mas et foem.

Tab. XLI. Fig. 1. Agrion hastulatum, mas et foem.; Fig.2. Agr. lunulatum, mas et foem.

Tab. XLII. Fig. 1. Agrion cyathigerum, mas et foem.; Fig. 2. Agr. mercuriale, mas et foem. adiecta secundi segmenti maris figura fundamentali.

Tab. XLIII. Fig. 1. Agrion armatum, mas, adiecto abdominis apice a latere et supine adspecto; Fig. 2. Agrion(Platycnemis) lacteum, mas et foem.

Tab. XLIV. Libellula (Diplax) caudalis, mas, foemina et foeminae varietas.

Tab. XLV. Fig. 1. Aeschna (Cyrtosoma) azurea, foem.; Fig. 2. Agrion (Epallage) Fatime, foem.

Tab. XLVI. Aeschna (Diastatomma) uncata, mas et foem.

Tab. XLVII.

Fig. 1. Labium Lib. bimaculatae.

Fig. 2. , , quadrimaculatae.

Fig. 3. ,9, vulgatae. 
Fig. 4. Labium Lib. flaveolae.

Fig. 5.,$\quad$, aeneae.

Fig. 6. $" \quad "$ metallicae.

Fig. 7. " Aesch. Serpentinae.

Fig. 8. " Agr. tuberculati.

Fig. 9. Ala superior Libellulae.

Fig. 10. , , Aeschnae.

Fig. 11. , " Calopterygis.

Fig. 12. , ,,$\quad$ Agrii.

Et quidem sub

$a$ et $b$ : callus axillaris superior et inferior.

$a, c, d_{2} e$ : margo anticus.

$b, l, e:$ margo posticus.

$A$ : membranula accessoria.

$c$ : nodus.

$d$ : parastigma.

$n, p$ : radius internodalis.

$o, e$ : radius principalis.

$q, k$ : radius medius.

$b, s$ :(Fig.9.); $b, t$ : (Fig. 10.11.) radius spurius seu infimus.

$v, w, x, f$ : sector principalis.

$c, p, g$ : sector nodalis.

$x, h$ : sector subnodalis.

$v, w, i$ : sector medius.

$t, l$ : sector trigonuli superior.

$l, m$ : sector trigonuli inferior.

$v, u$ : arculus.

$s, u, t$ : trigonulum.

$u, i i$ (Fig. 11.) : sector arculi.

Fig. 13. Capitis Aeschnae pars antica, et quidem sub

$a$ : labii pars cum laciniis, a latere anteriore inspecta.

b: labrum. 
$c, c$ : maxillarum stipites exstantes.

$d, d$ : genae.

$e$ : rhinarium.

$f$ : nasus.

$g$ : frons, pone quam, situ horizontali, vertex est, hic non conspicuus, plane latens.

$h$ : vesicula verticalis, ante quam ocellus medius, et utrimque ocelli laterales et antennae.

$i$ : cuneus, spatium oculorum conniventium implens. Oculi ipsi ad utrumque faciei latus.

Fig. 14. Aeschnae alitrunci pars supina :

$a, b$ : collare.

$c, c$ : septa seu septula.

$d, d, d, d$ : calli axillares seu alares.

$e$ : dorsulum.

$f:$ scutellum.

$g, g:$ frenum.

p: pnystega.

$h$ : postdorsulum.

$i$ : postscutellum.

$k$ : metapnystega.

$l, l$ : postfrena.

Fig. 15. Apex abdominis masculi Libellulae pectoralis.

Fig. 16. Apex abdominis masculi Libellulae caudalis.

Fig. 17. Prothorax subgeneris, ,Diplax ${ }^{66}$, ab antica parte adspectus.

Fig. 18-20, Aeschnidum abdomen:

$a-k$ : segmenta decem abdominalia.

$l, l$ : verrucae ventrales.

$\boldsymbol{m}$ : genitalia maris.

$n, n$ : appcndices caudales superiores.

$o$ : appendix inferior seu intermedia.

$p$ : sphincter. 
$q, q$ : squamulae duae in masculorum ventre, de quibus clar. Rathke disseruit: ef. supra.

Tab. XLVIII. Fig. 1. Libellulites Solenhofensis e Museo Regio Dresdensi communicatus. Fig. 2. et 3. Agrionides petrificatae, in petra calcaria Solenhofensi repertae.
\end{abstract}




\section{A n e r b i e t e n.}

Der grosse Anvachs meiner entomologischen Sammlung veranlasst mir einen grossen Raummangel: besonders aus dieser Ursache wünsche ich einige Theile derselben zu veräusseru, und namentlich die Sammlung der Lepidopteren und der Coleopteren. Beide bestehen in ausgezeichneten Exemplaren, und enthalten sehr seltene Gegenstände. Ihre äussere Einrichtung eignet selbige ganz vorzüglich für grössere öffentliche Anstalten, welches namentlich von den Lepidopteren gilt. Solche sind nimlich, jede Species für sich, in einzelnen kleinen Kästchen von Weissbuchen oder Lindenholz aufbewahrt, welche auf beiden Seiten durch, mit weissem Wachs vergossene, feine Glastafeln verschlossen sind, so dass das Eindringen ron Staub, zerstörenden Insecten a.dgl. gauz unmöglich ist. Die Schmetterlinge selbst, bis zur kleinsten Alucita, sind auf röllig fest aufgeleimte kleine Korkpfropfen, und zwar alle in gleichem Niveau, aufgestellt, und dem oberen Glase sehr nahe, welches der Beleuchtung wegen. wesentlich ist. Auf jedem Kästchen befindet sich an dessen Aussenseite eine Etikette mit Angabe des systematischen Namens, des Vaterlandes, der vorzüglichsten Schriftsteller, die über diesen Gegenstand geschrieben. Desgleichen eine Nummer, welche sich auf den sehr vollständiǵen Gatalog bezieht.

Die Sammlung der Glossaten oder Lepidopteren enthält gegen 1360 Europäische und 440 Ausländische Arten, in etwas über 2300 solcher Glaskästchen.

Die Anzahl der Individuen beträgt bei den Europäern 6400 Stück: bei den Ausländerı 700 Stück.

Die Anzahl der Europäischen Käfer beträgt gegen 12000 Stück in ungefähr 2500 Arten, besonders von grösseren Bildungen. Sie sind sämmtlich in dem saubersten Zustande und besonders reichhaltig an Südeuropäischen Arten. Sie sind fast sämmtlich richtig bestimmt, mit beigestecktem Nameı ' und Bezug auf einen sehr vollständigen Catalog, welcher zugleich Vaterland und die bezüglichen Schriftsteller-Allegate enthält. Unter den Käfern sind ebenfalls mehrere ungemein seltene Gegenstände und einige, die vielleicbt in keiner andern Sammlung gefunden werden. - Die ausländischen Käfer betragen gegen 1500 Stück, von denen rorzüglich Mexicanische zu den selteneren gehören. - Sämmlliche Käfer sind in zwei Mahagony-Schränken aufbewahrı.

Wer gesonnen ist, die Acquisition dieser Sammlungen zu machen, wolle deshalb mir nähere Nittheilung machen.

Brieg in Schlesien.

T. von Charpentier,

Königl. Berghauptmann. 

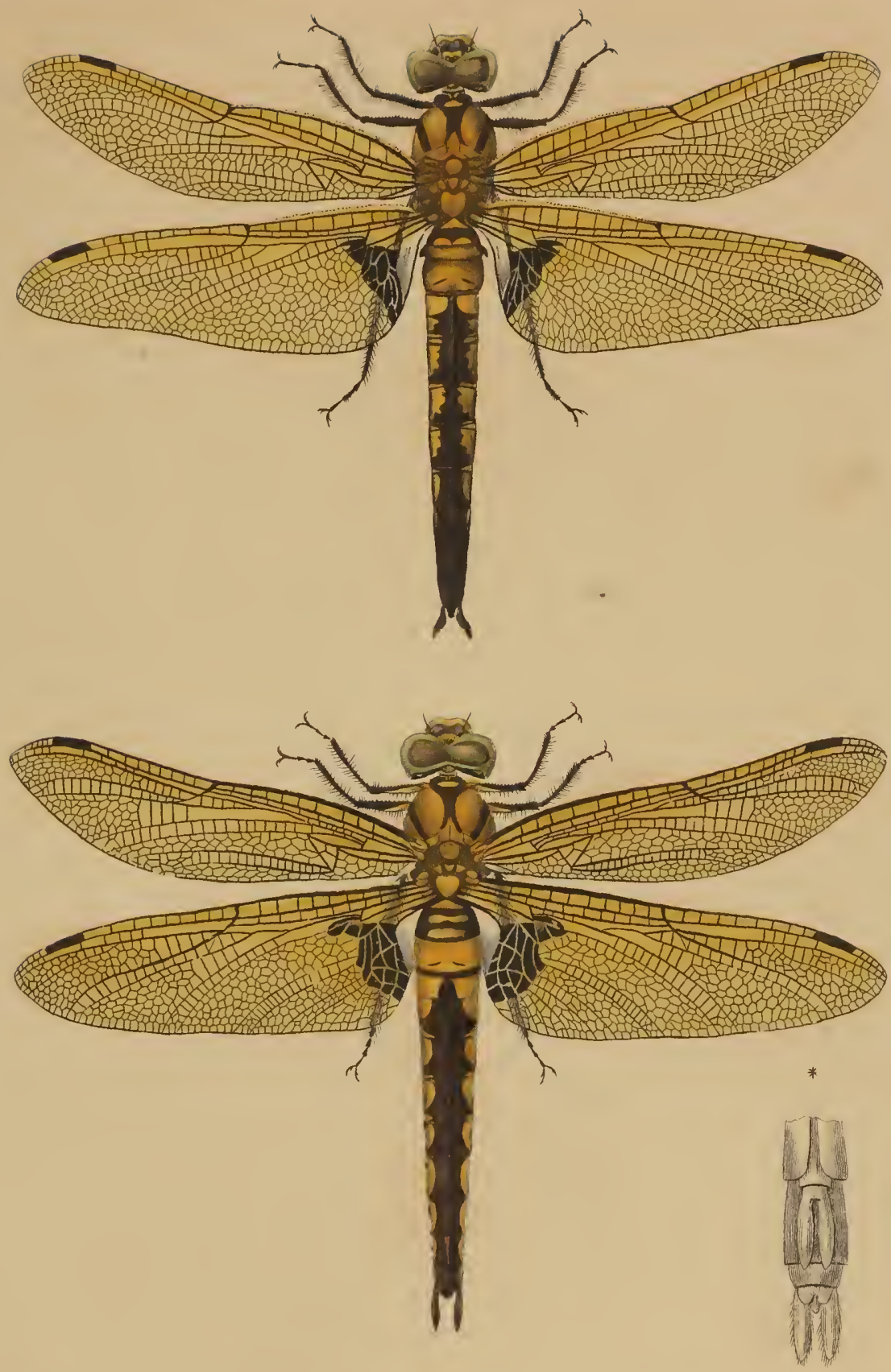

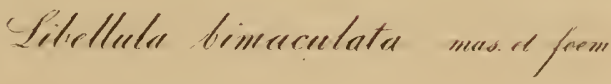



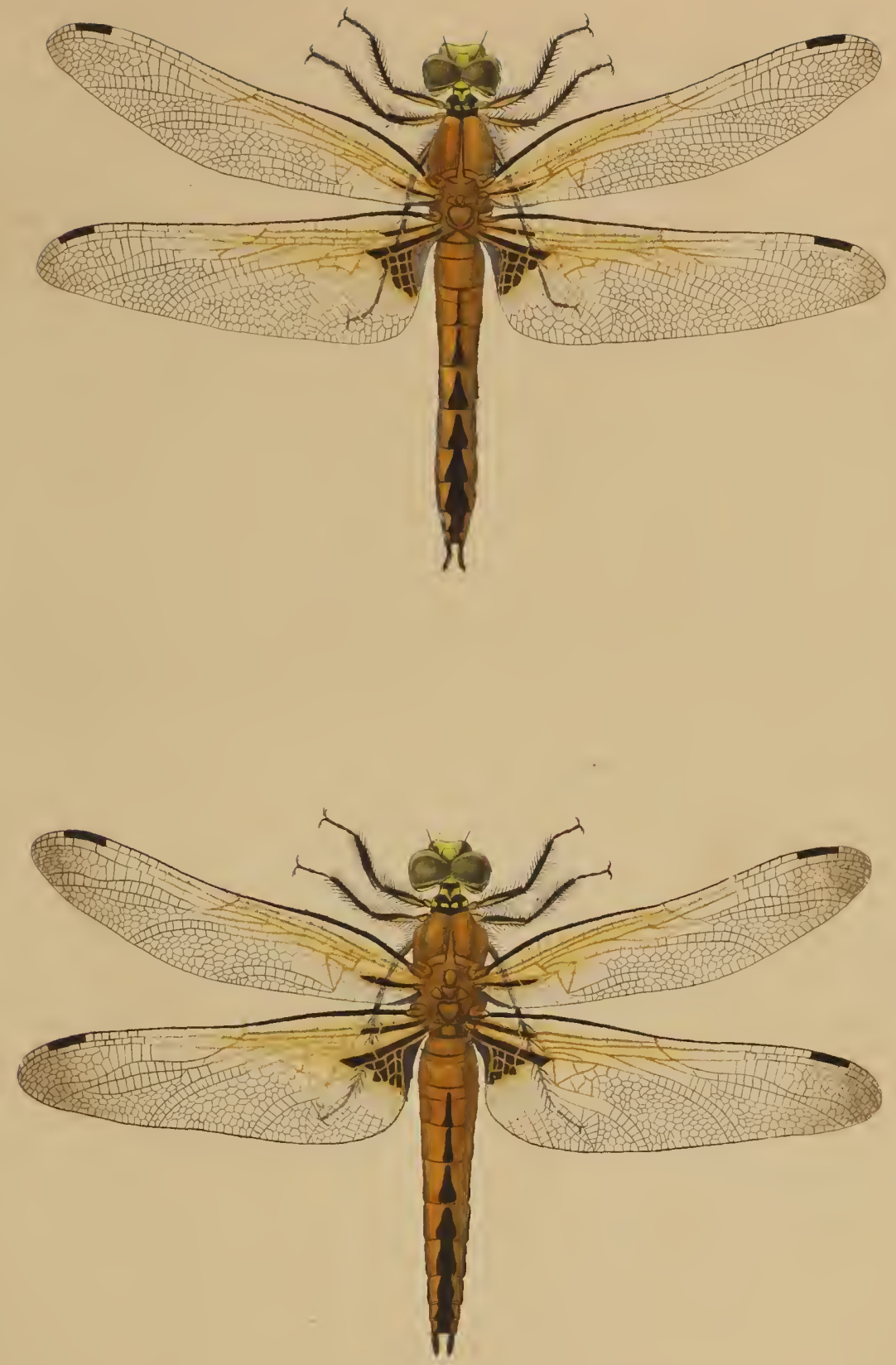

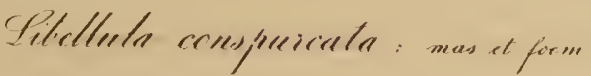



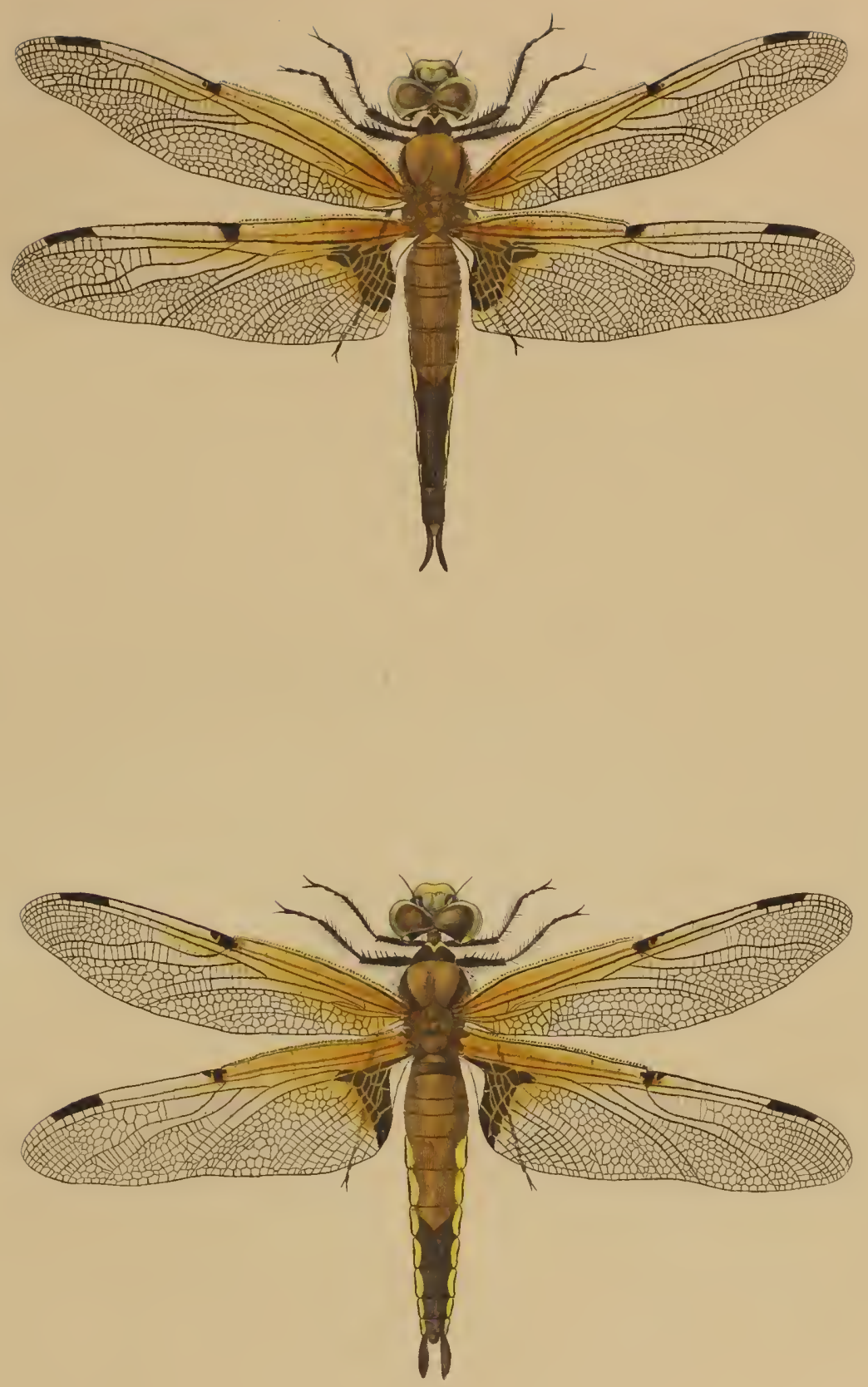

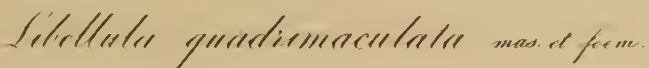




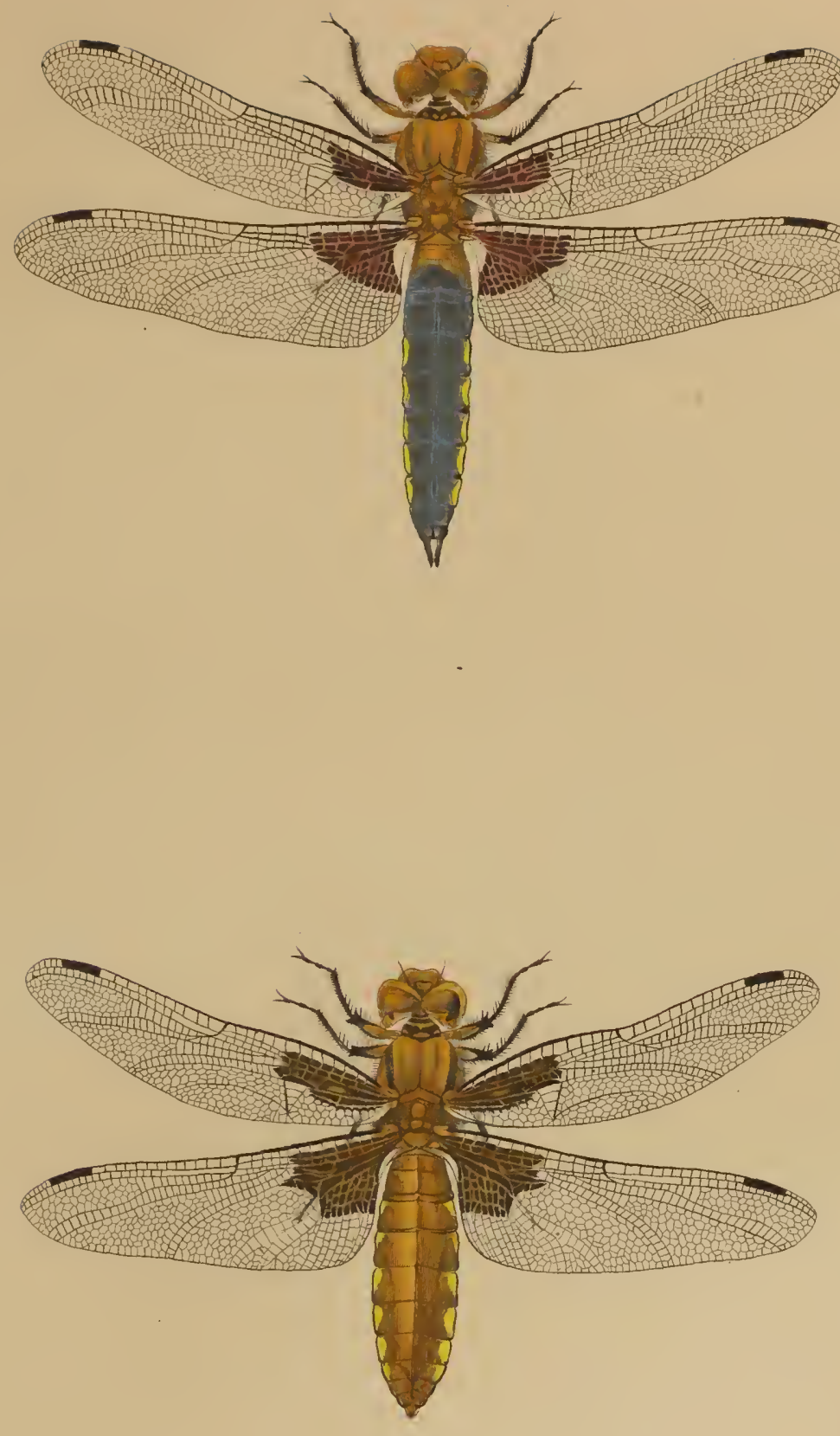

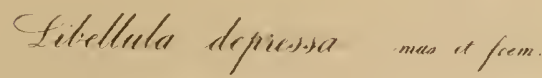


Tab. V.
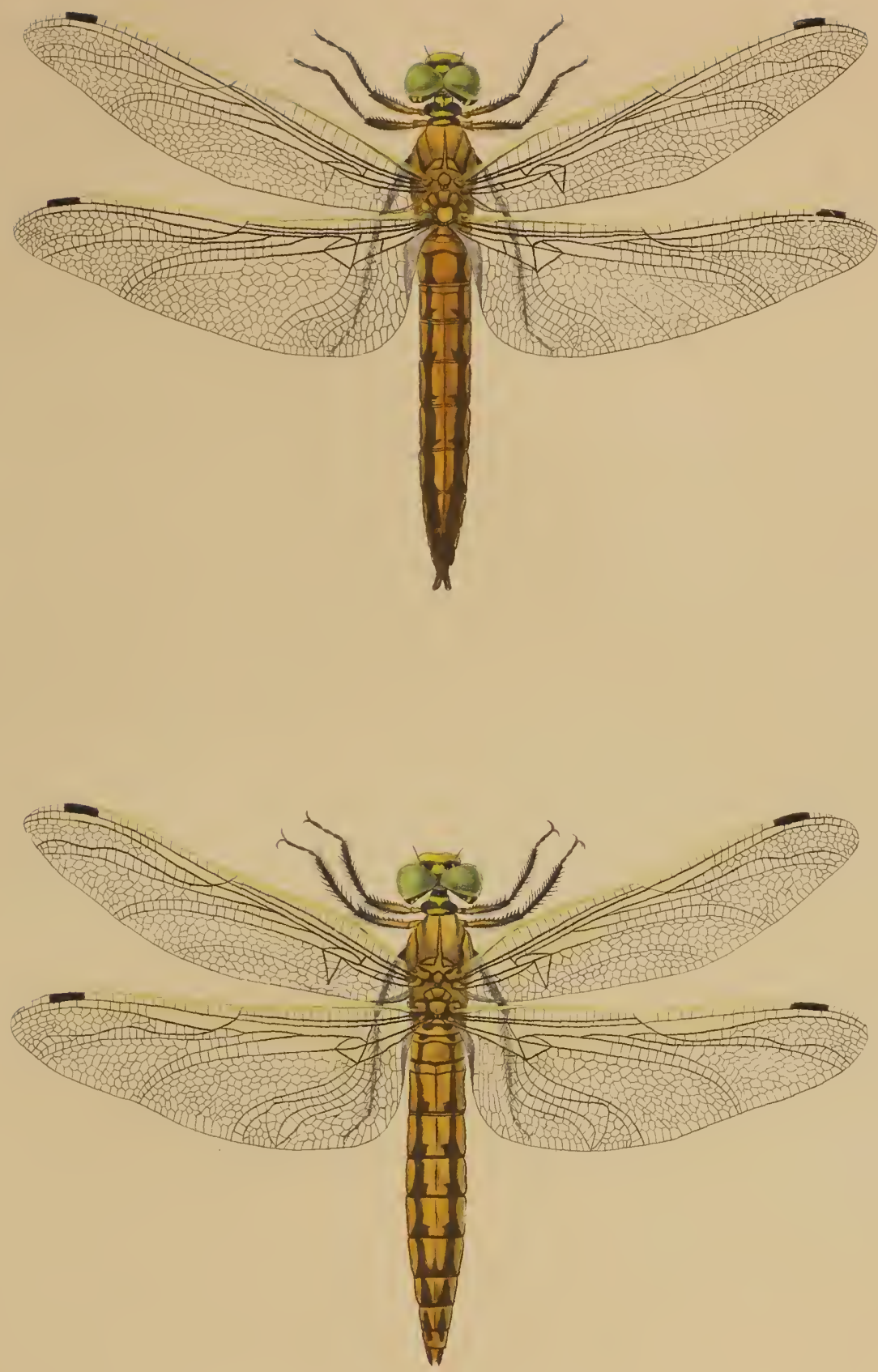

Siliellueta casscellata: mas. of form 
Tab IT
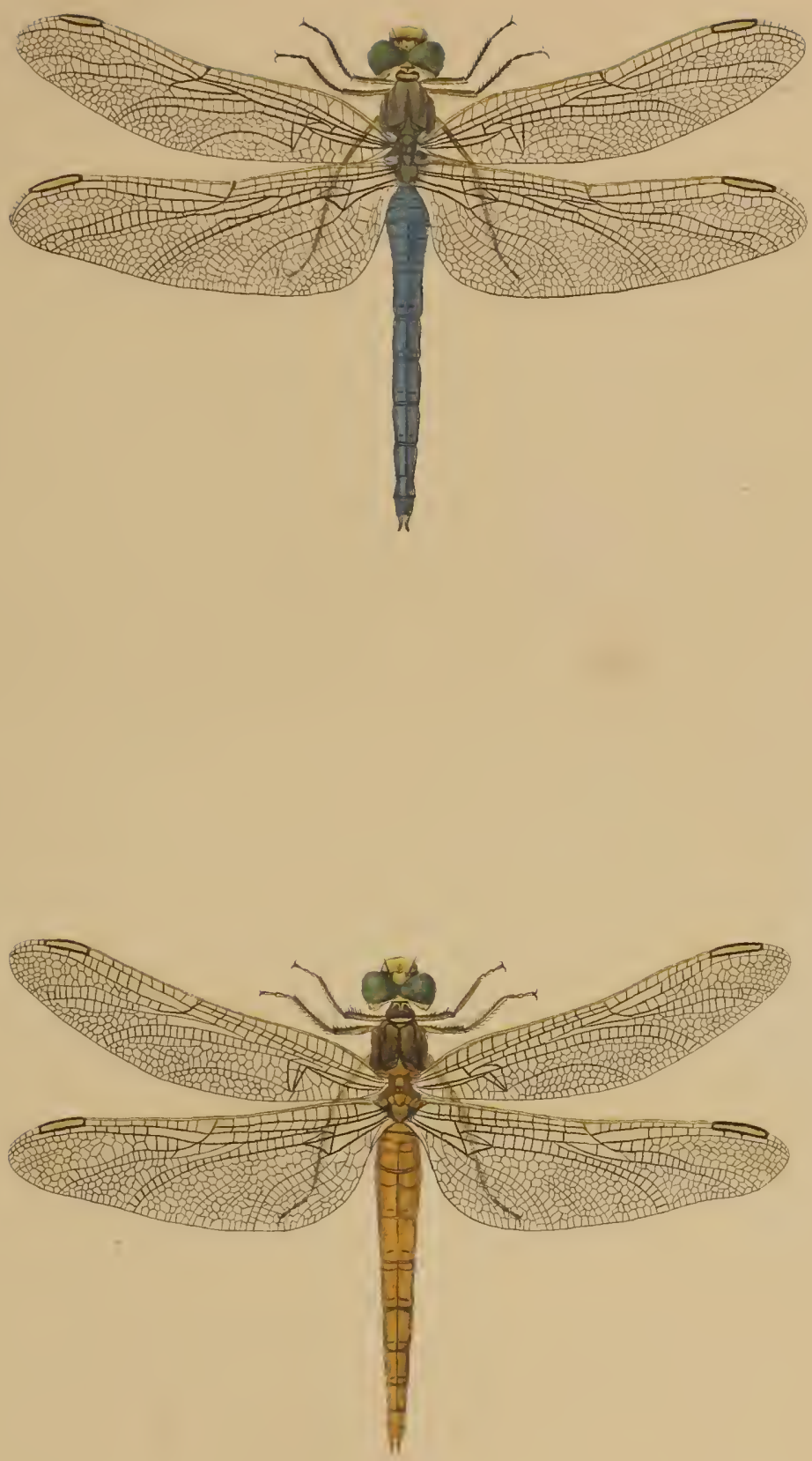

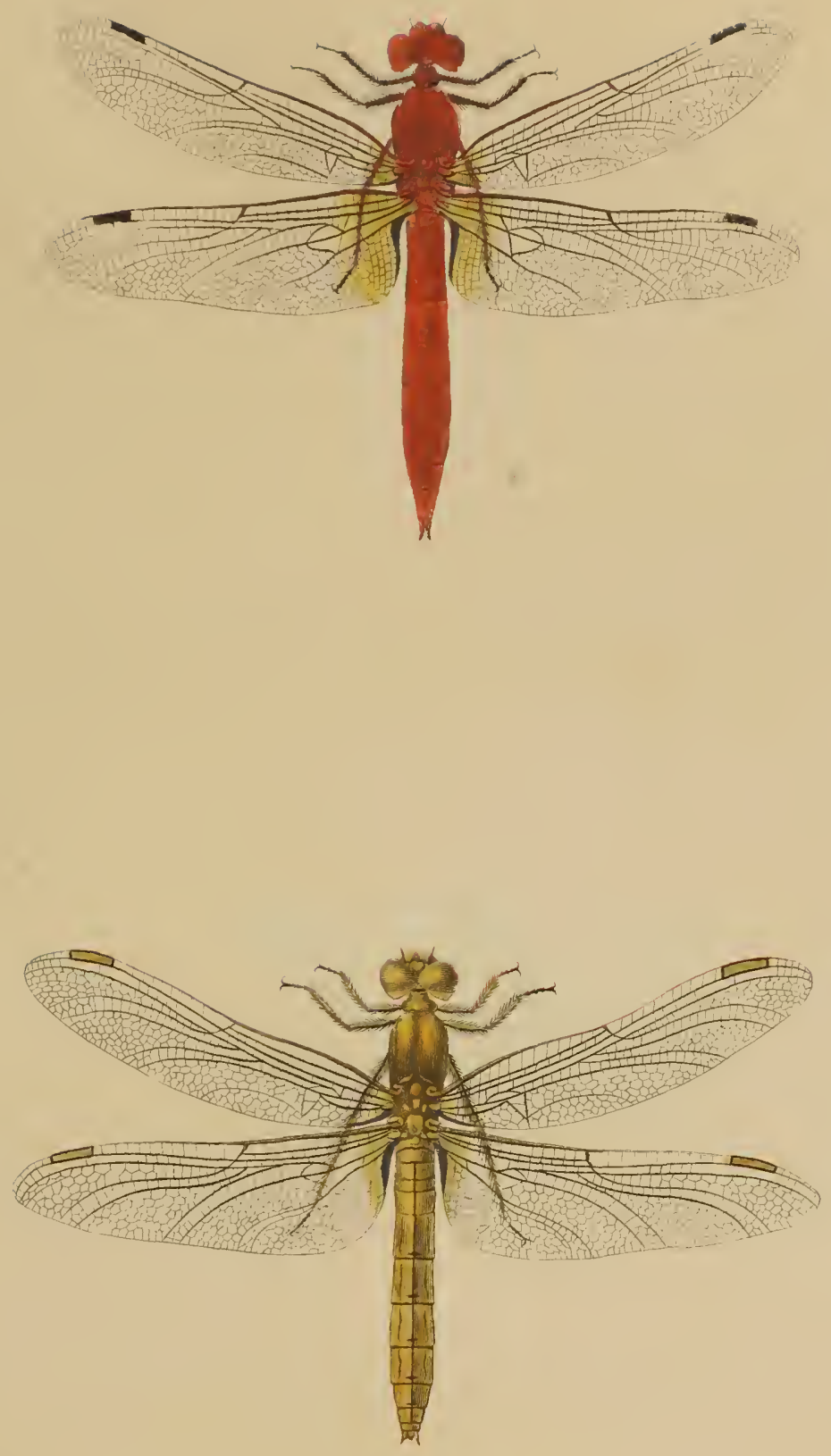

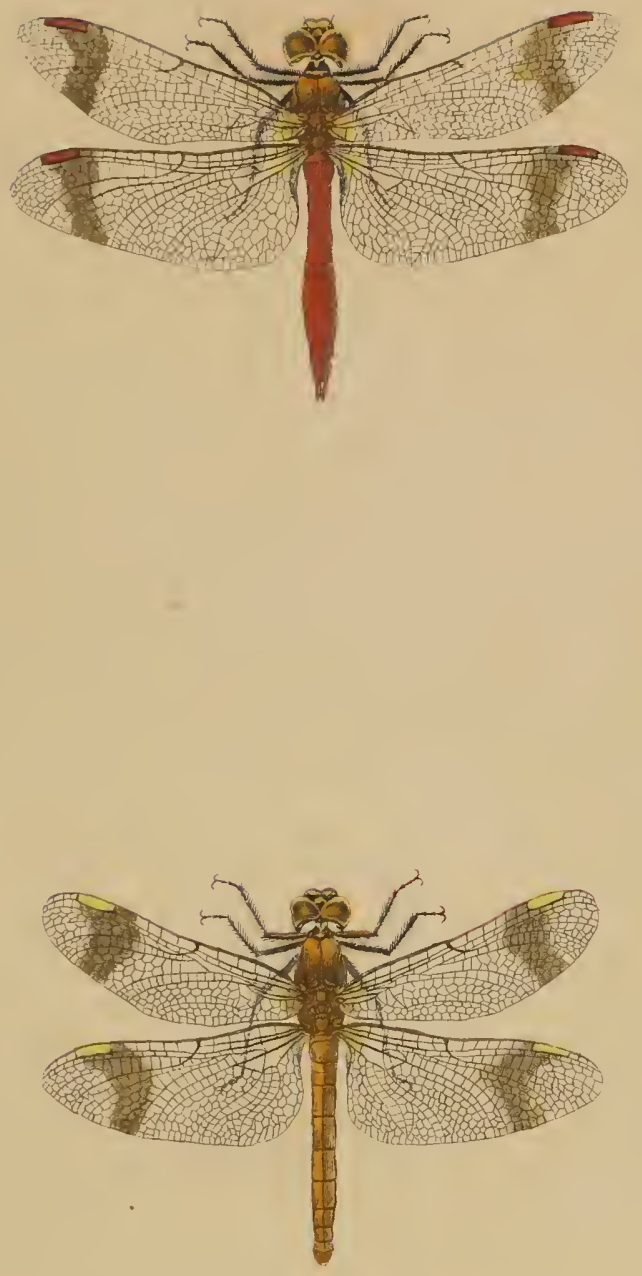

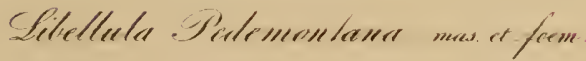



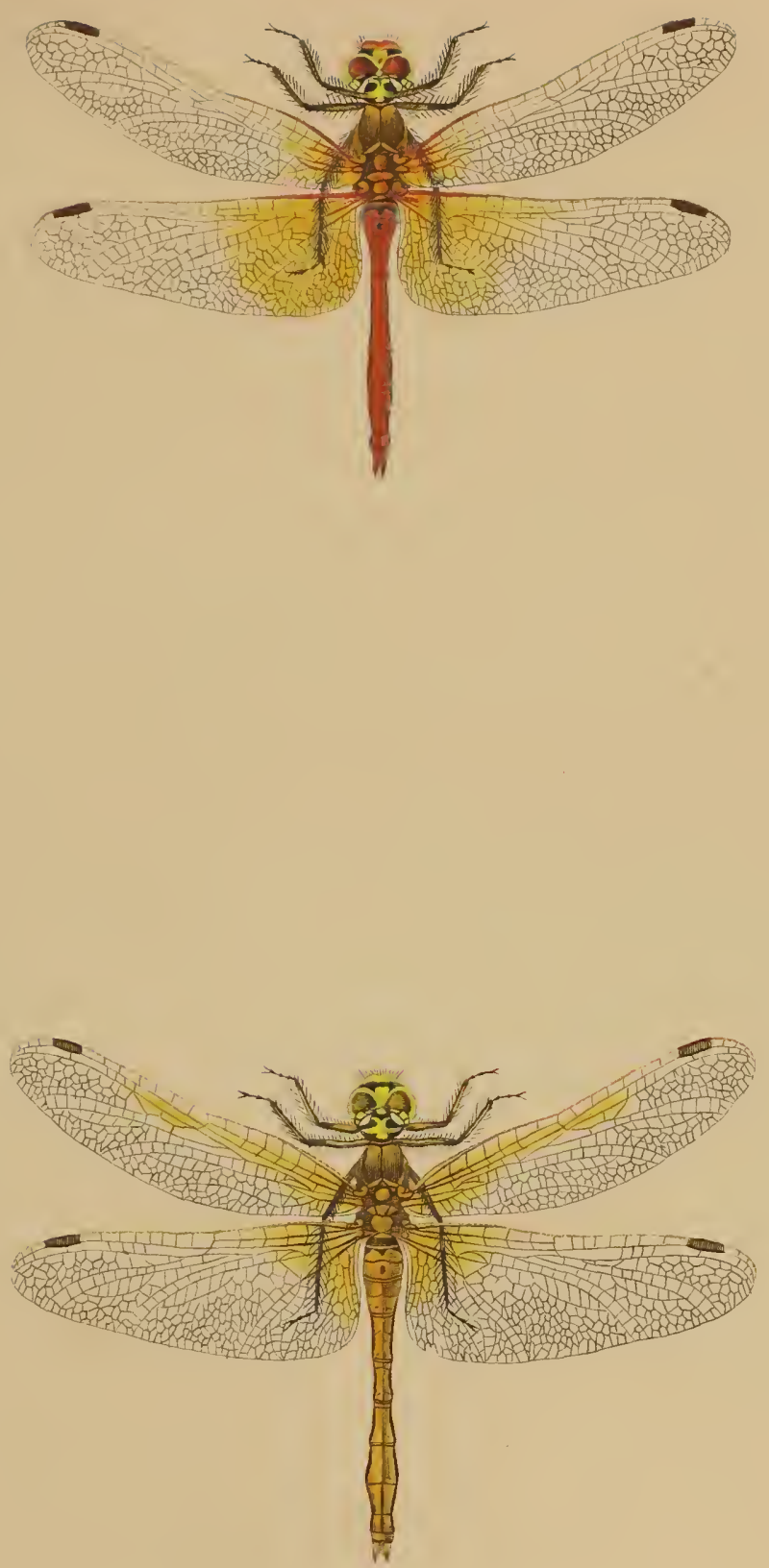

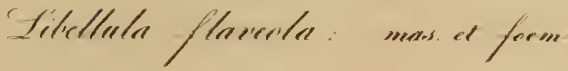



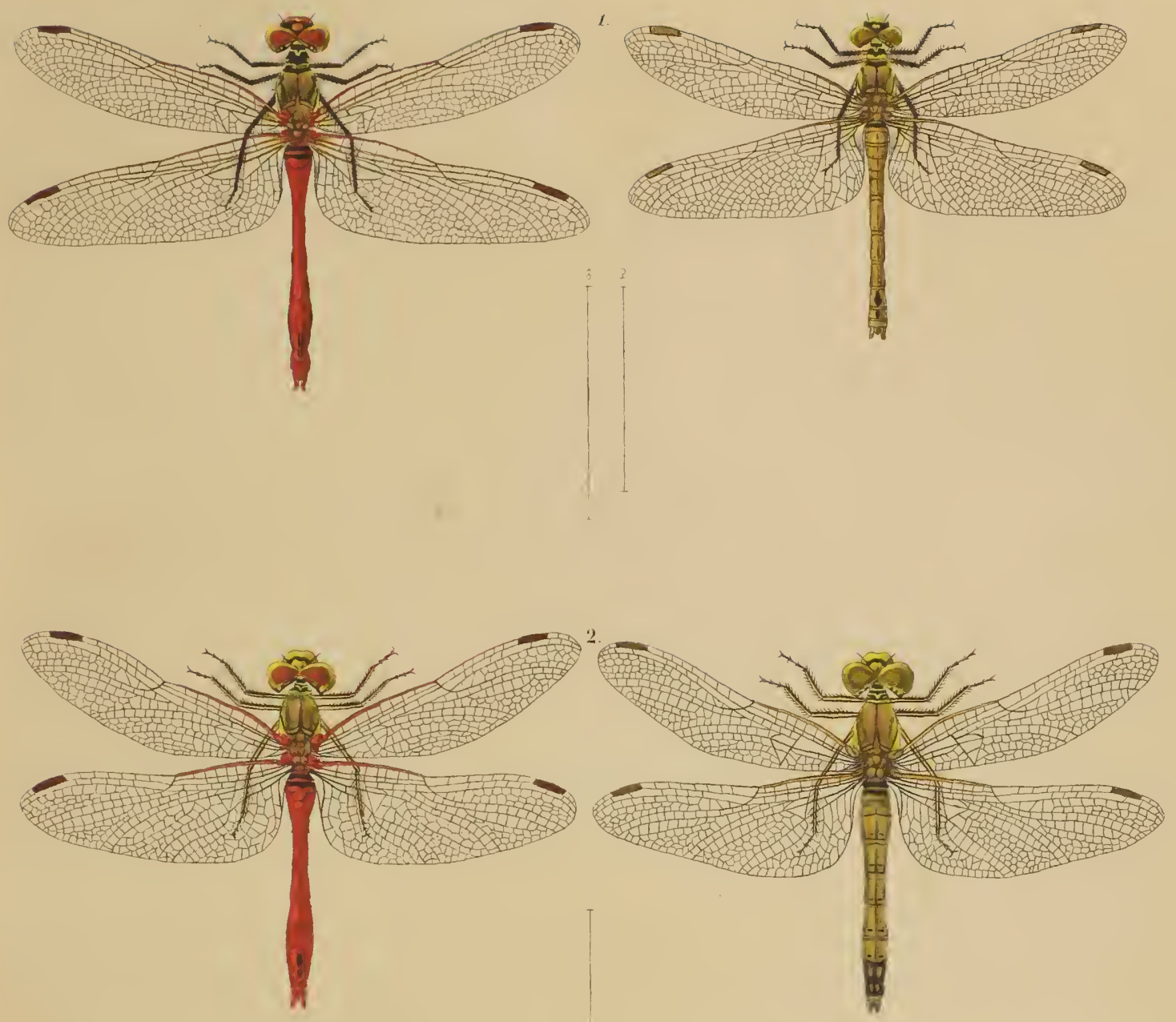

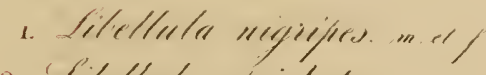

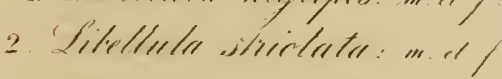



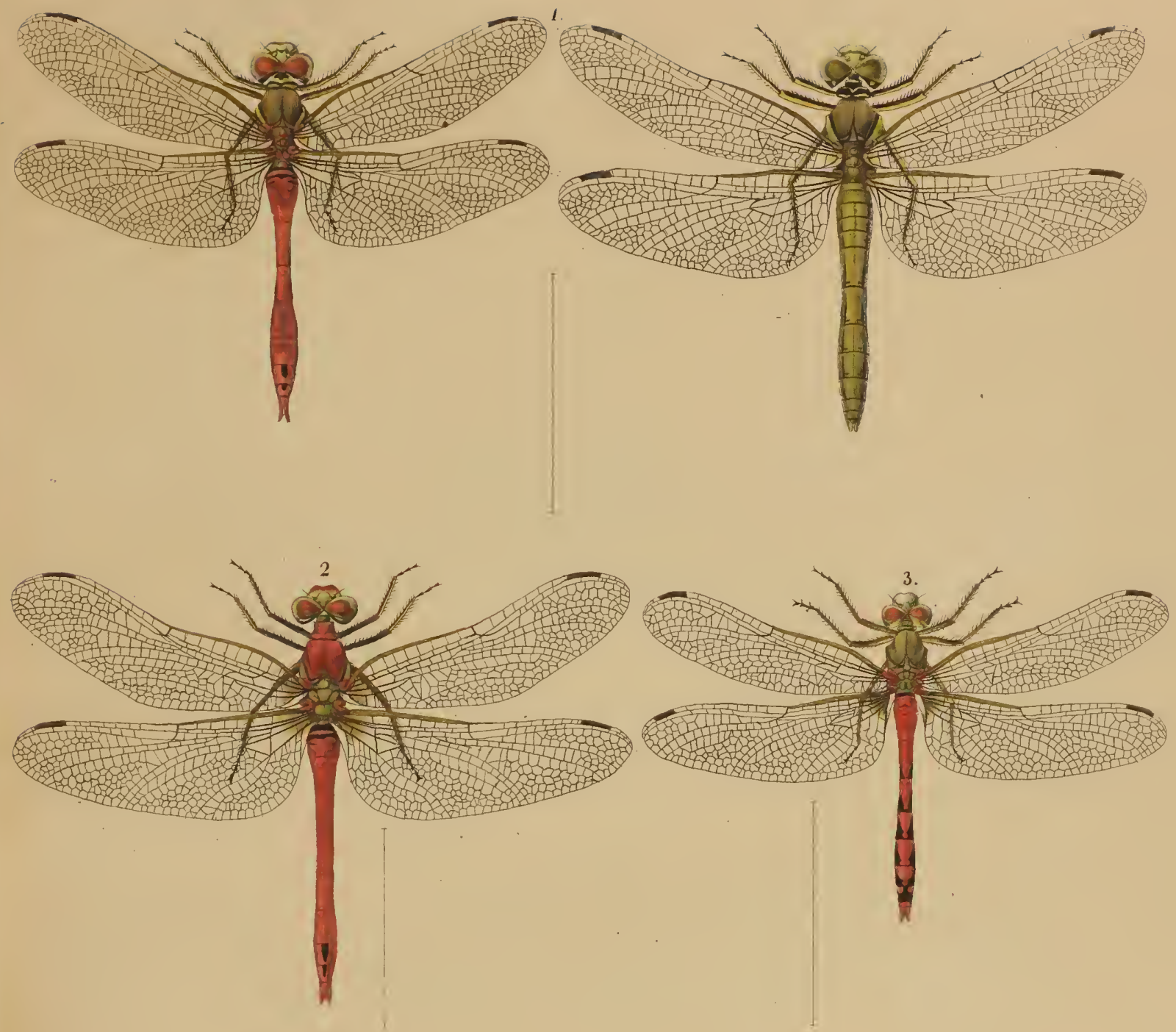

1. Litrlluter rutgaln medf

2. Lit. infirellis m.

3. Ril: allifiens: m 

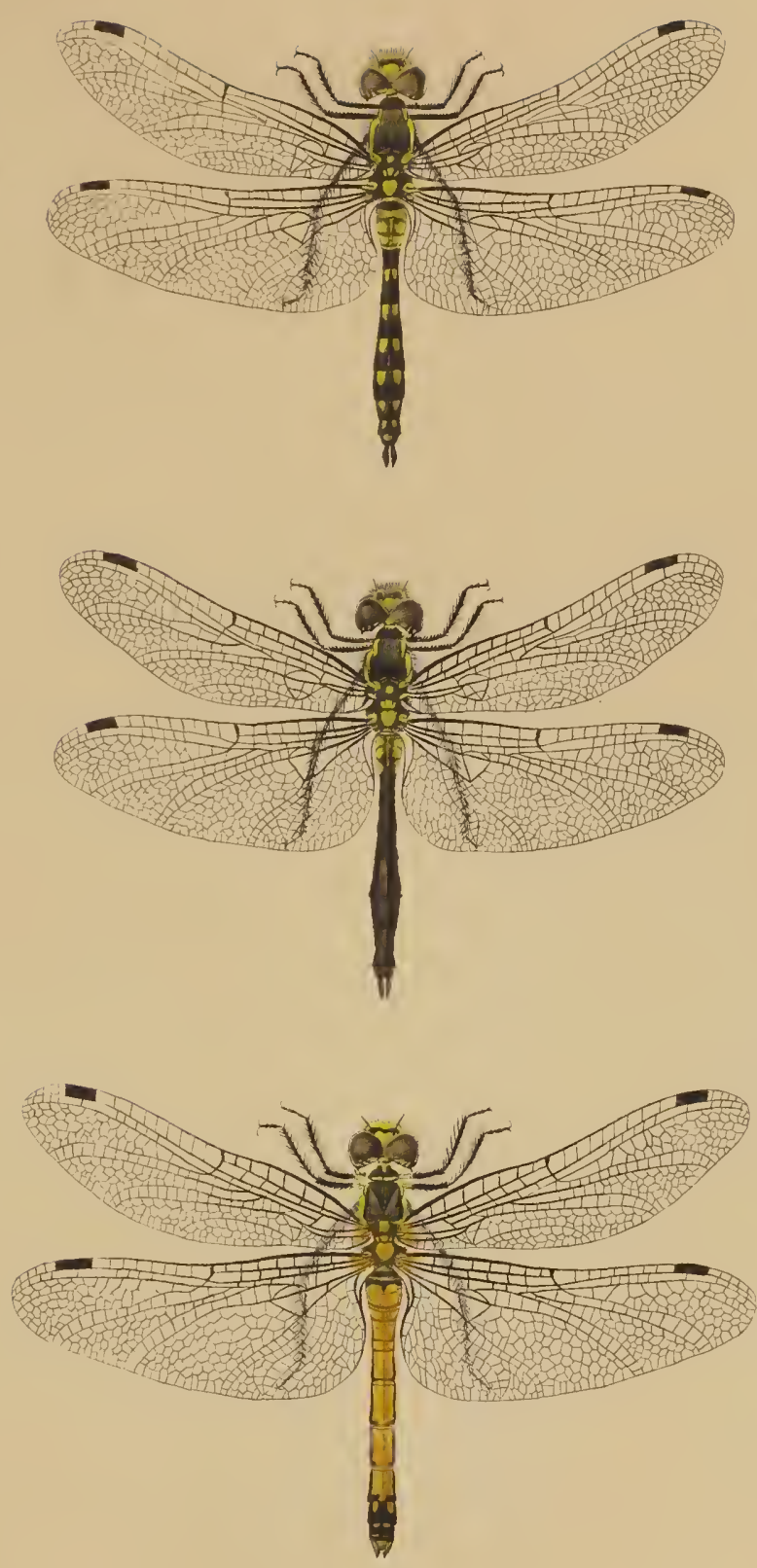

Libltule nigien merries el foem 


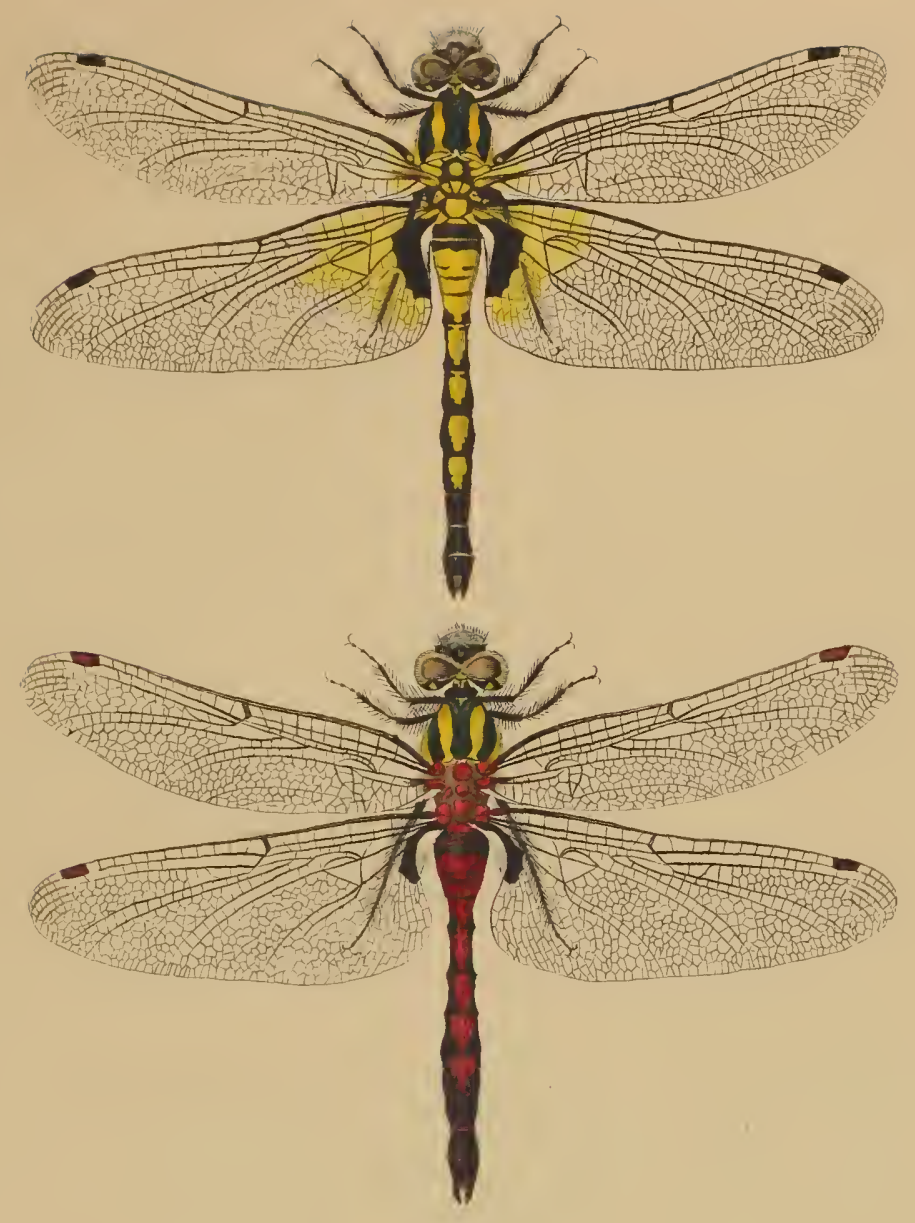

Tab. IIII.

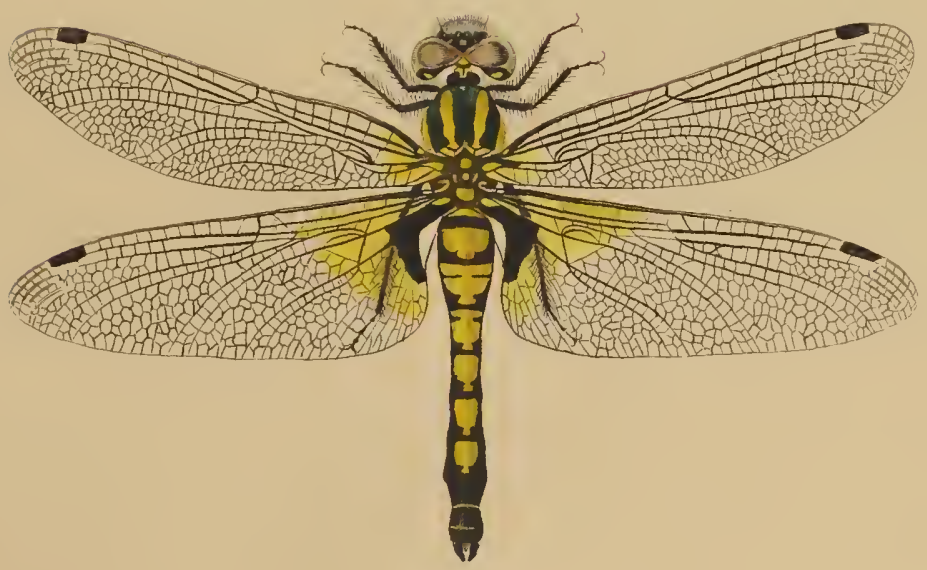

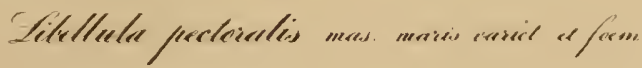


Tah. XIV.
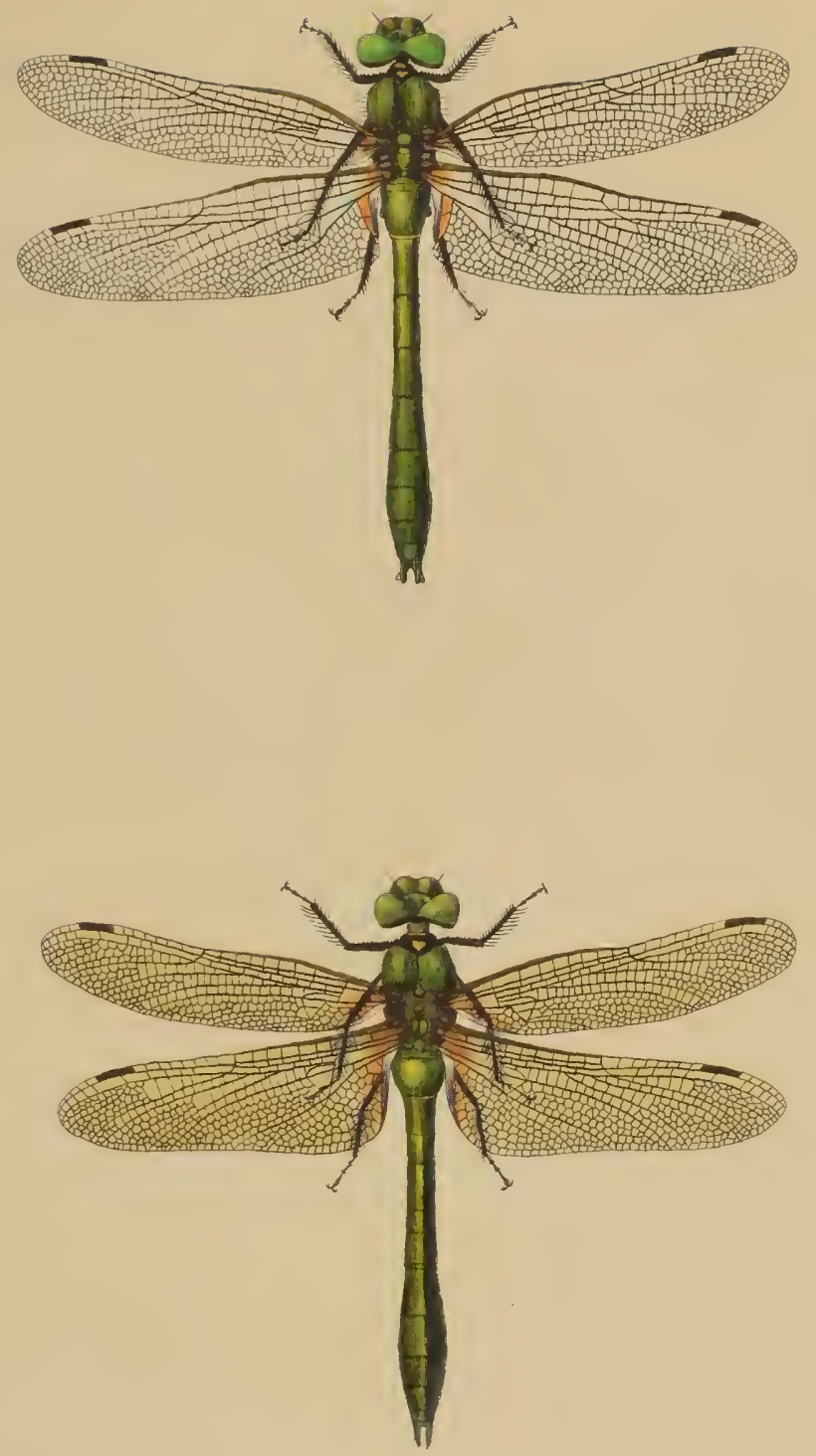

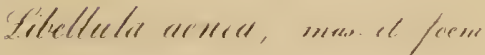



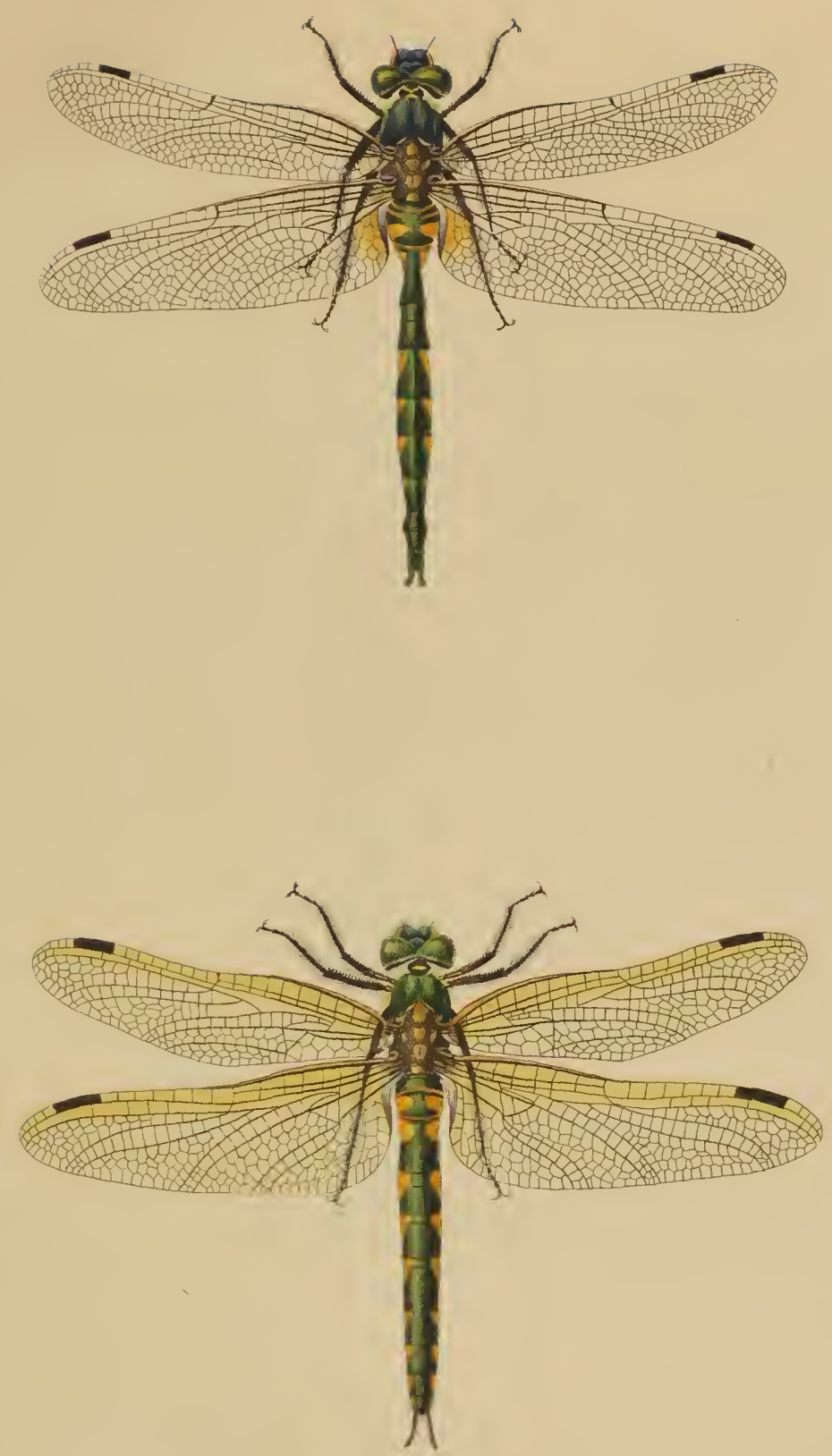

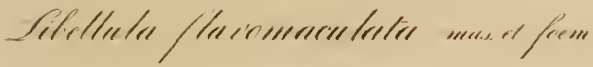


$T: 14.17 \%$

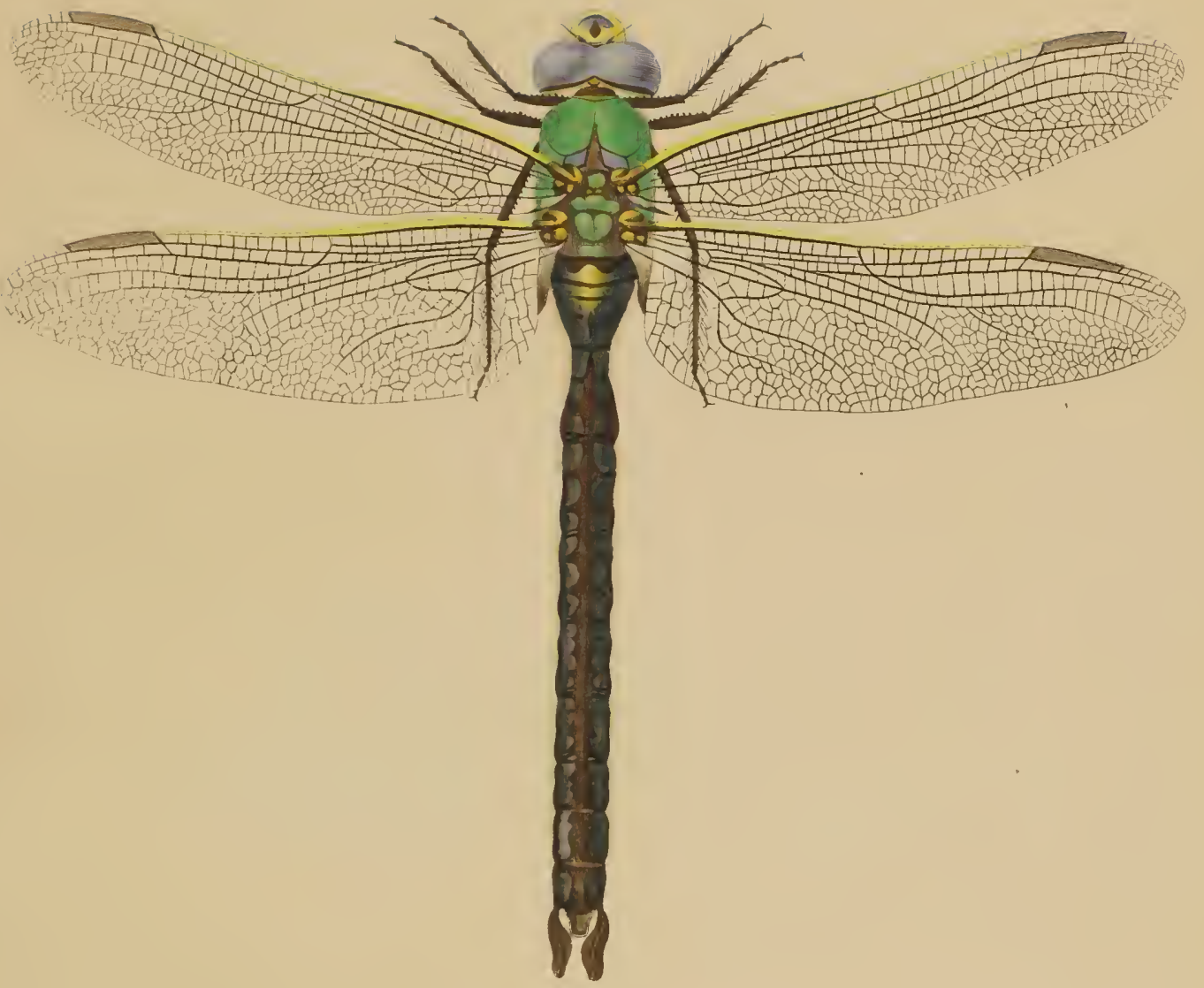

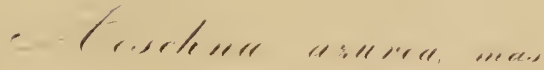


Tab XT7II.
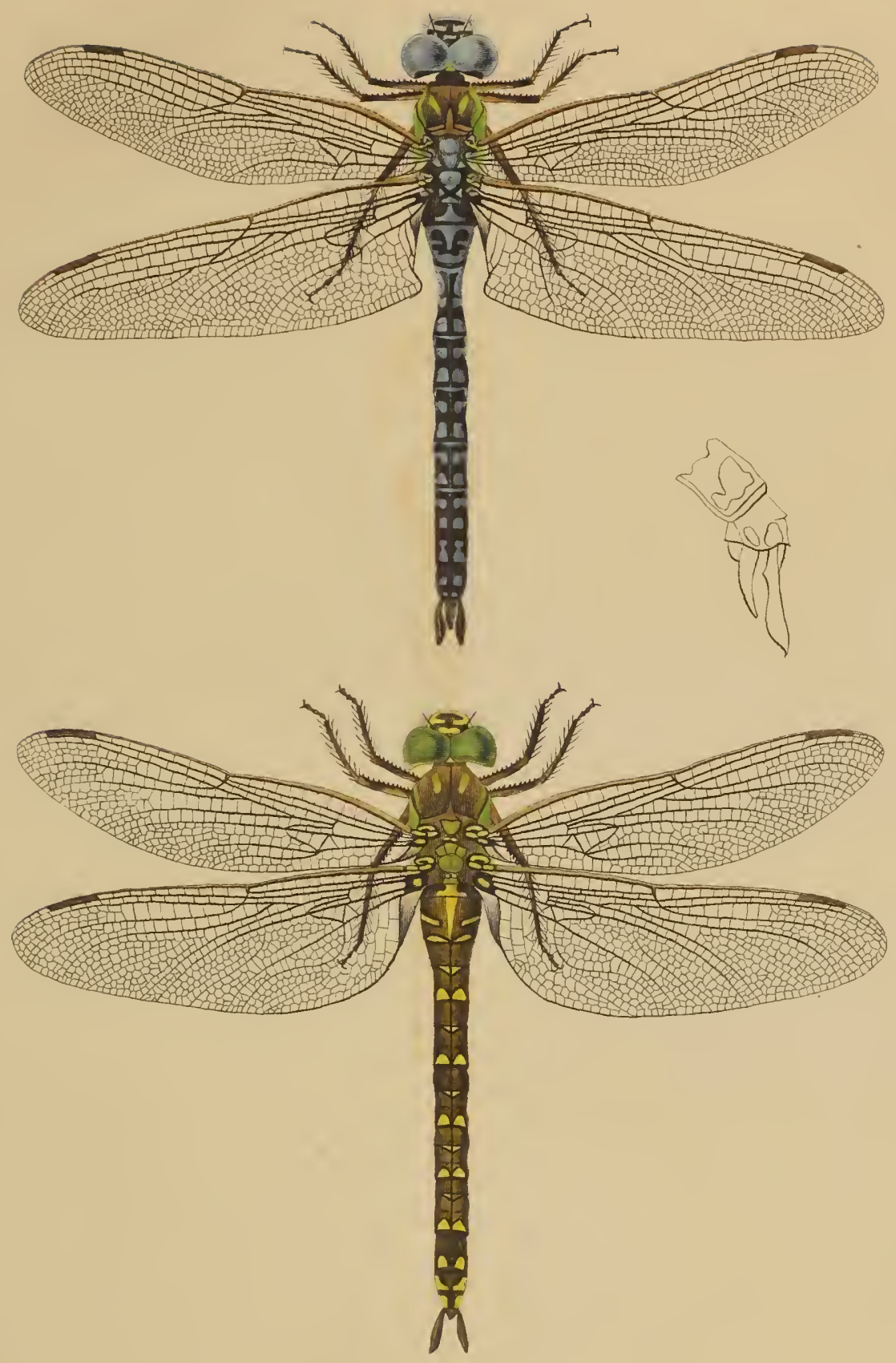

trorkenen affirris, mende er form 
Tab.XIS.
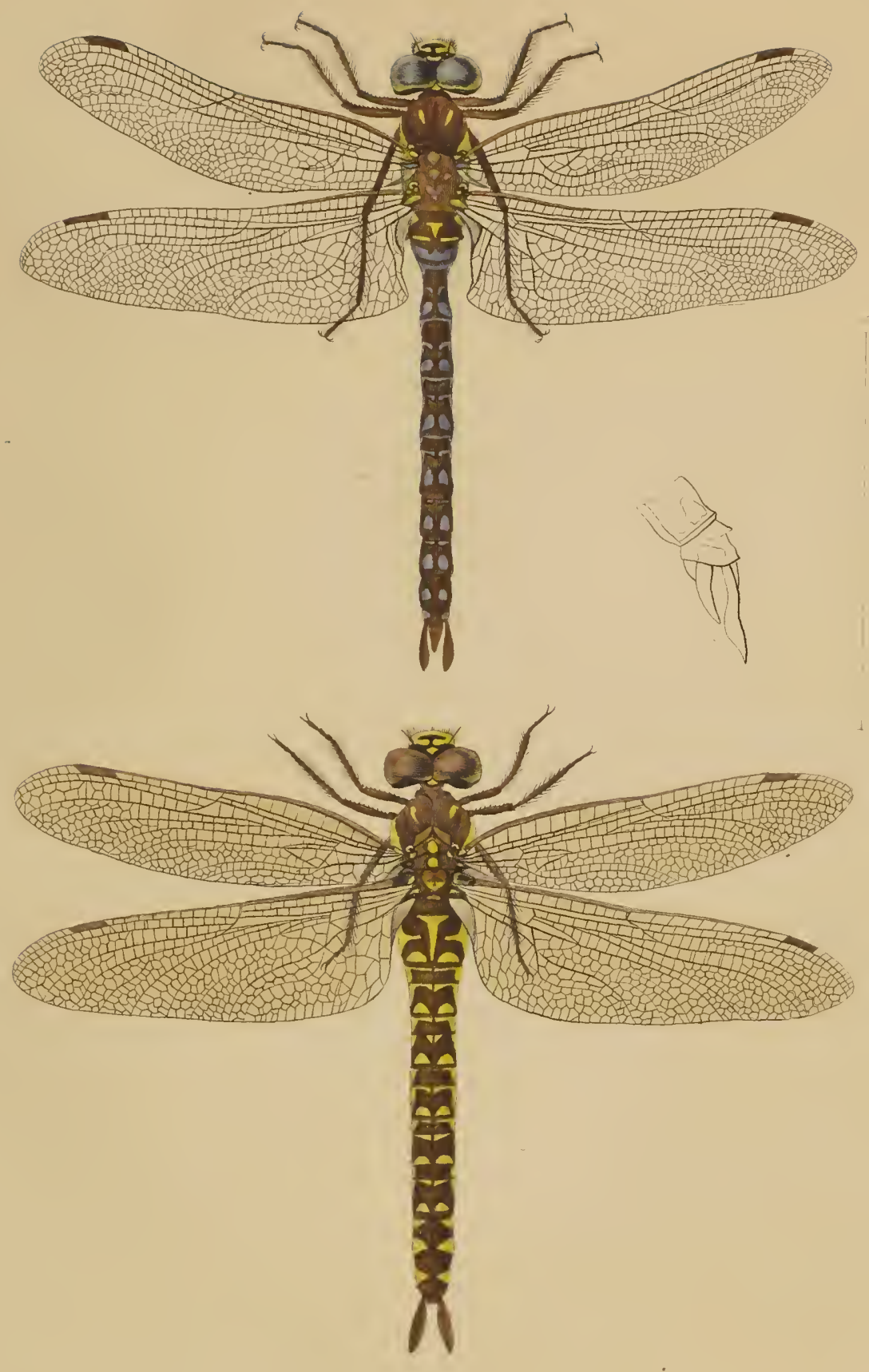

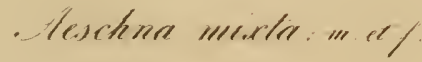




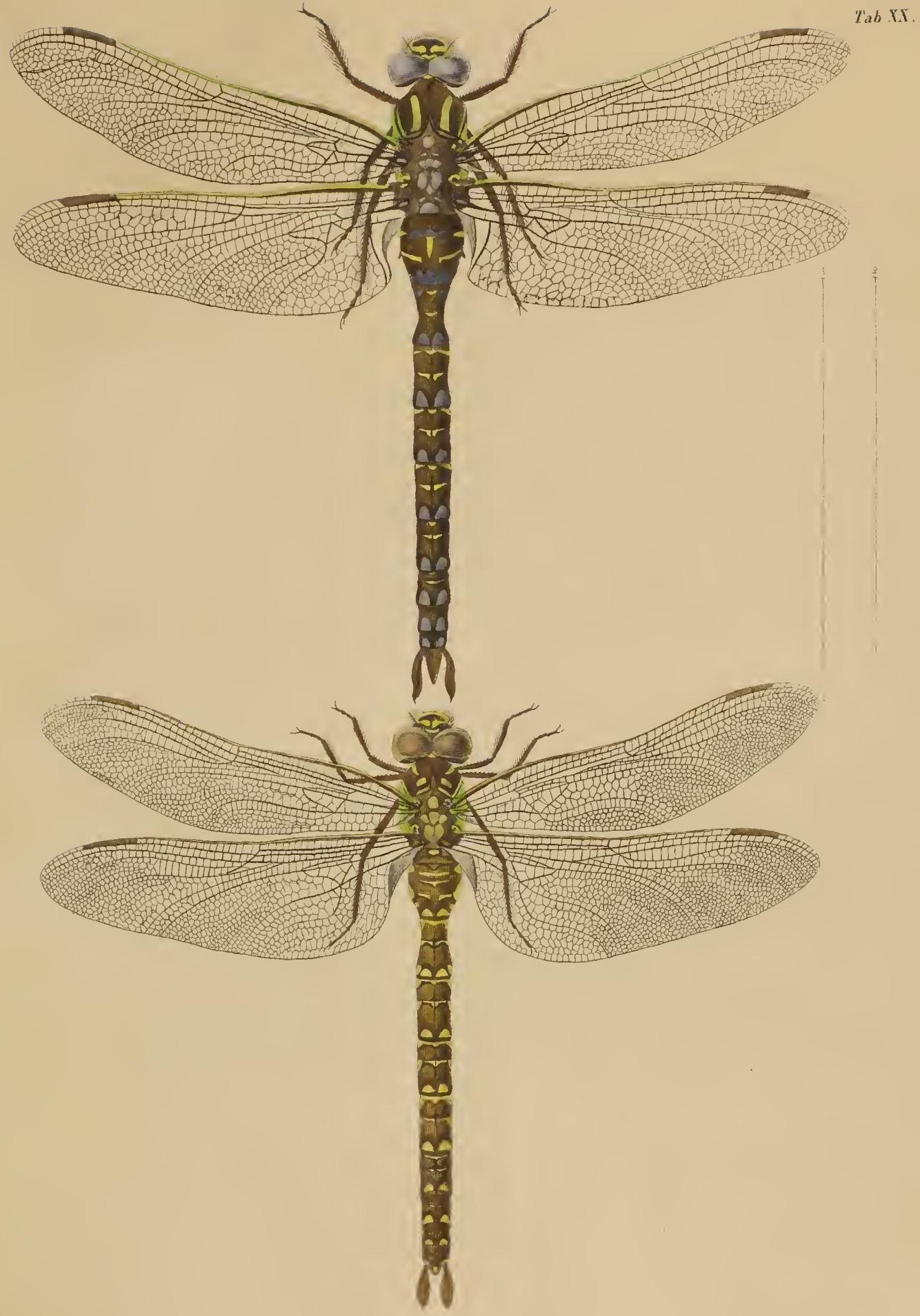

- trostenel firita matef 


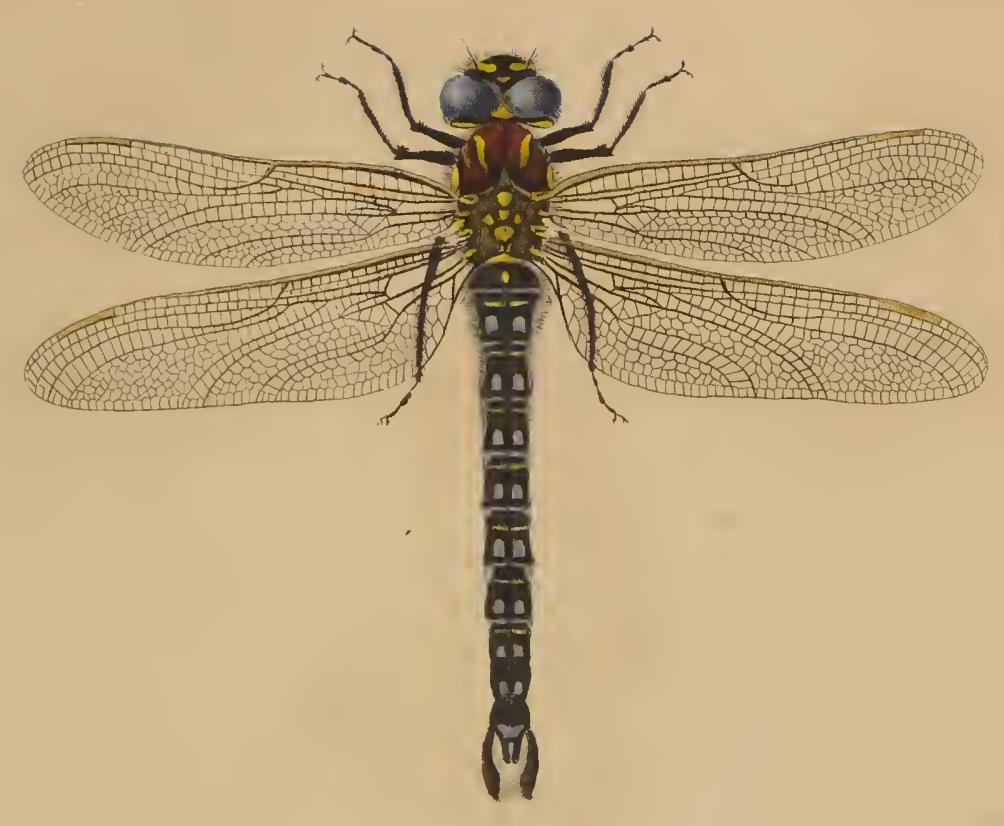

Tab. IXI

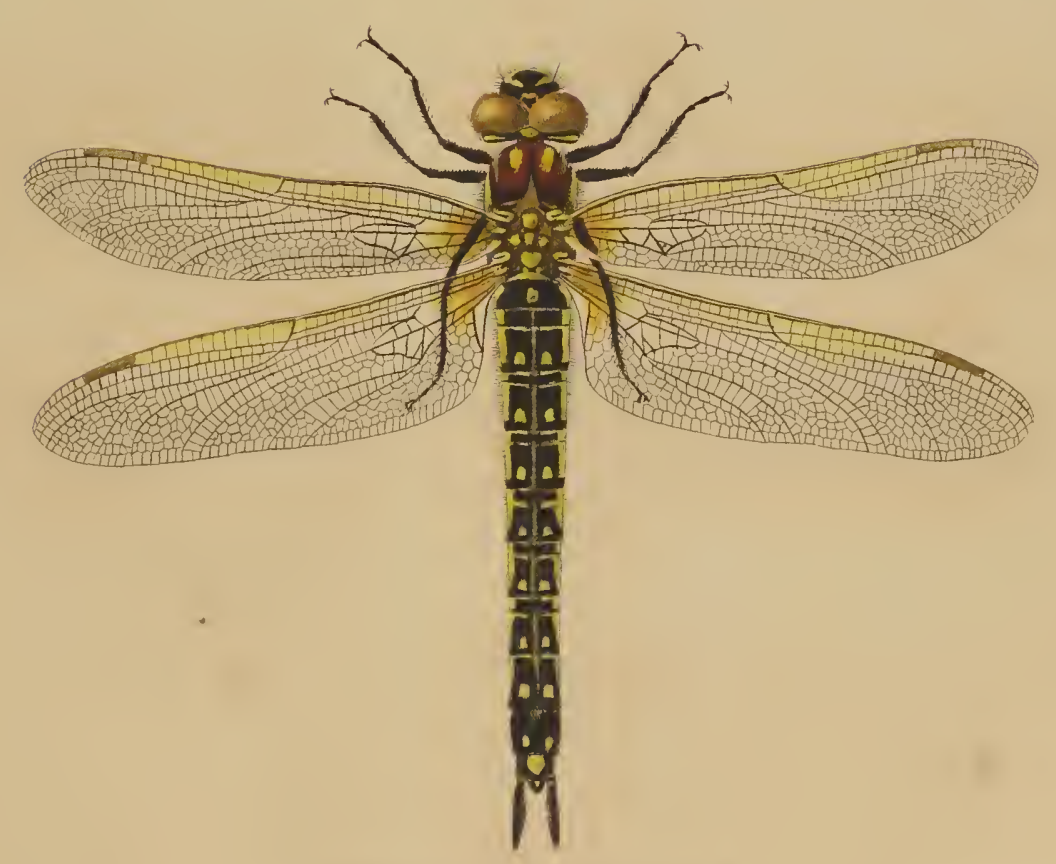

- truchiore pitruser imas.erfferm 


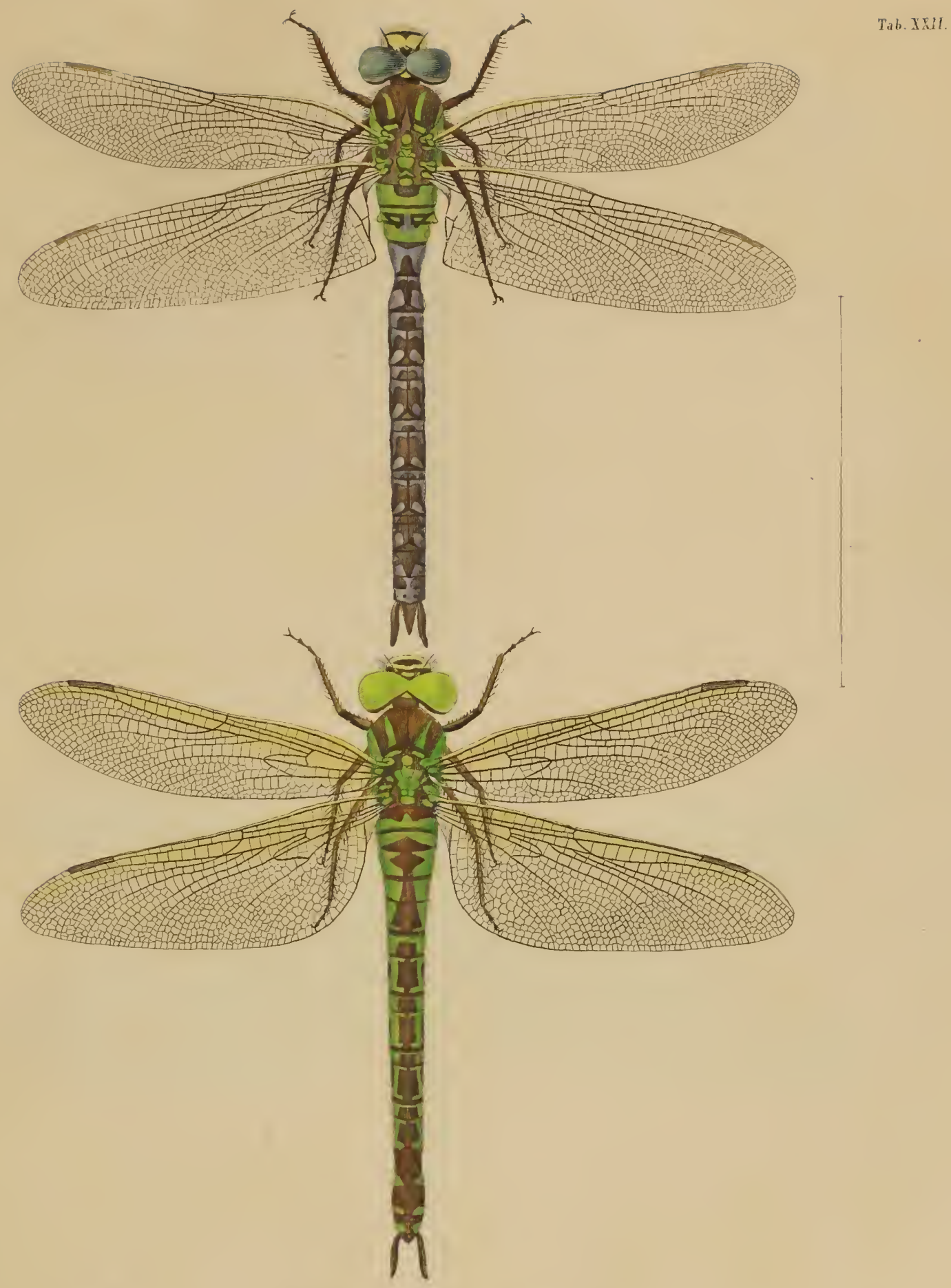

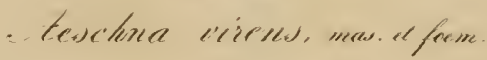




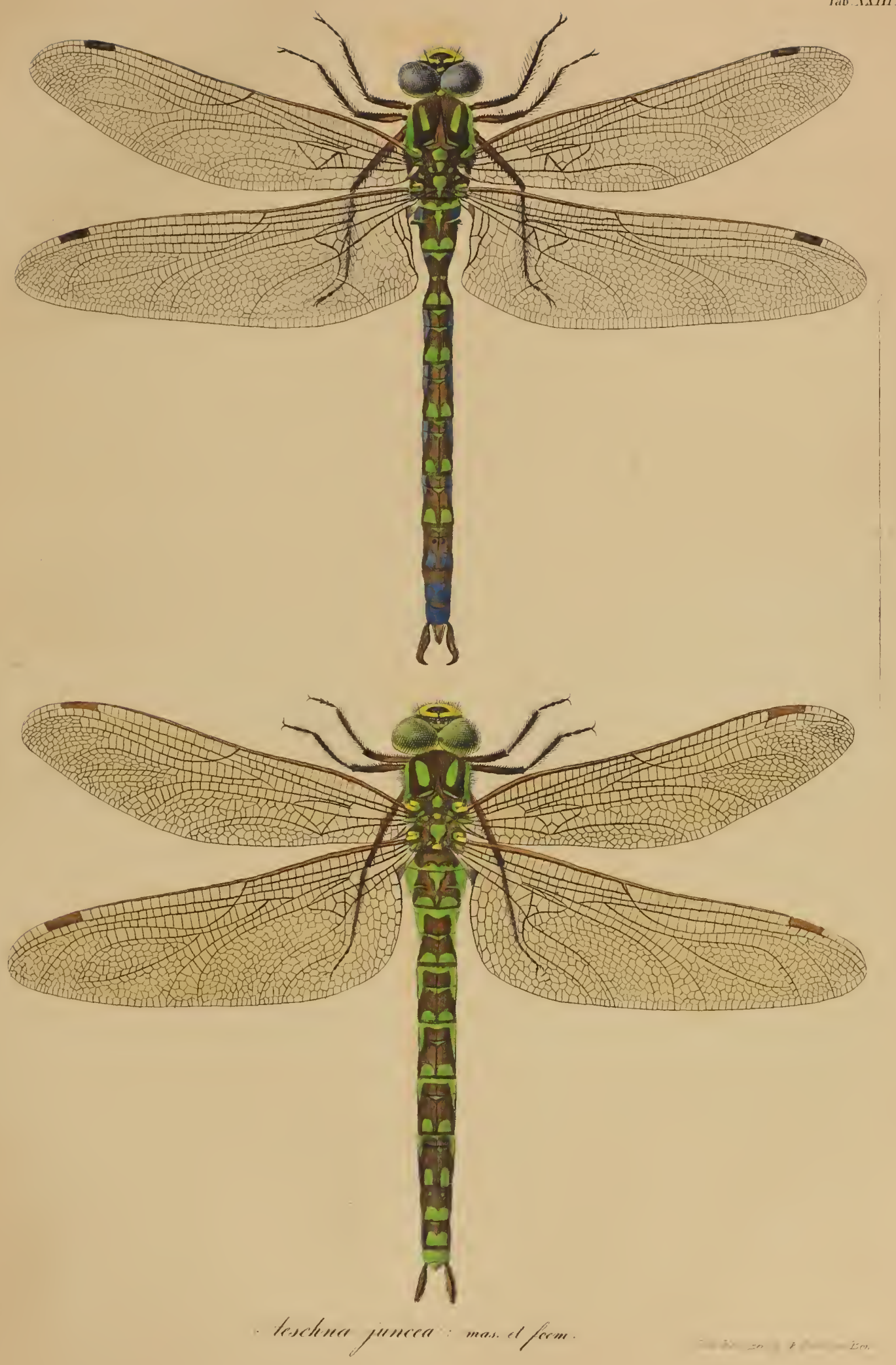




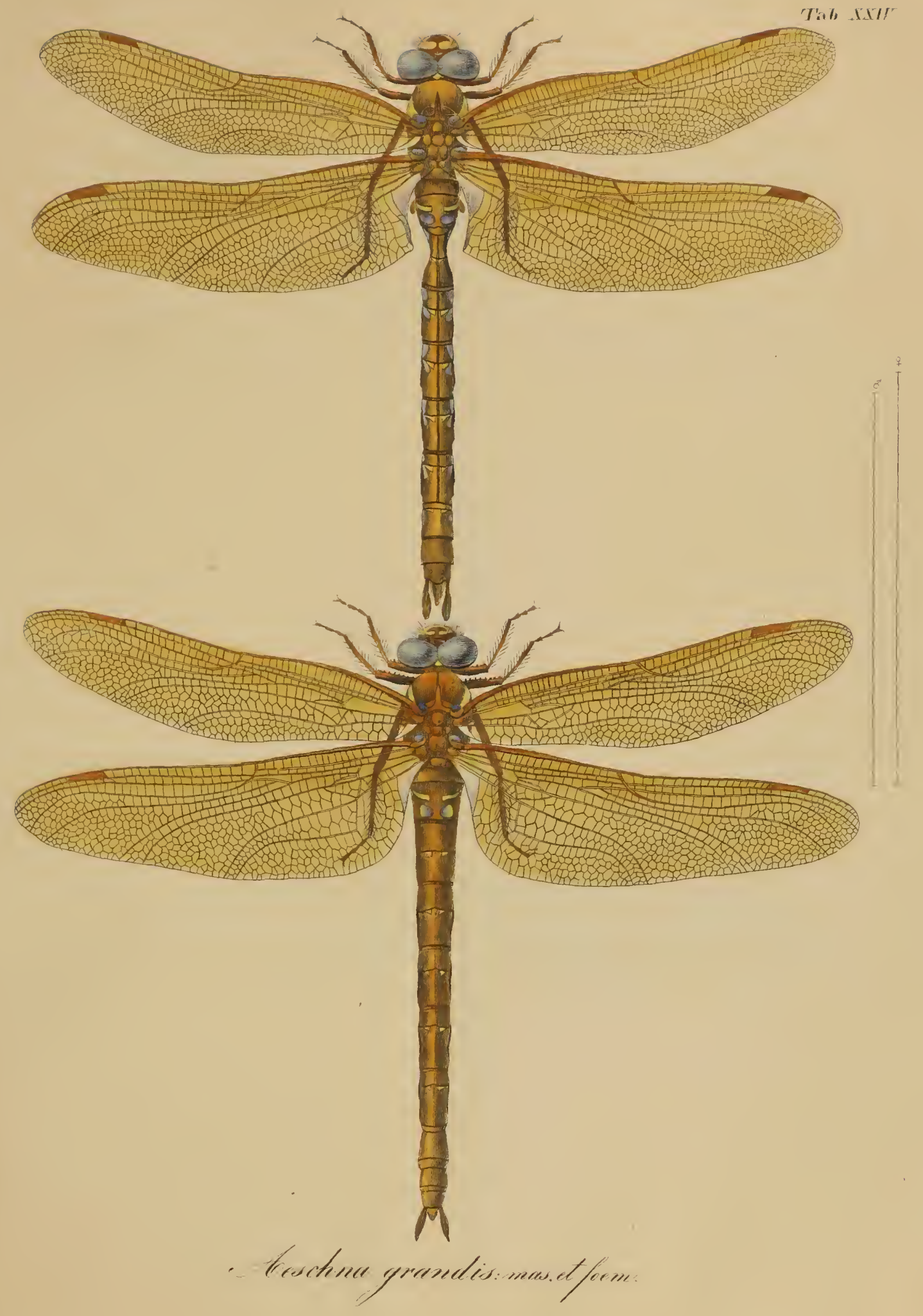




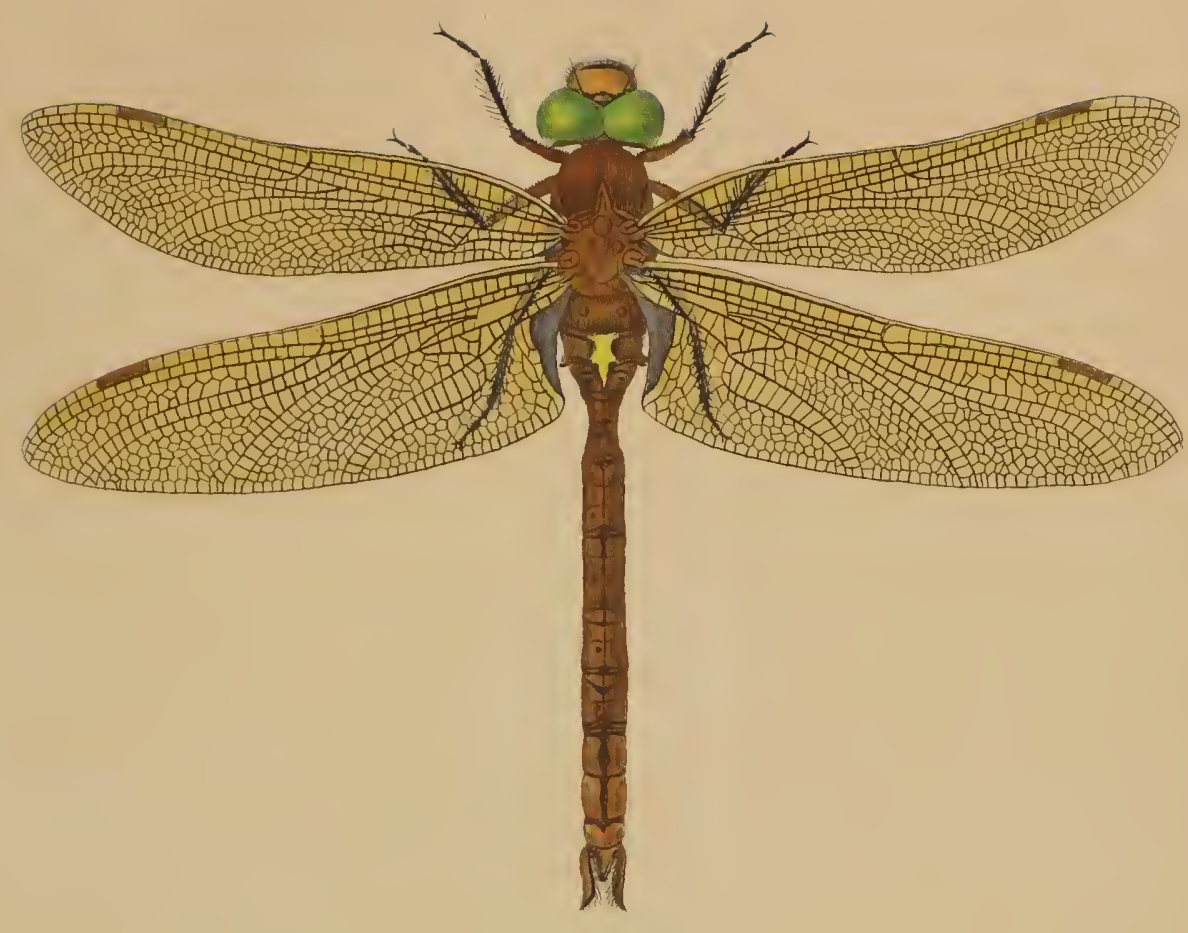

Tab.XXV?
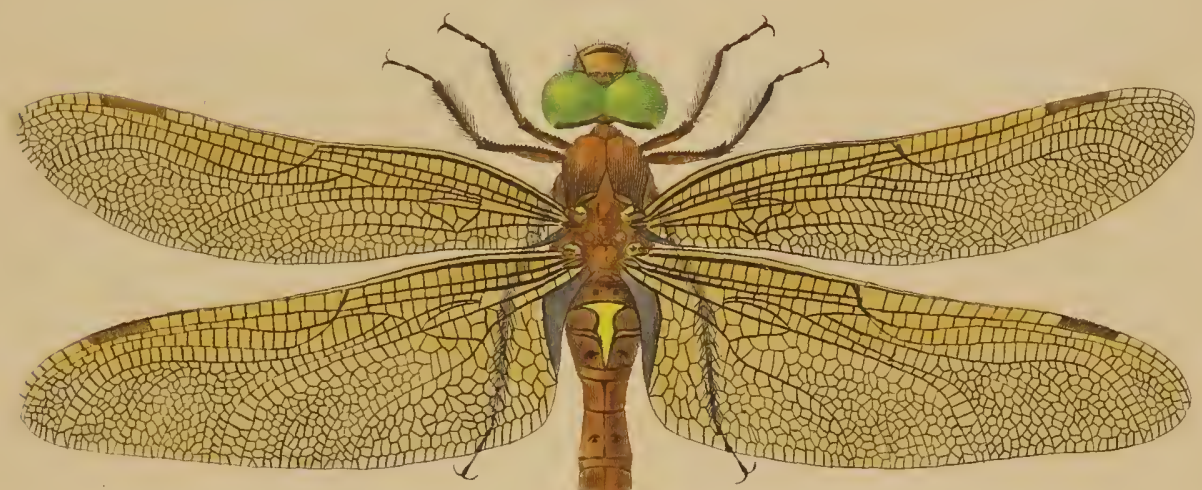

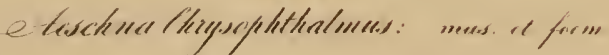


Tab.XXVI.

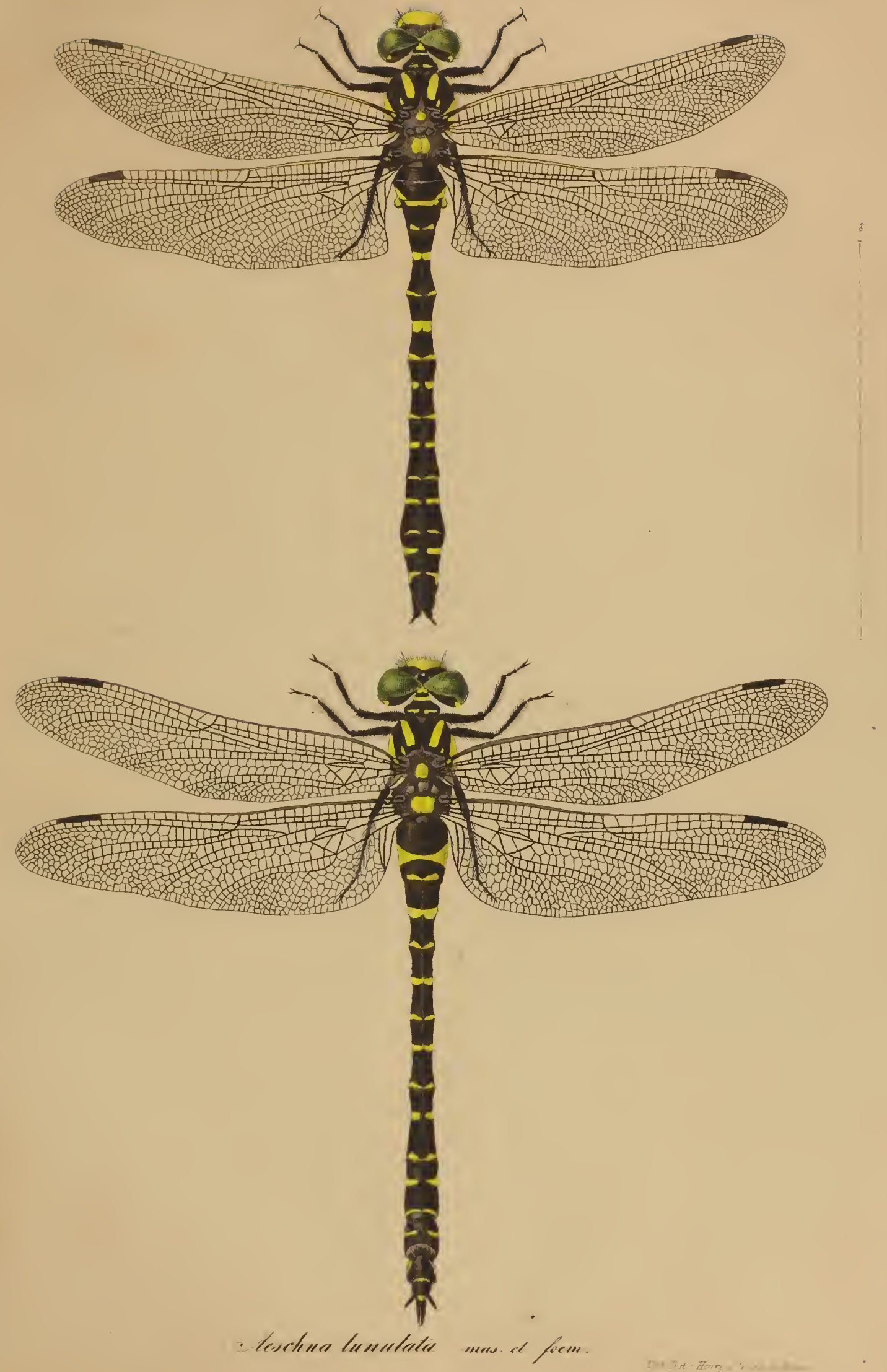




$$
\begin{aligned}
& \text { y } \\
& \text { y }
\end{aligned}
$$




$$
\text { F }
$$




$$
\begin{aligned}
& * \\
& *
\end{aligned}
$$


Tab. XXXI
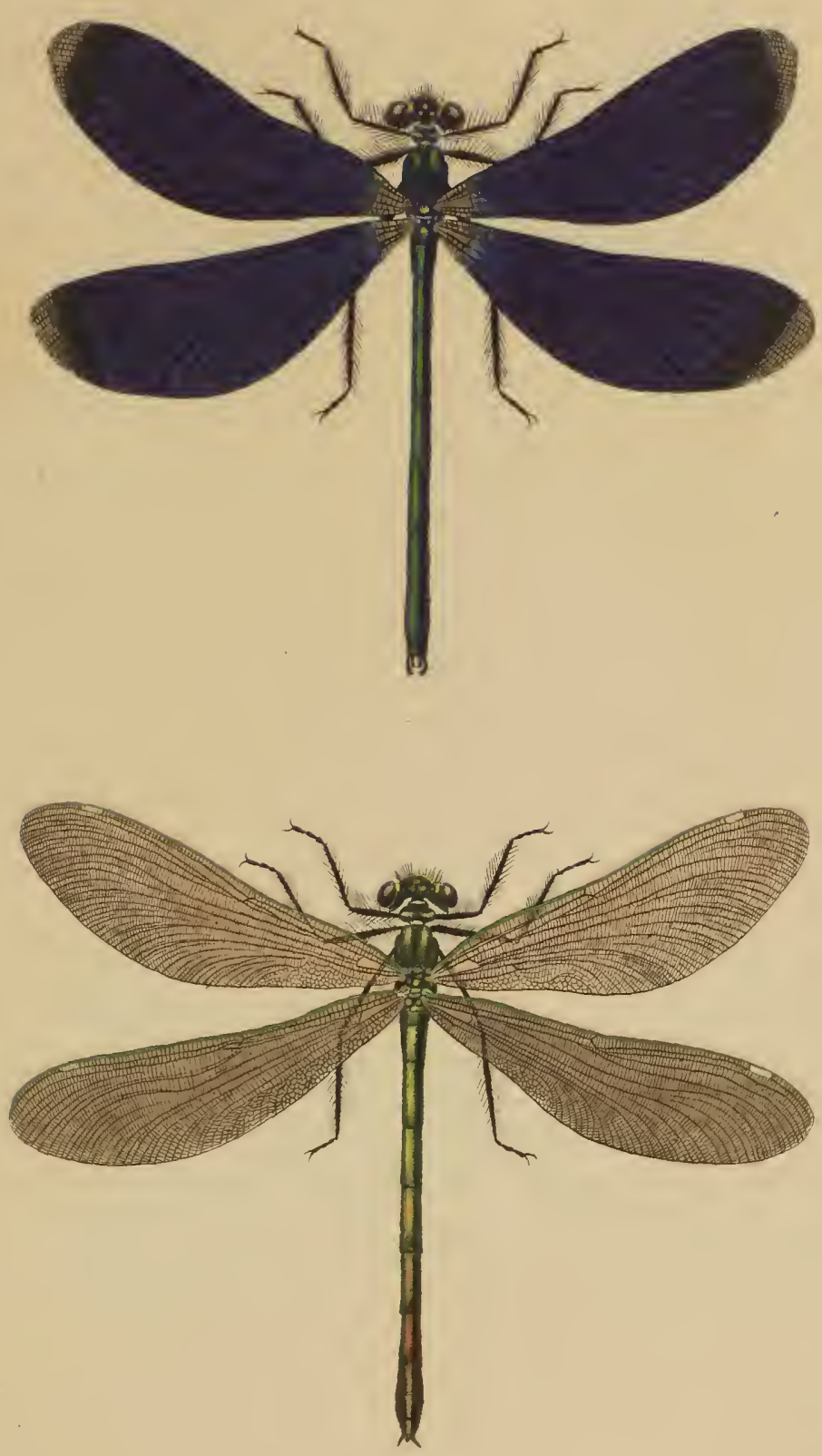

- lovirel Yrign: m.ef 
$\pi$

$\pi$ 


$$
\begin{aligned}
& \text { ip } \\
& \text { ye }
\end{aligned}
$$



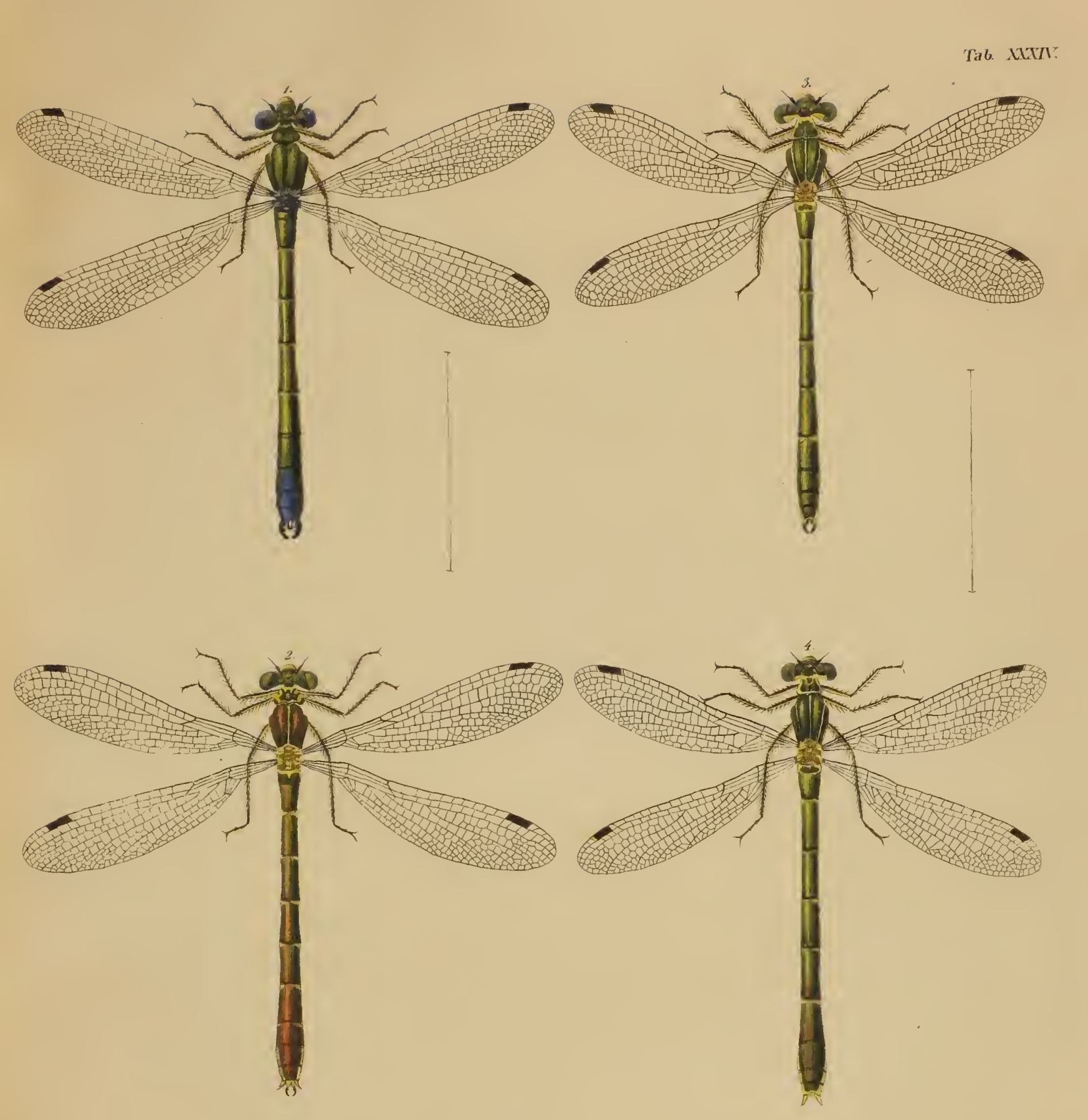
1.
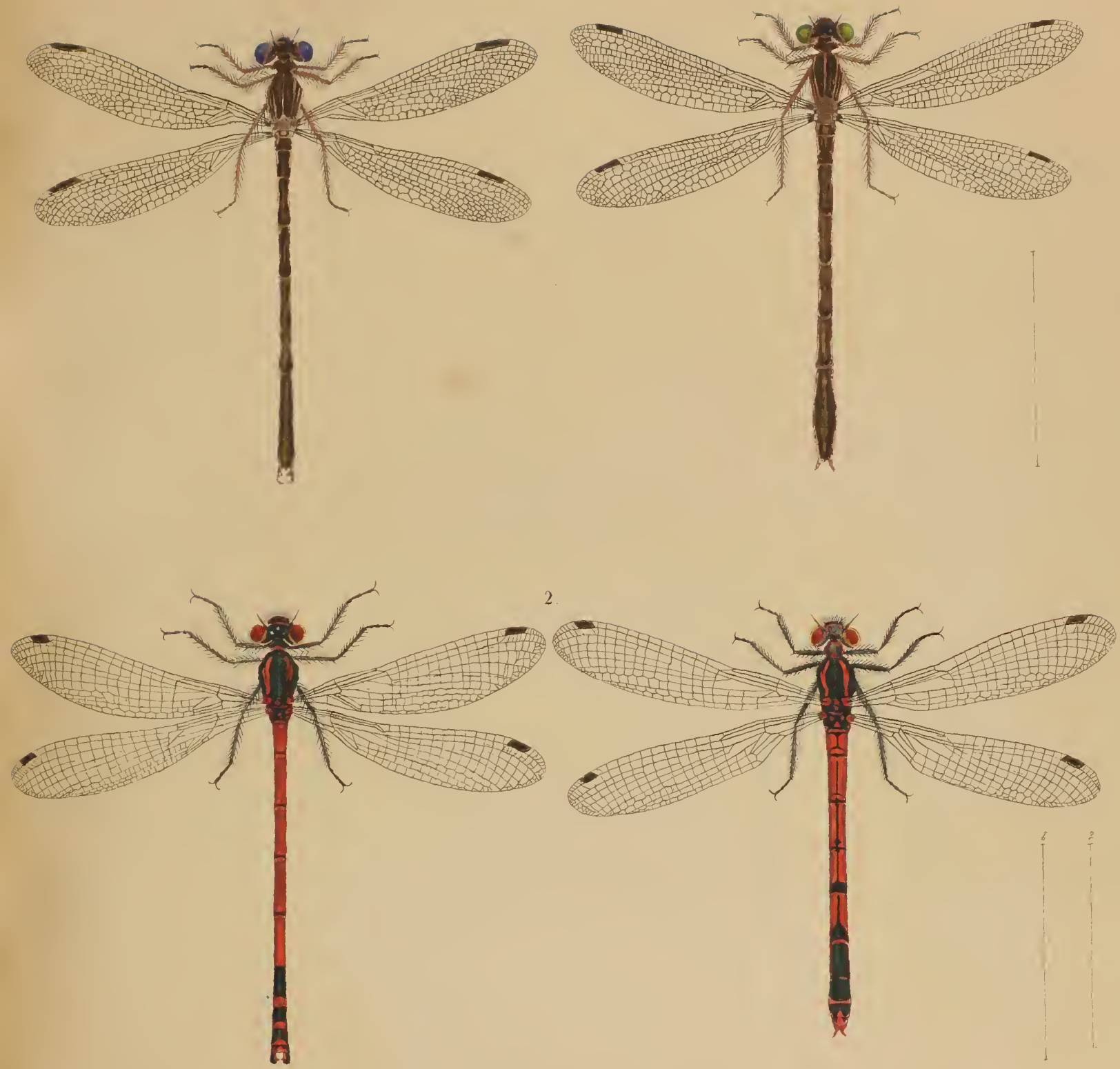

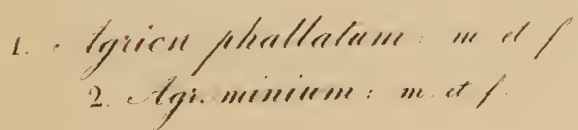



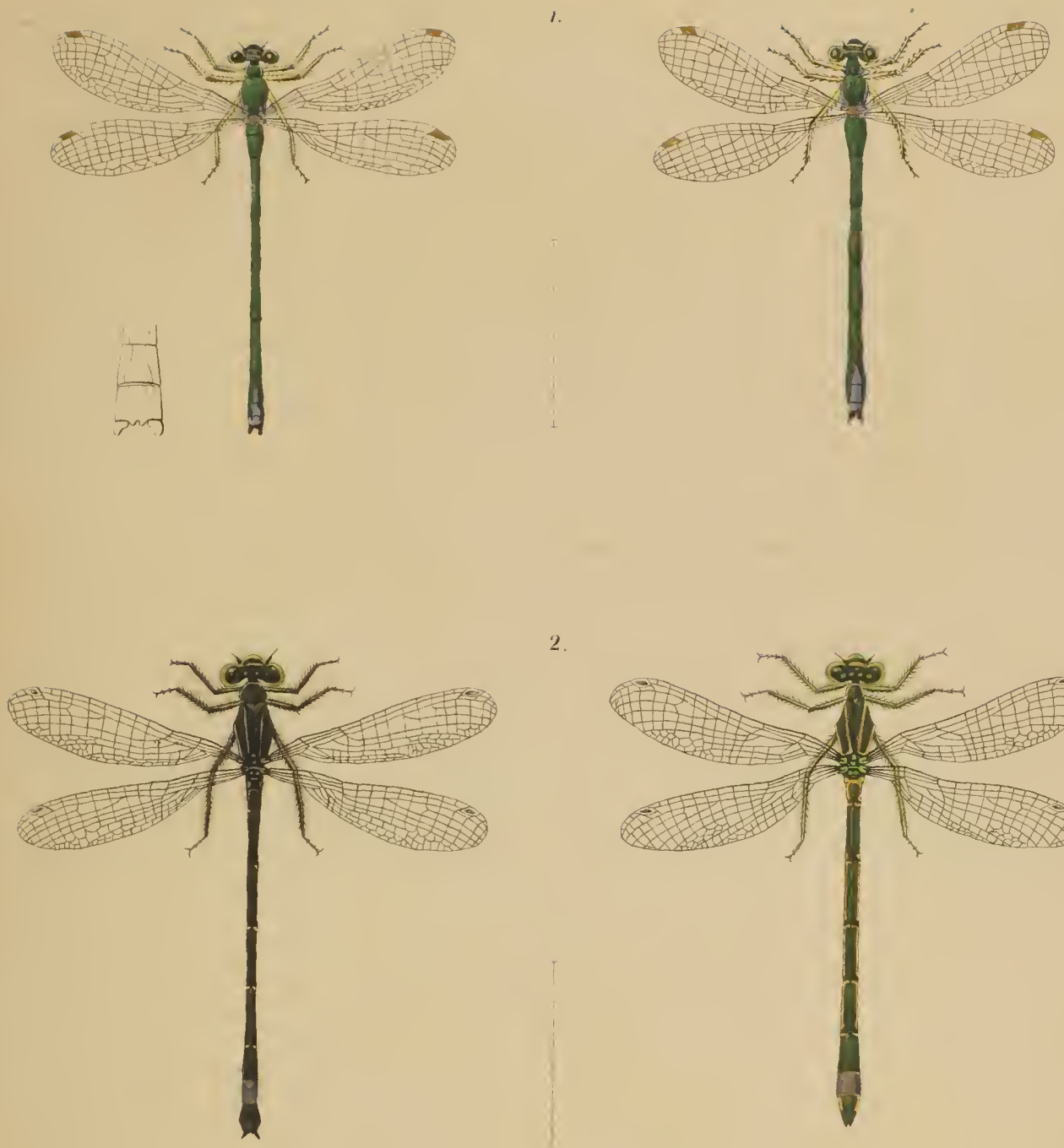

2.

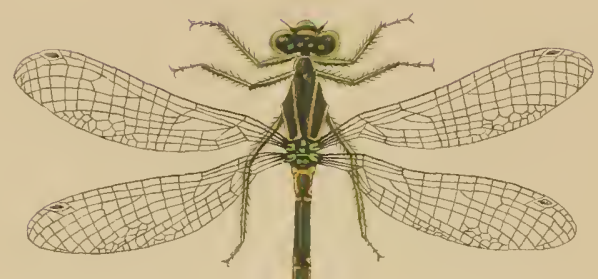

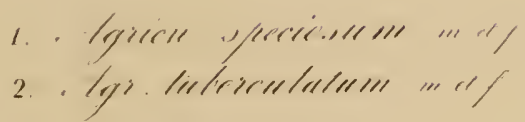


Tab. IXIII
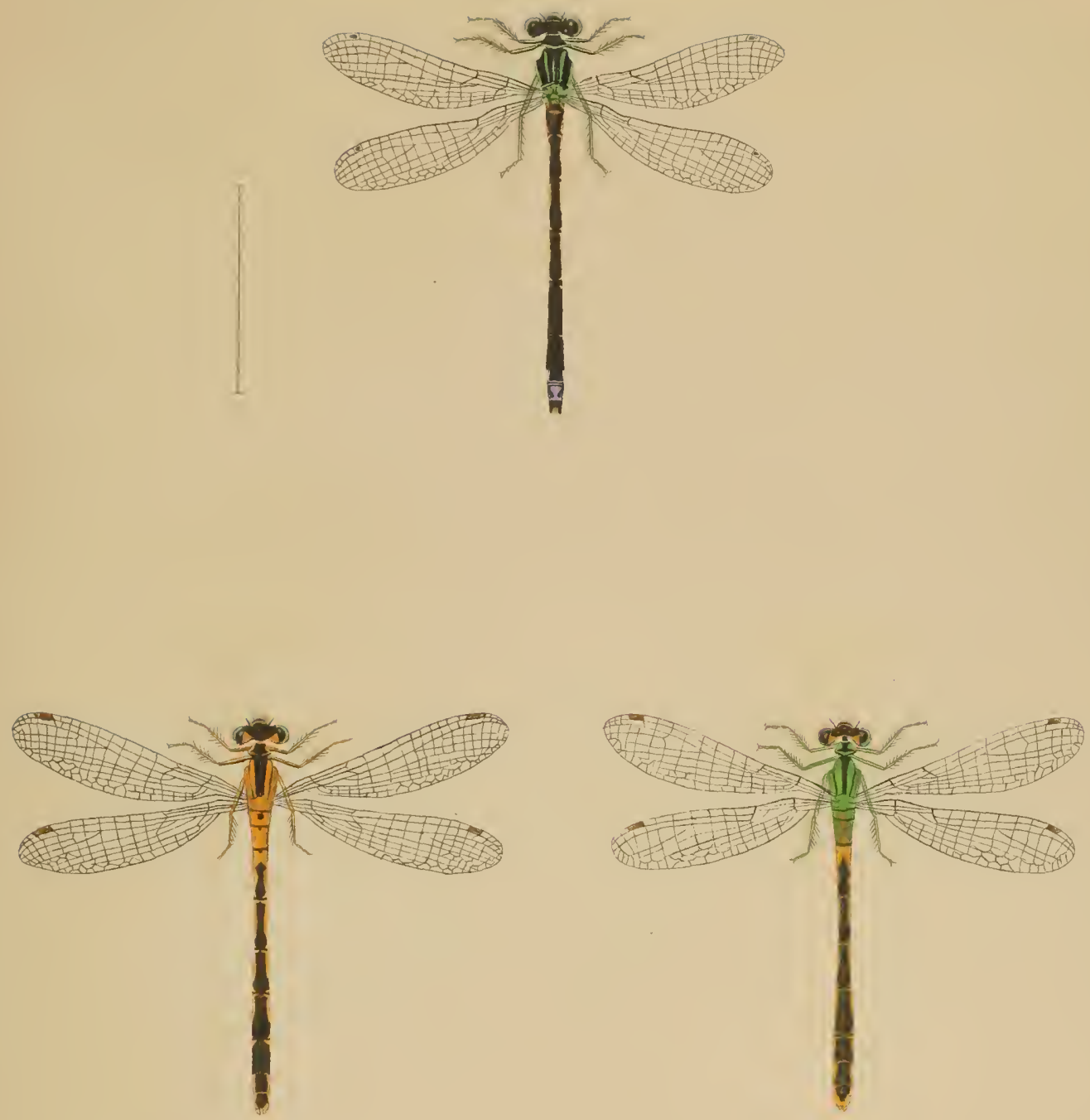

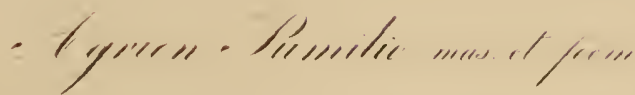


Tab. Xl
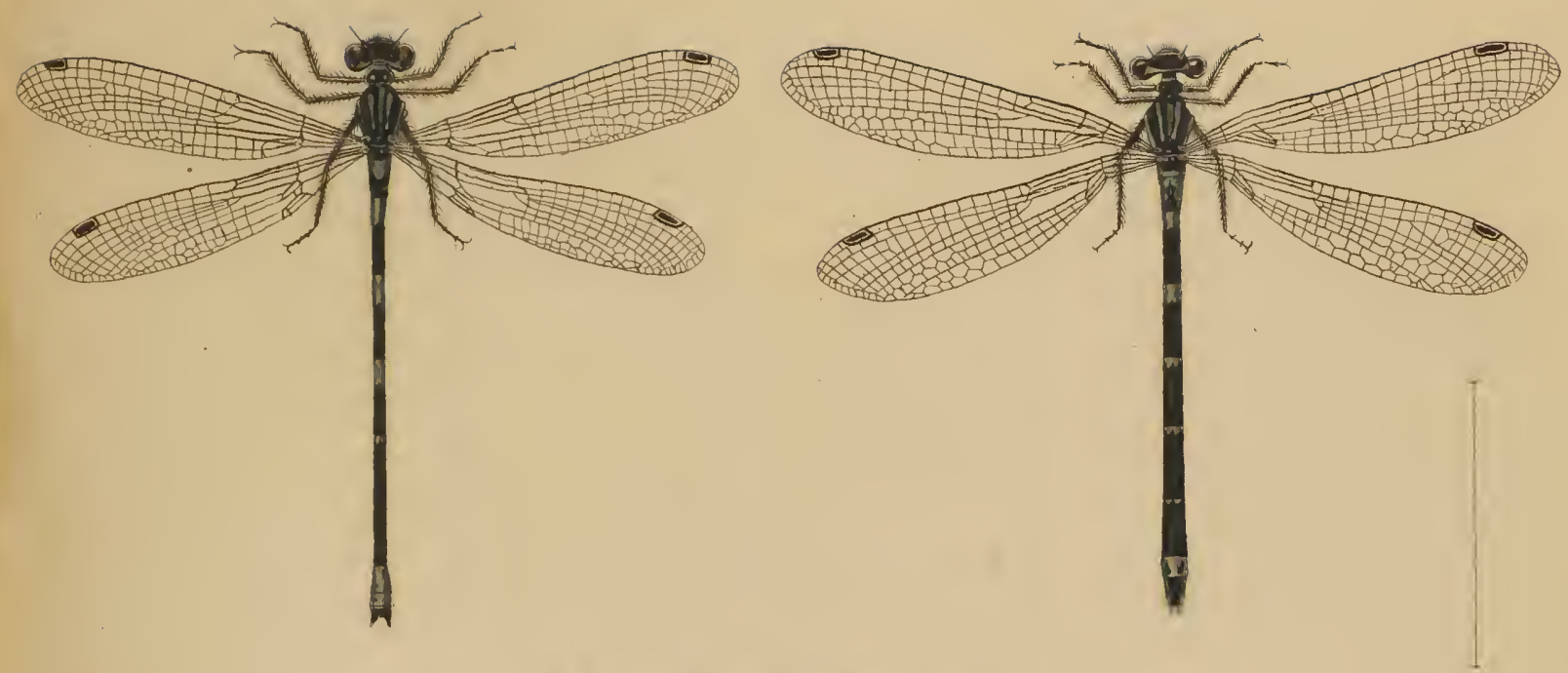

- tgrione intrimeflem: medf.
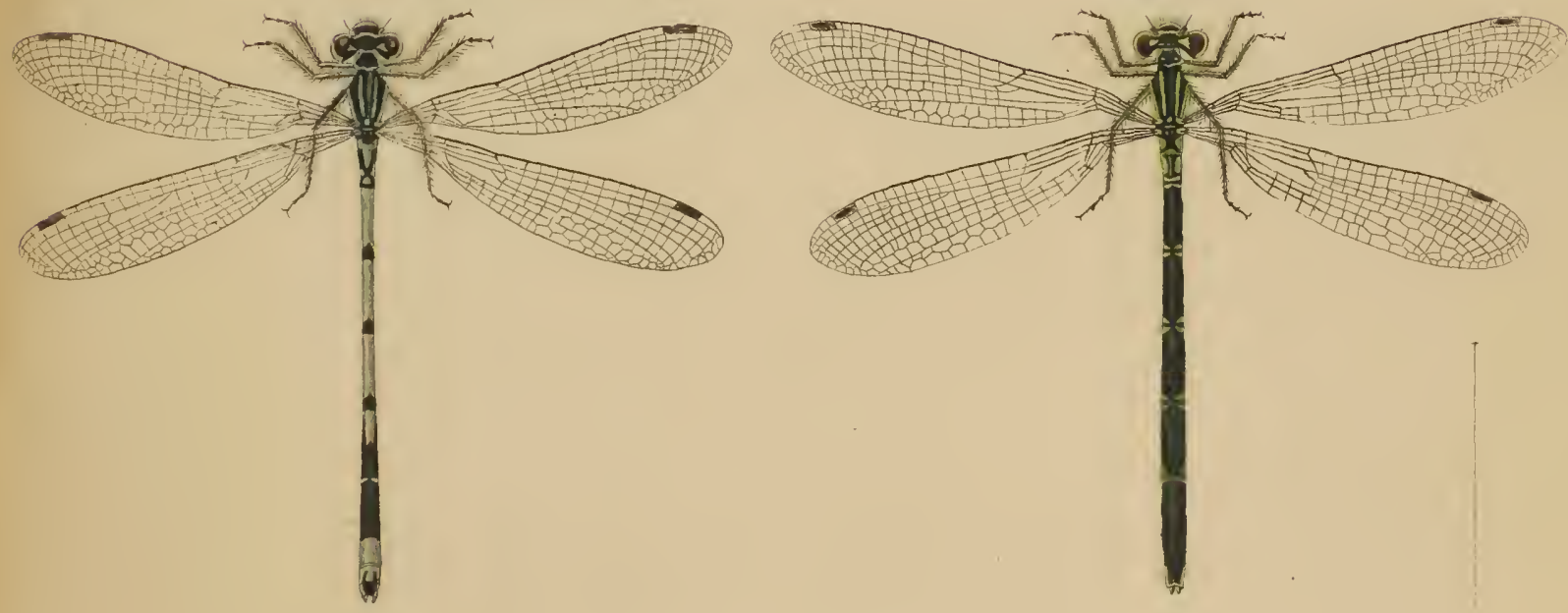

Lyp. fuicrotuese: un:elf 

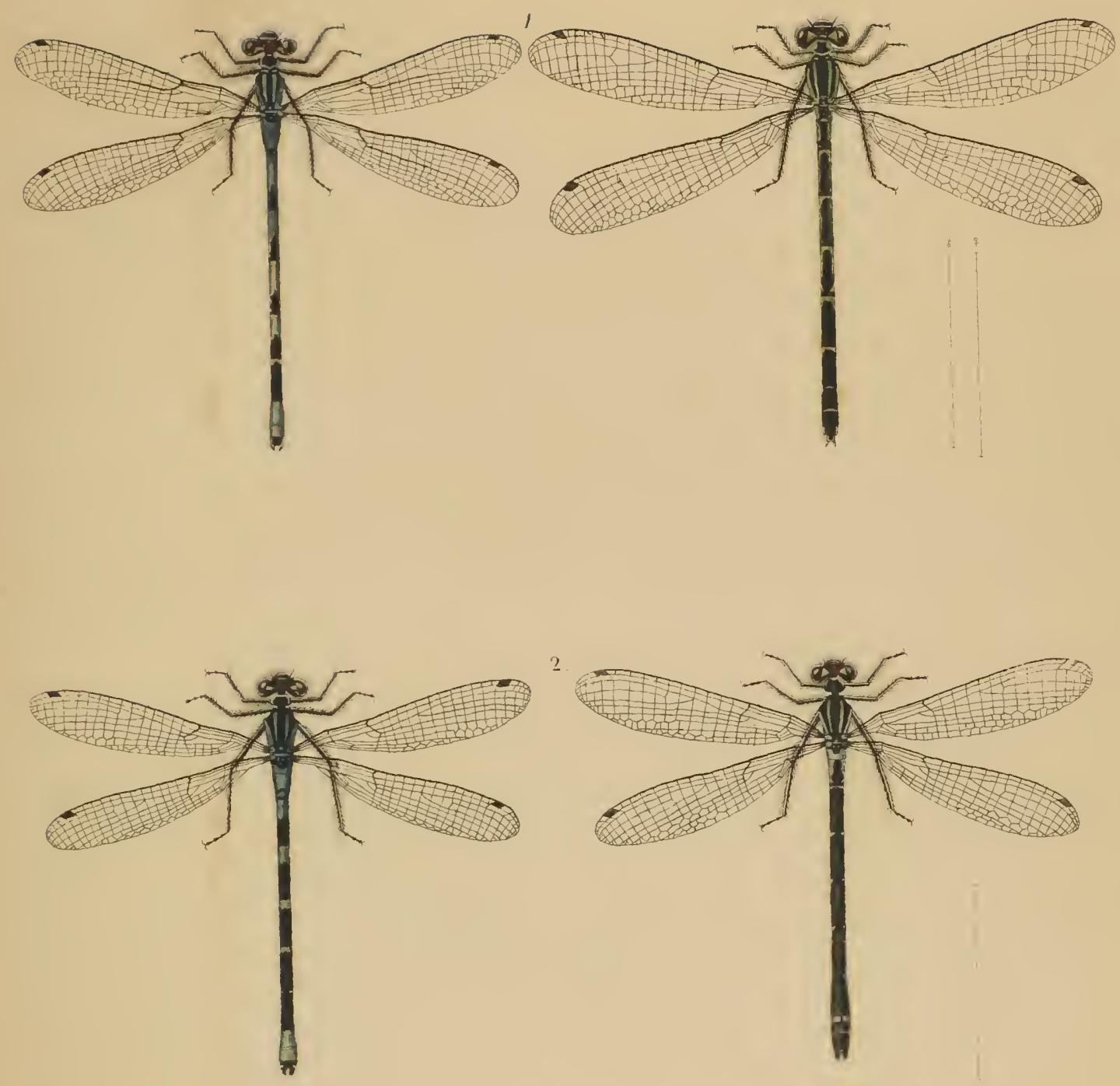

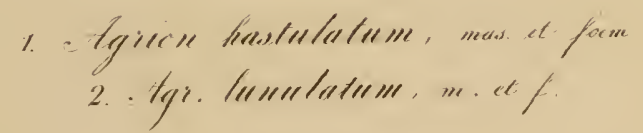



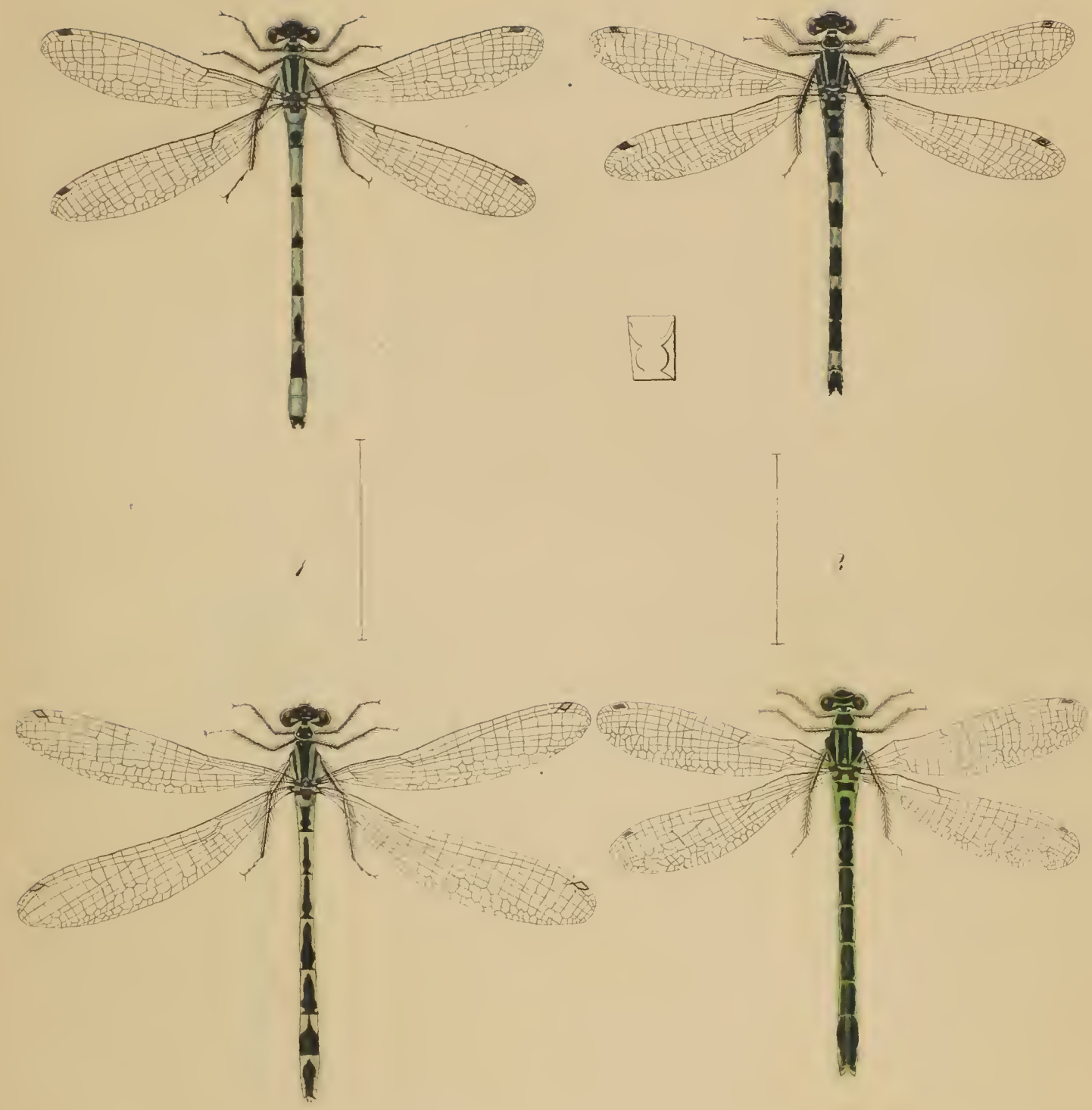

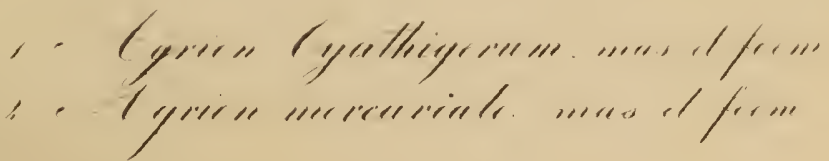


Tab. JJ,III
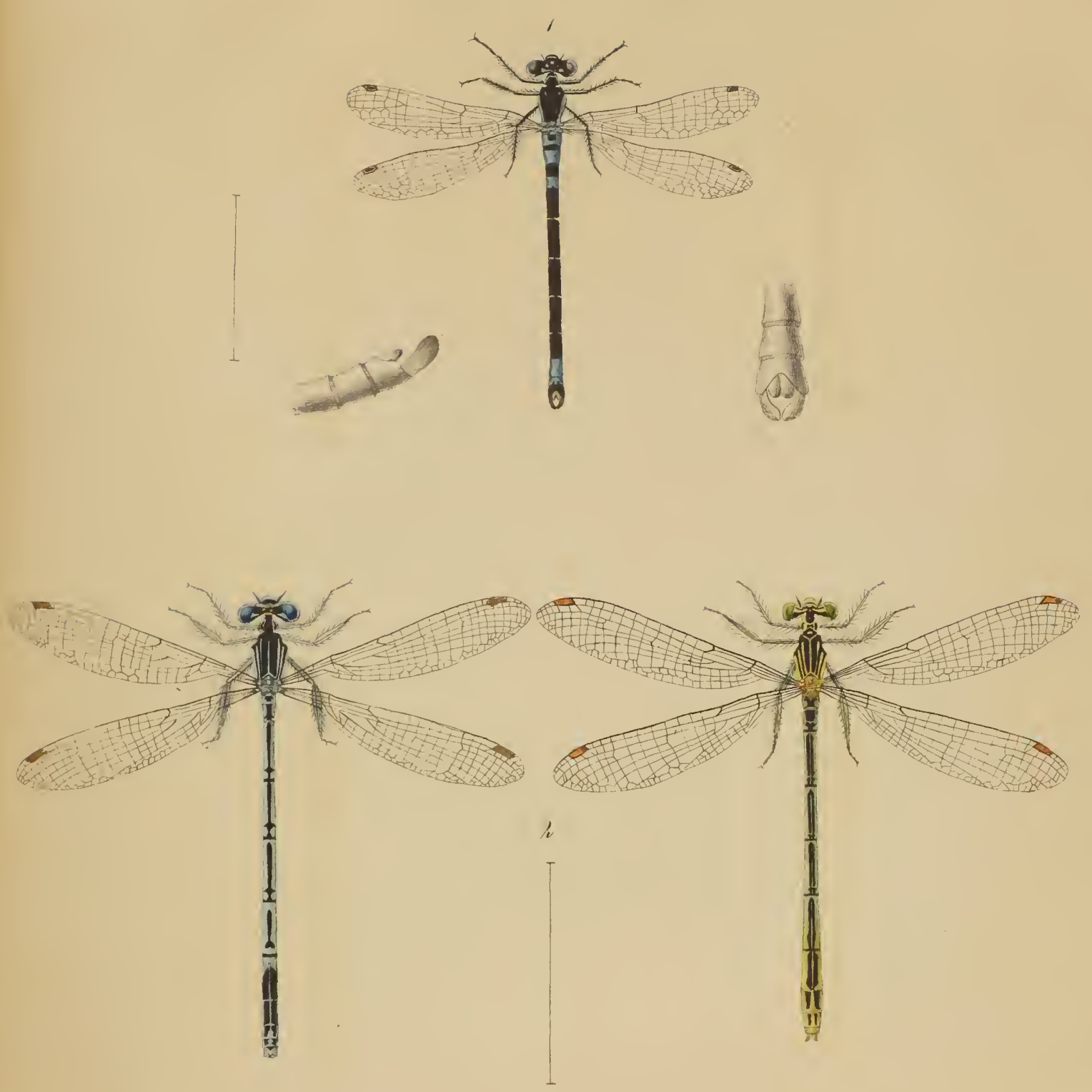

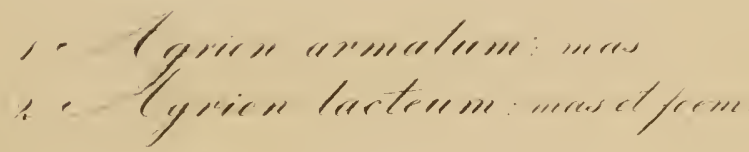


Tall XIIT.
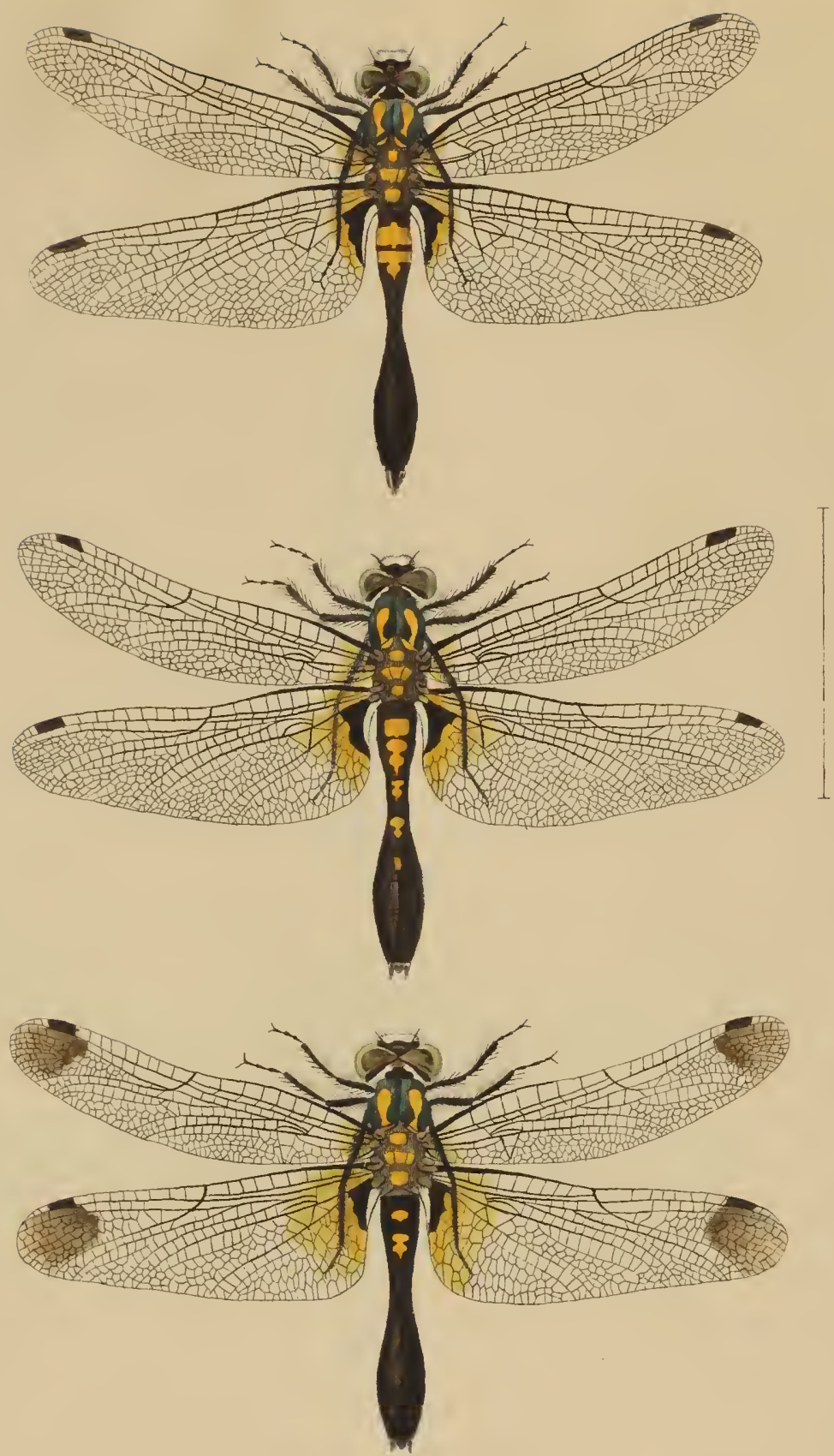

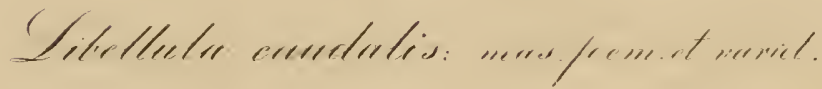




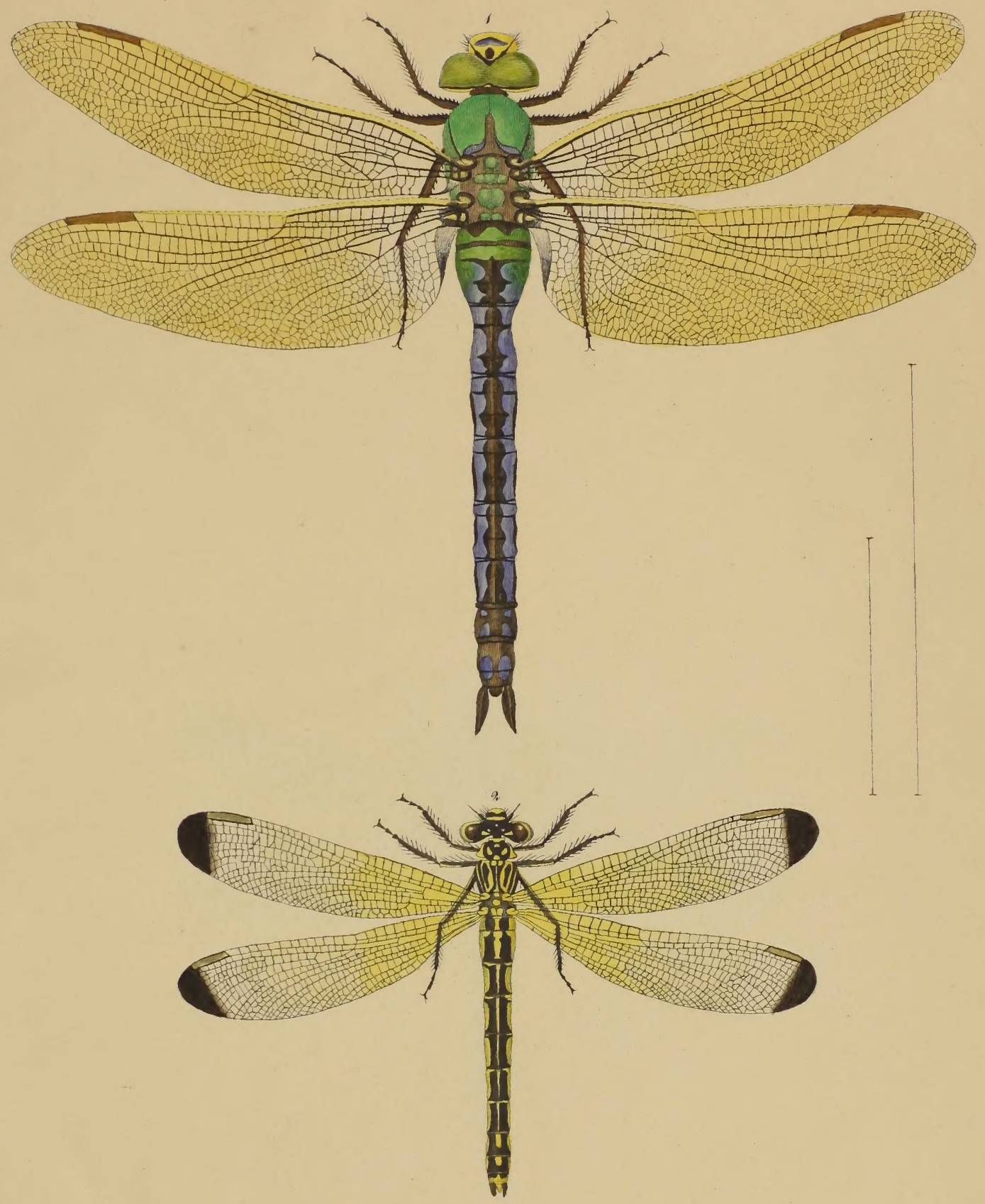

$$
\text { - Geschere asureca, foem }
$$


Tab. XLVI
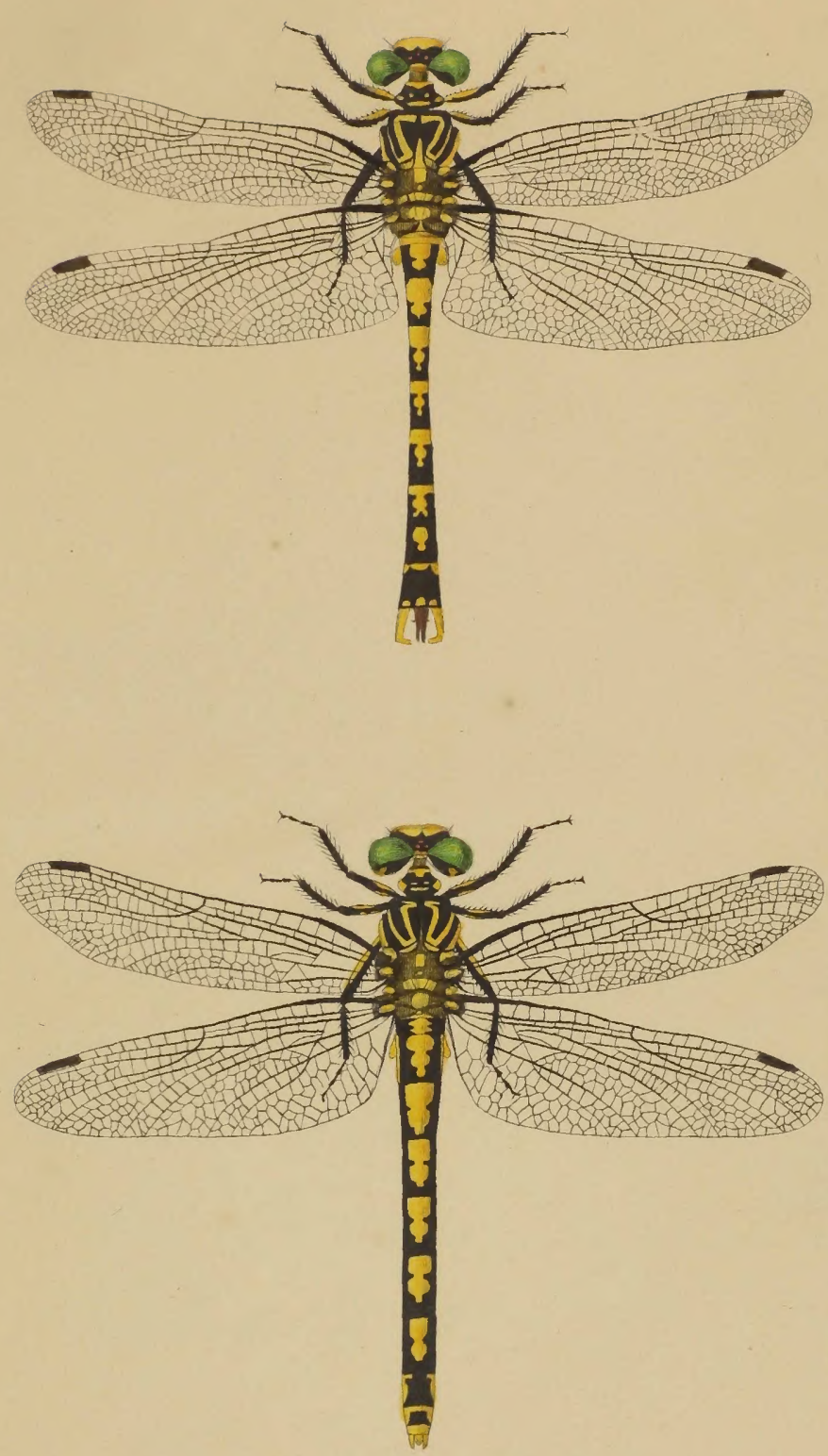

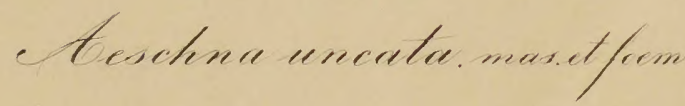


Tab. XLVII.

D.

$[-] 2$

[1]

(D) 4 .

(1) 5

Vo.

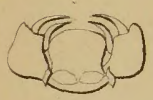

7.

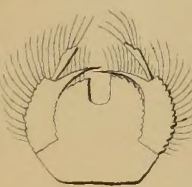

9.

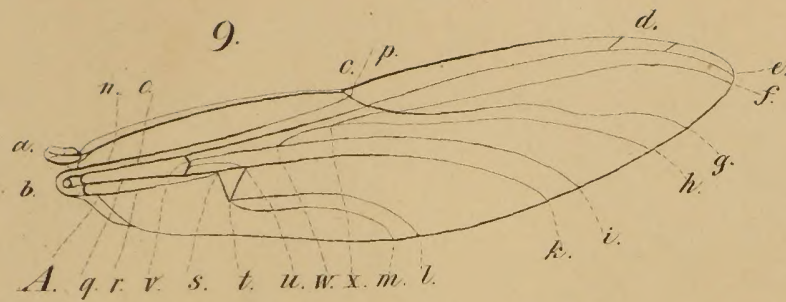

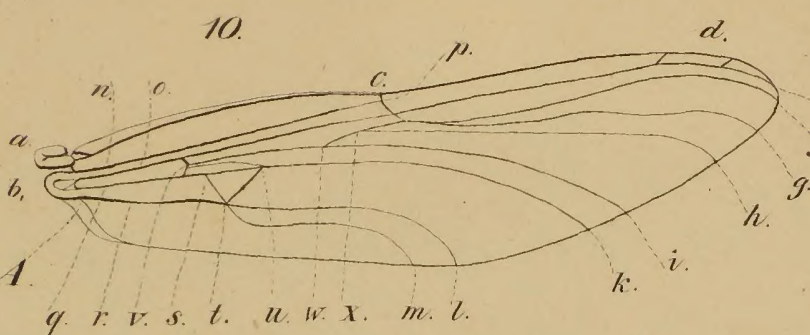

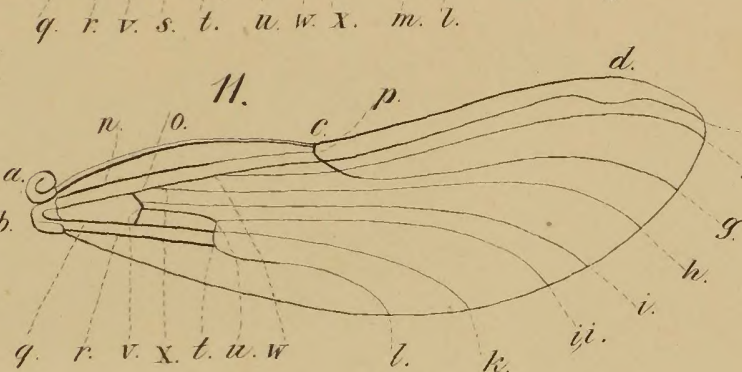

13.

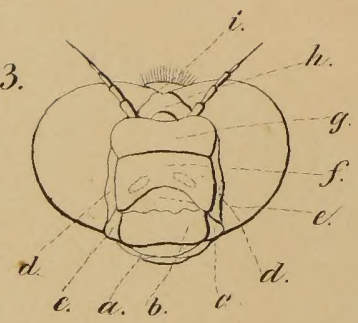

c $g$

d.

g.

14.

d. d.

p. $t h k$ k.
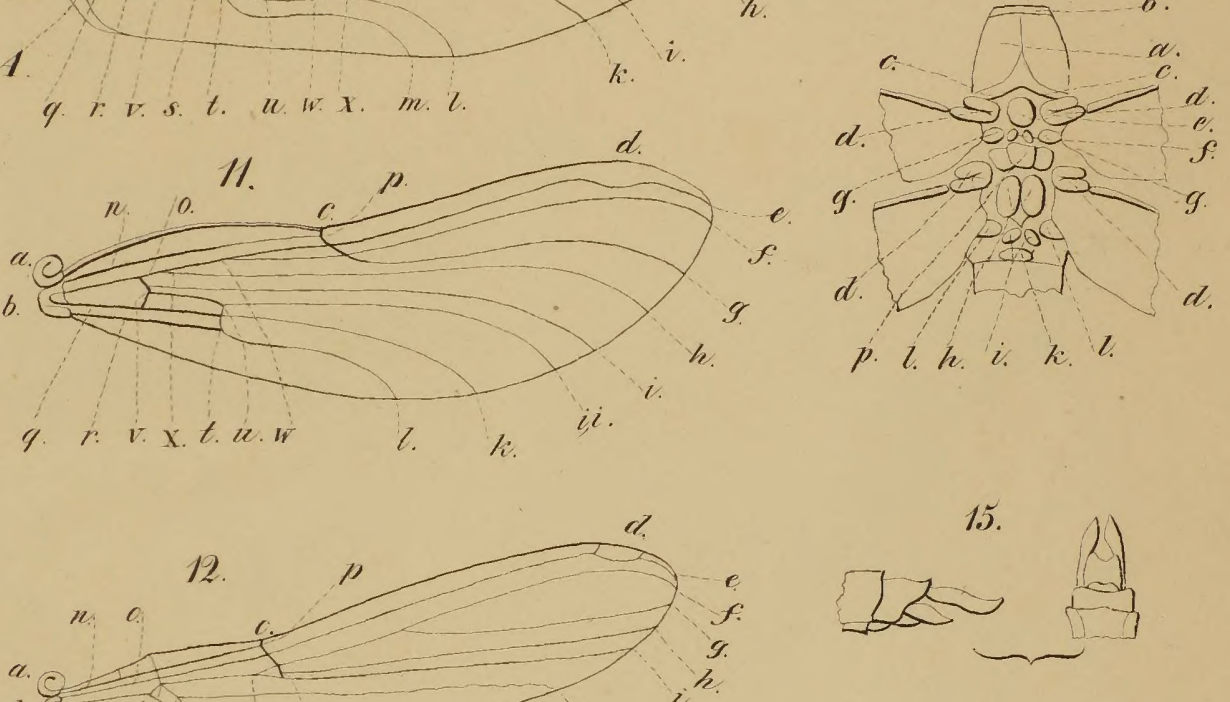

b. i.

16.

q. vu.t. w x m.

8.

a. b. c. ${ }^{18}$ e. f.g.h.i.k.
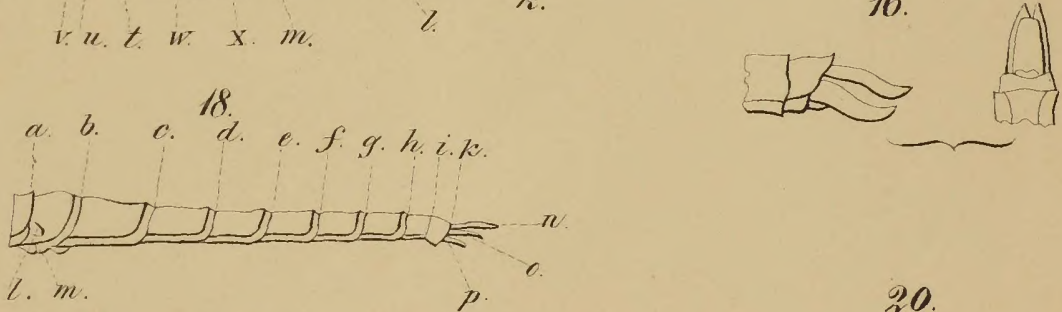

$1 \%$
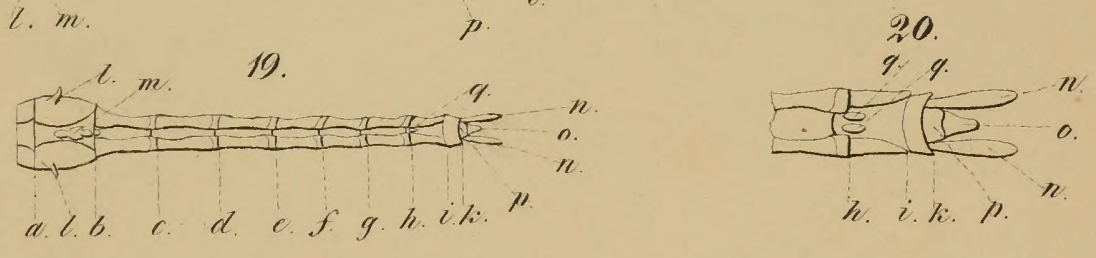

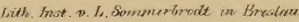




$$
9
$$

